\title{
IMPACTS OF DELAYED DRAWDOWN ON WATER QUALITY AND AQUATIC BIOTA IN SEASONAL WETLANDS OF THE GRASSLAND ECOLOGICAL AREA, LOS BANOS, CALIFORNIA
}

\author{
A Thesis \\ presented to \\ the Faculty of California Polytechnic State University, \\ San Luis Obispo
}

\author{
In Partial Fulfillment \\ of the Requirements for the Degree \\ Master of Science in Civil and Environmental Engineering
}

By

Kyle Nathan Poole

March 2009 
(C) 2009

Kyle Nathan Poole

ALL RIGHTS RESERVED 


\section{ERRATA}

This document is a corrected and improved version of the original thesis. The revisions were made on November 14, 2009 and consisted of the following:

Page vii:

1. "For total dissolved solids, the discharged load was 550 lbs, 990 lbs, and 49 lbs, respectively, for the same locations." was replaced with "For total dissolved solids, the discharged load was 290 tons, 520 tons, and 26 tons, respectively, for the same locations."

Page 62:

2. A legend was added to Figure 4-30.

Page 85:

3. Table 4-7 was replaced.

Page 90:

1. "Typical conversion factors range between 0.55 and 0.70 (Metcalf 2003). A conversion factor of 0.65 was chosen.” was replaced with "The California Regional Water Quality Control Board found that specific conductivity to total dissolved solids ratios ranged from 0.61 to 0.69 in the Grasslands Ecological Area (Grober 1998). The ratio for Salt Slough was found to be 0.68 . This ratio was used to convert specific conductivity to total dissolved solids."

2. Figure 4-68 was replaced.

Page 91:

4. Figure 4-69 was replaced.

\section{Page 95:}

1. "The seasonal load of total dissolved solids draining through the Buttonwillow site was estimated to be $550 \mathrm{lbs}$, while it was estimated to be $990 \mathrm{lbs}$ from the Los Banos 38 site." was replaced with "The seasonal load of total dissolved solids draining through the Buttonwillow site was estimated to be 290 tons, while it was estimated to be 520 tons from the Los Banos 38 site."

2. "Its seasonal load was estimated to be $770 \mathrm{lbs}$ volatile suspended solids, $1200 \mathrm{lbs}$ total organic carbon, $760 \mathrm{lbs}$ dissolved organic carbon, and 49 lbs for total dissolved solids." was replaced with "Its seasonal load was estimated to be 770 lbs volatile suspended solids, 1200 lbs total organic carbon, 760 lbs dissolved organic carbon, and 26 tons for total dissolved solids.” 


\section{COMMITTEE MEMBERSHIP}

TITLE:

Impacts of Delayed Drawdown on Water Quality and Aquatic Biota in Seasonal Wetlands of the Grassland Ecological Area, Los Banos, California

AUTHOR: Kyle Nathan Poole

DATE SUBMITTED: $\quad$ March 2009

COMMITTEE CHAIR: $\quad$ Dr. Tryg Lundquist, Assistant Professor

COMMITTEE MEMBER: Dr. Yarrow Nelson, Professor

COMMITTEE MEMBER: $\quad$ Dr. Tracy Thatcher, Assistant Professor 


\section{ABSTRACT \\ Impacts of Delayed Drawdown on Water Quality and Aquatic Biota in Seasonal Wetlands of the Grassland Ecological Area, Los Banos, California Kyle Nathan Poole}

The 178,000-acre Grassland Ecological Area in California's San Joaquin Valley is managed to provide overwintering habitat to waterfowl on the Pacific Flyway. The major management activity is the fall flooding and spring drawdown of wetlands, timed to optimize the availability of forage vegetation and invertebrates for ducks and shorebirds. Wetland drainage contains salt, boron, and trace elements that are, in part, derived from imported surface water but also concentrate during storage in the wetland impoundments. The spring drawdown drainage contributes to occasional water quality violations in the San Joaquin River (SJR) during dry years. Compliance with water quality objectives may be improved by delaying the traditional wetland drawdown period approximately one month to coincide with high SJR salt assimilative capacity during mid-March to midApril when reservoir releases are increased to aid salmon migration. However, this delayed drawdown may affect the quality and quantity of wetland vegetative forage, increase wetland soil salinity, and possibly alter the concentrations of algae, invertebrates, and pollutants in the wetlands. In the research presented herein, initial data were collected on the effects of delayed drawdown on algae, invertebrates, and wetland water quality. 
The experimental sites chosen were three pairs of matched wetland basins (20-100 acres each) that are part of the larger Modified Hydrology Study being conducted in the Grassland Ecological Area. For each pair, one wetland was managed with a traditional March drawdown; while for the second wetland, drawdown was delayed approximately one month to coincide with the period of high SJR assimilative capacity. During the second year of the study, two drainage sites were sampled to characterize drainage flowing to the SJR from an aggregated wetland area. Soil and water column samples were collected during the flooded periods at the inlets, outlets, and along transects within the wetlands. Water quality analyses included total/volatile suspended solids, conductivity, nitrogen $\left(\mathrm{NH}_{4}{ }^{+}, \mathrm{NO}_{2}{ }^{-}+\mathrm{NO}_{3}{ }^{-}\right.$, organic), phosphorus (total, $\mathrm{PO}_{4}{ }^{3-}$ ), organic carbon, alkalinity, turbidity, temperature, and $\mathrm{pH}$. Planktonic and benthic invertebrates were identified and enumerated. Data were collected between February and April in 2007 and again in 2008.

Identified phytoplankton were predominantly chlorophytes and diatoms. Zooplankton that feed on phytoplankton were found in abundance and consisted mostly of Cladocera. Benthic invertebrate densities were also measured to help explain the differences in algal concentrations between ponds. Benthic invertebrates were found to be predominantly Chironomidae.

Seasonal loads of volatile suspended solids, total dissolved solids, and total organic carbon were estimated at the two aggregate drainage sites and at one delayed drawdown wetland during the 2008 season. For volatile suspended solids, the discharged load was 
$1500 \mathrm{lbs}$ at the Buttonwillow drainage site, $2500 \mathrm{lbs}$ at the Los Banos 38 drainage site, and upstream of those sites, $770 \mathrm{lbs}$ were discharged from the Mud Slough $4 \mathrm{~b}$ wetland. For total dissolved solids, the discharged load was 290 tons, 520 tons, and 26 tons, respectively, for the same locations.

Of the factors potentially limiting phytoplankton concentrations, invertebrate grazing was likely the most important. Nutrients were not limiting in either the traditional or modified wetlands, as indicated by sufficient $\mathrm{N}$ and $\mathrm{P}$ content in the algae biomass. Likewise, inorganic $\mathrm{C}$ was not limiting, as indicated by $\mathrm{pH}(\operatorname{most}<9.0 \mathrm{pH})$. Sunlight intensity was not significantly attenuated by water depth or turbidity, and thus light limitation was not indicated. 


\section{ACKNOWLEDGMENTS}

\section{John Beam, Bill Cook, and Ric Ortega California Department of Fish and Game}

We appreciate the cooperation of DFG staff in providing access to the wetlands and in helping to guide the sampling design.

\section{Dr. Tryg Lundquist, Cal Poly}

Thank you for your guidance, friendship, and for long conversations during drives through the Central Valley. Without you I would have never enjoyed the luxuries of Wool Growers and the Sun Star Inn.

\section{Dr. Nigel Quinn, UC Merced and Lawrence Berkeley National Laboratory} Thank you for your help and guidance throughout this project and for facilitating coordination with the wetland managers, UC Merced, and other ongoing studies.

\section{Dr. Yarrow Nelson \& Dr. Tracy Thatcher, Cal Poly}

Thank you for your careful review of my thesis and for being great instructors.

\section{Ian Woetz and Adam Feffer, Cal Poly}

Thank you for teaching me the ways of the laboratory and for being great friends.

\section{Daniel Frost, Laura Fulton, and Laleh Rastegarzadeh, Cal Poly}

Thank you for your extensive help and camaraderie.

\section{Carrie Esaki, Nicole Look, Kyle Fooks, and all my lab helpers, Cal Poly Thank you for all of your hard work and contributions.}

\section{UC Salinity Drainage Program}

Funding for this project was provided by the University of California Salinity Drainage

Program via a grant to UC Merced 


\section{TABLE OF CONTENTS}

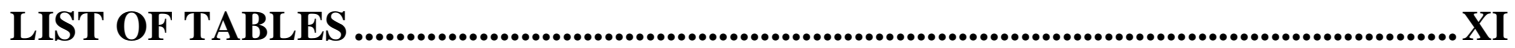

LIST OF FIGURES

CHAPTER 1:INTRODUCTION............................................................................... 1

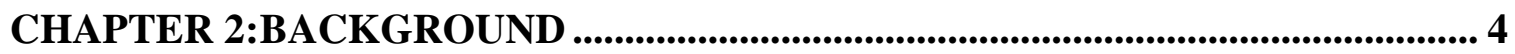

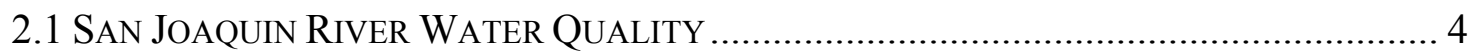

2.2 Real Time Water Quality MANAGEMENT ……….......................................... 5

2.3 GRASSLANDS BASIN SEASONAL WETLANDS ......................................................... 6

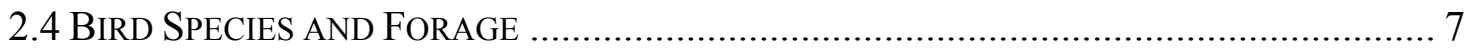

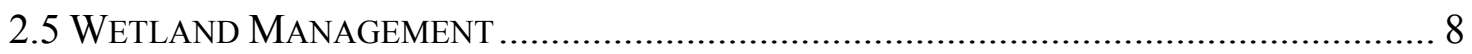

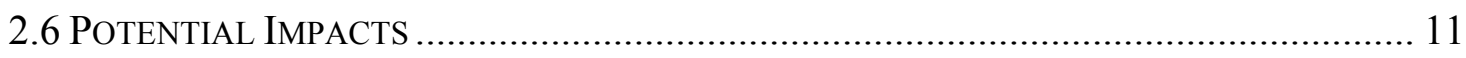

CHAPTER 3:MATERIALS AND METHODS .......................................................... 14

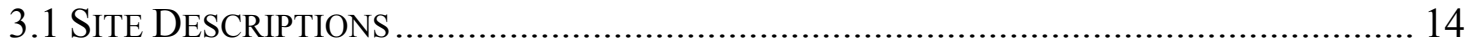

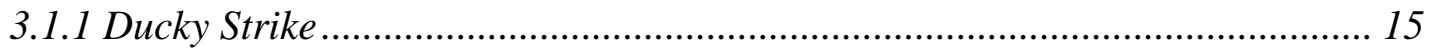

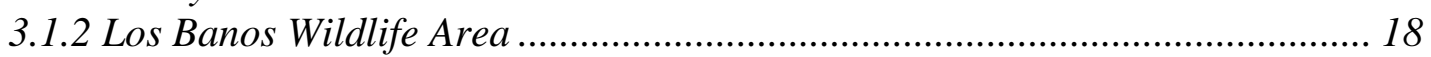

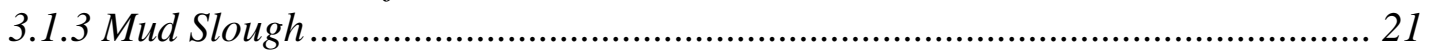

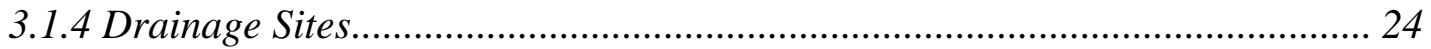

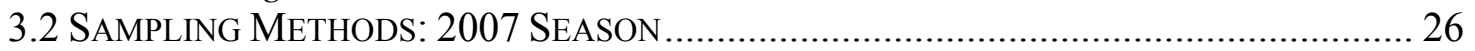

3.2.1 Inflow and Outflow Sampling ................................................................... 26

3.2.2 Transect Sampling ..................................................................................... 26

3.3 SAMPLING METHODS: CHANGES FOR 2008 SEASON ………………..................... 28

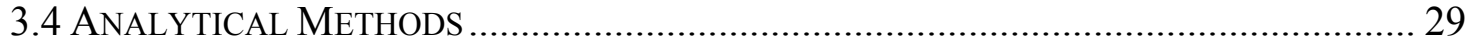

3.4.1 Water Quality Analysis ............................................................................... 30

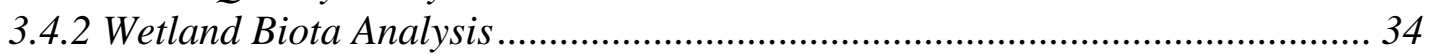

CHAPTER 4:RESULTS AND DISCUSSION ....................................................... 37

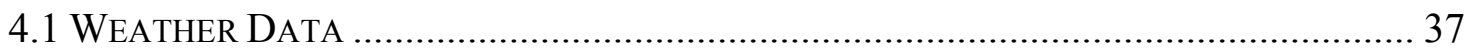

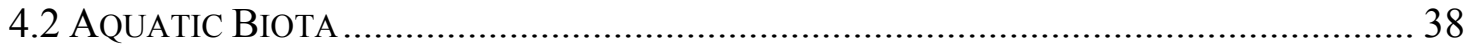

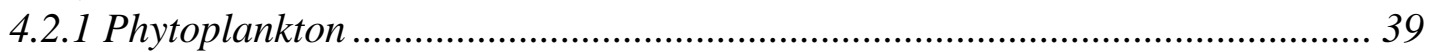

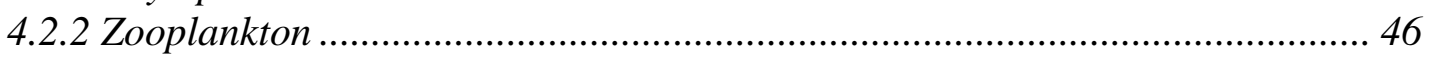

4.2.3 Benthic Invertebrates.................................................................................. 51

4.2.4 Aquatic Biota Summary ………………………………............................ 53

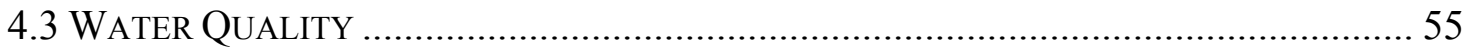

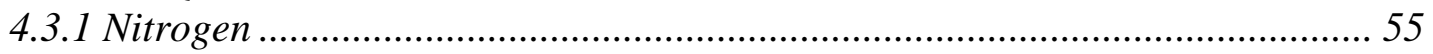

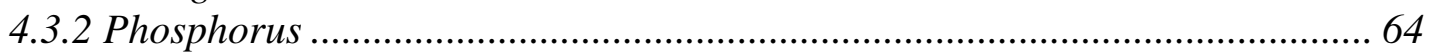

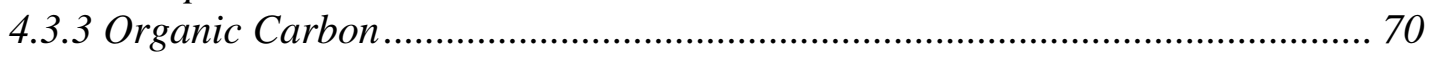

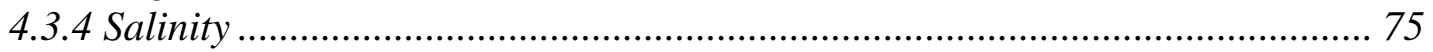

4.3.5 Turbidity-Volatile Suspended Solids Correlation............................................ 80

4.3.6 Water Quality Summary .............................................................................. 83

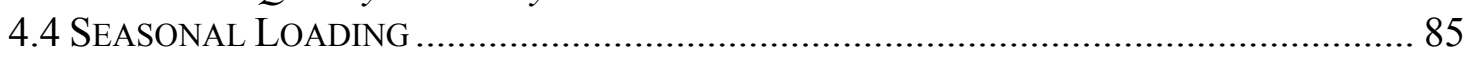

4.4.1 Volatile Suspended Solids ......................................................................... 85

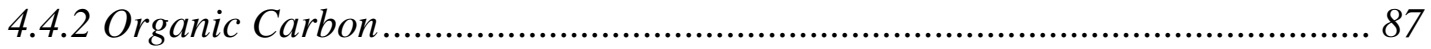




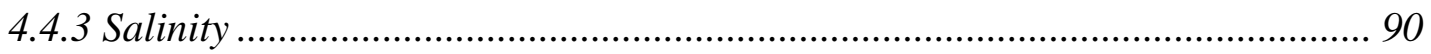

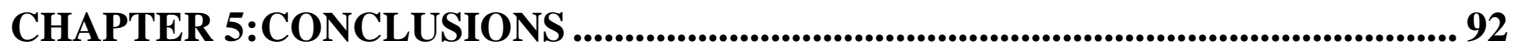

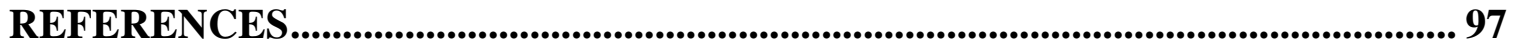

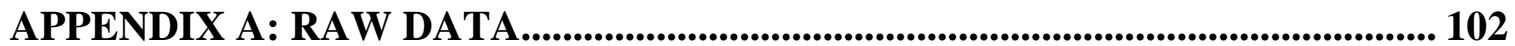

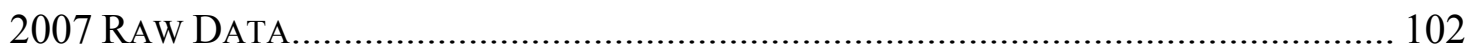

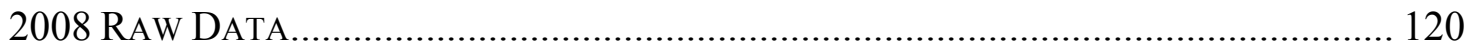

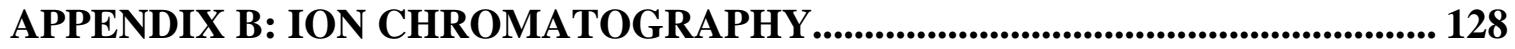




\section{LIST OF TABLES}

Table 3-1: Water quality methods of analysis. APHA methods are from the 2005 edition.

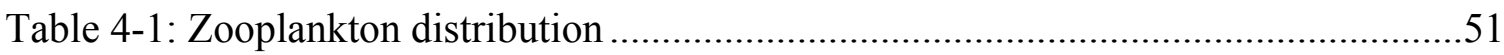

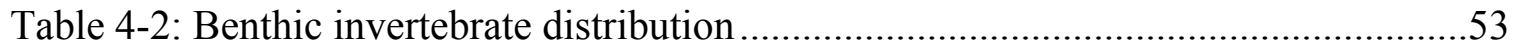

Table 4-3: Aquatic biota data summary for 2007. Data is expressed as the mean $+/-$ the standard deviation of the mean with the number of samples analyzed in parentheses.

Table 4-4: Aquatic biota data summary for 2008. Data is expressed as the mean $+/-$ the standard deviation of the mean with the number of samples analyzed

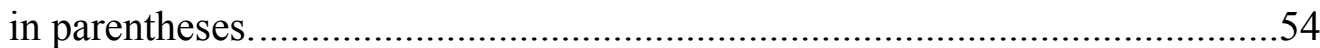

Table 4-5: Water quality data summary for 2007. Data is expressed as the mean $+/-$ the standard deviation of the mean with the number of samples analyzed in parentheses.

Table 4-6: Water quality data summary for 2008. Data is expressed as the mean $+/-$ the standard deviation of the mean with the number of samples analyzed

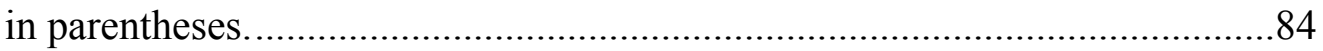

Table 4-7: Seasonal loading during the 2008 sampling season. .85 


\section{LIST OF FIGURES}

Figure 2-1: A gaggle of Canada geese taking flight near Buttonwillow Lake in the Los Banos Wildlife Area.

Figure 2-2: Timing of wetland drawdown to coincide with periods of San Joaquin River assimilative capacity. Note the large assimilative capacity during May due to the Vernalis Adaptive Management Program. .10

Figure 3-1: Ducky Strike North and South wetlands during the dry season. Image captured using Google Earth.

Figure 3-2: Ducky Strike North Google Earth image with inlet, outlet, and transect locations shown.

Figure 3-3: Ducky Strike North picture taken from outlet weir. .16

Figure 3-4: Ducky Strike South Google Earth image with inlet, outlet, and transect locations shown.

Figure 3-5: Ducky Strike South picture taken from outlet weir. Kyle Poole and Laleh Rastegarzadeh are shown collecting grab samples.

Figure 3-6: Los Banos 31B and 33B wetlands during the dry season. Image captured using Google Earth.

Figure 3-7: Los Banos Wildlife Area 31B Google Earth image with inlet, outlet, and transect locations shown.

Figure 3-8: Los Banos Wildlife Area 31B picture taken from outlet weir.

Figure 3-9: Los Banos Wildlife Area 33 Google Earth image with inlet, outlet, and transect locations shown.

Figure 3-10: Los Banos Wildlife Area 33 picture taken from outlet weir. .20 
Figure 3-11: Mud Slough 31B and 33B wetlands during the dry season. Image captured using Google Earth.

Figure 3-12: Mud Slough 3B Google Earth image with inlet, outlet, and transect locations shown.

Figure 3-13: Mud Slough 3B picture taken near the backwater transect.

Figure 3-14: Mud Slough 4B Google Earth image with inlet, outlet, and transect locations shown

Figure 3-15: Mud Slough 4B picture taken from outlet weir.

Figure 3-16: Buttonwillow drainage site. .25

Figure 3-17: Los Banos Wildlife Area 38 drainage site with auto-sampler in place.........25

Figure 3-18: VSS samples after oven drying. The seven samples on the left are screened samples for phytoplankton quantification while the right seven are unscreened for zooplankton analysis. The sample in the upper left corner is an analytical blank. .36

Figure 4-1: Average air temperatures during both sampling seasons.............................38

Figure 4-2: Daily solar radiation for both sampling seasons. .38

Figure 4-3: A group of phytoplankton found in a Mud Slough 3B sample during the 2007 sampling season (1000x). Phytoplankton genera Scenedesmus, Euglena, and Chlorella are present.

Figure 4-4: Diatoms found in a Ducky Strike North sample during the 2007 sampling season (1000x). Navicula gracilis on the left and a Diatoma species on the right. 
Figure 4-5: Decaying filamentous algae, Zygnema stellinum, mixed in with detritus found in a Los Banos 33 sample during the 2007 sampling season $(1000 x)$

Figure 4-6: Phytoplankton concentrations in traditional drainage wetlands for the 2007 sampling season. Error bars represent the standard error of the mean

Figure 4-7: Phytoplankton concentrations in traditional drainage wetlands for the 2008 sampling season.

Figure 4-8: Phytoplankton concentrations in modified drainage wetlands for the 2007 sampling season. Error bars represent the standard error of the mean.

Figure 4-9: Phytoplankton concentrations in modified drainage wetlands for the 2008 sampling season. The drawdown period is indicated by the line with arrows.

Figure 4-10: Phytoplankton concentrations at drainage sites for the 2008 sampling season

Figure 4-11: A mat of filamentous algae found early in the season near the Buttonwillow drainage site.

Figure 4-12: Remains of filamentous algae bloom seen in Figure 4-11 later in the season

Figure 4-13: Micrograph of filamentous algae (Nodularia) found near the Los Banos 38 drainage site. 
Figure 4-14: Zooplankton concentrations in traditional drainage wetlands for the 2007 sampling season.

Figure 4-15: Zooplankton concentrations in traditional drainage wetlands for the 2008 sampling season.

Figure 4-16: Zooplankton concentrations in modified drainage wetlands for the 2007 sampling season. .48

Figure 4-17: Zooplankton concentrations in modified drainage wetlands for the 2008 sampling season. The drawdown period is indicated by the line with arrows

Figure 4-18: Zooplankton concentrations at drainage sites for the 2008 sampling season

Figure 4-19: Benthic invertebrate density in traditional drainage wetlands for the 2007 sampling season.

Figure 4-20: Benthic invertebrate density in modified drainage wetlands for the 2007 sampling season.

Figure 4-21: Nitrate + Nitrite nitrogen concentrations in traditional drainage wetlands for the 2007 sampling season.

Figure 4-22: Nitrate + Nitrite nitrogen concentrations in traditional drainage wetlands for the 2008 sampling season.

Figure 4-23: Total ammonia nitrogen concentrations in traditional drainage wetlands for the 2007 sampling season.

Figure 4-24: Total ammonia nitrogen concentrations in traditional drainage wetlands for the 2008 sampling season. 
Figure 4-25: Total Kjeldahl Nitrogen concentrations in traditional drainage wetlands for the 2008 sampling season.

Figure 4-26: Nitrate + Nitrite nitrogen concentrations in modified drainage wetlands for the 2007 sampling season. .60

Figure 4-27: Nitrate + Nitrite nitrogen concentrations in modified drainage wetlands for the 2008 sampling season. The drawdown period is indicated by the line with arrows.

Figure 4-28: Total ammonia nitrogen concentrations in modified drainage wetlands for the 2007 sampling season.

Figure 4-29: Total ammonia nitrogen concentrations in modified drainage wetlands for the 2008 sampling season. The drawdown period is indicated by the line with arrows.

Figure 4-30: Total Kjeldahl nitrogen concentrations in modified drainage wetlands for the 2007 sampling season. The drawdown period is indicated by the line with arrows.

Figure 4-31: Nitrate + Nitrite nitrogen concentrations at the drainage sites for the 2008 sampling season.

Figure 4-32: Total ammonia nitrogen concentrations at the drainage sites for the 2008 sampling season.

Figure 4-33: Total Kjeldahl nitrogen concentrations at the drainage sites for the 2008 sampling season.

Figure 4-34: Phosphate concentrations in traditional drainage wetlands for the 2007 sampling season. 
Figure 4-35: Phosphate concentrations in traditional drainage wetlands for the 2008 sampling season.

Figure 4-36: Total phosphorus concentrations in traditional drainage wetlands for the 2007 sampling season. .66

Figure 4-37: Total phosphorus concentrations in traditional drainage wetlands for the 2008 sampling season. .66

Figure 4-38: Phosphate concentrations in modified drainage wetlands for the 2007 sampling season.

Figure 4-39: Phosphate concentrations in modified drainage wetlands for the 2008 sampling season. The drawdown period is indicated by the line with arrows

Figure 4-40: Total phosphorus concentrations in modified drainage wetlands for the 2007 sampling season.

Figure 4-41: Total phosphorus concentrations in modified drainage wetlands for the 2008 sampling season. The drawdown period is indicated by the line with arrows.

Figure 4-42: Phosphate concentrations at drainage sites for the 2008 sampling season. .70

Figure 4-43: Total phosphorus concentrations at drainage sites for the 2008 sampling season.

Figure 4-44: Dissolved organic carbon concentrations in traditional drainage wetlands for the 2008 sampling season. 
Figure 4-45: Total organic carbon concentrations in traditional drainage wetlands for the 2008 sampling season. Particulate organic carbon was estimated at $52 \%$ of VSS.

Figure 4-46: Dissolved organic carbon concentrations in modified drainage wetlands for the 2008 sampling season. The drawdown period is indicated by the line with arrows. .73

Figure 4-47: Total organic carbon concentrations in modified drainage wetlands for the 2008 sampling season. Particulate organic carbon was estimated at $52 \%$ of VSS. The drawdown period is indicated by the line with arrows.....73

Figure 4-48: Dissolved organic carbon concentrations at drainage sites for the 2008 sampling season. .74

Figure 4-49: Total organic carbon concentrations at drainage sites for the 2008 sampling season. Particulate organic carbon was estimated at $52 \%$ of VSS. .75

Figure 4-50: Correlation between specific conductivity and chloride concentration.

Data is from the 2007 sampling season. .76

Figure 4-51: Specific conductivity readings from traditional drainage wetlands for the 2007 sampling season. .77

Figure 4-52: Specific conductivity readings from traditional drainage wetlands for the 2008 sampling season.

Figure 4-53: Specific conductivity readings from modified drainage wetlands for the 2007 sampling season. 
Figure 4-54: Specific conductivity readings from modified drainage wetlands for the 2008 sampling season. The drawdown period is indicated by the line with arrows

Figure 4-55: Specific conductivity readings from drainage sites for the 2008 sampling season.

Figure 4-56: Correlation between volatile suspended solids and turbidity using drainage data from the 2008 sampling seasons.

Figure 4-57: Correlation between volatile suspended solids and turbidity using Los Banos data from both sampling seasons.

Figure 4-58: Correlation between volatile suspended solids and turbidity using Mud Slough data from both sampling seasons. .82

Figure 4-59: Correlation between volatile suspended solids and turbidity using Ducky Strike data from both sampling seasons. .82

Figure 4-60: Correlation between volatile suspended solids and turbidity using all data from both sampling seasons.

Figure 4-61: Volatile suspended solids loading from drainage sites during the 2008 season. The area under the curve represents the seasonal load. .86

Figure 4-62: Flow from drainage sites during the 2008 season .86

Figure 4-63: Volatile suspended solids loading from Mud Slough 4b during the 2008 season. The area under the curve represents the seasonal load. The drawdown period is indicated by the line with arrows.

Figure 4-64: Dissolved organic carbon loading from drainage sites during the 2008 season. The area under the curve represents the seasonal load. 
Figure 4-65: Total organic carbon loading from drainage sites during the 2008 season. Particulate organic carbon was estimated at $52 \%$ of VSS. The area under the curve represents the seasonal load.

Figure 4-66: Dissolved organic loading from Mud Slough 4b during the 2008 season. The area under the curve represents the seasonal load. The drawdown period is indicated by the line with arrows.

Figure 4-67: Total organic carbon loading from Mud Slough 4b during the 2008 season. The area under the curve represents the seasonal load. Particulate organic carbon was estimated at $52 \%$ of VSS. The drawdown period is indicated by the line with arrows.

Figure 4-68: Total dissolved solids loading from drainage sites during the 2008 season. The area under the curve represents the seasonal load...

Figure 4-69: Total dissolved solids loading from Mud Slough 4b during the 2008 season. The area under the curve represents the seasonal load. The drawdown period is indicated by the line with arrows. 


\section{CHAPTER 1: INTRODUCTION}

The 178,000-acre Grassland Ecological Area (GEA) in California's San Joaquin Valley provides over-wintering habitat to waterfowl on the Pacific Flyway, a 10,000 mile migratory pathway from Alaska to South America (Grassland 2008). Wetlands in the GEA are home to millions of waterfowl and shorebirds, a diverse community of moistsoil vegetation, and other common and endangered wildlife (Mason, 1969; Cogswell, 1977; Grassland Water District, 1986). Wetlands in this area are a component of the Western Hemisphere Shorebird Reserve Network and are now internationally recognized for their importance to shorebirds (Grassland 2008). However, contaminants in the discharge from these wetlands may be harmful to aquatic wildlife downstream in the San Joaquin River (SJR).

The SJR has been listed as an impaired water body by the California Water Quality Control Board (SWRCB, 2007). Pollutants of concern include salinity and biochemical oxygen demand (BOD). These pollutants can be detrimental to aquatic wildlife and agricultural uses downstream. However, to the extent that BOD is a source of allochthonous food for downstream habitats, it might be considered beneficial. A potential source of salinity and BOD is seasonal wetlands of the Central Valley. Wetlands concentrate salts from receiving waters through evapotranspiration. Decaying algae, respiring algae, detritus and ammonia discharged from the wetlands contribute to BOD downstream. Real-time management of seasonal wetlands to minimize these effects has been proposed. However, a balance needs to be found between minimizing impacts on the SJR and maintaining the functions of the seasonal wetlands as wildlife habitat. 
One proposed real-time management scheme is to time the drawdown of seasonal wetlands with reservoir releases along the SJR during dry seasons, when water pollution concerns are highest. Reservoir releases aid the migration of salmon. During this time there is significantly more water flowing in the river, which increases the assimilative capacity of salinity and BOD. However, the secondary impacts of this delay on the ecology of the wetlands are still unknown.

Delaying wetland drawdown is one of several practices available to better manage salt in the SJR. The true merit needs to be assessed by measuring the direct and indirect secondary impacts of its implementation at all levels of the wetland ecosystem. Along with other information from the larger Modified Hydrology Study, an improved understanding of the consequences of delayed draw-down on wetland water quality and aquatic biota would help determine when and where delayed drawdown might be employed with minimal risk to wetland and river ecosystems.

This project was coordinated with a large-scale, multi-year Modified Hydrology Study led by multiple institutions that is studying the impacts of delayed wetland drawdown on water quality, moist soil plant productivity, and wetland ecology. The current project attempts to quantify the rate of algae biomass increase during the delayed drawdown period and determine the factors that affect final algae biomass concentrations at selected sites within the study area. 
Wetland water quality and biotic data are typically highly variable, and the cumulative effects of delayed drawdown may not be statistically discernable for many years. However, the following hypotheses were formulated in the proposal stage of the project to guide the data collection.

1. The increase in salt concentrations will be greater in the delayed wetland discharges than in the traditionally drained wetland discharges, on an annual average basis.

2. Concentrations of oxygen-demanding substances (e.g. phytoplankton) will be the

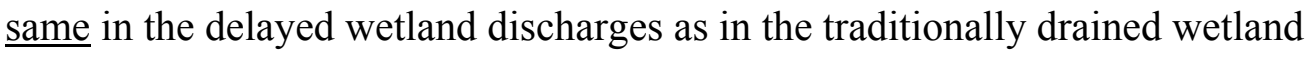
discharges.

3. Nutrient concentrations and discharged mass will be less in the traditionally drained wetland discharges than in the delayed wetland discharges.

4. Zooplankton densities will increase in the treatment wetlands during the extended flooded period.

The short term of the current research did not allow formal statistical testing of these hypotheses, but qualitative observations were compared to the hypothesis, as described in the conclusion of this thesis. 


\section{CHAPTER 2: BACKGROUND}

\subsection{San Joaquin River Water Quality}

The San Joaquin River (SJR) has been listed by the California Water Quality Control Board (CWQCB) as an impaired water body. Pollutants contributing to water quality problems include mercury, metals, pesticides, and salinity. In addition, one of the most important water quality problems is the intermittent low dissolved oxygen (DO) at the Deep Water Ship Channel (DWSC) near Stockton. These low DO periods hinder critical fish migrations. Among the major factors contributing to the DO sags are transport of oxygen-consuming substances from the upper SJR into the DWSC. These substances, together measured as biochemical oxygen demand (BOD), include detritus, respiring and decaying phytoplankton, and ammonia. The factors contributing to low DO become critical during periods of low flow and warm weather (SJVDA 2003).

Approximately $10 \%$ of the SJR's annual flow and $30 \%$ of its annual salt load passes through wetlands within the Grasslands Basin, which includes the Grassland Water District (Grober et al., 1995; Quinn et al., 1997; Quinn and Karkoski, 1998). Despite the major habitat importance and the influential salt discharge of the wetland refuges, few studies have yet considered how management for decreased salinity in the SJR might affect the wetland habitats and other water quality constituents in the drainage such as phytoplankton concentration.

The CRWQCB declared its intention to promote salinity management schemes including timed discharges, real-time monitoring, and source control for all agricultural and 
wetland dischargers of salt to the SJR. To date, Grassland Water District and Lawrence Berkeley National Laboratory have developed the only pilot system capable of meeting the CRWCB definition of real-time wetland monitoring and management. Now, a large multi-agency, cross-disciplinary study on six paired wetlands within the Grassland Wildlife Management Area and the California Department of Fish and Game's Wildlife Area's has been developed. This pilot study is occurring at a relatively small scale in wetland units ranging in area from 20 acres to 100 acres. The small scale is used in part to allow credible water and salinity balances to be developed, but also to address the concerns already voiced by many wetland managers that promotion of delayed drawdown practices, while improving salinity conditions in the SJR, could lead to irrecoverable changes to the wetland landscape and the function of these wetlands as an overwintering sanctuary for waterfowl.

\subsection{Real Time Water Quality Management}

To improve the SJR ecosystem, in 1990 the Department of Water Resources (DWR) formed the San Joaquin River Management Program (SJRMP), a stakeholder group. One of the SJRMP's mandates was to reconcile and coordinate the various uses and competing interests along the river. Real-time management of river inputs was one solution developed by the SJRMP. The SJRMP dissolved as of January 2008, and its activities are now conducted by the Cal Fed ERP. By coordinating Sierra reservoir releases with westside drainage releases, river water quality can be improved for the benefit of migrating fish, south Delta irrigators, and other uses. 
Wetland drainage is one component of the west-side drainage that could be scheduled to coincide with the peak assimilative capacity in the SJR (Grober et al., 1995; Quinn et al., 1997; Quinn and Karkoski, 1998). The increased surface water allocations under the Central Valley Project Improvement Act provide more opportunity for this type of coordination, which will help achieve salt and boron water quality objectives. Improved scheduling of west-side discharges can assist in avoiding conflict with critical time periods for early season irrigation, as well as with fish rearing.

The operational changes suggested are to delay the draining or drawdown of the wetlands in order to discharge salt load when the assimilative capacity of the SJR is sufficient. The timing of the discharges would be determined from real time data on SJR flow and wetland water quality.

\subsection{Grasslands Basin Seasonal Wetlands}

Preservation and enhancement of wetlands in California's Central Valley is important to ensuring wildlife and habitat diversity. The regional wetlands are home to millions of waterfowl and shorebirds, a diverse community of moist-soil vegetation, and other common and endangered wildlife (Mason, 1969; Cogswell, 1977; Grassland Water District, 1986). The 178,000-acre Grassland Ecological Area in California's San Joaquin Valley provides over-wintering habitat to waterfowl on the Pacific Flyway, a 10,000 mile migratory pathway from Alaska to South America (Grassland 2008). Within the Grassland Ecological Area is the Grassland Resource Conservation District (Grassland RCD) near Los Banos, CA. The Grassland RCD is composed of approximately 75,000 acres of private hunting clubs, private owned land, and state and federal refuges. As 
much as $30 \%$ of California's Central Valley wintering ducks use this area, and it is ranked by the U.S. Fish and Wildlife Service as the most important wetland complex in the San Joaquin Valley. Wetlands of the Grassland RCD are a component of the Western Hemisphere Shorebird Reserve Network and are now internationally recognized for its importance to shorebirds (Grassland 2008).

\subsection{Bird Species and Forage}

Migrating waterfowl within the Grassland Ecological Area include Canada geese (Figure

2-1), Northern Pintail, Green winged teal, Northern Shoveler, Ross and Lesser Snow

Gesse. Besides these migrating waterfowl the wetlands also provide wintering habitat to Lesser Sandhill Cranes, White Faced Ibis, and shorebirds such as Least and Western Sandpiper and Long Billed Dowitchers. 


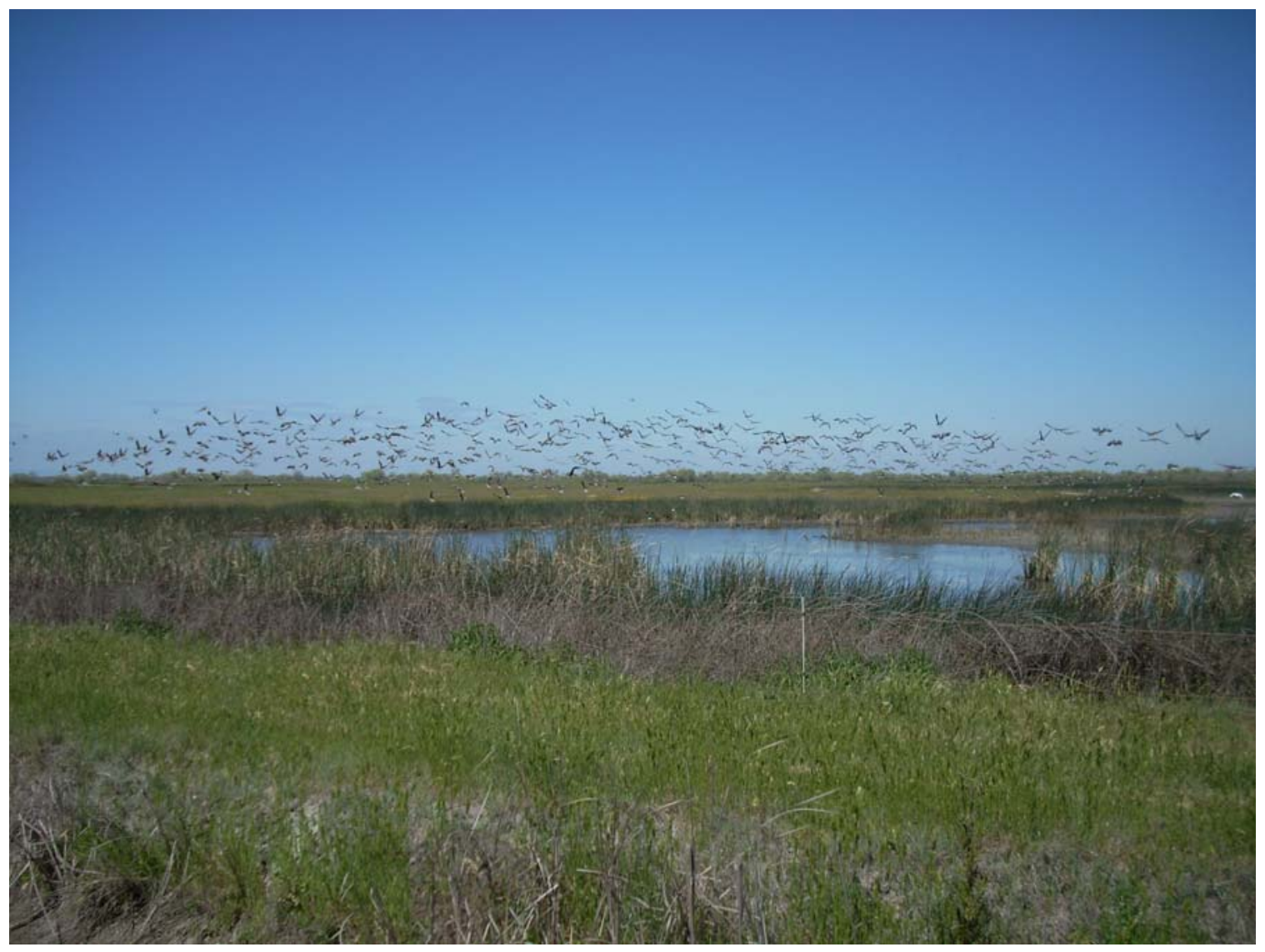

Figure 2-1: A gaggle of Canada geese taking flight near Buttonwillow Lake in the Los Banos Wildlife Area.

Invertebrates are important food for ducks, shorebirds, songbirds, and others. Aquatic invertebrate populations, in turn, depend in large part on the production and type of algae available for their diets. Increased phytoplankton concentrations can lead to increased densities of benthic and nektonic aquatic invertebrates which are, in turn, eaten by bird forage organisms such as fish and predatory midge larvae (Chaoborus) (Horne and Goldman, 1994).

\subsection{Wetland Management}

The Grassland Ecological Area wetlands are intensively managed to produce crops of moist-soil food plants and invertebrates that have high value to wildlife, particularly 
waterfowl. Best management practices (BMPs) have been developed to achieve these goals. These BMPs can include grading, discing, mowing, grazing, burning, herbicide application, dry season irrigations, and the timing of wetland flood-up and drawdown. The fall flood-up occurs during the months of September and October, and the spring drawdown occurs during the months of February, March, and April. By timing flood-up and drawdown in the San Joaquin Valley, managers mimic the wet/dry seasonal cycle that these wetlands experienced historically. This seasonal cycle improves wetland habitat and can be adapted to promote desired species (Frederickson and Taylor, 1982).

Research has been undertaken to understand the role of water manipulation, irrigation, waterfowl habitat requirements, and both vegetation and waterbird responses to different management techniques. Altering wetland drainage schedules affects the timing and rate of drawdown of wetland ponds and hence may affect the forage value of the wetlands for migrating and wintering waterbirds. Wetland salinity management also affects the productivity and diversity of vegetation that can be grown in wetlands (Mushet et al., 1992).

Wetland drawdown is timed to make seed and invertebrate resources available during peak waterbird migrations and to correspond with optimal germination conditions (primarily soil moisture and temperature) for moist-soil plants (Smith et al., 1995). Swamp Timothy is one of the dominant species. Other species occur as well with different hydrological requirements. Spring drainage that is timed for optimal habitat conditions occurs at a sensitive time for agriculture in the South Delta in that these 
drainage releases occur during the time crops are being irrigated for the first time and are germinating - potentially affecting crop yields.

To achieve salt and boron objectives in the SJR using real-time wetland drainage management, drawdown can be delayed until SJR flows are artificially increased in late April due to the Vernalis Adaptive Management Program (VAMP), which currently is used to aid salmon migration. As seen in Figure 2-2, the VAMP discharges can more than double the usual seasonal flow in the SJR, creating considerable assimilative capacity for salts. However, VAMP is a practice subject to changes in policy.

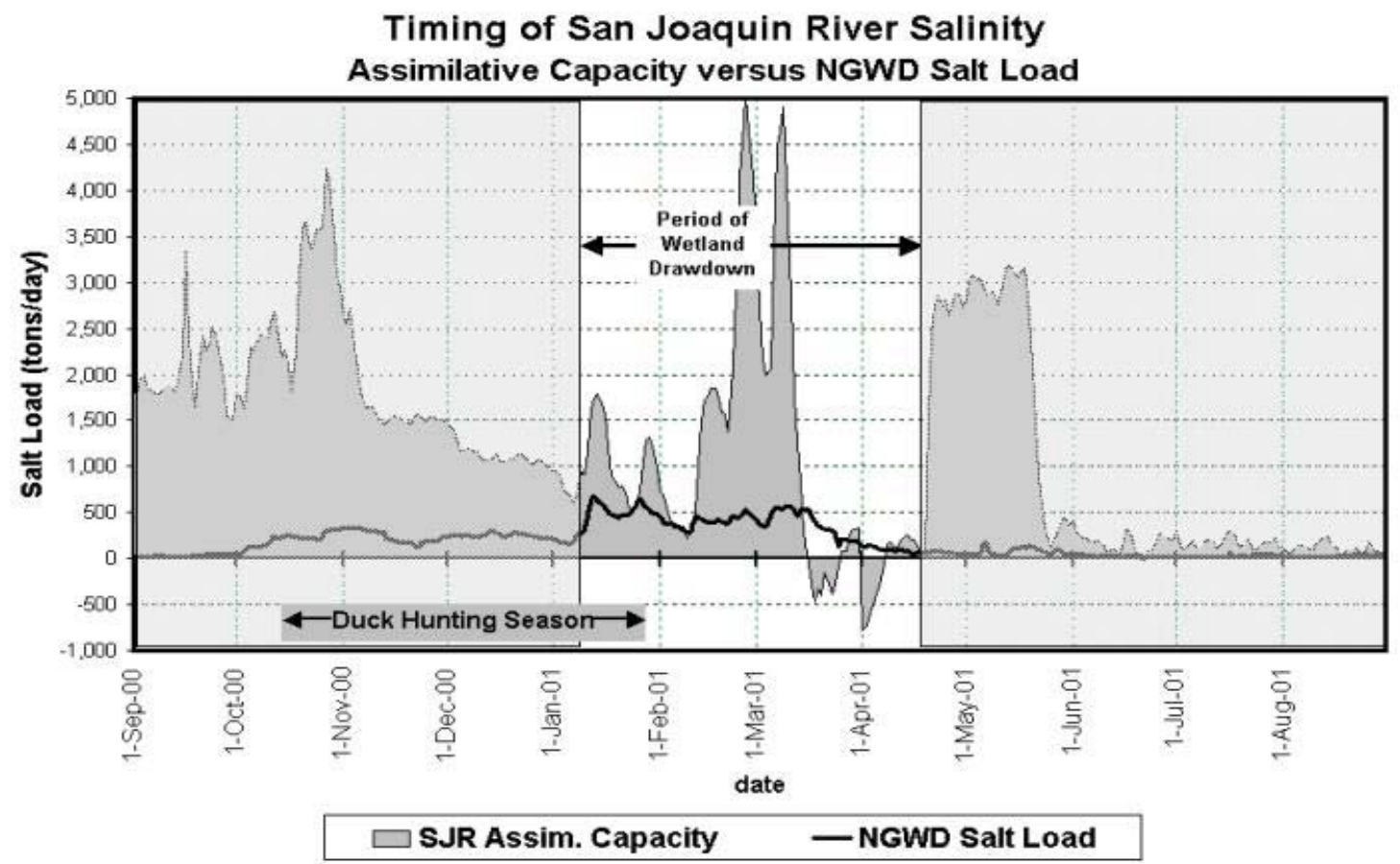

Figure 2-2: Timing of wetland drawdown to coincide with periods of San Joaquin River assimilative capacity. Note the large assimilative capacity during May due to the Vernalis Adaptive Management Program. 


\subsection{Potential Impacts}

Phytoplankton have the potential to be a considerable component of the organic matter entering the SJR from the Grasslands Basin wetlands. In many settings, algae growth responds strongly to the increases in light and temperature during the transition from spring to summer. Delaying the start of the wetland drawdown from March $15^{\text {th }}$ until May $1^{\text {st }}$ is likely to increase the gross growth of phytoplankton and possibly the discharge of suspended solids to the SJR. Actual net growth and discharged mass will depend on the extent of algae losses due to invertebrate grazing, sedimentation, and other factors. Prolonging the flooded period into May also gives attached and metaphyton algae more time to grow. This added growth time could lead to greater areas of the wetlands being covered with floating algae mats or scum (e.g., Cladophora, Oscillatoria, Anabaena) and mats of benthic algae that have floated to the surface.

The increase in phytoplankton productivity is expected in proportion to the increase in insolation. In the San Joaquin Valley, daily insolation typically increases about $40 \%$ from late March to early May $\left(\sim 250 \mathrm{~W} / \mathrm{m}^{2}\right.$ up to $\left.\sim 350 \mathrm{~W} / \mathrm{m}^{2}\right)$ and air temperature increases by $5-7^{\circ} \mathrm{C}$. For similar light increases, green algae phytoplankton productivity has increased 40\%-60\% in eutrophic ponds (Oswald, 1996). The production of

periphyton can increase even more, rising from 8 to $18 \mathrm{~g} / \mathrm{m}^{2} / \mathrm{d}$ (volatile solids) from March to May in shallow raceways flowing with nutrient-rich treated wastewater (Craggs, et al. 1994). 
In shallow prairie lakes, phytoplankton gross productivity is about $10 \mathrm{~g} / \mathrm{m}^{2} / \mathrm{d}$ during summer (Hickman and Jenkerson 1978). If the depth were $0.5 \mathrm{~m}$ and no losses occurred, the resulting suspended solids concentration would increase by $20 \mathrm{mg} / \mathrm{L}$ in one day. Epiphytic algae biomass in wetlands ranges widely due to various light and nutrient conditions. As little as $5 \mathrm{~g} / \mathrm{m}^{2}$ of wetland to as much as $65 \mathrm{~g} / \mathrm{m}^{2}$ has been measured (Hooper and Robinson 1976, Hooper-Reid and Robinson 1978a). Measuring net algae production (with losses) under various conditions is one objective of the present project.

Algae growth during delayed drawdown could be limited by nutrients instead of by light and time. However, nutrient limitations seem unlikely given the mass of decaying vegetation and bird waste present in these wetlands. Water quality testing will be used to determine if nutrients or light limit algae growth during the delayed drawdown.

Delayed drawdown may result in higher concentrations of phytoplankton in wetland discharge and greater attached-algae biomass retained in the wetlands. Greater phytoplankton discharge would be a detriment to SJR water quality if these algae consume oxygen in the Stockton ship channel, and the algae would be undesirable in the intake to potable water treatment facilities due to its organic carbon content. On the other hand, soluble nutrients such as nitrogen and phosphorus assimilated by the additional algae and then retained in the wetland would improve the wetland discharge quality in terms of nutrients. Algae biomass typically contains $8 \%-10 \%$ nitrogen and 1\%-2\% phosphorus (Oswald, 1996) so an increase in phytoplankton concentration of $20 \mathrm{mg} / \mathrm{L}$, for example, should decrease soluble nitrogen by about $2 \mathrm{mg} / \mathrm{L}$ and soluble phosphorus 
by about $0.2 \mathrm{mg} / \mathrm{L}$. If the algae are retained in the wetland, soil organic matter and nutrient content would likely increase. This change in soil may influence wetland vegetation growth over many years.

A counter effect to water nutrient decreases would be the possible increased nutrient release rate from the sediments due to the warmer temperatures of April and May. Whether additional algae growth assimilates these additional nutrients is a topic of the present research.

Increased algae primary productivity should have a cascading positive effect on invertebrate populations including those invertebrates important as bird forage. The timing and extent of algae population increases is a major focus of the present research. 


\section{CHAPTER 3: MATERIALS AND METHODS}

\section{1 $\underline{\text { Site Descriptions }}$}

Three wetland sites were chosen with different hydraulic and vegetative characteristics in

order to gain information on a range of wetlands types, as described below. Images of the wetlands were copied from Google Earth. The images were then edited so that the traditionally drained wetlands (drained mid-March) are highlighted blue while the modified drainage wetlands (drained mid-April) are highlighted red. Transects used for sampling during 2007 are overlaid. Inlet and outlet weirs are marked. 


\subsubsection{Ducky Strike}

The Ducky Strike wetlands are located on private land within the Grassland Ecological Area (Figure 3-1). The wetlands are notably shallower than the other studied wetland pairs, which intensifies evaporation. Influent into these wetlands is typically higher in salinity compared to the other studied wetlands. The wetlands also operate flow through, in which the outlet of Ducky Strike South (DSS) is the inlet to Ducky Strike North (DSN).

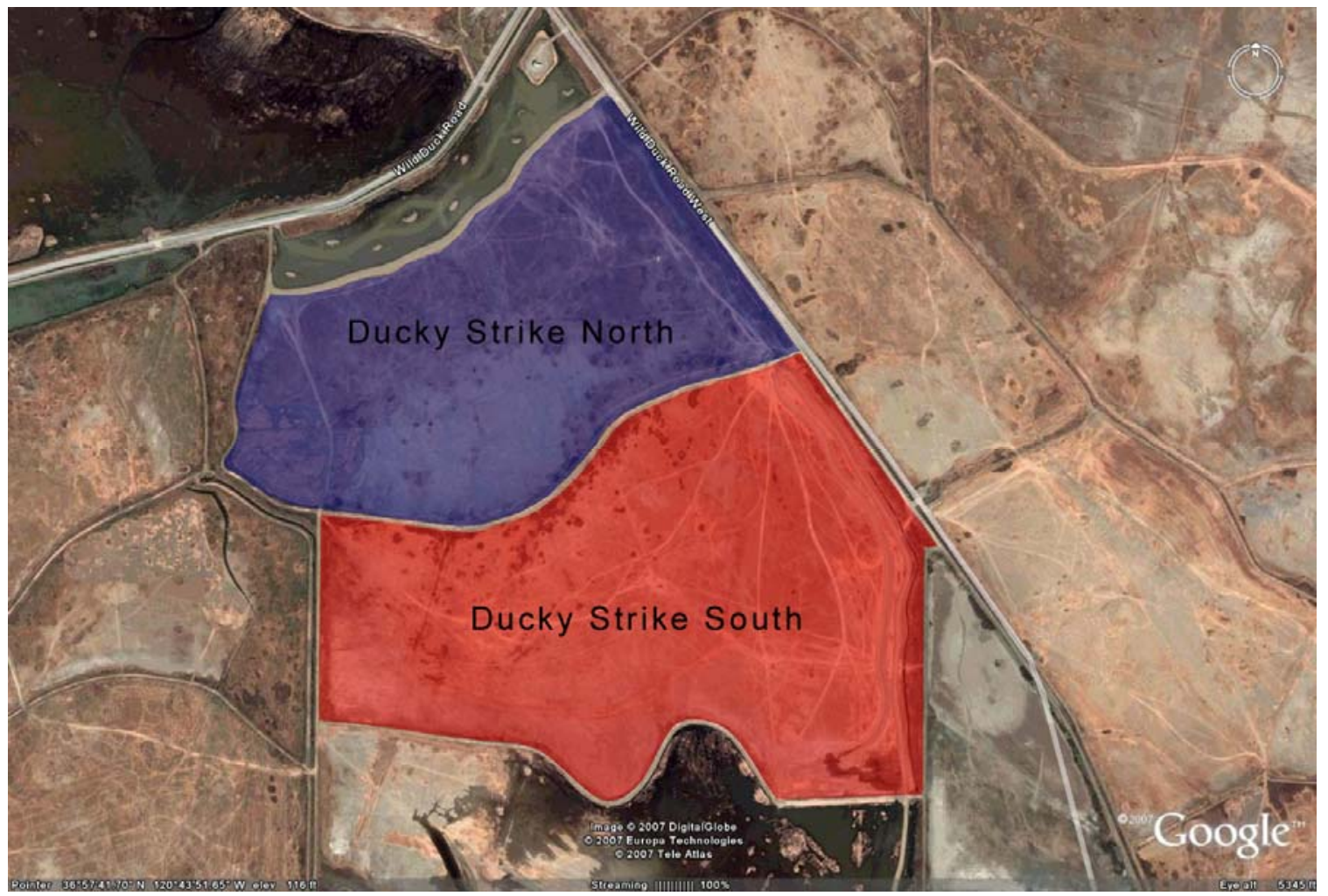

Figure 3-1: Ducky Strike North and South wetlands during the dry season. (Source: Google Earth.) 


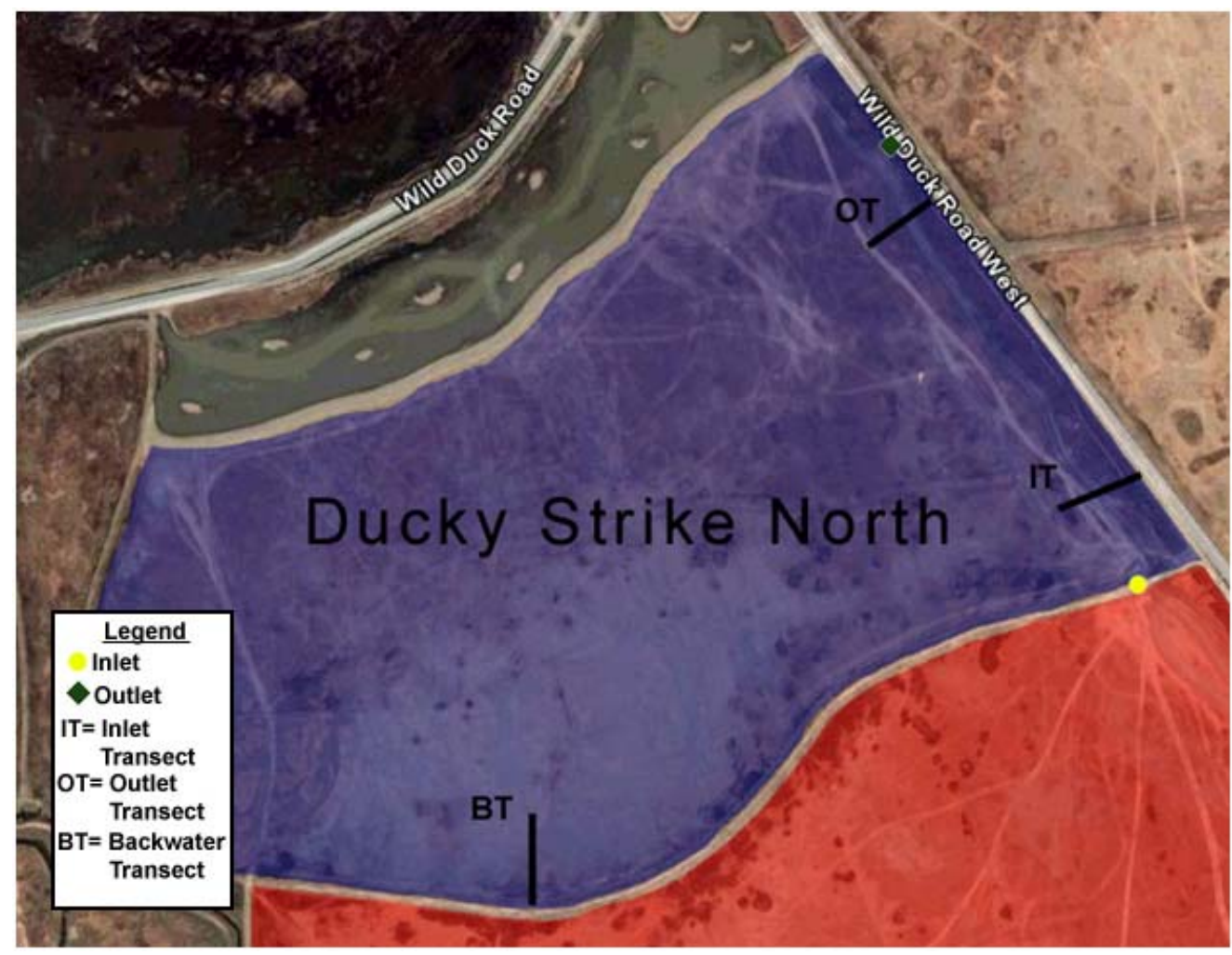

Figure 3-2: Ducky Strike North Google Earth image with inlet, outlet, and transect locations shown.

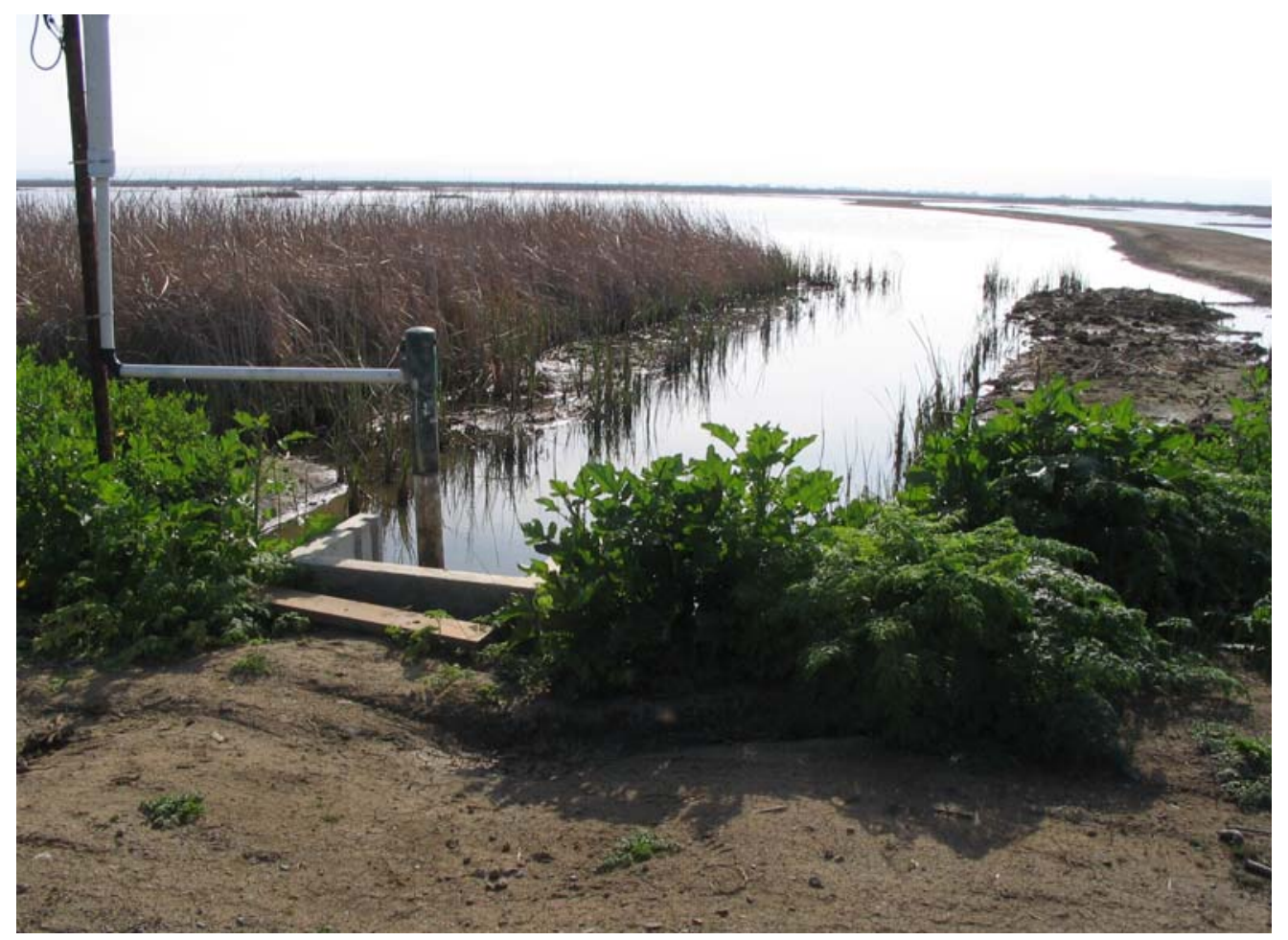

Figure 3-3: Ducky Strike North picture taken from outlet weir. 


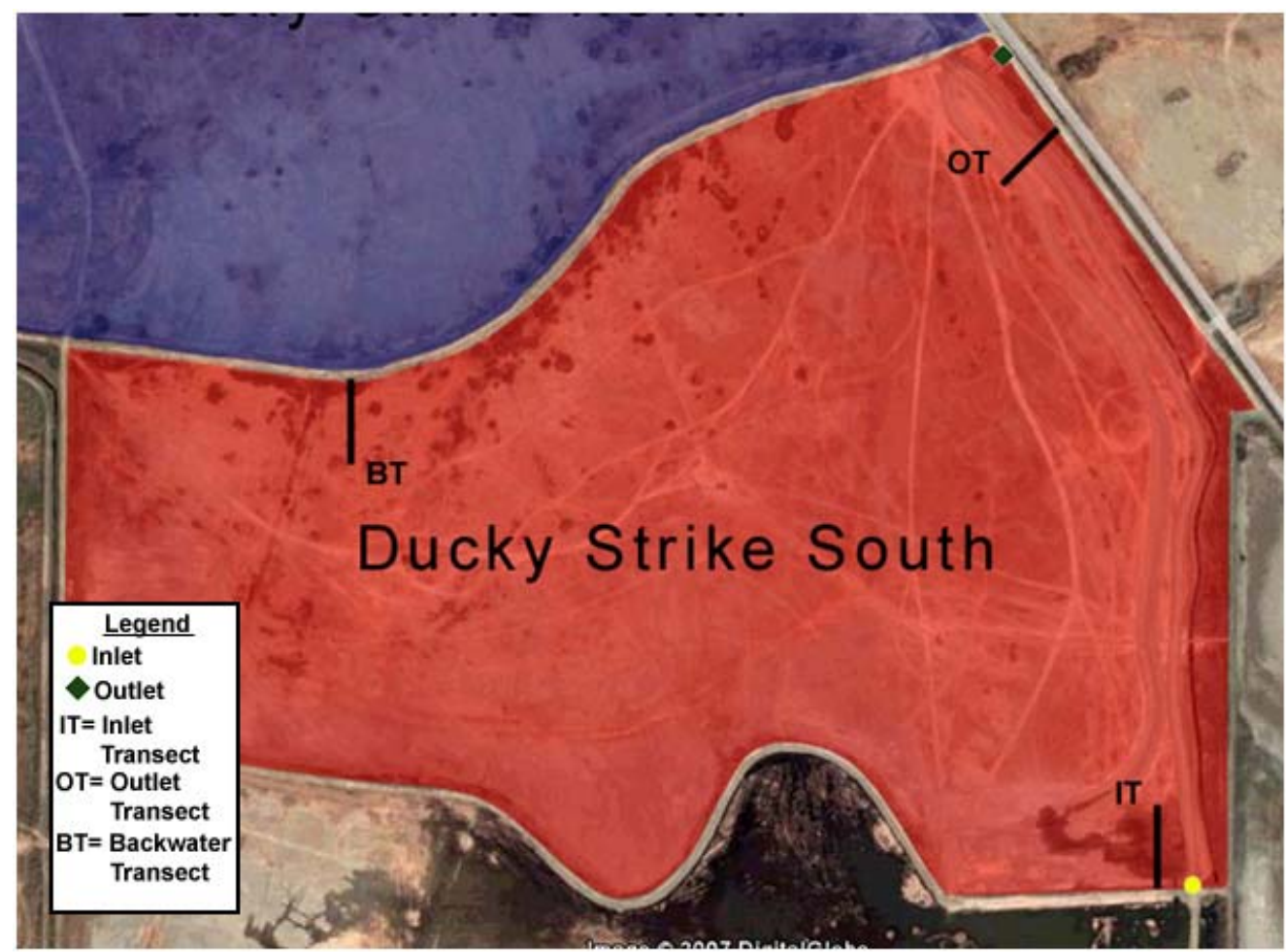

Figure 3-4: Ducky Strike South Google Earth image with inlet, outlet, and transect locations shown.

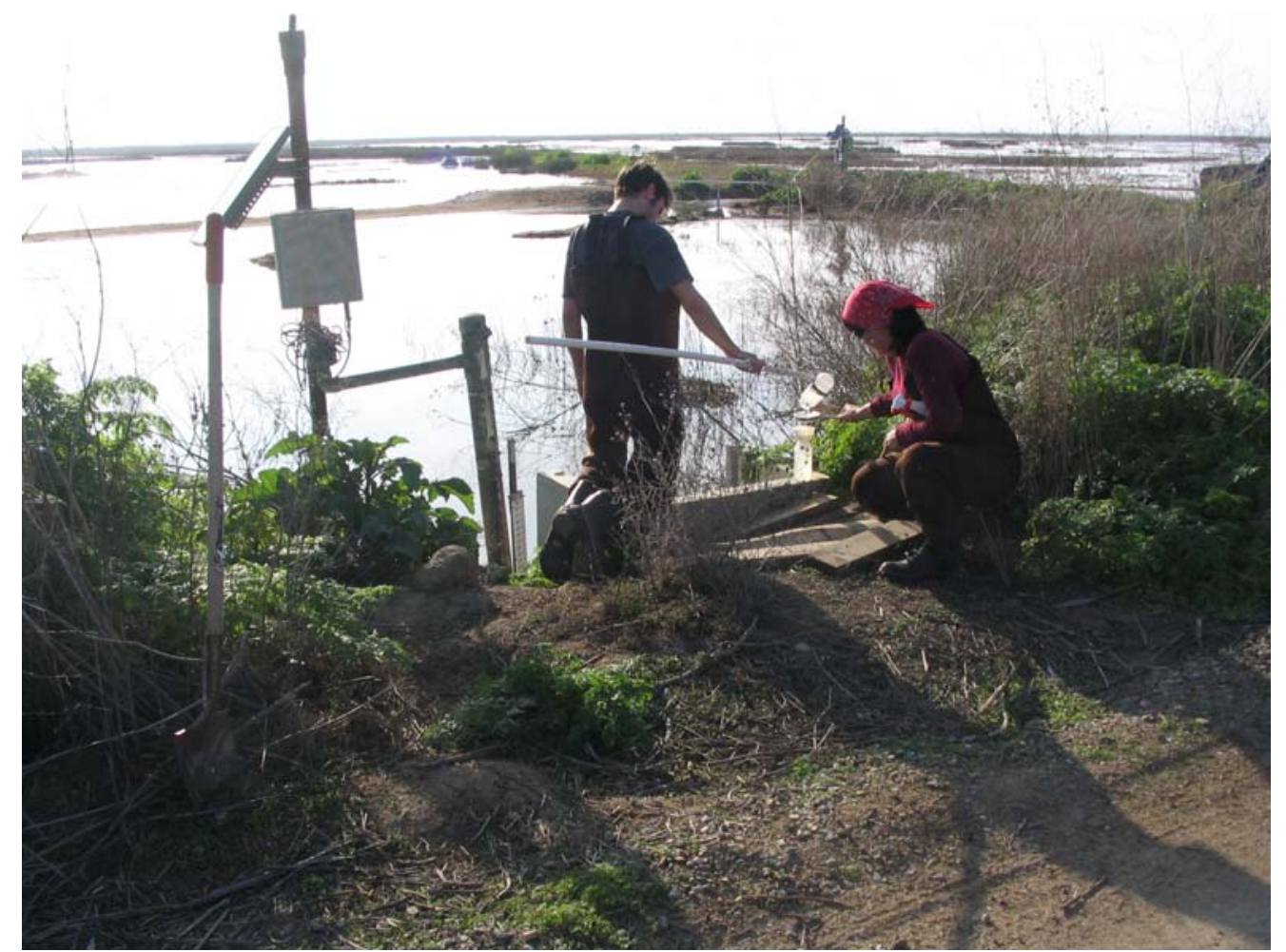

Figure 3-5: Ducky Strike South picture taken from outlet weir. Kyle Poole and Laleh Rastegarzadeh are shown collecting grab samples. 


\subsubsection{Los Banos Wildlife Area}

Los Banos Wildlife Area 33 and 31B wetlands (LBWA 33 and LBWA 31B respectively) are located in Los Banos Wildlife Area (Figure 3-6). These wetlands are deeper than the other studied wetlands and store a larger volume. The influent of these wetlands comes from the same source as the Mud Slough wetlands.

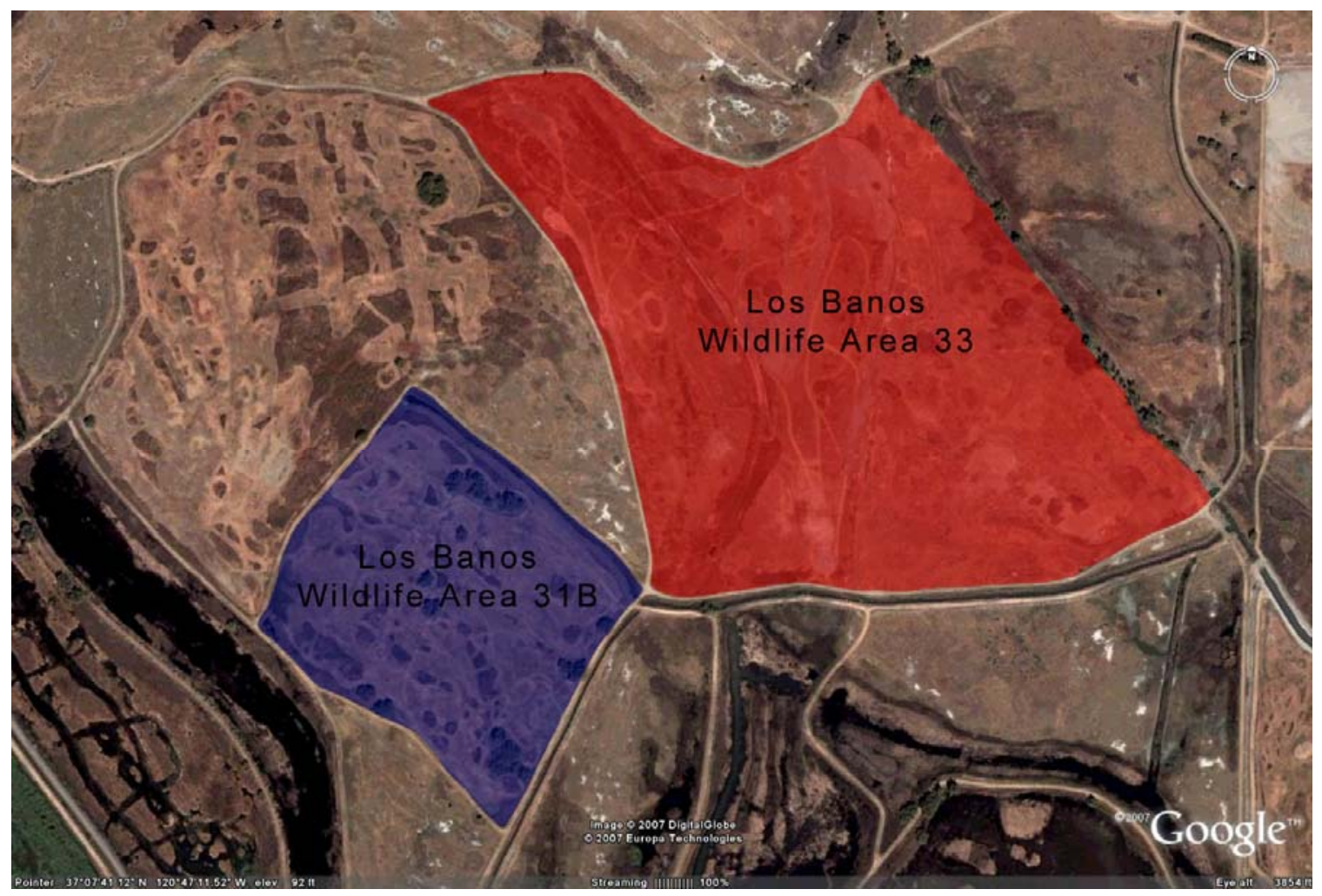

Figure 3-6: Los Banos 31B and 33B wetlands during the dry season. (Source: Google Earth.) 


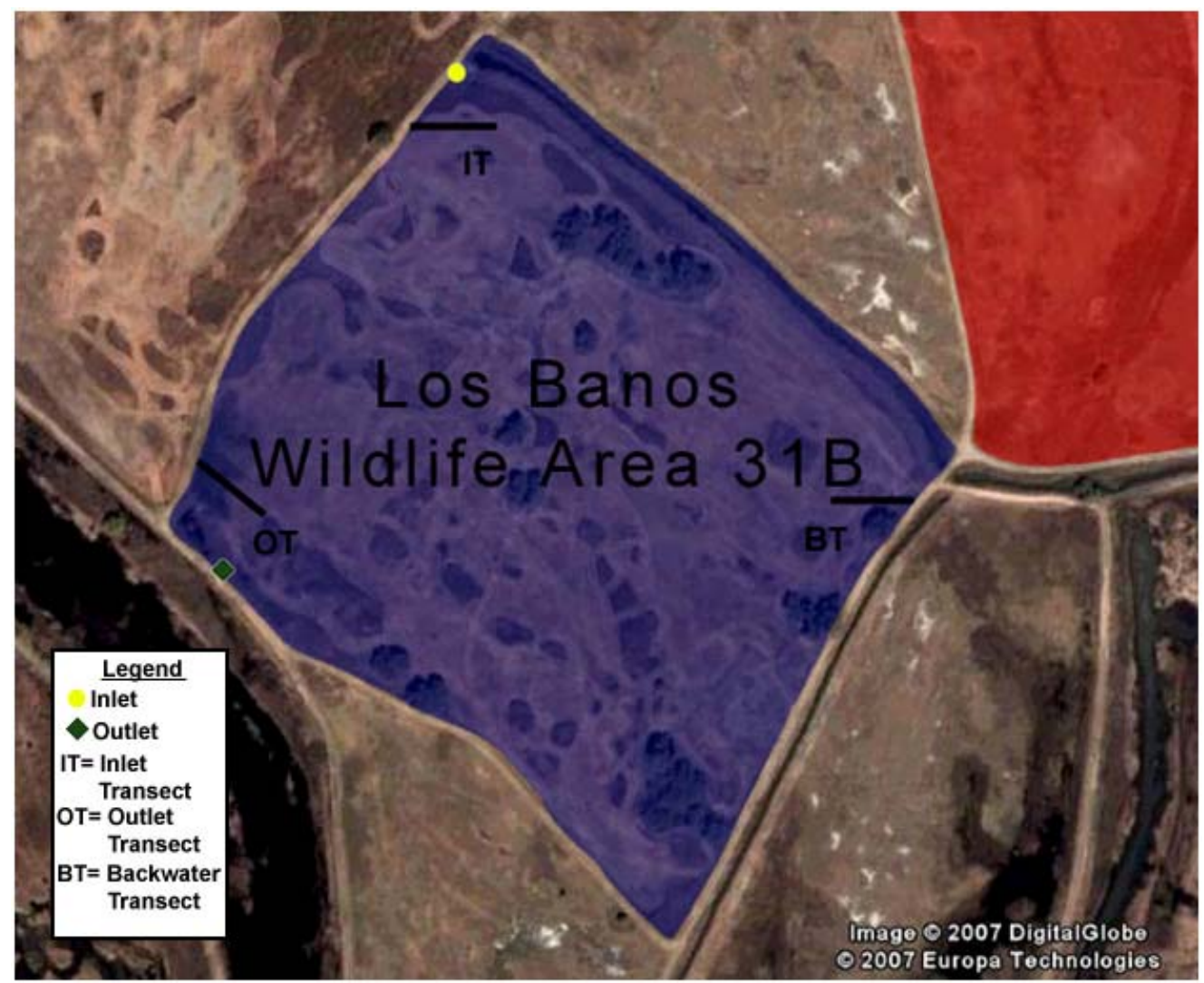

Figure 3-7: Los Banos Wildlife Area 31B Google Earth image with inlet, outlet, and transect locations shown.

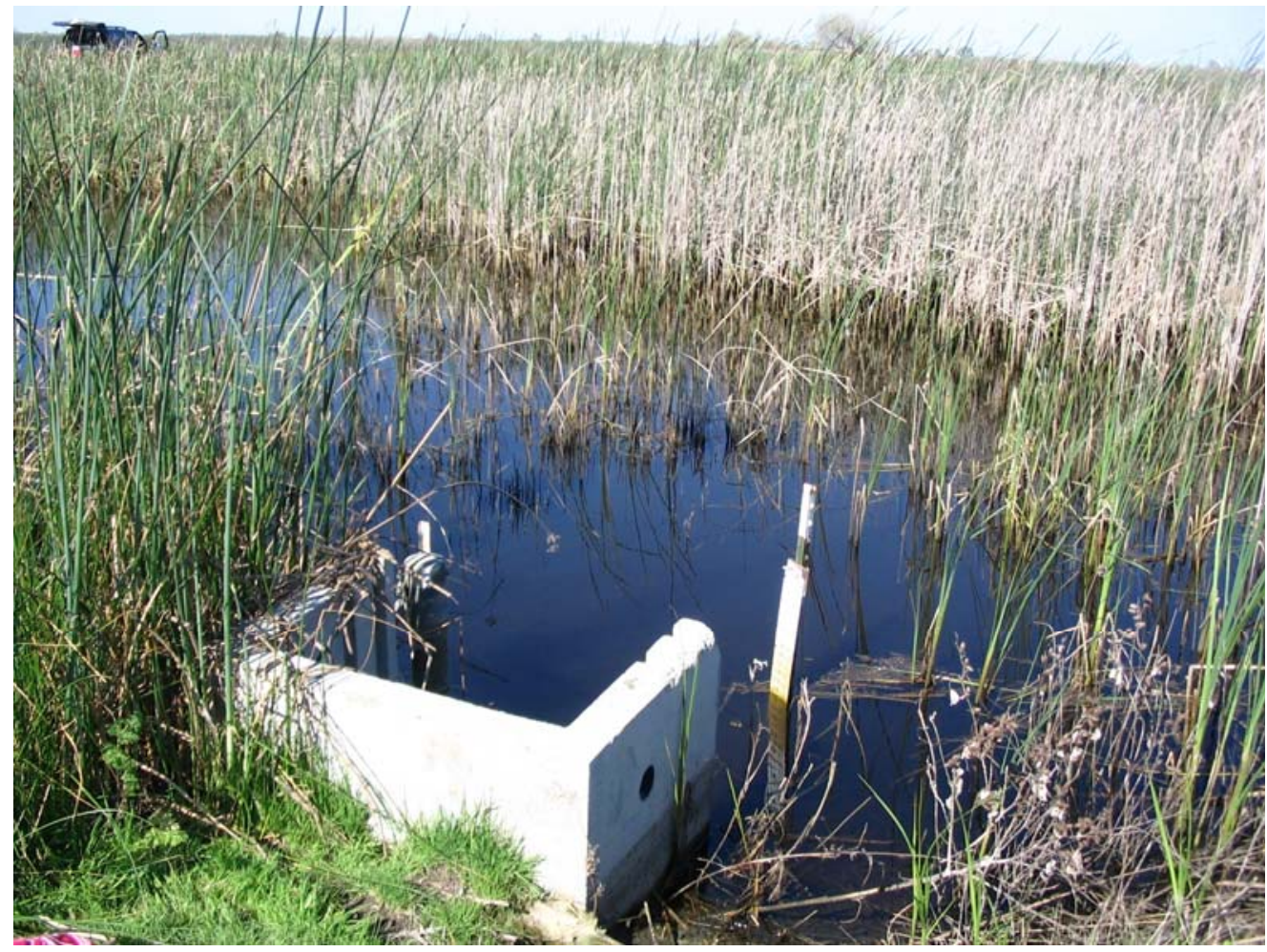

Figure 3-8: Los Banos Wildlife Area 31B picture taken from outlet weir. 


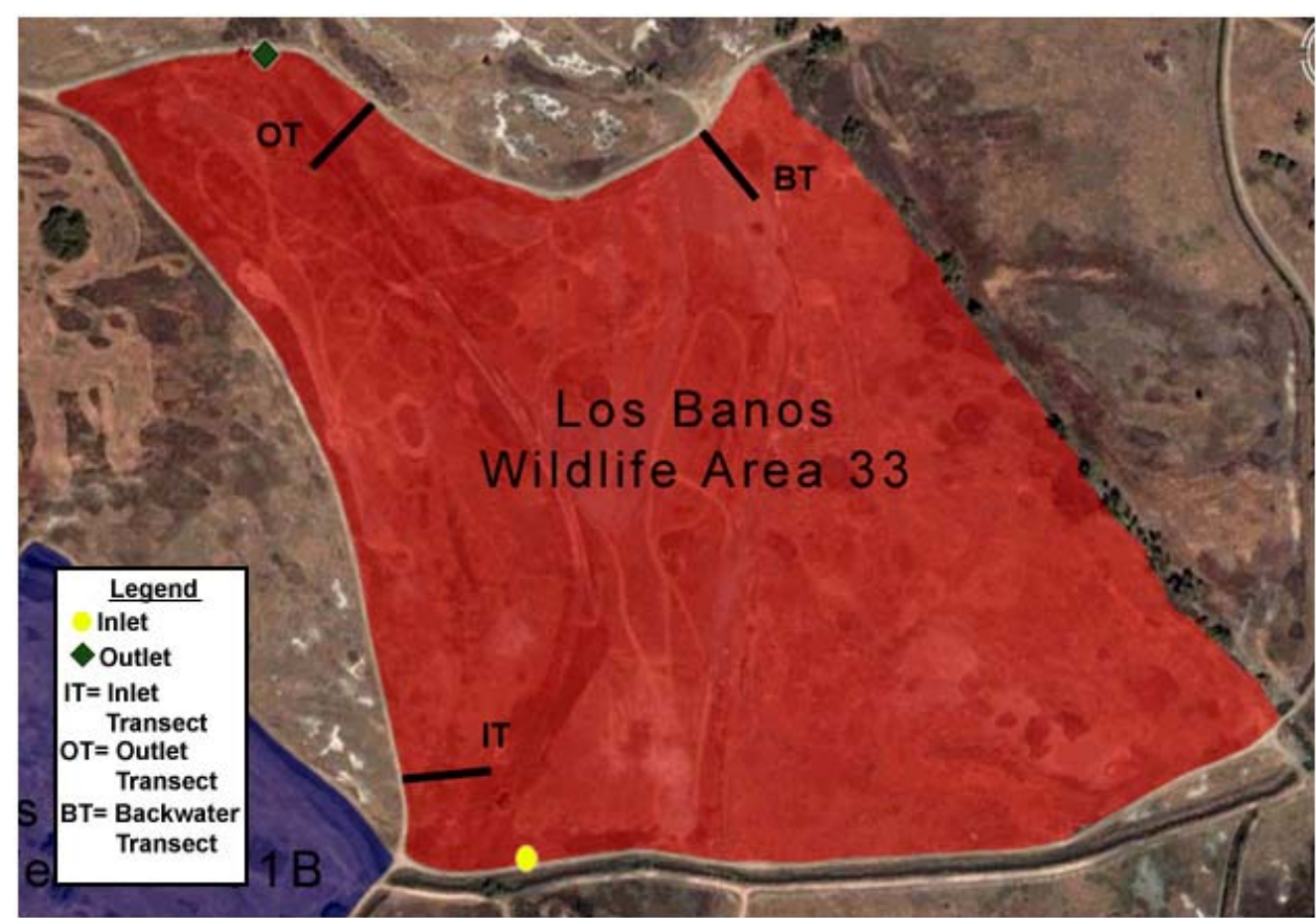

Figure 3-9: Los Banos Wildlife Area 33 Google Earth image with inlet, outlet, and transect locations shown.

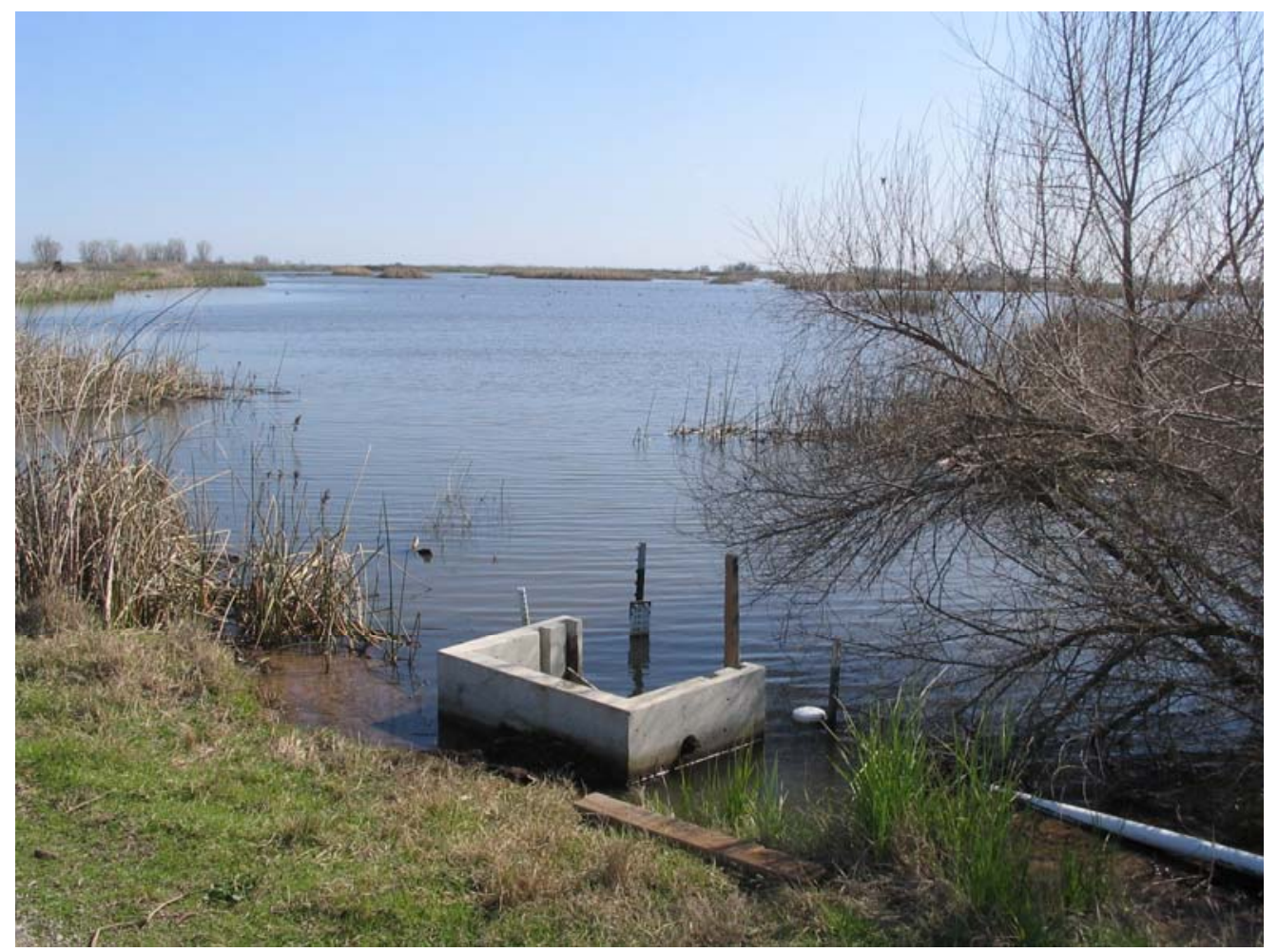

Figure 3-10: Los Banos Wildlife Area 33 picture taken from outlet weir. 


\subsubsection{Mud Slough}

Mud Slough 3B and Mud Slough 4b wetlands are located in the Mud Slough Wildlife Area. These wetlands have the most similar geometry. These wetlands have the same influent as the Los Banos wetlands.

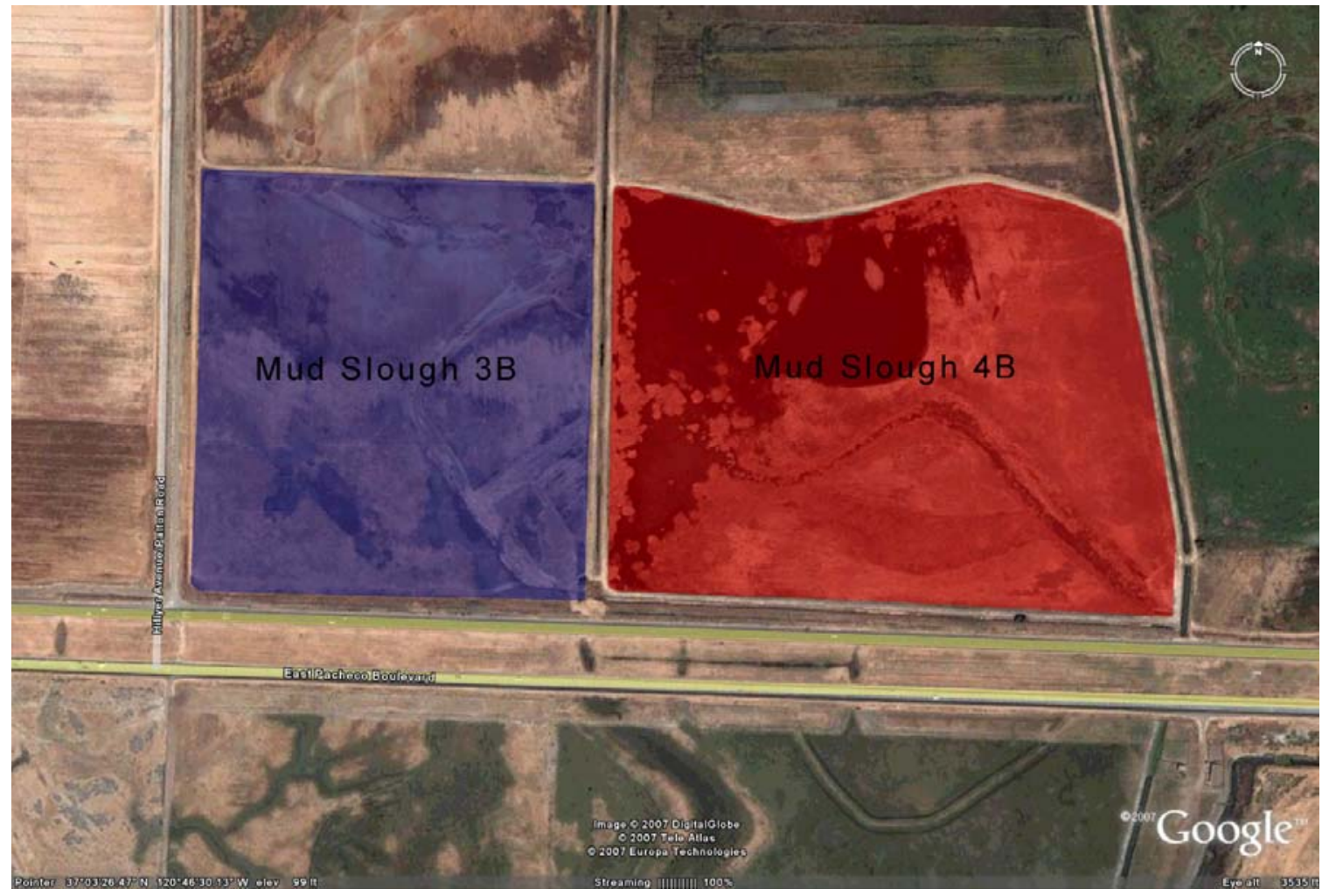

Figure 3-11: Mud Slough 31B and 33B wetlands during the dry season. (Source: Google Earth.) 


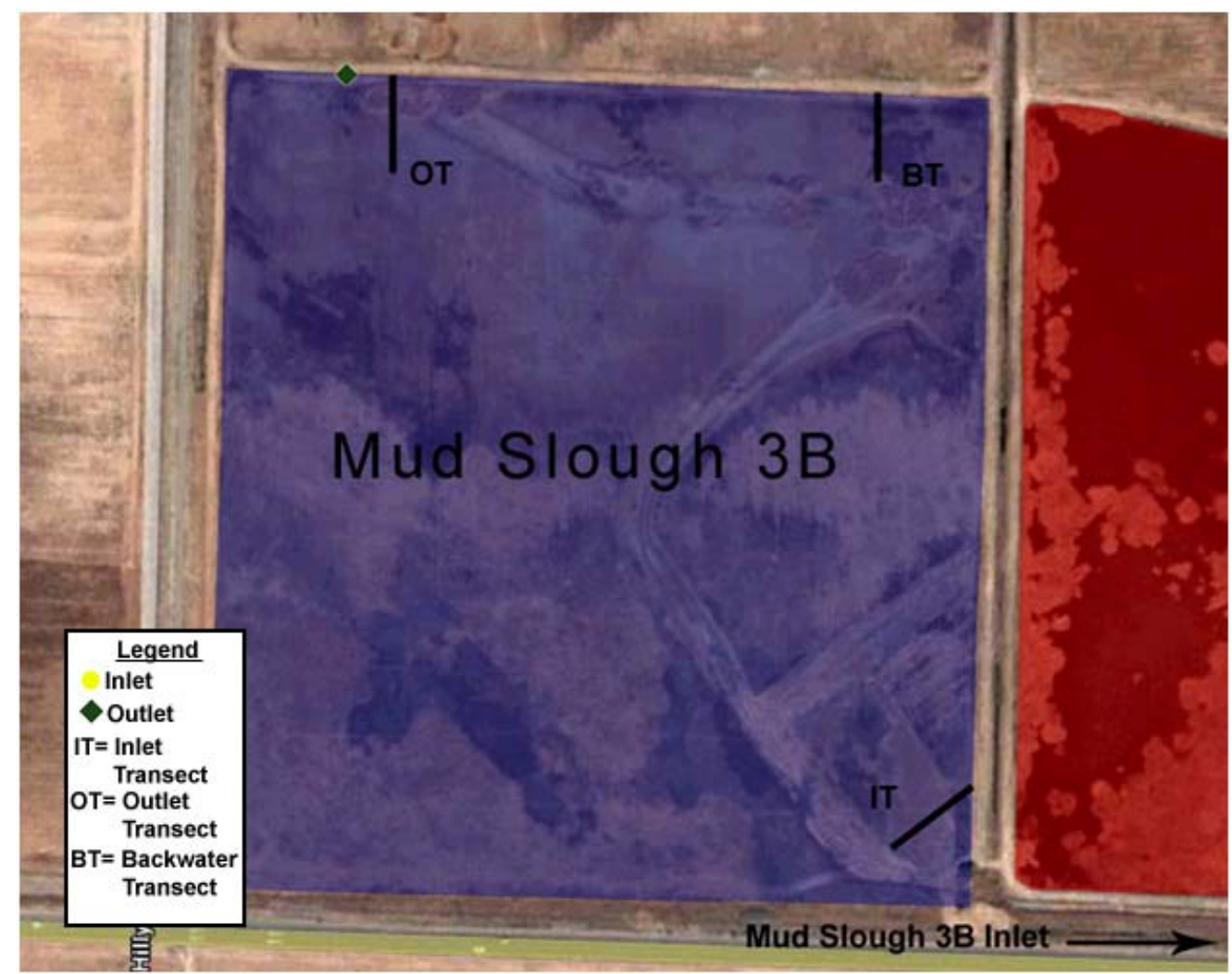

Figure 3-12: Mud Slough 3B Google Earth image with inlet, outlet, and transect locations shown.

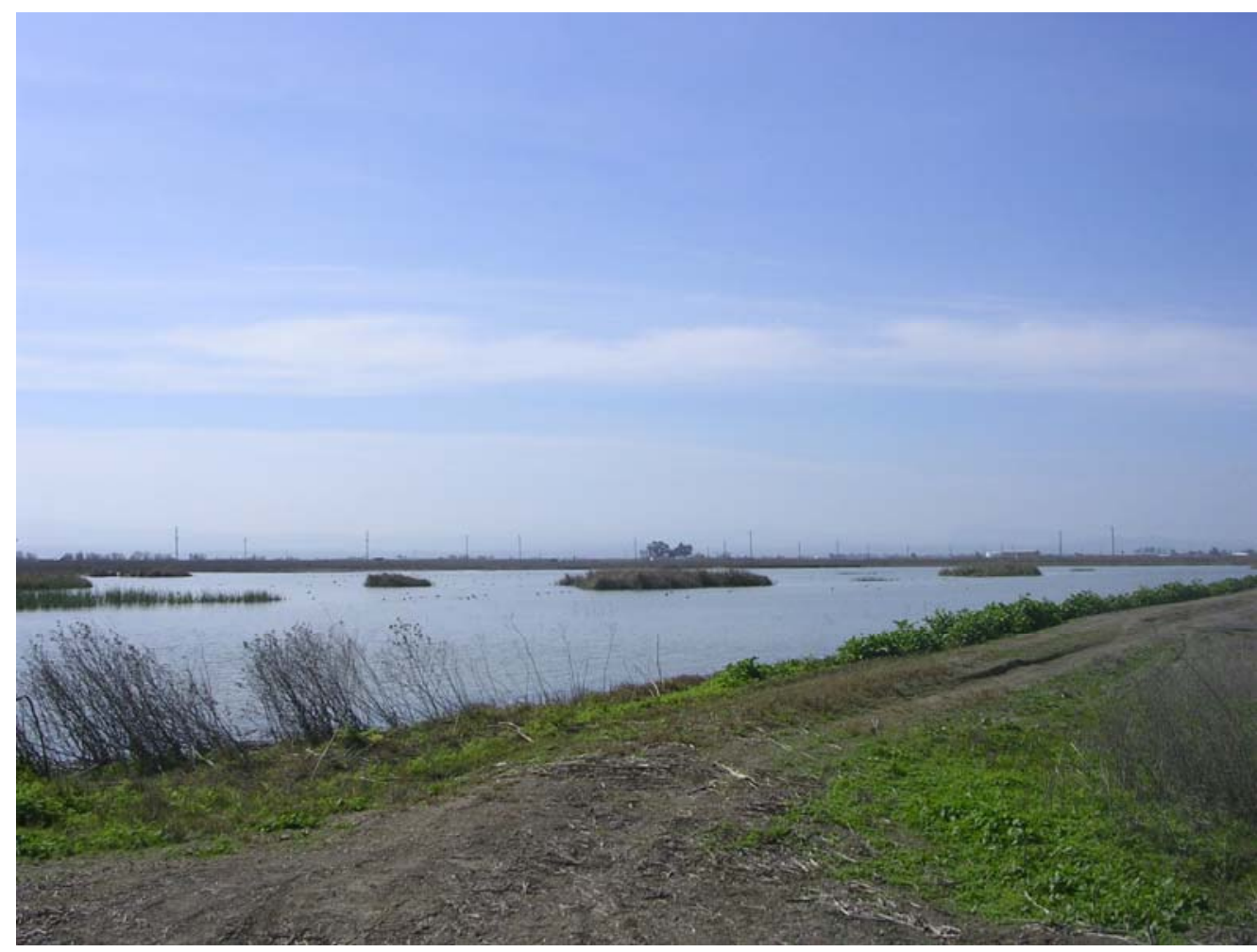

Figure 3-13: Mud Slough 3B picture taken near the backwater transect. 


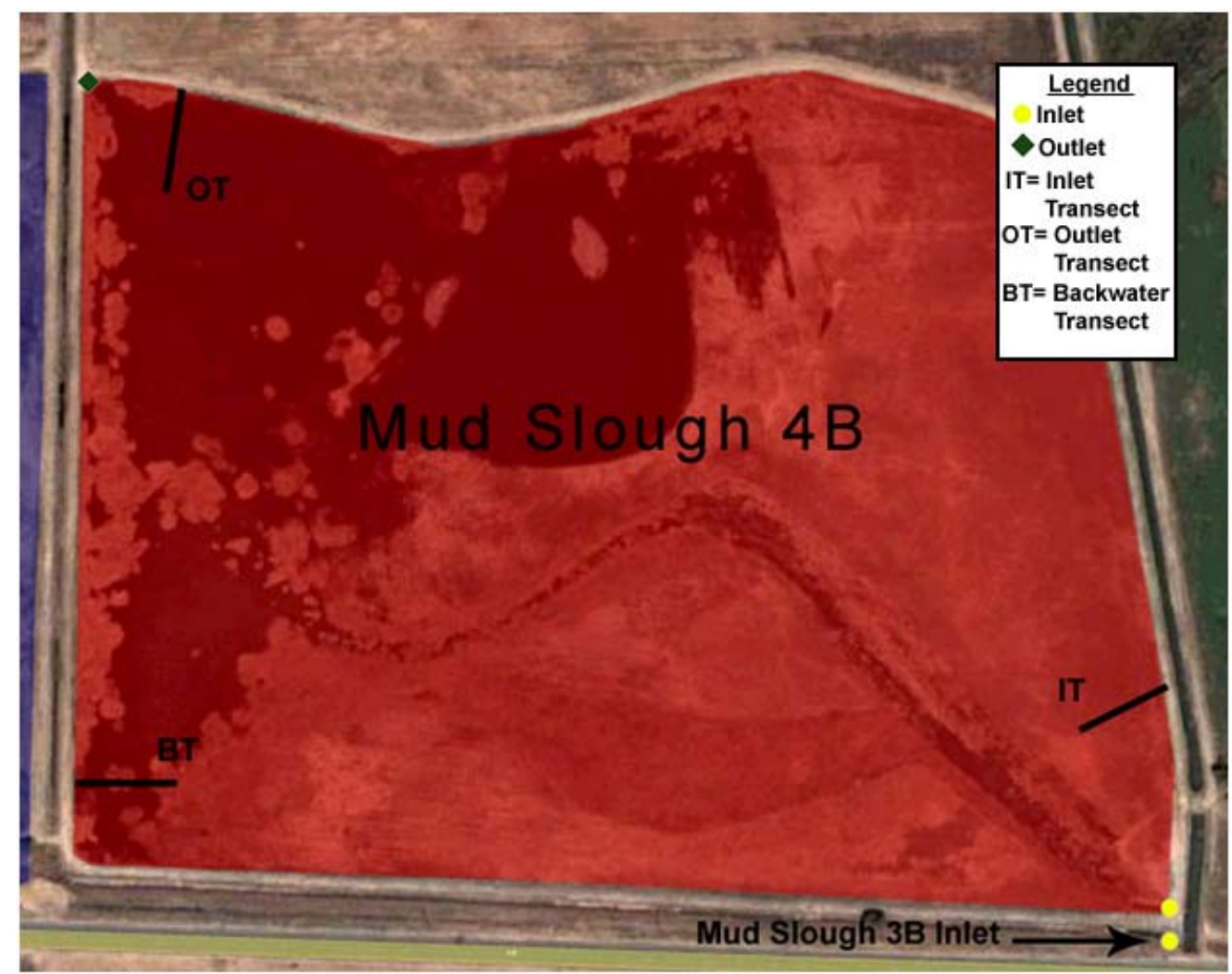

Figure 3-14: Mud Slough 4B Google Earth image with inlet, outlet, and transect locations shown.

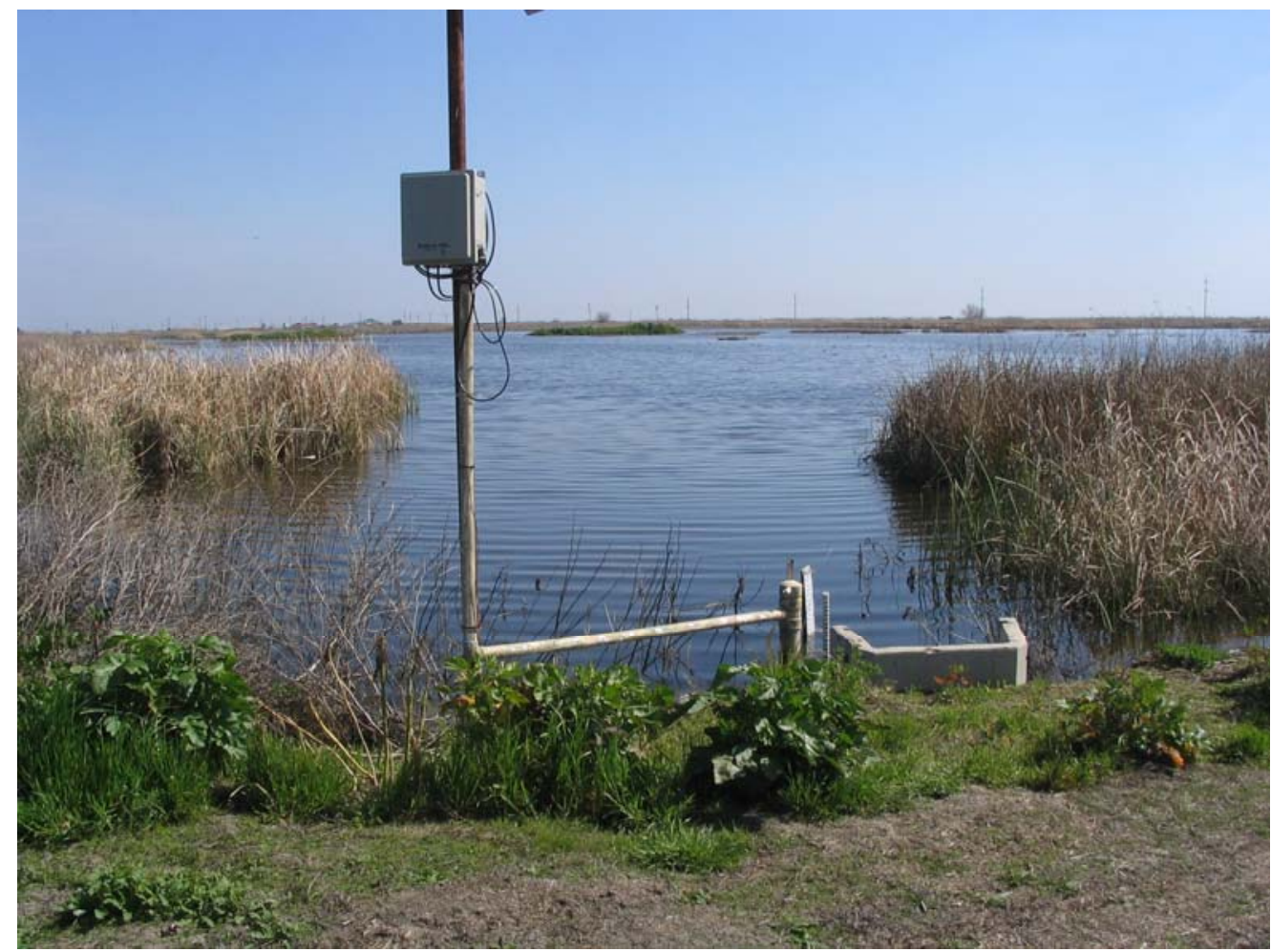

Figure 3-15: Mud Slough 4B picture taken from outlet weir. 


\subsubsection{Drainage Sites}

Buttonwillow and Los Banos 38 drainage sites were added during the 2008 season to better characterize the water quality of the drainage from the Los Banos Wildlife Area wetland complex after mixing with water from other management activities. This water is similar to the water that will actually be discharged to the SJR. These sites were chosen because the drainage from approximately $50 \%$ of the wetlands in the Los Banos Wildlife Area flow through these sites (Cooke, pers. comm., 2007).

These sites are not chosen study sites shared with collaborative efforts. Therefore, they do not have instrumentation for continuous measurement of flow. Flow was calculated by taking a depth measurement, which was used to calculate the cross-sectional area of the flow based on the known discharge pipe diameter. A velocity meter was used to measure the face velocity at three depths. The average of the three velocity measurements was used in combination with the cross-sectional area to calculate the flow rate. 


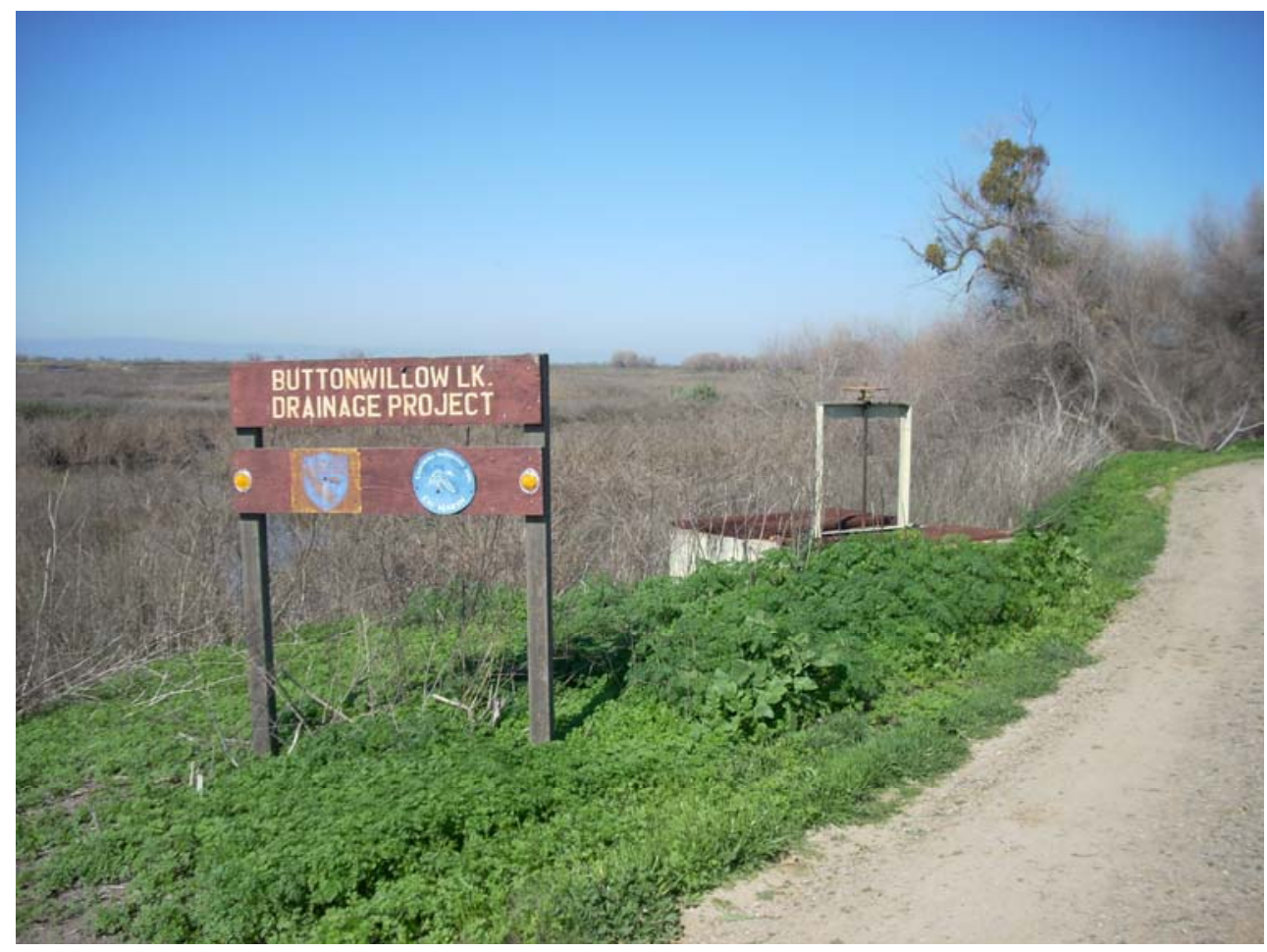

Figure 3-16: Buttonwillow drainage site.

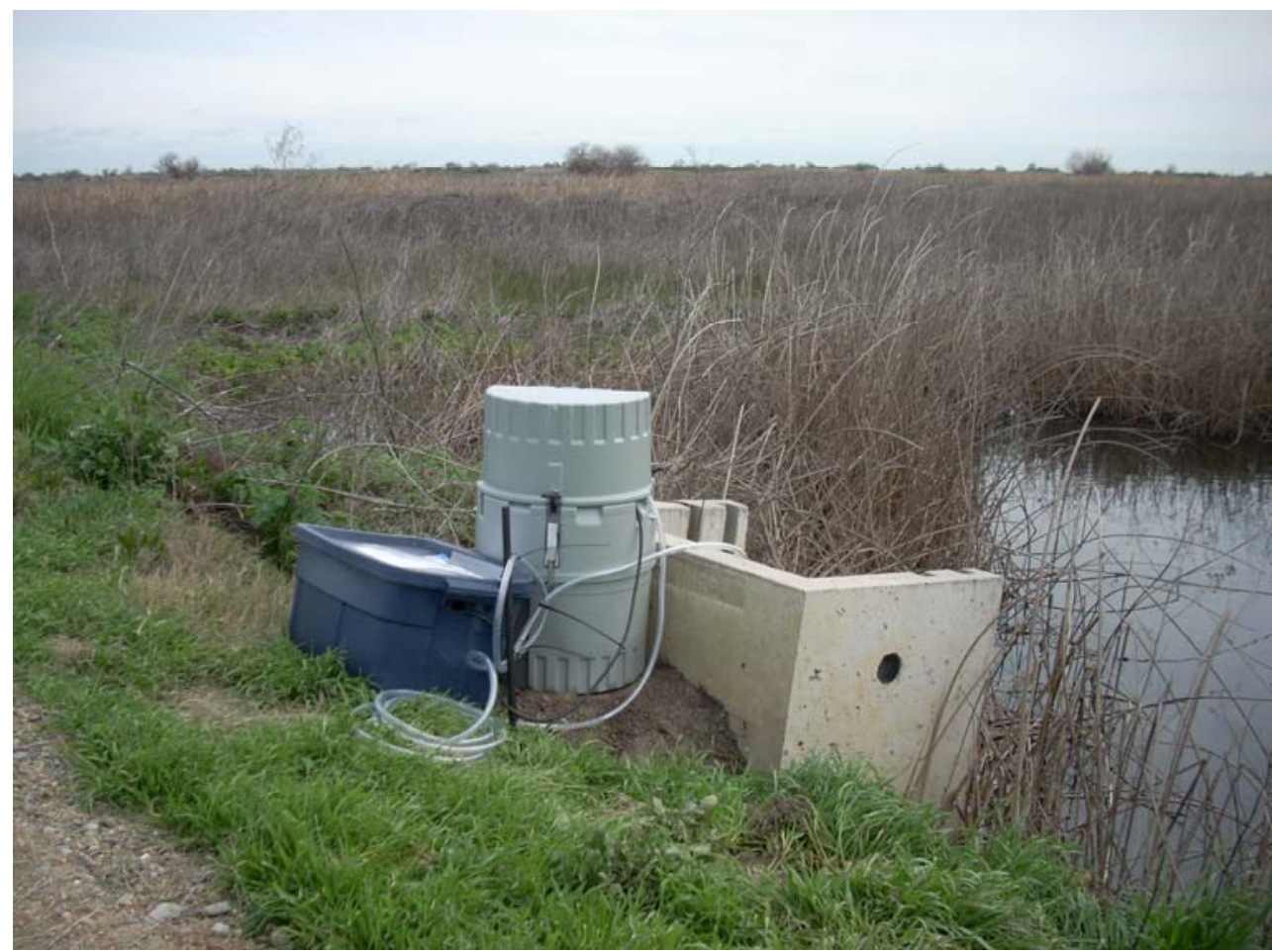

Figure 3-17: Los Banos Wildlife Area 38 drainage site with auto-sampler in place. 


\subsection{Sampling Methods: 2007 Season}

Sampling during 2007 consisted of inlet and outlet grab sampling as well as transect sampling as described in the following sections. Sampling was conducted across two days while the control wetlands were flooded and on one day when the control wetlands were drained. Samples were taken from each wetland on three sampling sessions: March 2/3, March 17/18, and April 17. Since phytoplankton concentrations vary diurnally, sampling was conducted as close to 9:00 AM as possible for consistency. Past freshwater studies have shown that sampling at 9:00 AM best represents the day's average for phytoplankton, nutrients, and oxygen demand (Green et al., 1996). Water samples were stored in $0.5 \mathrm{~L}$ high density polyethylene containers.

The drawdown of treatment wetlands was delayed by approximately one month. The traditional wetlands were drained on March 17 (traditionally drained in mid-March), while the modified wetlands were drained on April 17. The wetlands were flooded at the same time since flood-up timing can alter invertebrate densities (Batzer et al. 1997).

\subsubsection{Inflow and Outflow Sampling}

A 2-L grab sample was taken from each wetland's inlet and outlet weir by placing the opening of an HDPE container in the weir flow stream. Continuous flow, depth, conductivity, and temperature data were metered at the inlet and outlet weirs by collaborative studies.

\subsubsection{Transect Sampling}

Three transects were used at each wetland to characterize changes in the wetlands along the "flow line" (defined as the line connecting the inlet and outlet weirs) and in the 
backwater dead zones. To accomplish this, a transect was made near the inlet, inlet transect (IT); near the outlet, outlet transect (OT); and in the corner furthest from the flow line, backwater transect (BT). Transects did not completely cross the width of the wetland to minimize disturbances to other ongoing research. Each transect was made at a random distance between 20'-50' from the inlet/outlet/backwater corner. The orientation of the transects was made perpendicular to the flow line except for the BT, which was made to be perpendicular to the prevailing wind. Three samples were collected along each transect; 1 within $3^{\prime}$ of the shoreline and 2 at random distances between 10'-100'. Random numbers were selected from a random number table generated using a Texas Instruments TI-83 Plus graphing calculator. Numbers were thrown out if they were not within the set limits (e.g. less than 10' or second sample passed the far edge of the wetland). At each sampling location temperature, depth, $\mathrm{pH}$, and habitat type data were recorded. Water and soil samples were collected as described in sections 3.2.2.1 and 3.2.2.2.

\subsubsection{Water Column Samples}

All sample containers were triple DI rinsed prior to sampling and rinsed once more with water from the sampling location before collection. Multiple samples were taken at locations with low visible turbidity to ensure adequate sample volume for analysis. Water samples were collected using a 6' pole sampler with a $0.5 \mathrm{~L}$ high density polyethylene sampling container. The sample was collected upstream of the transect line. The sampling device was submerged to a depth near the bottom of the wetland with the opening of the container face down. At sampling locations with a depth $>15 \mathrm{~cm}$, the sampling device was brought to a depth of $5 \mathrm{~cm}$. For sampling locations with a depth $<15$ 
$\mathrm{cm}$, the sampling device was carefully lowered close enough to the soil to collect a representative sample without disturbing sediments. The pole was then rotated and lifted to collect the sample. This method was used to integrate the sample throughout the depth of the sample location. The collected sample was then poured into a $0.5 \mathrm{~L}$ high density polyethylene container. Samples were stored on ice during transport to laboratory. Upon arrival to the laboratory, the samples were divided, analyzed, and preserved as described in the section 3.4.

\subsubsection{Soil Samples}

Soil samples were collected along each transect at water sample locations to identify and enumerate benthic organisms living within the top $5 \mathrm{~cm}$ of topsoil. Soil samples were taken using 6" diameter plastic corer with a sharp rim. The cup was pressed through loose detritus and then $5 \mathrm{~cm}$ into the soil. A gardening spade was then placed under the corer to aid in bringing the soil to the water surface. The soil sample was stored in a low density polyethylene zip lock bag and placed on ice during transport to the laboratory.

\subsection{Sampling Methods: Changes for 2008 Season}

Sampling methods were changed to further minimize disturbances for avian and moist soil studies as well as concentrate the focus of this project's research. To truly characterize the wetlands with transect sampling would have required more resources and caused much greater disturbances to other ongoing research. Transect sampling was replaced by more frequent outlet sampling. Inlet grab sampling was planned; however no sampling occurred since the inlets were not flowing on any of the chosen sample dates. Still, flow and electro-conductivity data was collected through continuous sampling from 
other allied projects. Since no transect sampling took place, benthic sampling was also removed.

During the 2008 season, the traditional wetlands were drained on March 17 while the modified wetlands were drained on April 18. Outlet sampling occurred on a bi-monthly basis. Sampling at the drainage sites were increased to a bi-weekly basis for one week after each drawdown to observe any spike in water quality constituents due to the drawdown of the wetlands. In place of grab samples, 4 auto-samplers (2x Teledyne ISCO 6712, 1x SIGMA 900 MAX, and 1x SIGMA 1350) were used to sample the six wetland pairs and two drainage sites over two days. Auto-samplers were utilized to produce daily averages of water quality constituents as well as phytoplankton and zooplankton densities. Auto-samplers were also used to observe diurnal fluctuations in phytoplankton densities. The auto-samplers were placed near the outlets and took samples every 2 hours for a period of 24 hours (12 samples total), which created a daily composite sample.

During the drawdown of the modified drainage wetlands (mid-April drawdown), multiple grab samples were taken from the outlets. This was done to characterize the change in water quality during the drawdown due to scouring of sediment. The wetlands are drained by removing weir boards individually to maximize forage for water birds. After each weir board was removed a grab sample was taken until the wetland was drained.

\subsection{Analytical Methods}

Upon arrival at the laboratory, water samples were either analyzed immediately or divided and preserved according to APHA Standard Methods. 


\subsubsection{Water Quality Analysis}

Water quality analyses were performed to characterize the discharge from the wetlands as well as determine limiting factors affecting phytoplankton growth. Table 3-1 summarizes the water quality tests performed and methods used for analysis. 
Table 3-1: Water quality methods of analysis. APHA methods are from the 2005 edition.

\begin{tabular}{|c|c|}
\hline Parameter & Method of Analysis \\
\hline Alkalinity & APHA 2320-B: Titrimetric method. \\
\hline Ammonia & Fluorometry (Holmes 1999) \\
\hline Conductivity & APHA 2510-B \\
\hline Hydrogen Ion Concentration (pH) & APHA $4500-\mathrm{H}^{+}-\mathrm{B}$ : Potentiometry. \\
\hline $\begin{array}{l}\text { Nitrate }\left(\mathrm{NO}_{3}^{-}\right) \text {, Nitrite }\left(\mathrm{NO}_{2}^{-}\right) \text {, Phosphate } \\
\left(\mathrm{PO}_{4}^{3-}\right) \text {, Chloride }\left(\mathrm{Cl}^{-}\right)\end{array}$ & Ion exchange chromatography. \\
\hline Total Kjeldahl Nitrogen (TKN)* & $\begin{array}{l}\text { APHA } 4500-\mathrm{N}-\mathrm{N}_{\text {org }}-\mathrm{B} \text { and } 4500-\mathrm{NH}_{3}-\mathrm{C} \text { : } \\
\text { Distillation with titrimetric finish. }\end{array}$ \\
\hline Organic Carbon* & $\begin{array}{l}\text { APHA 5310-B: High temperature combustion } \\
\text { method }\end{array}$ \\
\hline $\begin{array}{l}\text { Total Phosphorus, Phosphate }\left(\mathrm{PO}_{34}^{3-}\right) \\
{[2008]}\end{array}$ & $\begin{array}{l}\text { APHA 4500-P-B and 4500-P-E: Persulfate } \\
\text { digestion followed by ascorbic acid } \\
\text { colorimetry. }\end{array}$ \\
\hline Total and Volatile Suspended Solids & $\begin{array}{l}\text { APHA 2540-B, 2540-C, 2540-E, 2540-F: } \\
\text { Filtration, oven drying, and ashing. }\end{array}$ \\
\hline Turbidity & Method 2130-B: Light dispersion. \\
\hline
\end{tabular}

*Not measured during 2007 sampling season

\subsubsection{Alkalinity}

Although unlikely in freshwater wetlands, alkalinity was measured to determine if algae growth might have been limited by bicarbonate-C concentration. Alkalinity was measured within 12 hours of sampling. Alkalinity measurements were taken only when a samples $\mathrm{pH}$ was greater than 9.0, which indicates the beginning of bicarbonate-C 
limitation and the likelihood of a decreased number of algal species thriving (Vymazal 1995). Alkalinity was determined by the APHA 2320-B. Titration Method.

\subsubsection{Nutrients}

Nutrient testing was performed to determine the amount of soluble nutrients being discharged from the wetlands and to determine if nutrient concentrations in the wetlands were limiting phytoplankton growth. Nitrate $\left(\mathrm{NO}_{3}{ }^{-}\right)$, nitrite $\left(\mathrm{NO}_{2}{ }^{-}\right)$, and phosphate $\left(\mathrm{PO}_{4}{ }^{3-}\right)$ were analyzed using ion exchange chromatography. The $\mathrm{PO}_{4}{ }^{3-}$ method was changed to APHA 4500-P-E: ascorbic acid colorimetry during the 2008 season to decrease the detection limit and increase accuracy. A detailed ion chromatography method is described in Appendix B: Ion Chromatography. Ammonia concentrations were determined using fluorometry (Holmes 1999).

Nitrogen testing was performed to monitor the amount of $\mathrm{NO}_{3}{ }^{-}, \mathrm{NO}_{2}{ }^{-}$, total ammonia, and TKN present in the wetlands discharges. Nitrogen testing also was used to determine nitrogen content of the phytoplankton. Phytoplankton nitrogen content was calculated by subtracting the total ammonia present in a sample from the TKN. This concentration was then divided by the volatile suspended solids concentration to find the percentage of nitrogen in the cells.

Phosphorus testing was performed to determine the amount of soluble phosphate $\left(\mathrm{PO}_{4}{ }^{3-}\right)$ and total phosphorus present in the wetlands' discharge. Phosphorus testing was also used to calculate the amount of phosphorus present in the phytoplankton. This was calculated by subtracting the $\mathrm{PO}_{4}{ }^{3-}$ present in a sample from the total phosphorus (TP). 
This concentration was then divided by the volatile suspended solids concentration to find the percentage of phosphorus in the cells.

\subsubsection{Suspended Solids}

Volatile suspended solids (VSS) measurements were used to quantify the mass of phytoplankton present in a sample and to determine the amount of insoluble biodegradable organic matter being discharged to the SJR. Due to low volatile suspended solids concentrations, the volume of filtered sample was increased to as much as one liter to ensure the an adequate amount of volatile solids were present.

\subsubsection{Organic Carbon}

Dissolved organic carbon (DOC) was analyzed to determine the amount of soluble organic carbon being discharged from the wetlands. Samples were filtered $(0.2 \mu \mathrm{m})$ and analyzed using a Shimadzu TOC-5000A analyzer, which uses the high-combustion NDIR detection method, as described in APHA 5310-B. Samples of $10 \mathrm{~mL}$ volume were acidified and sparged with Ultra-Zero grade compressed air for 10 minutes before injection. The mean of three injections was recorded once the covariance of the results was less than $5 \%$.

The Shimadzu TOC-5000A analyzer's circuit board malfunctioned during analysis of total organic carbon (TOC). Therefore, TOC was estimated by using a percentage of volatile suspended solids (particulate organic carbon) and adding this to the DOC. Studies reported in Table 4-1 of Jan Vymazal's Algae and Element Cycling in Wetlands 
were used to estimate average carbon content in fresh water algae. Eight studies yielded an average of $52.8+/-9 \%$ dry mass (mean $+/$ - standard deviation).

\subsubsection{Turbidity}

Turbidity measurements were used to determine if insolation was limiting growth in deep $(>30 \mathrm{~cm})$ areas of the wetlands. Turbidity was also used to create correlations with other water quality constituents to create possible real-time monitoring tools. Turbidity was analyzed using a Hach 2100P Portable Turbidimeter.

\subsubsection{Wetland Biota Analysis}

Analysis of wetland biota was conducted to observe changes in benthic invertebrate, phytoplankton, and planktonic invertebrate densities as described below.

\subsubsection{Phytoplankton}

Phytoplankton samples were preserved with Lugol's solution upon arrival to the laboratory. Phytoplankton concentrations were below the level necessary for statistical enumeration through direct counting. However, predominant algae species were identified using a trinocular Olympus CX 41 optical microscope with phase contrast and an Infinity 2 digital camera. Algal biomass was estimated by volatile suspended solids.

\subsubsection{Zooplankton}

Zooplankton were separated and collected from each sample using a 100- $\mu \mathrm{m}$ plankton screen. Invertebrates were removed from the screen with water after inverting the screen into a $45 \mathrm{~mL}$ polypropylene container with the use of a funnel. Zooplankton were enumerated through direct microscopic counting. Samples were poured into a divided 
Petri dish and counted under an optical dissecting microscope. Invertebrates were identified to the order level using Freshwater Invertebrates of the United States (Pennak, 1989). During the 2007 season, several random zooplankton samples were saved for VSS analysis. The VSS data were used to determine average biomass per invertebrate. This value allowed the conversion of numerical concentration data to mass concentration data so that invertebrate data could be compared directly with phytoplankton data. During the 2008 season, identification was discontinued along with transect sampling since the effluent samples were no longer representative of the wetland as a whole. In 2008, zooplankton biomass was recorded by conducting VSS analysis on both screened (100 $\mu \mathrm{m})$ and unscreened samples. The difference was recorded as the mass of zooplankton in the discharge. Any debris noticed in the unscreened samples was carefully removed in order to minimize error from detritus. Figure 3-18 shows screened and unscreened samples after oven drying. 


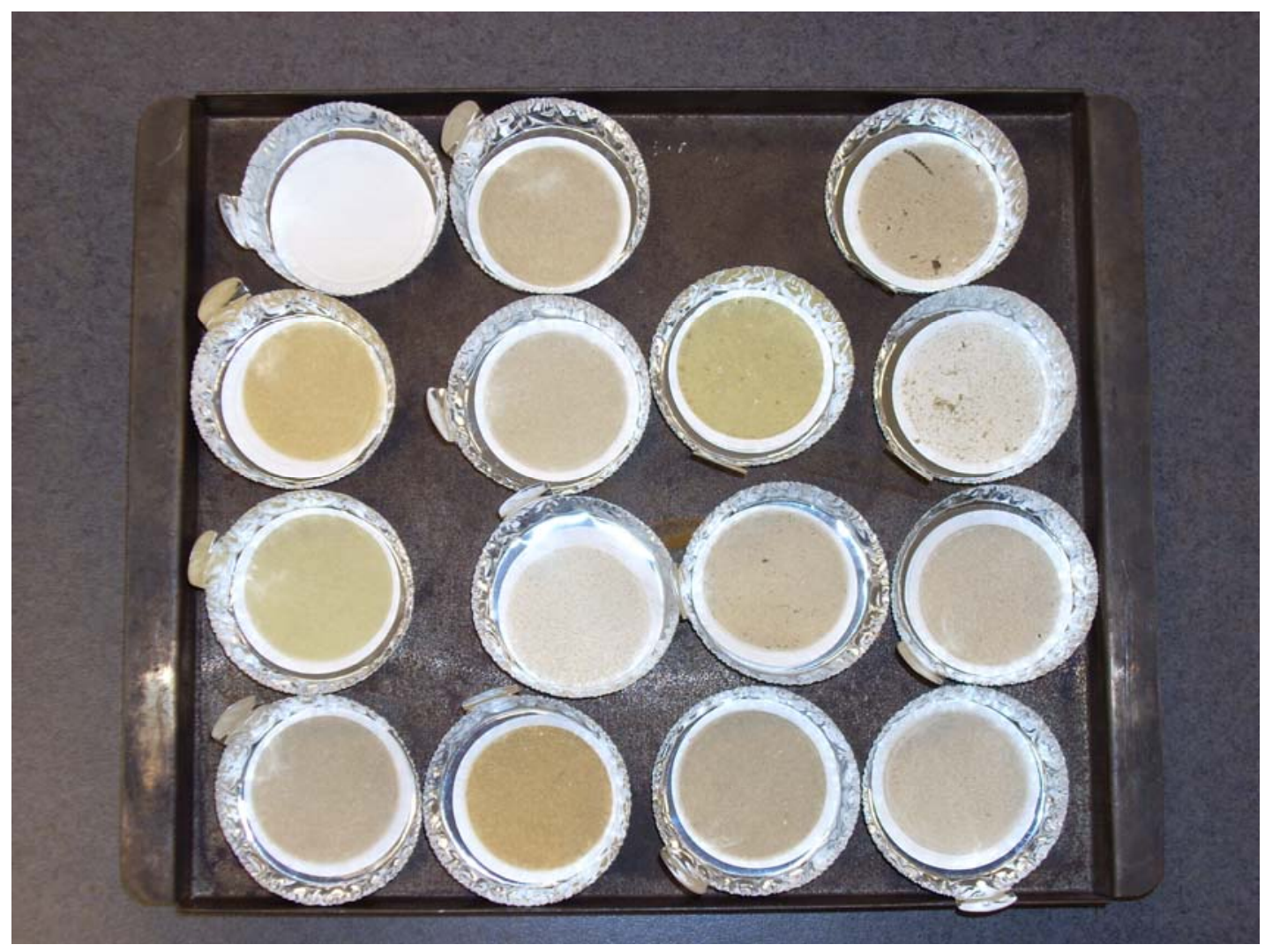

Figure 3-18: VSS samples after oven drying. The seven samples on the left are screened samples for phytoplankton quantification while the seven on the right are unscreened for zooplankton analysis. The sample in the upper left corner is an analytical blank.

\subsubsection{Benthic Invertebrates}

Benthic invertebrates were enumerated by screening of the soil samples. The samples were initially screened through a 5-mm mesh, where debris was washed and removed. Then the samples were screened though a $500-\mu \mathrm{m}$ mesh. Invertebrates were separated and then identified to the family level. 


\section{CHAPTER 4: RESULTS AND DISCUSSION}

Water quality and biota line charts below show each wetland in the group (modified, traditional, or drainage). Trend lines were removed for data sets with less than five data points. For the 2007 season, data points for the individual wetlands are the mean of all the samples collected within the wetland. For 2008 data, the data points are the outlet samples since these were the only samples taken. Charts in the these sections use the following abbreviations;

- Ducky Strike North: DN

- Ducky Strike South: DS

- Los Banos Wildlife Area 31b: L1

- Los Banos Wildlife Area 33: L3

- Mud Slough 3b: M3

- $\quad$ Mud Slough 4b: M4

- Los Banos Wildlife Area 38: L8

- Button Willow Lake: BW

\subsection{Weather Data}

The following charts contain data collected from the CIMIS website. The 2007 season was warmer $(\mathrm{p}=0.06)$ and may have contributed to greater growth of algae populations. Solar insolation was similar between both seasons. 


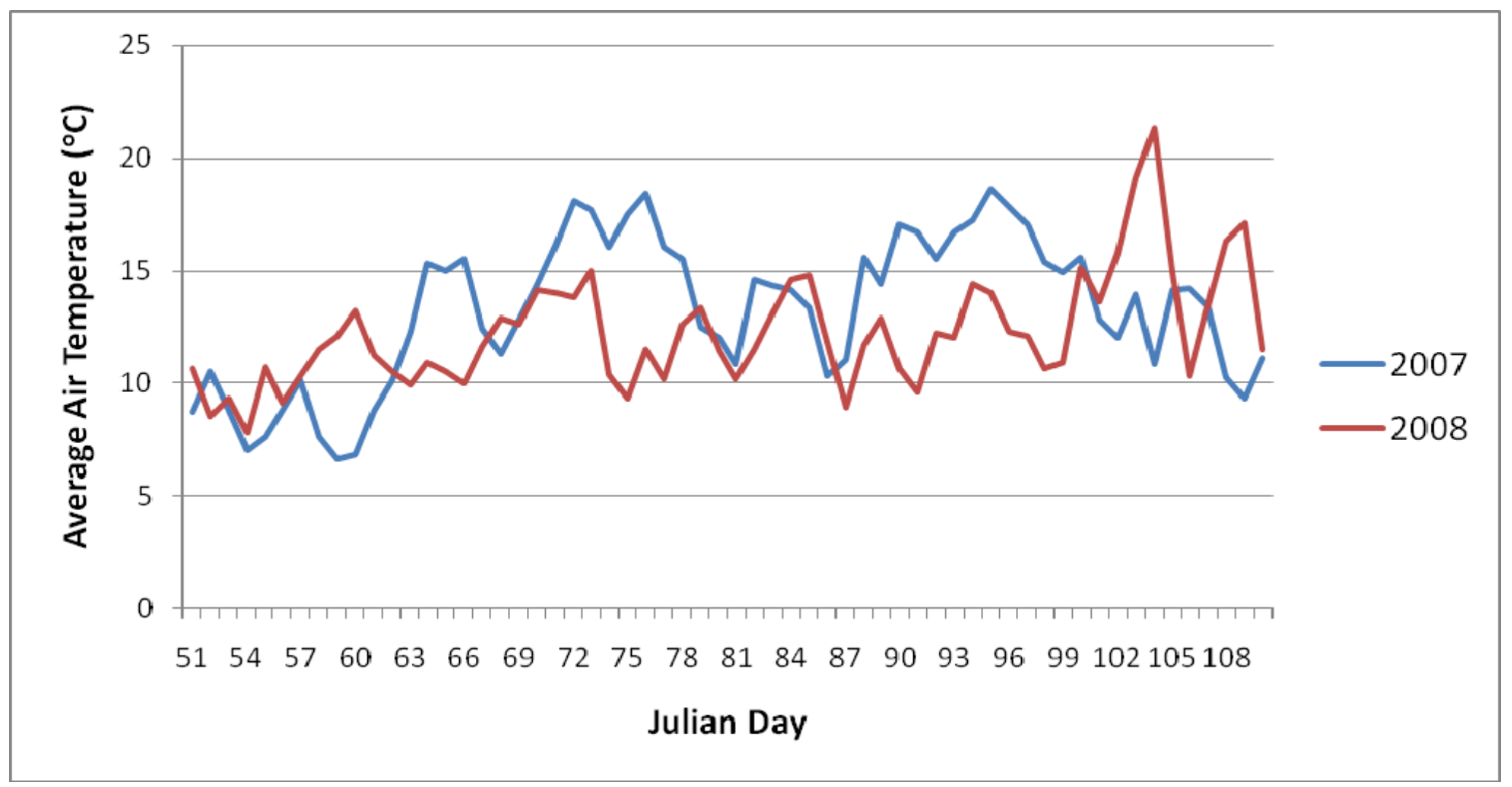

Figure 4-1: Average air temperatures during both sampling seasons.

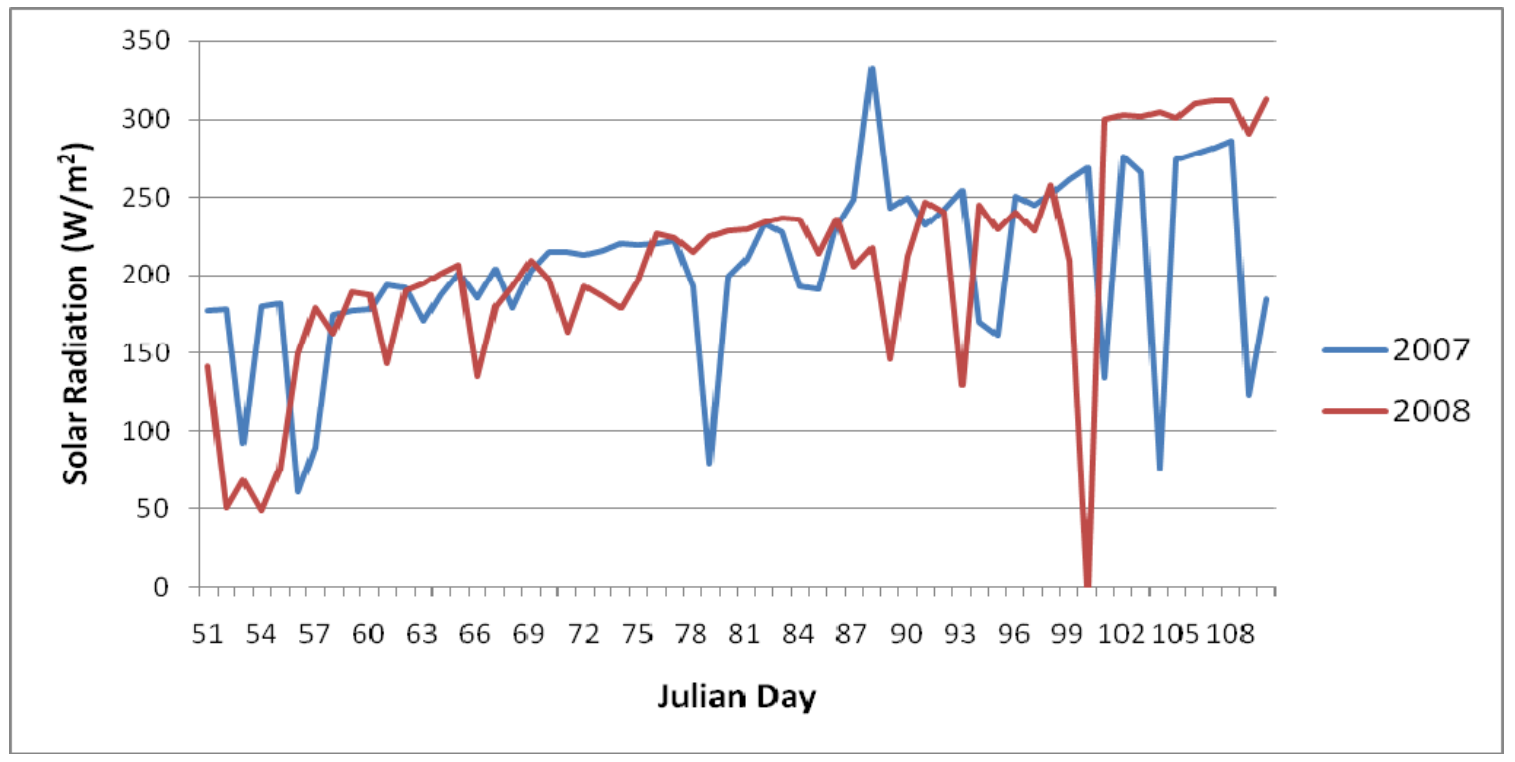

Figure 4-2: Daily solar radiation for both sampling seasons.

\subsection{Aquatic Biota}

The following sections contain the aquatic biota results. Phytoplankton, zooplankton, and benthic invertebrates were analyzed. 


\subsubsection{Phytoplankton}

VSS concentrations after screening with a $100-\mu \mathrm{m}$ mesh were used to represent phytoplankton concentrations. The concentrations of phytoplankton were too low for enumeration. However, observations showed that the phytoplankton were predominantly diatoms. Figure 4-3, Figure 4-4, and Figure 4-5 are micrographs of some of the observed species.

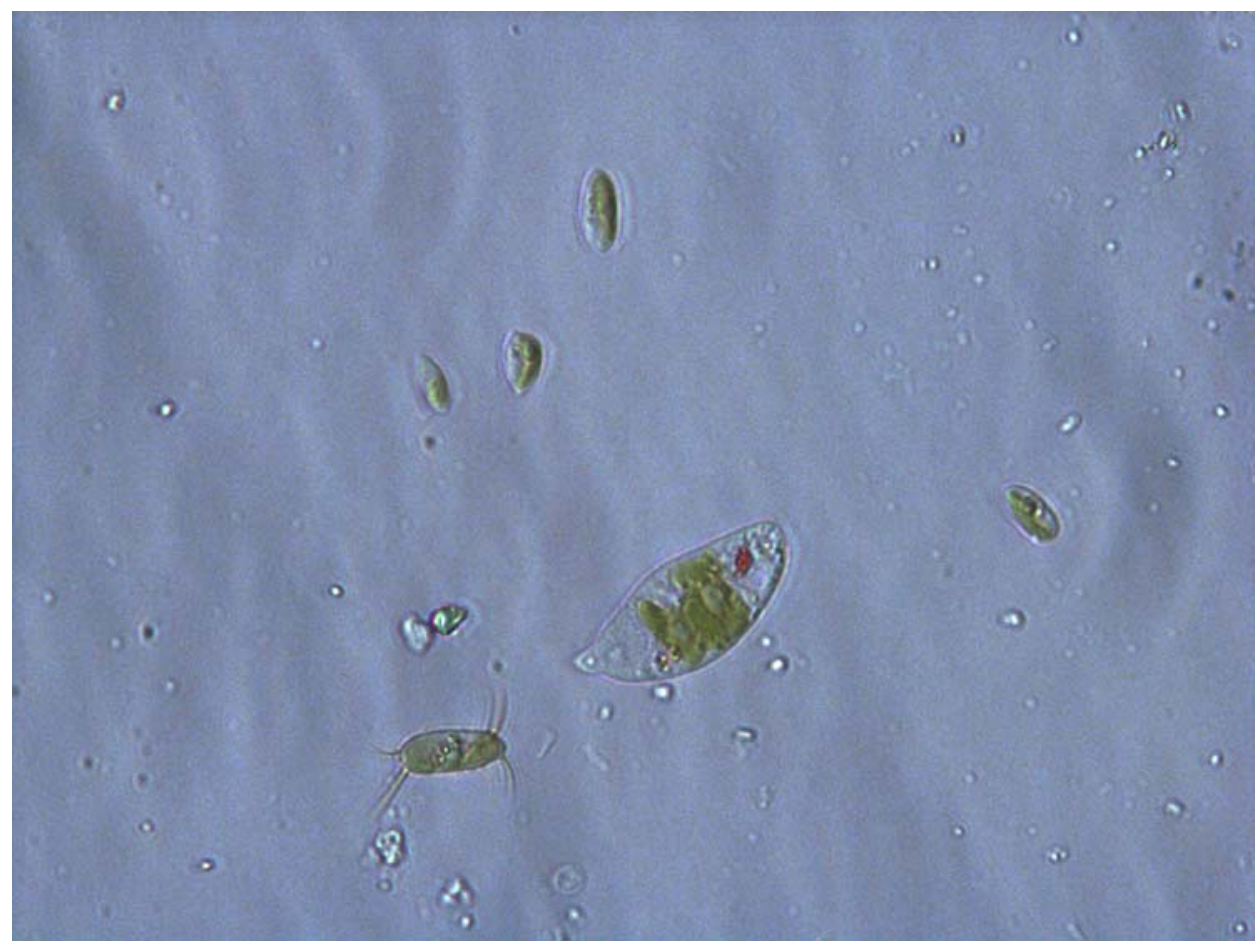

Figure 4-3: A group of phytoplankton found in a Mud Slough 3B sample during the 2007 sampling season (1000x). Phytoplankton genera Euglena, Chlorella, and Chodatella are present. 


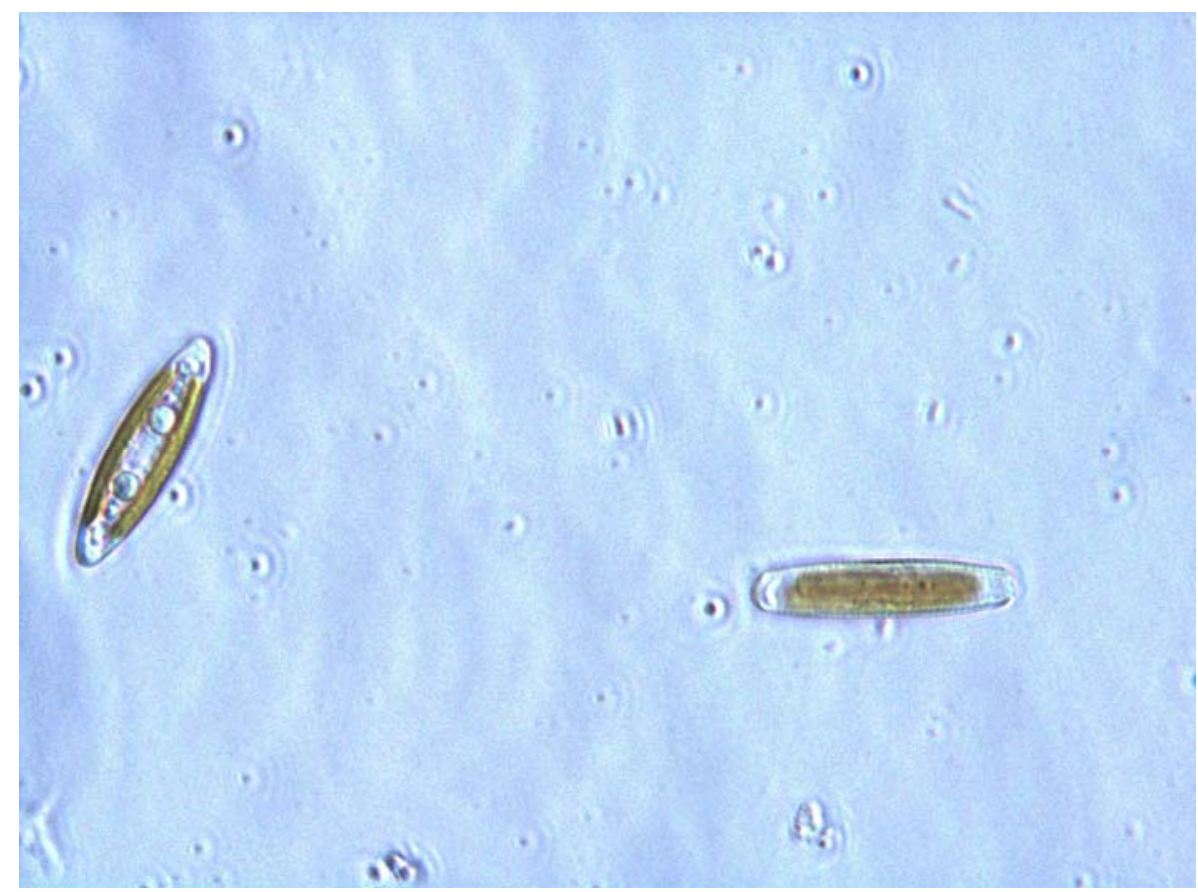

Figure 4-4: Diatoms found in a Ducky Strike North sample during the 2007 sampling season (1000x). Navicula gracilis on the left and a Diatoma species on the right.

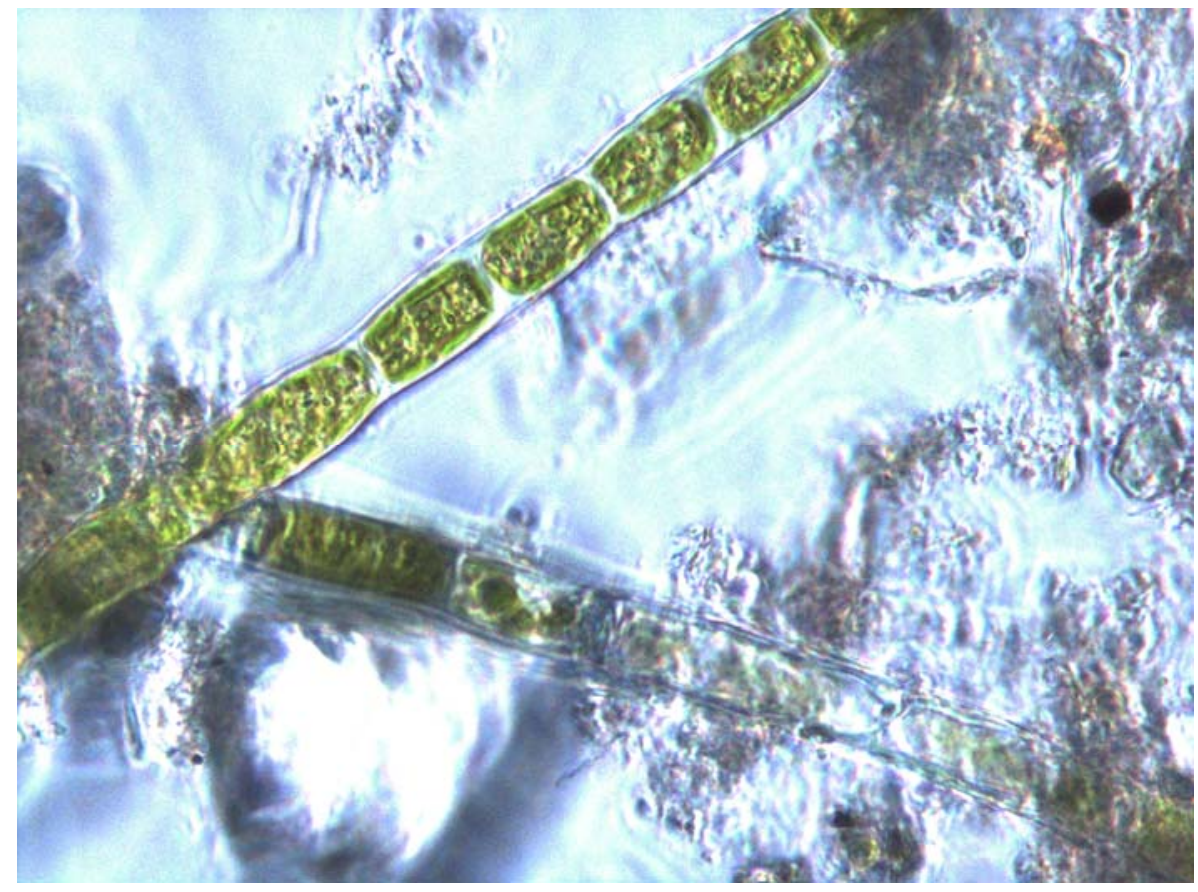

Figure 4-5: Decaying filamentous algae, Zygnema stellinum, mixed in with detritus found in a Los Banos 33 sample during the 2007 sampling season (1000x). 


\subsubsection{Traditional Wetlands}

In the traditionally drained wetlands, all wetlands increased in phytoplankton concentrations during the 2007 season (Figure 4-6). However, during the 2008 season two of three wetlands slightly decreased in phytoplankton concentrations (Figure 4-7). Greater increases in phytoplankton concentrations during the 2007 season could be due to either a warmer growing season or due to sampling after drawdown had already begun during the 03/17/07 sampling date. The standard error in the last sampling date of both seasons increased dramatically, which indicates that phytoplankton growth conditions are different between the studied wetlands.

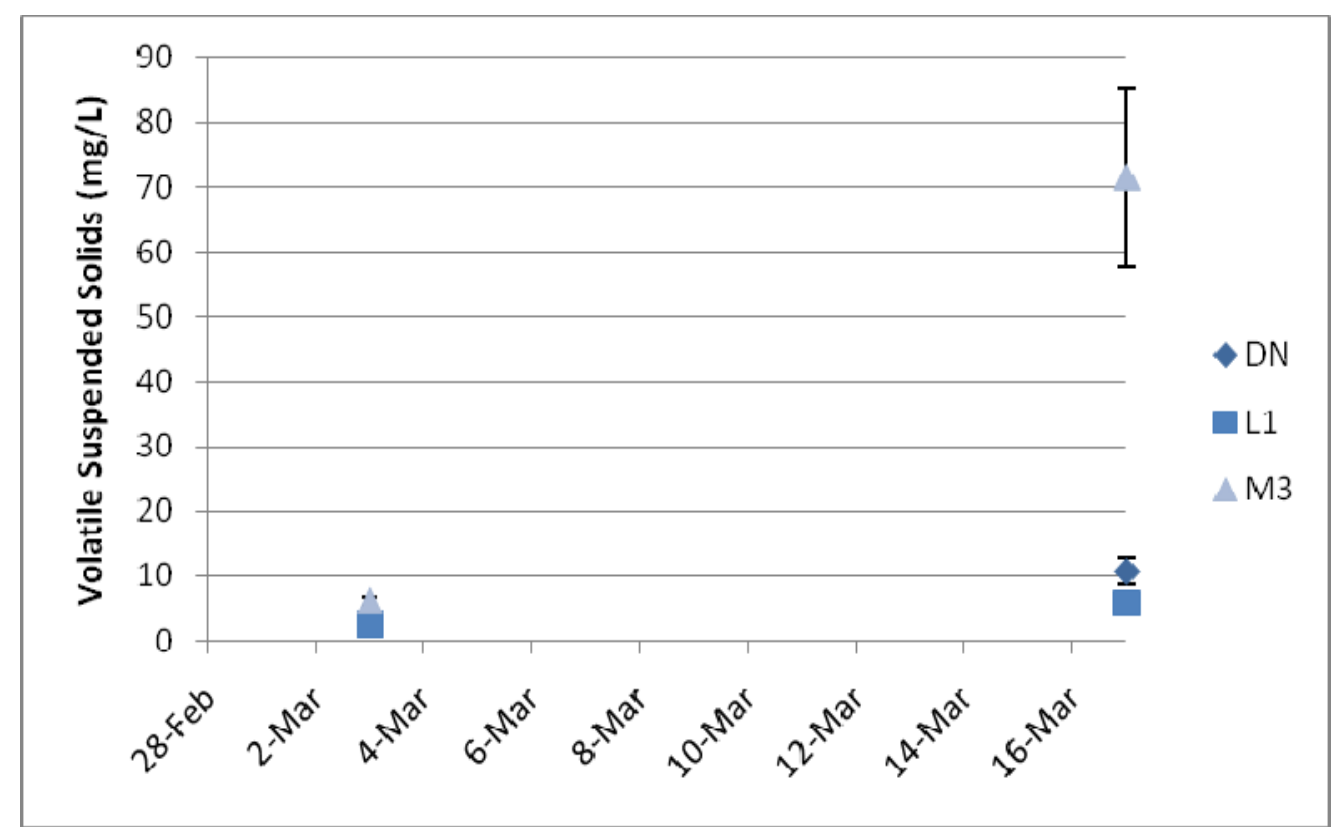

Figure 4-6: Phytoplankton concentrations in traditional drainage wetlands for the 2007 sampling season. Error bars represent the standard error of the mean. 


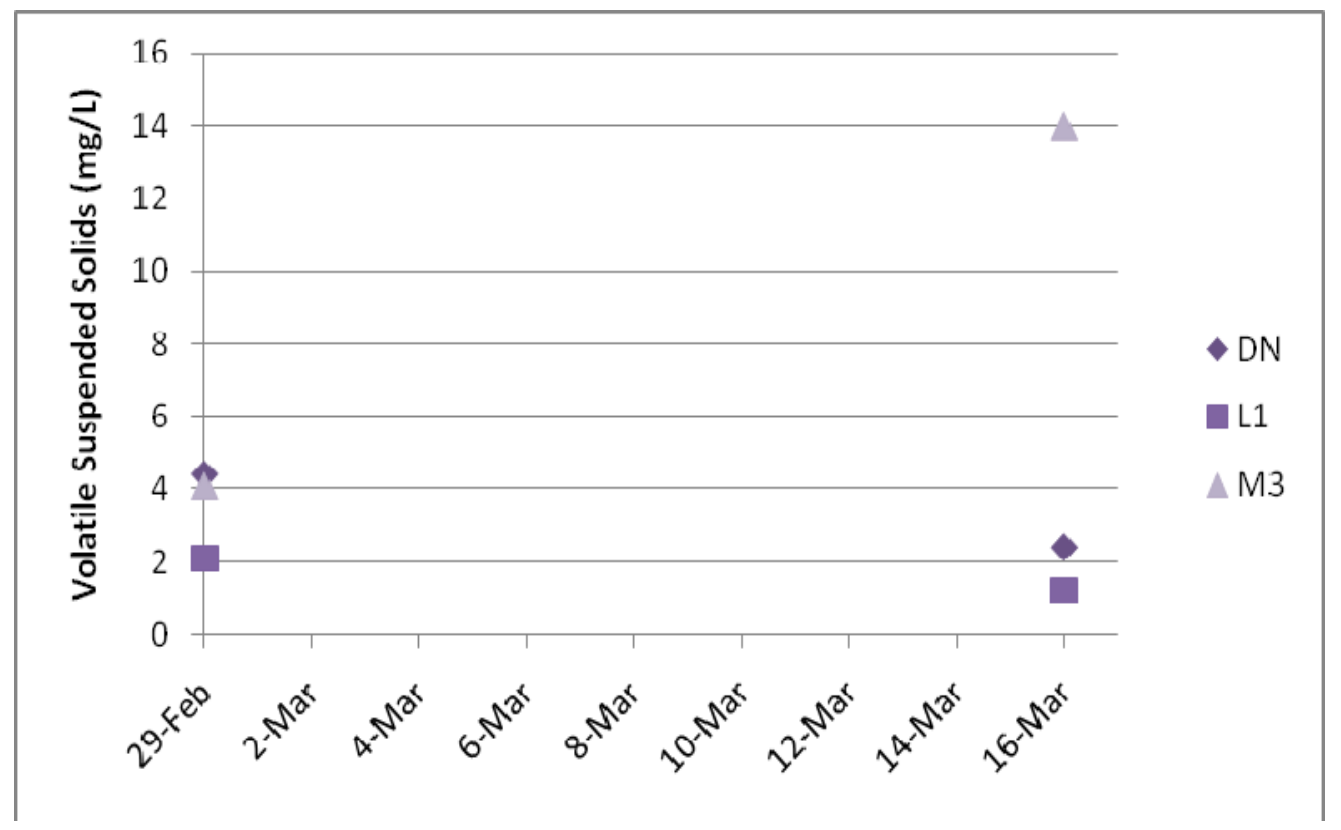

Figure 4-7: Phytoplankton concentrations in traditional drainage wetlands for the 2008 sampling season.

\subsubsection{Modified Wetlands}

Phytoplankton growth in the modified drainage wetlands varied. Phytoplankton concentrations increased in two of three wetlands during the 2007 season (Figure 4-8). This increase is most likely due to sampling once drainage had begun. Phytoplankton concentrations decreased in Los Banos 33b, which has the largest storage volume of the studied wetlands. The large volume delays the effect of drawdown scour, as seen in Figure 4-9 where significant increases in phytoplankton do not occur until the final sampling session. During the 2007 season, phytoplankton concentrations increased initially and then stabilized at less than $10 \mathrm{mg} / \mathrm{L}$ (Figure 4-9). After drawdown began (4/18/08), phytoplankton concentrations increased substantially in all three wetlands. This increase is likely due to scouring of periphyton caused by increased flow. 


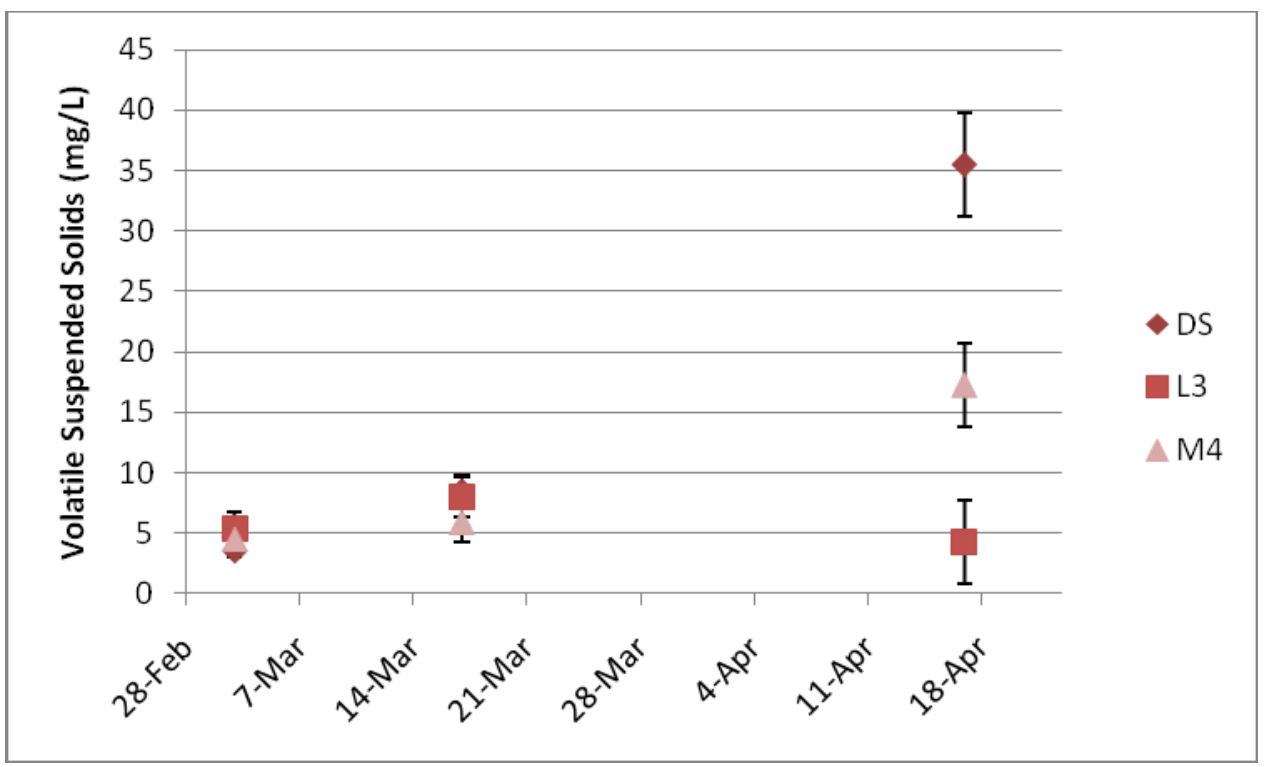

Figure 4-8: Phytoplankton concentrations in modified drainage wetlands for the 2007 sampling season. Error bars represent the standard error of the mean.

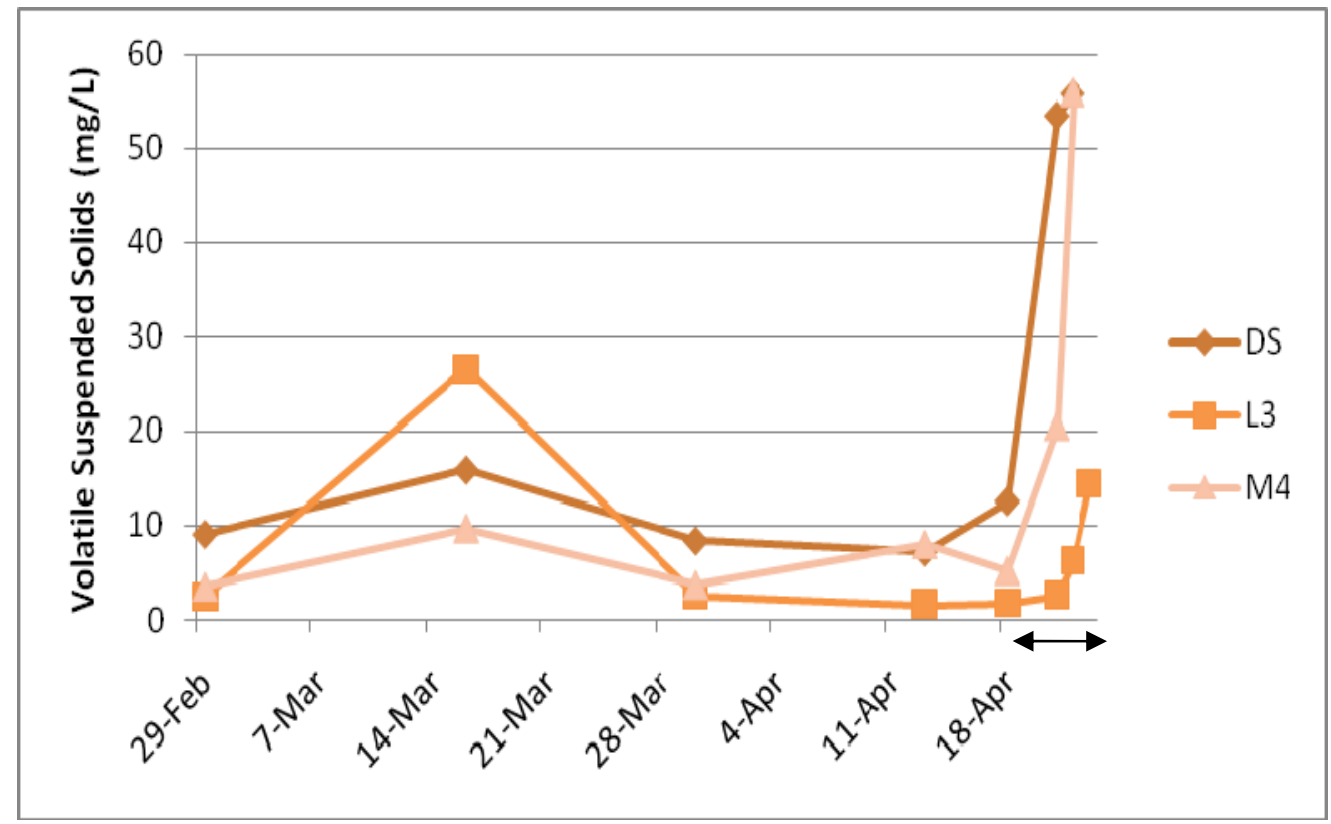

Figure 4-9: Phytoplankton concentrations in modified drainage wetlands for the 2008 sampling season. The drawdown period is indicated by the line with arrows.

\subsubsection{Drainage Sites}

In the drainage sites of the 2008 season, there was an observed trend of increasing phytoplankton concentrations throughout the season (Figure 4-10). After the drawdown 
dates $(03 / 17 / 08$ and $04 / 18 / 08)$, there appeared to be an increase in phytoplankton concentrations at the Los Banos 38 drainage site. However, at the Buttonwillow lake drainage site, there was a decrease in phytoplankton concentrations. This decrease may be due to other management practices that may dilute the discharge from the studied wetlands.

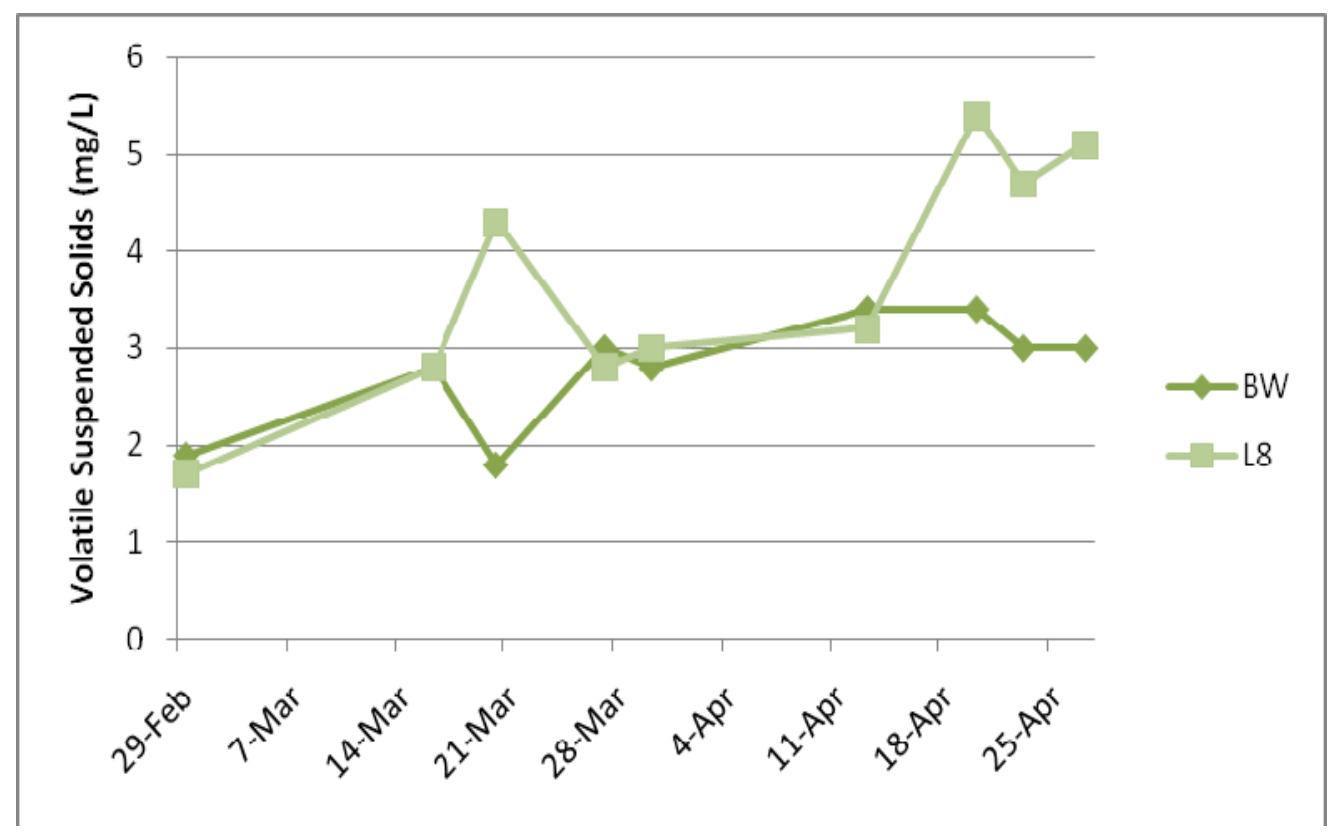

Figure 4-10: Phytoplankton concentrations at drainage sites for the 2008 sampling season.

A filamentous algae bloom was observed during the February 29, 2008 sampling session as seen in Figure 4-11. By the March 30, 2008 sampling session the algae mat had receded as seen in Figure 4-12. The primary algal species was identified as Nodularia (Figure 4-13). This type of growth was expected in the studied wetlands, but was only observed in wetlands that were not a part of this study. This observation is provided for the possible benefit of future studies. 


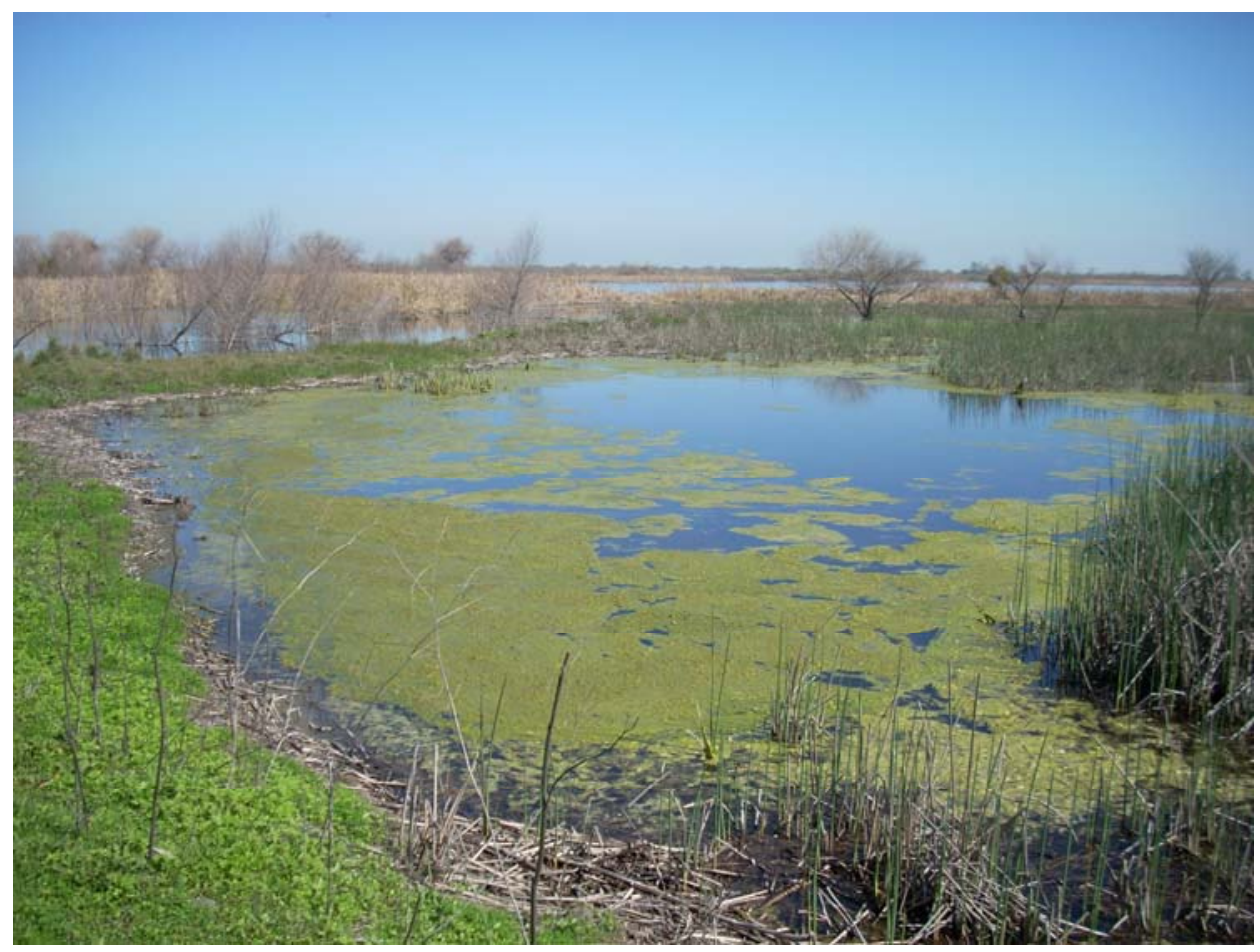

Figure 4-11: A mat of filamentous algae found early in the season near the Buttonwillow drainage site.

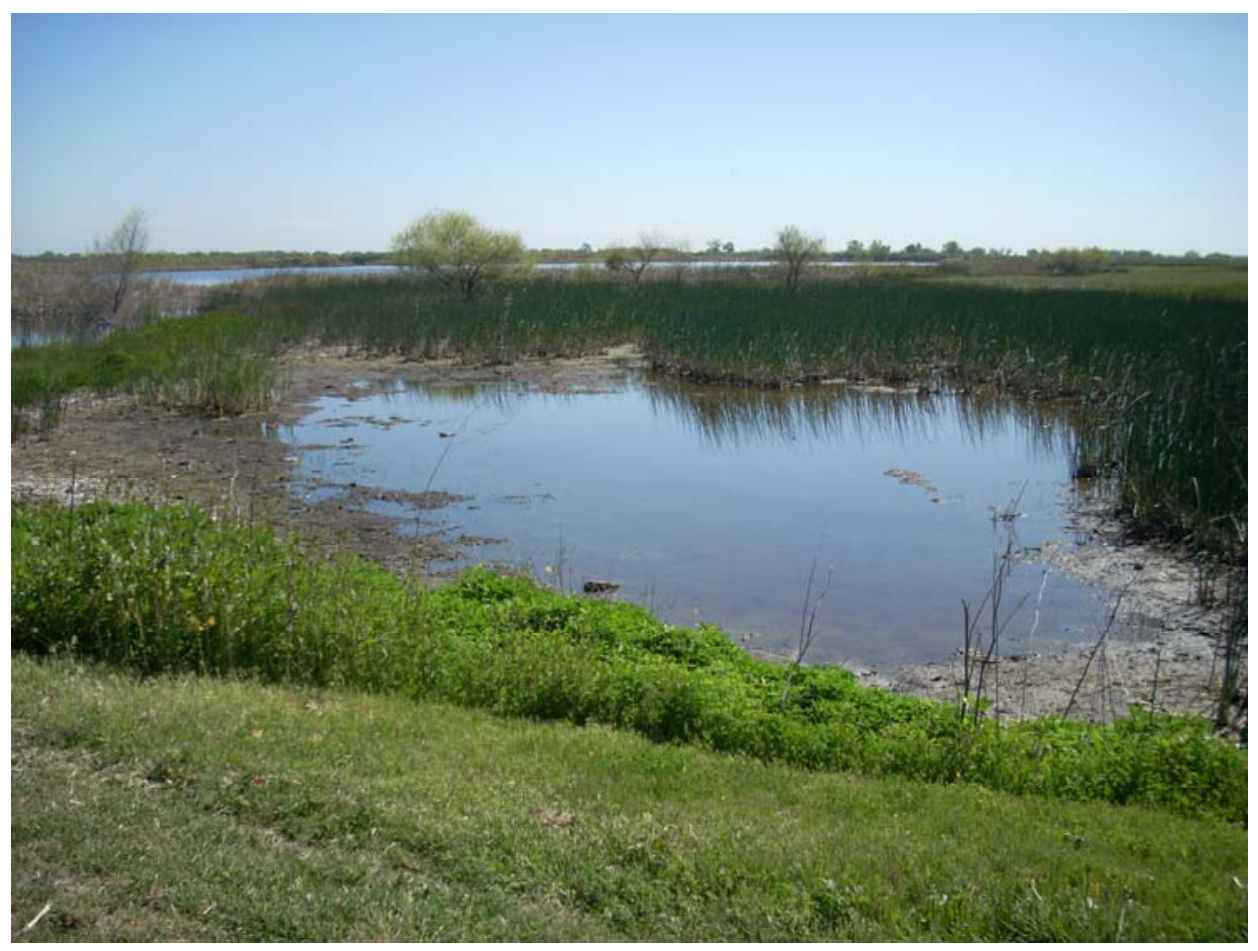

Figure 4-12: Remains of filamentous algae bloom seen in Figure 4-11 later in the season. 


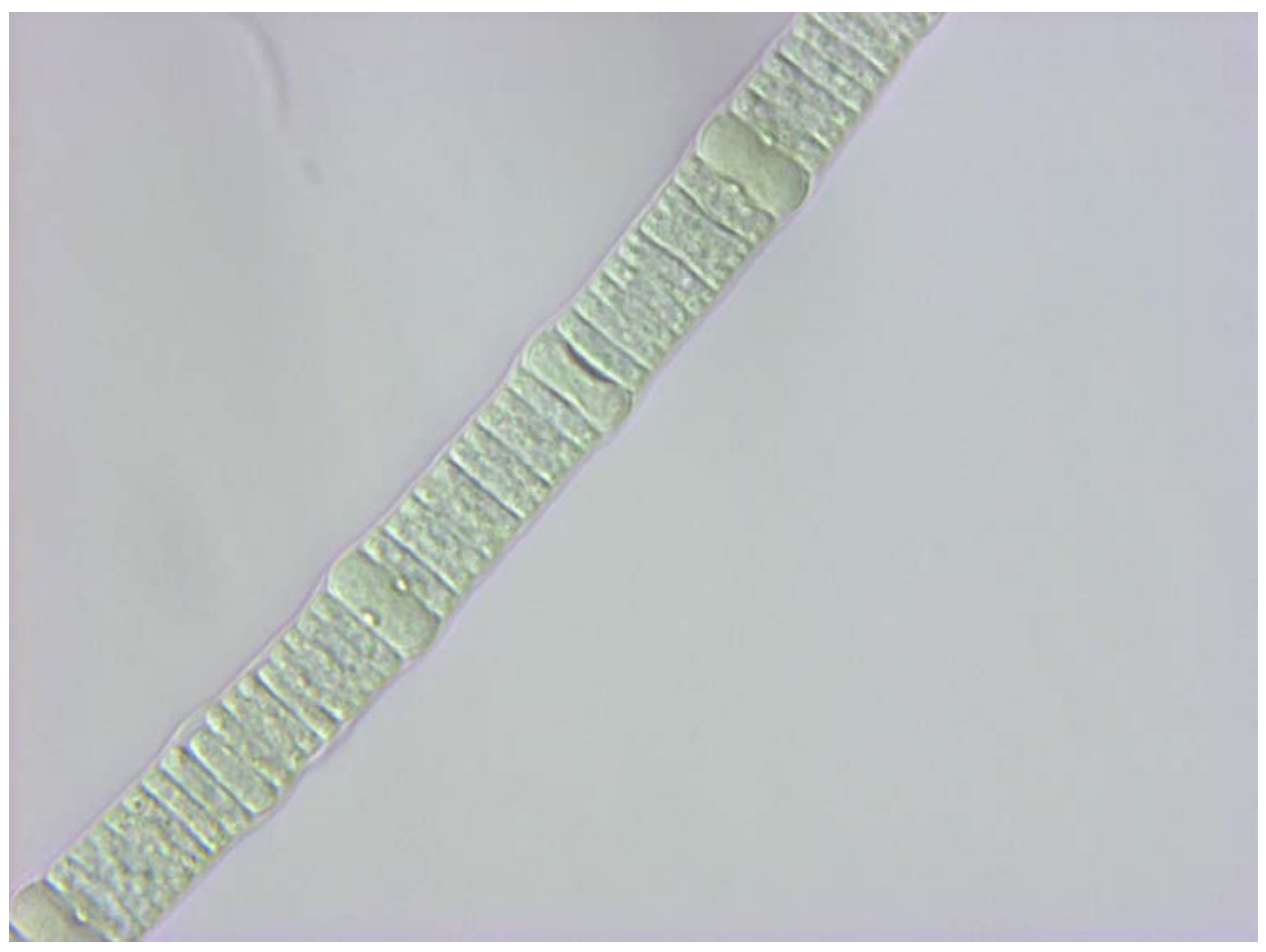

Figure 4-13: Micrograph of filamentous algae (Nodularia) found near the Los Banos 38 drainage site.

\subsubsection{Zooplankton}

Zooplankton concentrations were calculated by counting zooplankton and then using an average weight per specimen to convert to a weight basis during the 2007 season. This allowed identification of zooplankton. During the 2008 season, concentrations were calculated by taking the difference between screened $(100 \mu \mathrm{m})$ and unscreened volatile suspended solids values. This allowed more direct analysis.

\subsubsection{Traditional Wetlands}

In traditional wetlands during the 2007 season, zooplankton concentrations increased in two of three wetlands while it decreased in the third (Figure 4-14). During the 2008 season, all three wetlands showed decreases in zooplankton concentrations (Figure 4-15). 


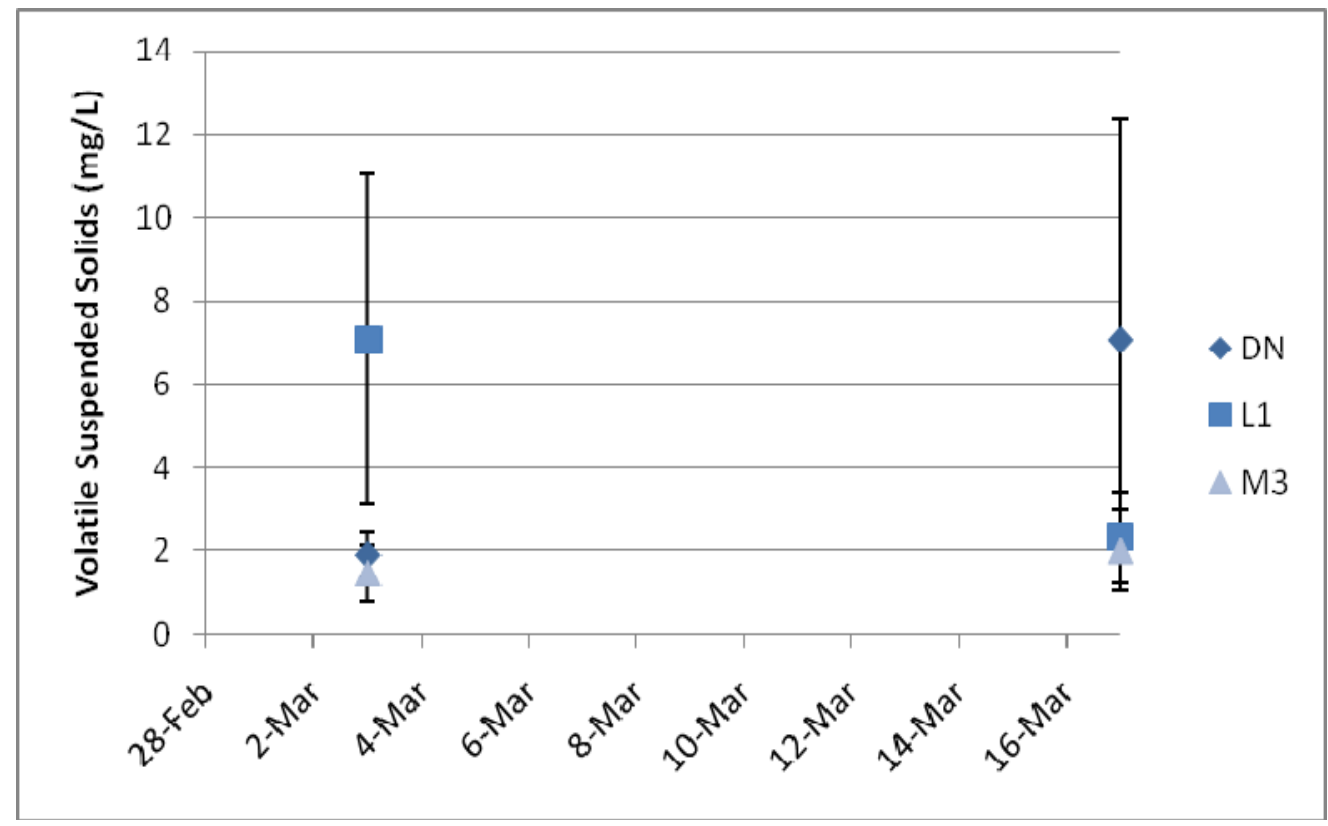

Figure 4-14: Zooplankton concentrations in traditional drainage wetlands for the 2007 sampling season.

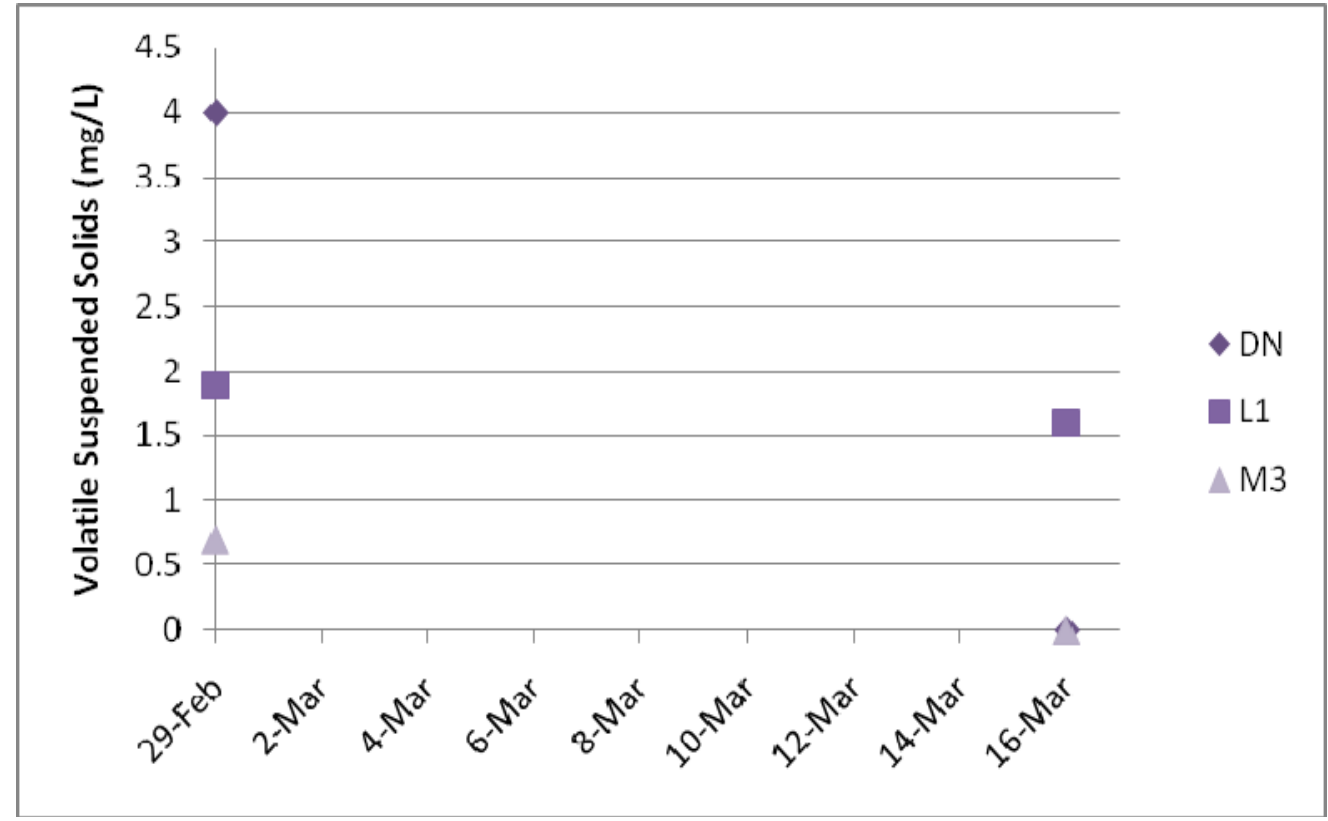

Figure 4-15: Zooplankton concentrations in traditional drainage wetlands for the 2008 sampling season.

\subsubsection{Modified Wetlands}

In modified wetlands during the 2007 season, increases in zooplankton concentrations were seen during the extended flood period (March 17 through April 17) (Figure 4-16). 
These increases are due to better growing conditions and concentration during the drawdown period. During the 2008 season, concentrations fluctuated throughout the season and then concentrated during the drawdown period (Figure 4-17).

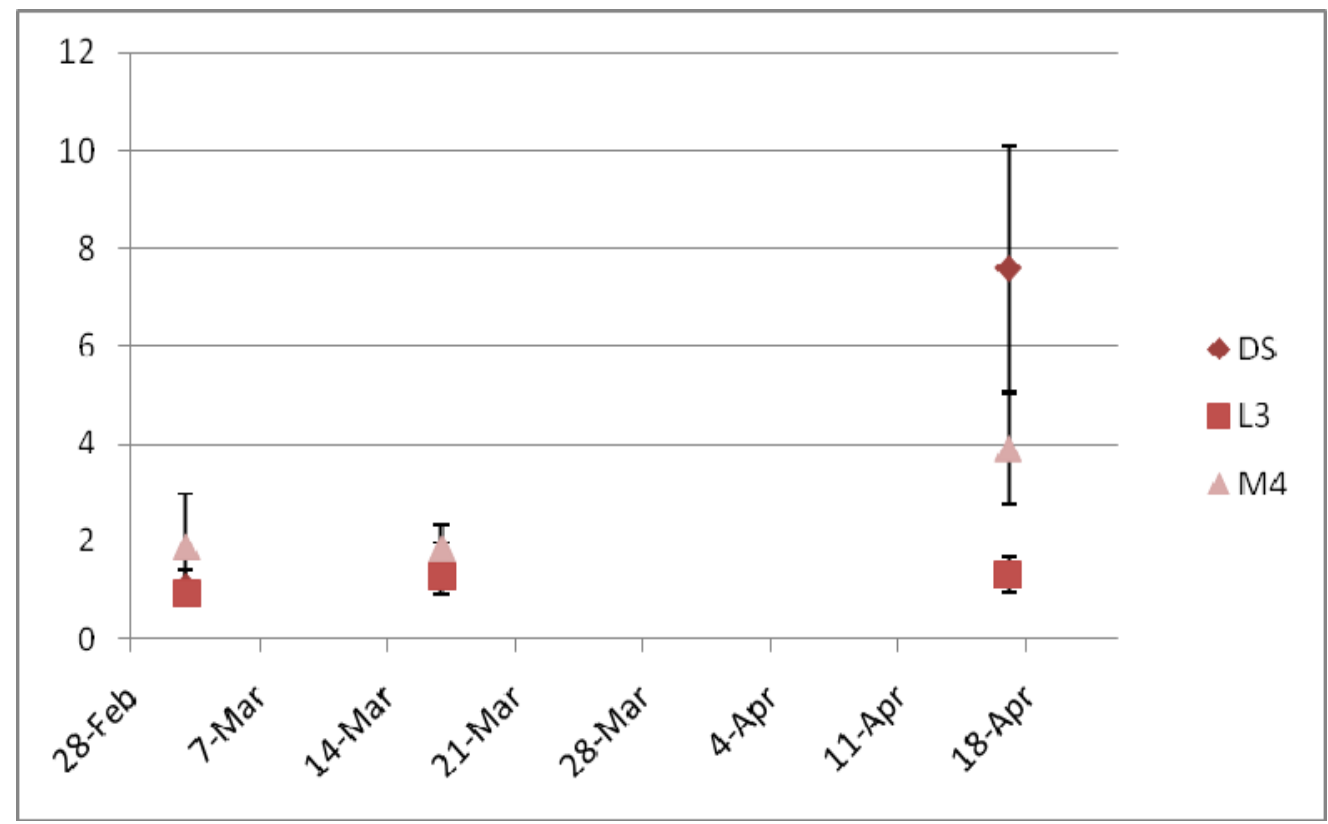

Figure 4-16: Zooplankton concentrations in modified drainage wetlands for the 2007 sampling season.

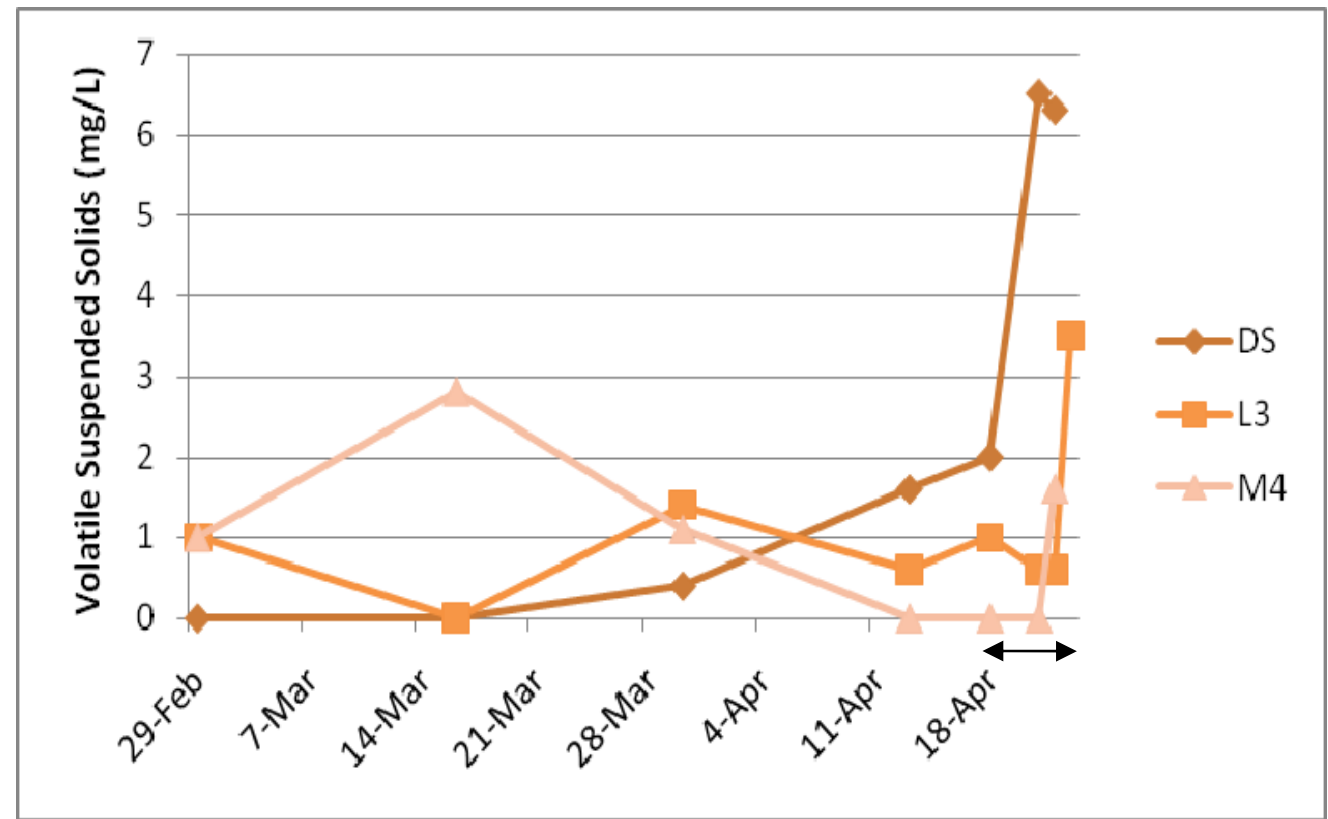

Figure 4-17: Zooplankton concentrations in modified drainage wetlands for the 2008 sampling season. The drawdown period is indicated by the line with arrows. 


\subsubsection{Drainage Sites}

At the drainage sites during the 2008 season, zooplankton concentrations fluctuated greatly. This variation could have been due to boom-bust events or changes in influent source.

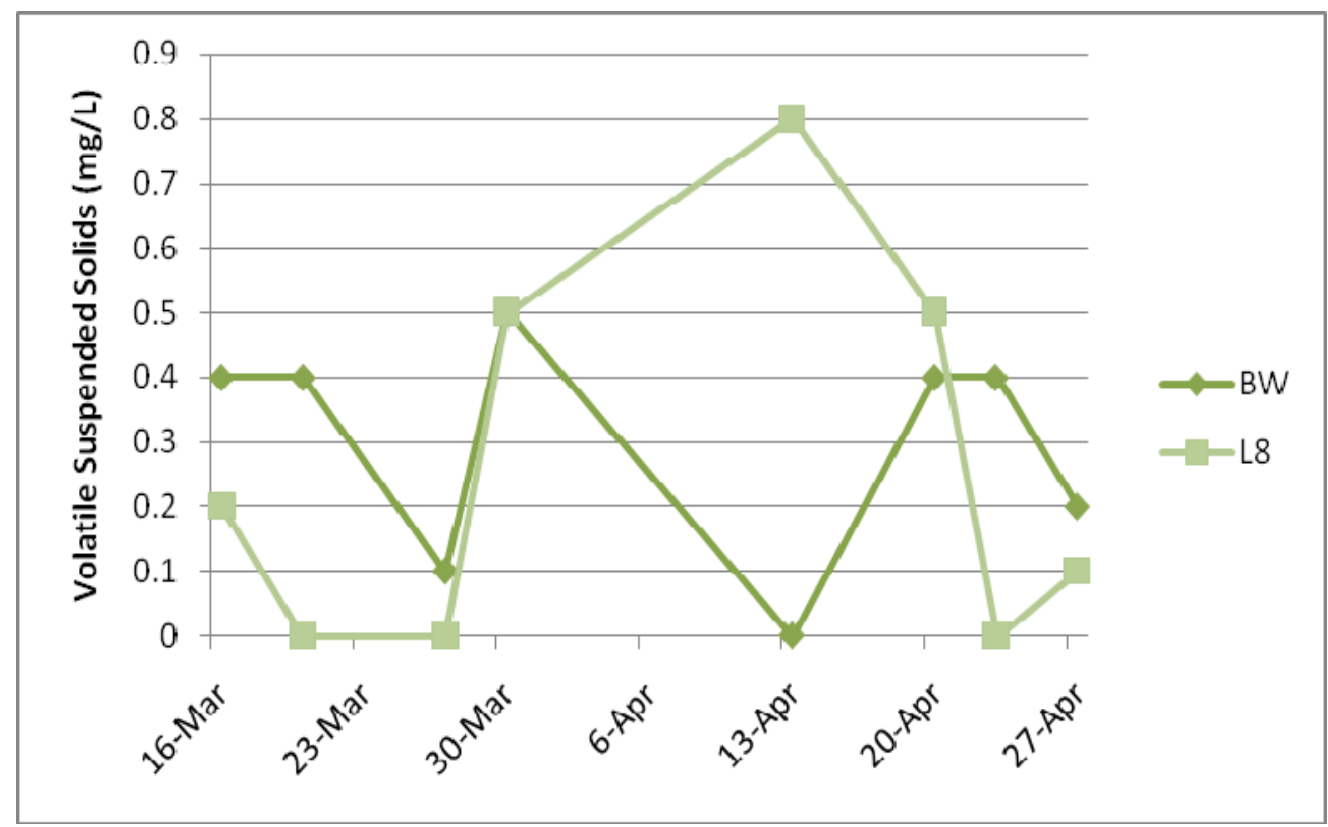

Figure 4-18: Zooplankton concentrations at drainage sites for the 2008 sampling season.

\subsubsection{Distribution}

Zooplankton enumeration and identification data was compiled in 
Table 4-1, which shows the distribution of zooplankton species in the studied wetlands. Zooplankton were predominantly Cladocera. However, at the end of the season the Cladocera population declined while the Ostracoda population increased. This change may be due to either grazing or a change in environmental conditions. The overall density of zooplankton increased during the extended drawdown period. 
Table 4-1: Zooplankton distribution

\begin{tabular}{|c|c|c|c|}
\hline \multirow[t]{2}{*}{ Taxa } & \multicolumn{3}{|c|}{$\%$ of Total Collected } \\
\hline & March 3, 2007 & March 17, 2007 & April 17, 2007 \\
\hline \# of Samples & $N=62$ & $N=42$ & $N=27$ \\
\hline \# Counted & $n=4150$ & $n=1981$ & $\mathrm{n}=1874$ \\
\hline${ }^{\star}$ Density (\#/L) & 90 & 90 & 130 \\
\hline Cladocera & $76.5 \%$ & $75.3 \%$ & $56.1 \%$ \\
\hline Ostracoda & $14.6 \%$ & $17.4 \%$ & $31.9 \%$ \\
\hline Copepoda & $6.3 \%$ & $3.7 \%$ & $8.8 \%$ \\
\hline Corixidae & $1.9 \%$ & $1.9 \%$ & $2.6 \%$ \\
\hline Other & $0.7 \%$ & $1.6 \%$ & $0.5 \%$ \\
\hline $\begin{array}{c}\text { TOTAL } \\
\text { *Standard errors }\end{array}$ & $\begin{array}{l}100.0 \% \\
26-30 \# / L\end{array}$ & $100.0 \%$ & $100.0 \%$ \\
\hline
\end{tabular}

\subsubsection{Benthic Invertebrates}

Benthic invertebrates were monitored during the 2007 season. In traditionally drained wetlands, Mud Slough $3 \mathrm{~b}$ was the only wetland that declined in benthic invertebrate density (Figure 4-19). In modified drainage wetlands, the invertebrate density increased in all three wetlands initially. During the extended drawdown period, the invertebrate density in Ducky Strike South decreased (Figure 4-20). 


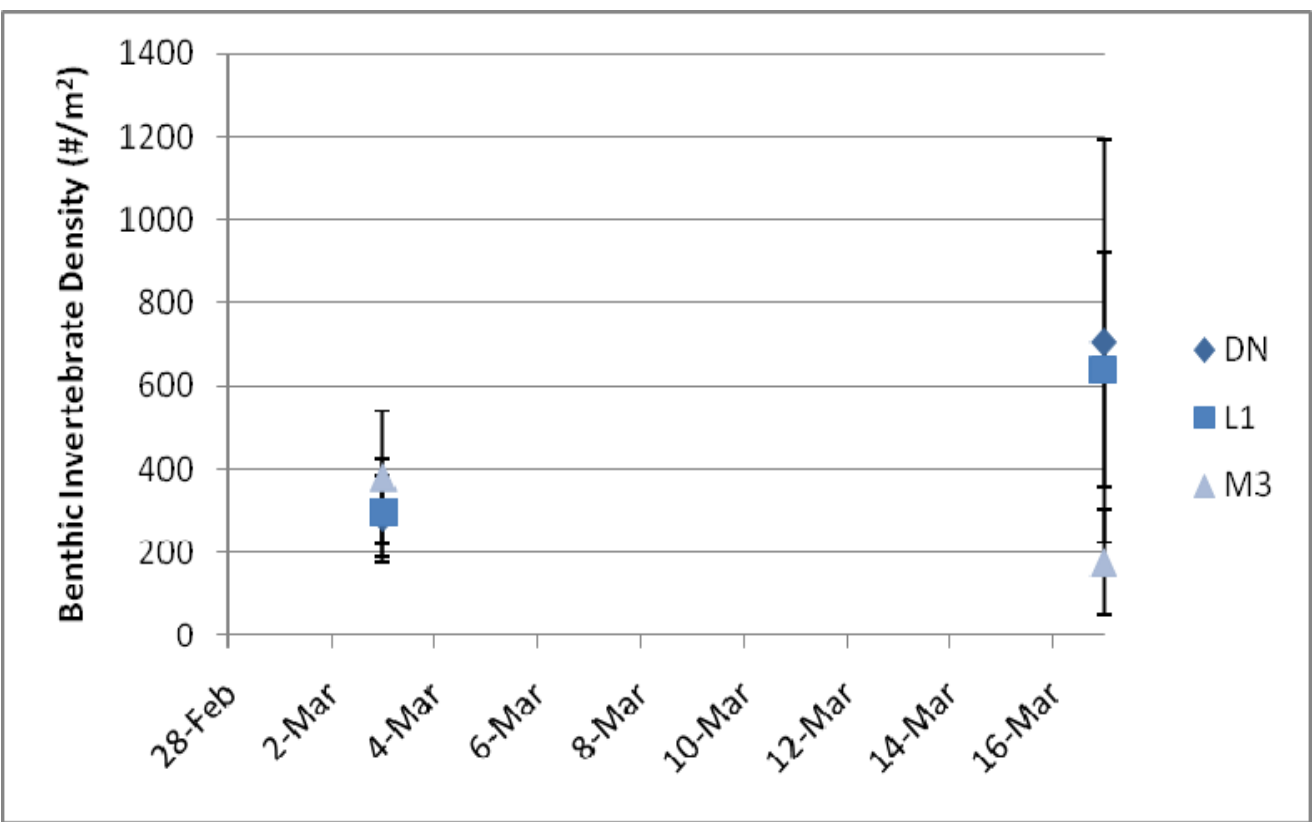

Figure 4-19: Benthic invertebrate density in traditional drainage wetlands for the 2007 sampling season.

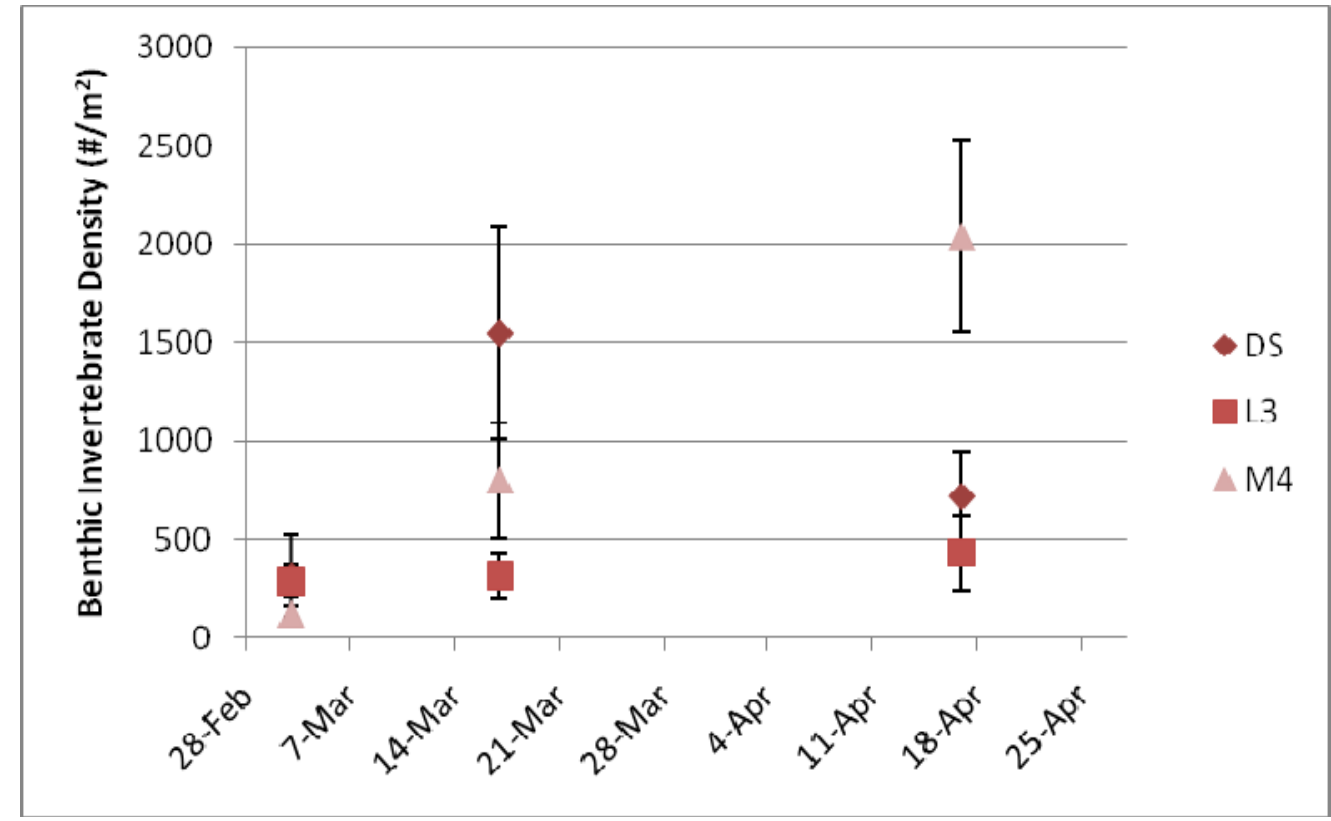

Figure 4-20: Benthic invertebrate density in modified drainage wetlands for the 2007 sampling season.

\subsubsection{Distribution}

Benthic invertebrate enumeration and identification data is compiled in Table 4-2.

Benthic invertebrates were predominantly Blood Worms (Chironomidae) and Tubifex 
Worms (Tubificidae). The overall density of benthic invertebrates increased throughout the season.

Table 4-2: Benthic invertebrate distribution

\begin{tabular}{lccc}
\hline \multicolumn{1}{c}{ Taxa } & \multicolumn{3}{c}{ \% of Total Collected } \\
\hline & March 3, 2007 & March 17, 2007 & April 17, 2007 \\
\cline { 2 - 3 } \# of Samples & $\mathrm{N}=54$ & $\mathrm{~N}=36$ & $\mathrm{~N}=27$ \\
\# Counted & $\mathrm{n}=124$ & $\mathrm{n}=308$ & $\mathrm{n}=235$ \\
*Density $\left(\# / \mathrm{m}^{2}\right)$ & 280 & 700 & 1070 \\
\hline Chironomidae & $67.7 \%$ & $56.8 \%$ & $74.0 \%$ \\
Tubificidae & $22.6 \%$ & $29.5 \%$ & $20.4 \%$ \\
Hydrophilidae & $9.7 \%$ & $2.9 \%$ & $2.6 \%$ \\
Other & $0.0 \%$ & $10.7 \%$ & $3.0 \%$ \\
\hline TOTAL & $100.0 \%$ & $100.0 \%$ & $100.0 \%$ \\
*Standard errors ranged from $50-200 \mathrm{\#} / \mathrm{m}^{2}$ & &
\end{tabular}

\subsubsection{Aquatic Biota Summary}

Table 4-3 and

Table 4-4 summarize the aquatic biota data in three columns:

1. Traditional

This column contains average values from all data points taken at the traditional wetland sites (Ducky Strike North, Los Banos 31B, and Mud Slough 4B).

2. Modified: Traditional Period

This column contains average values from all data points taken at the modified wetland sites (Ducky Strike South, Los Banos 33, and Mud Slough 3B) prior to the drawdown of the traditional wetlands.

3. Modified: Extended Period 
This column contains average values from all data points taken at the modified wetland sites (Ducky Strike South, Los Banos 33, and Mud Slough 4B) after the drawdown of the traditional wetlands, but before drainage of the modified wetlands had begun.

As noted previously, VSS data were used to estimate phytoplankton biomass. During the 2007 sampling season, the average VSS concentrations from all the transects and effluent points were similar. No trends in the data were observed except that the VSS concentrations increased during the extended drawdown period during the 2007 sampling season. There was a large difference between the mean of the traditional and modified wetlands during the traditional flooded period. This suggests that the wetland pairs were not behaving similarly.

Table 4-3: Aquatic biota data summary for 2007. Data is expressed as the mean +/the standard deviation of the mean with the number of samples analyzed in parentheses.

\begin{tabular}{|c|c|c|c|}
\hline & \\
\hline & Traditional & $\begin{array}{l}\text { Moditied: } \\
\text { Traditional } \\
\text { Period }\end{array}$ & $\begin{array}{c}\text { Modified: } \\
\text { Extended Period }\end{array}$ \\
\hline VSS (mg/L) & $5.4+/-3.4(43)$ & $5.6+/-4.8(62)$ & $16+/-15(27)$ \\
\hline Zooplankton Mass (mg/L) & $4.0+/-8.3(39)$ & $1.4+/-1.7(54)$ & $3.7+/-4.2(24)$ \\
\hline Benthic Density (\#/L) & $510+/-850(37)$ & $580+/-900(55)$ & $1000+/-1200(24)$ \\
\hline
\end{tabular}

Table 4-4: Aquatic biota data summary for 2008. Data are expressed as the mean +/the standard deviation of the mean with the number of samples analyzed in parentheses.

\begin{tabular}{|c|c|c|c|}
\hline & \multicolumn{3}{|c|}{ Modified: } \\
\hline & Traditional & $\begin{array}{l}\text { Traditional } \\
\text { Period }\end{array}$ & $\begin{array}{c}\text { Modified: } \\
\text { Extended Period }\end{array}$ \\
\hline VSS (mg/L) & $5.9+/-4.3(6)$ & $10+/-7.1(6)$ & $6.5+/-3.8(9)$ \\
\hline Zooplankton Mass (mg/L) & $1.4+/-1.5(6)$ & $0.81+/-1.0(6)$ & $0.90+/-0.70(9)$ \\
\hline
\end{tabular}




\subsection{Water Quality}

The following sections contain the water quality results for this study, including nitrogen, phosphorus, organic carbon, and salinity.

\subsubsection{Nitrogen}

Nitrogen results are presented below. Nitrate, nitrite, ammonia, and total Kjeldahl forms were analyzed.

\subsubsection{Traditional Wetlands}

Concentrations of $\mathrm{NO}_{3}{ }^{-}+\mathrm{NO}_{2}{ }^{-}$were low during both seasons $(<1 \mathrm{mg} / \mathrm{L}) . \mathrm{NO}_{3}{ }^{-}+\mathrm{NO}_{2}{ }^{-}$ decreased in all three traditionally drained wetlands during the 2007 season (Figure 4-21). This corresponded with increases in phytoplankton concentrations in all three wetlands (Figure 4-6). During the 2008 season $\mathrm{NO}_{3}{ }^{-}+\mathrm{NO}_{2}{ }^{-}$concentrations increased in two of three wetlands (Figure 4-22). This corresponded to a decrease in phytoplankton concentrations in the same two wetlands (Figure 4-7). $\mathrm{NO}_{3}{ }^{-}+\mathrm{NO}_{2}{ }^{-}$concentrations decreased in the Mud Slough 3b wetland, which corresponded with increases in phytoplankton concentrations.

Ammonia concentrations increased in all three traditionally drained wetlands during the 2007 season while they decreased in all three wetlands during the 2008 season (Figure 4-23 and Figure 4-24 respectively). Large increases in ammonia during the 2007 season were likely due to scour since samples were taken after draining of the wetlands had begun. 
Total Kjeldahl nitrogen concentrations remained constant in the traditionally drained wetlands at around $1.5 \mathrm{mg} / \mathrm{L}$ (Figure 4-25).

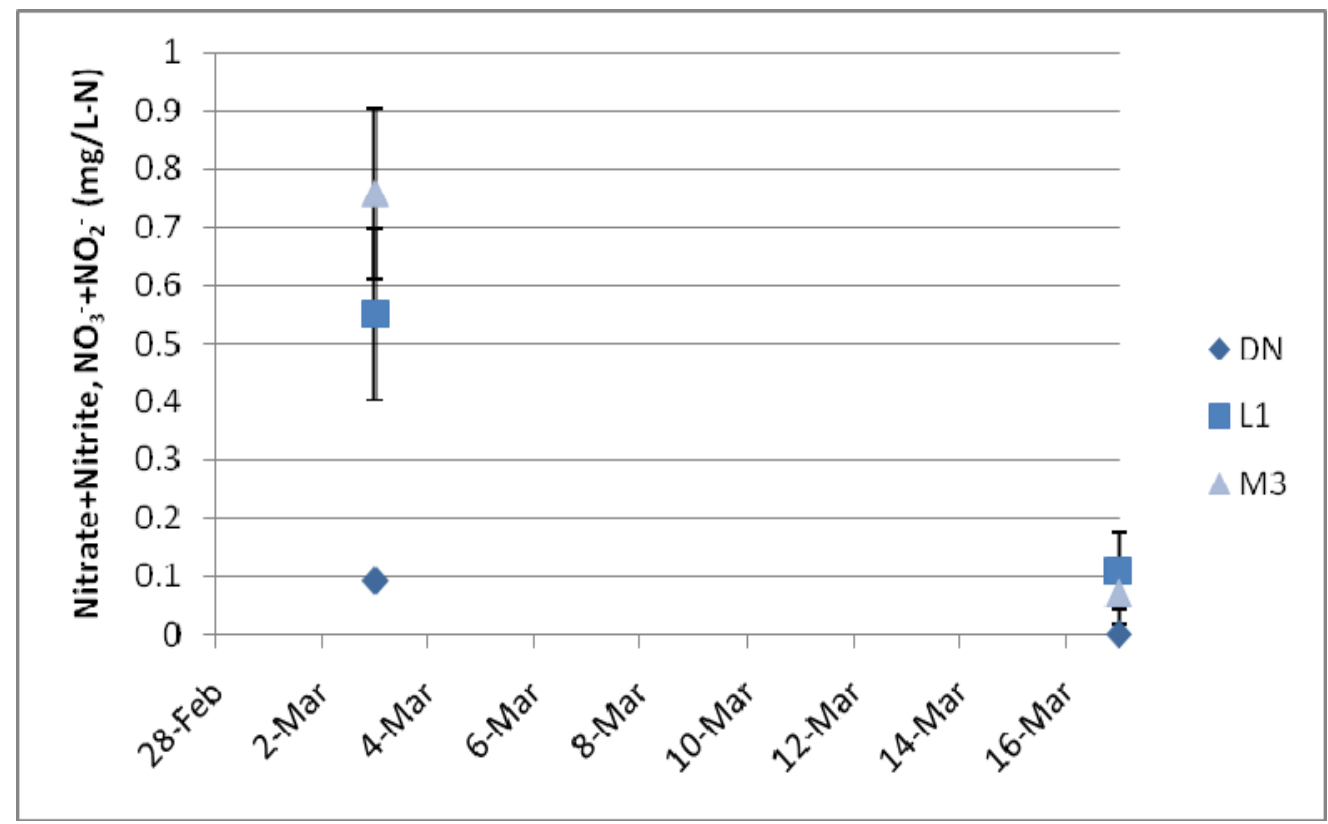

Figure 4-21: Nitrate + Nitrite nitrogen concentrations in traditional drainage wetlands for the 2007 sampling season.

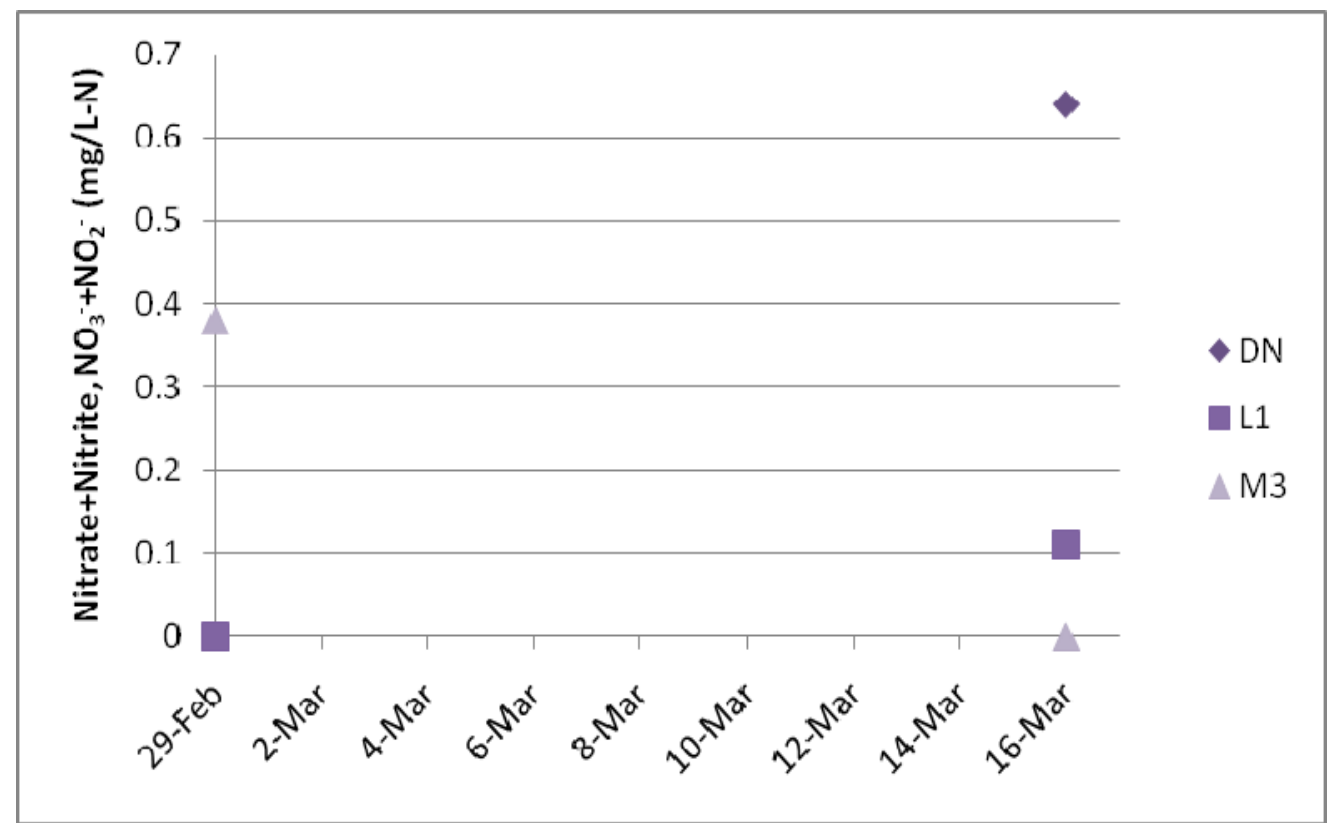

Figure 4-22: Nitrate + Nitrite nitrogen concentrations in traditional drainage wetlands for the 2008 sampling season. 


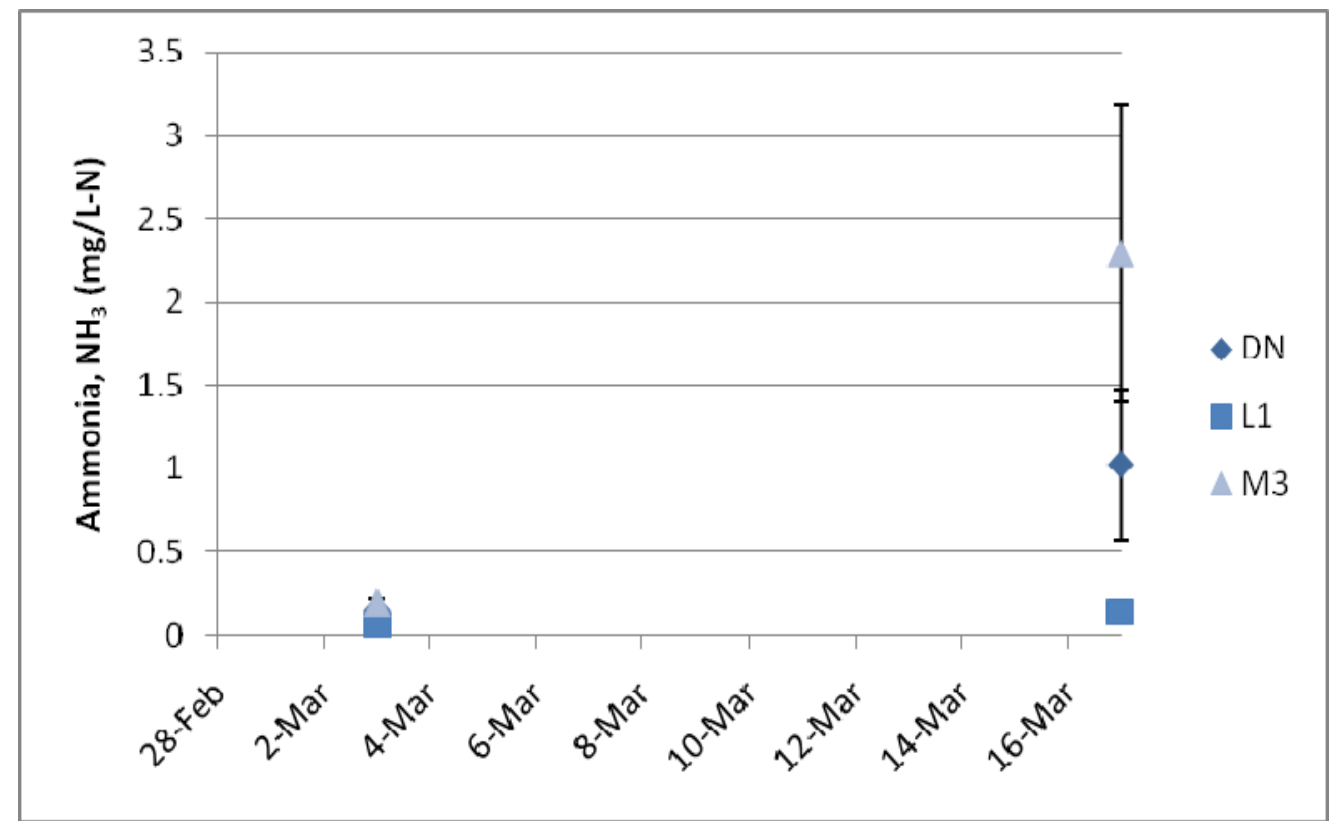

Figure 4-23: Total ammonia nitrogen concentrations in traditional drainage wetlands for the 2007 sampling season.

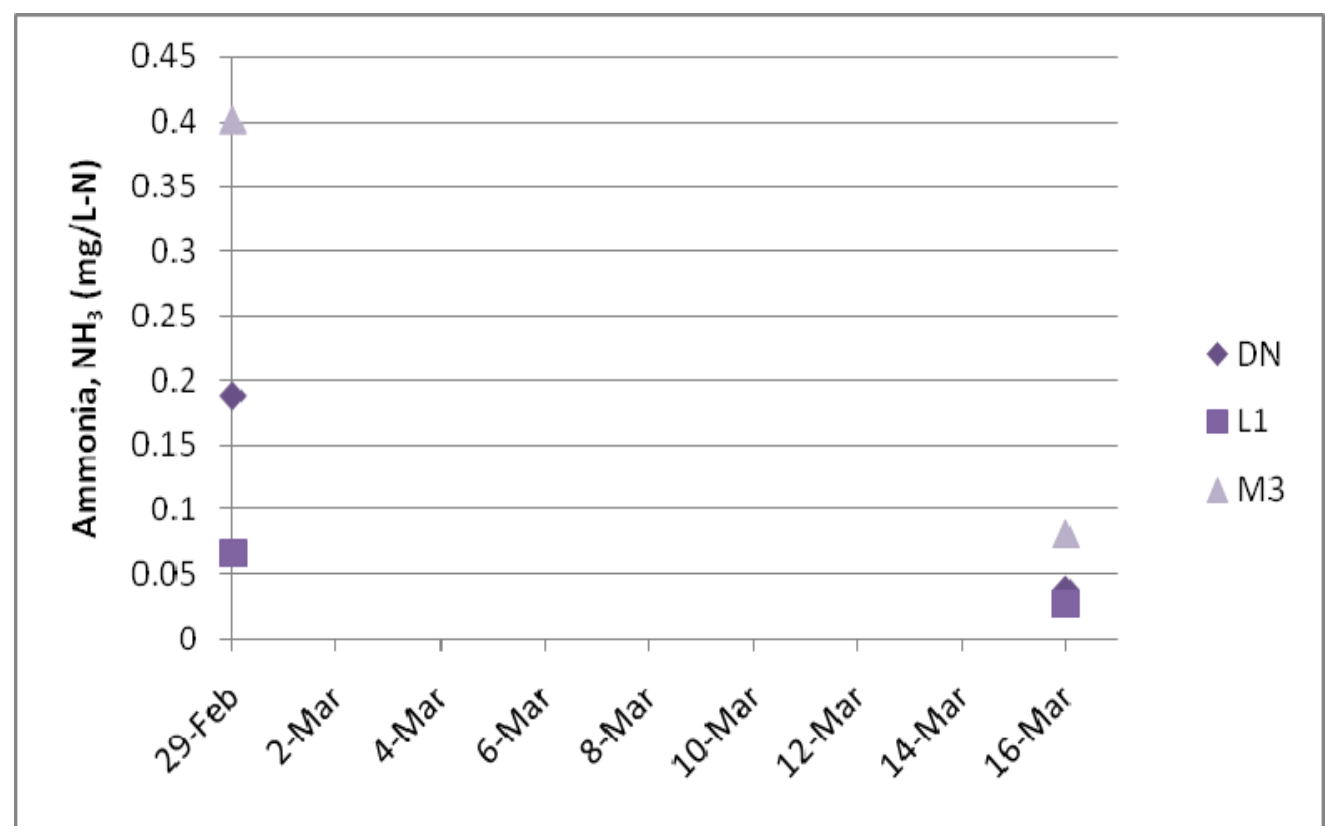

Figure 4-24: Total ammonia nitrogen concentrations in traditional drainage wetlands for the 2008 sampling season. 


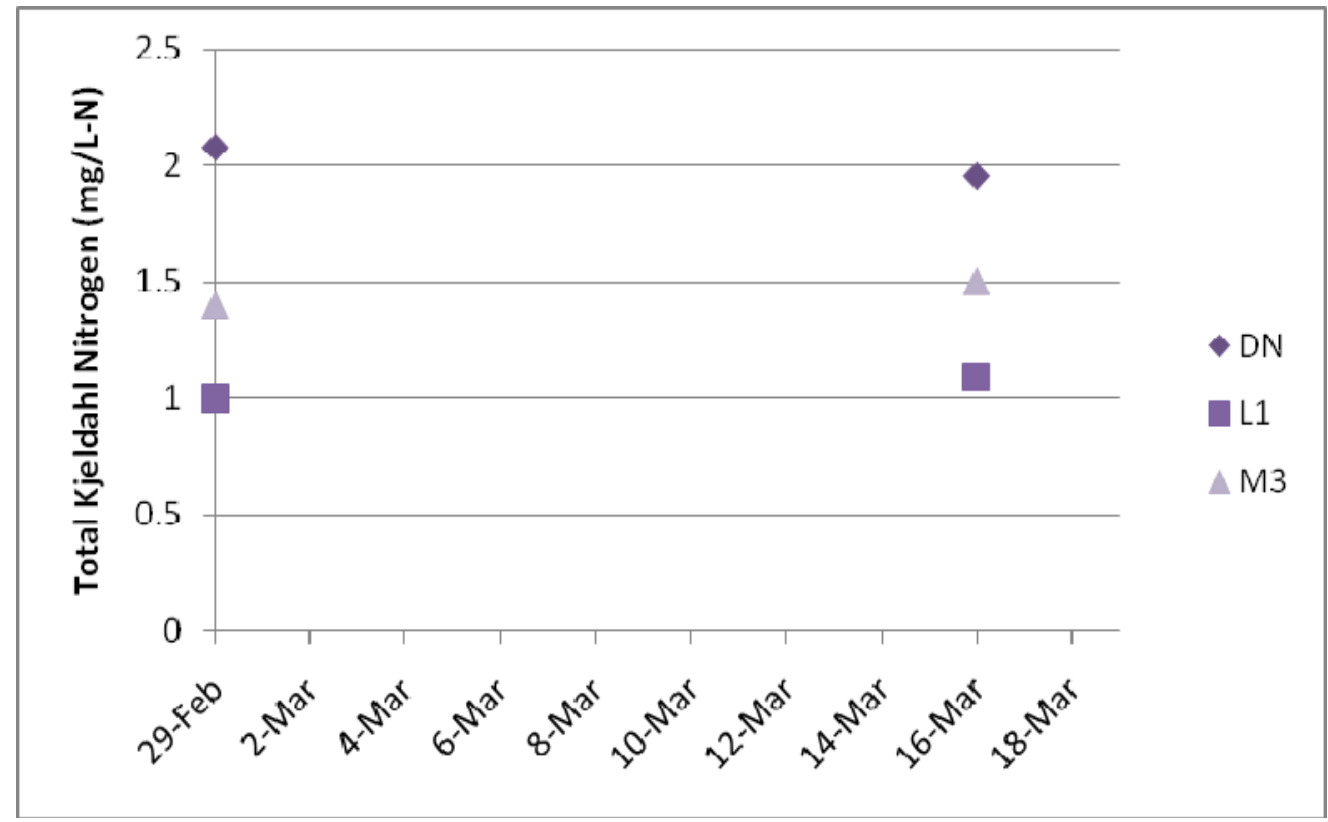

Figure 4-25: Total Kjeldahl Nitrogen concentrations in traditional drainage wetlands for the 2008 sampling season. 


\subsubsection{Modified Wetlands}

Concentrations of $\mathrm{NO}_{3}{ }^{-}+\mathrm{NO}_{2}{ }^{-}$were low during both seasons $(<1 \mathrm{mg} / \mathrm{L})$. $\mathrm{NO}_{3}{ }^{-}+\mathrm{NO}_{2}{ }^{-}$in decreased in all three modified drainage wetlands throughout the 2007 season (Figure 4-26). This corresponded with increases in phytoplankton concentrations in all but the Los Banos 33b wetland (Figure 4-8). During the 2008 season, $\mathrm{NO}_{3}{ }^{-}+\mathrm{NO}_{2}{ }^{-}$concentrations decreased initially and reduced to non-detect in all three wetlands during the drawdown period. This slightly follows the trend of phytoplankton concentrations (Figure 4-9) by decreasing during phytoplankton increases and vice versa.

Ammonia concentrations were also low during both seasons $(<0.5 \mathrm{mg} / \mathrm{L})$. Ammonia levels initialy increased and then decreased in modified drainage wetlands during the 2007 season (Figure 4-28). Ammonia concentrations decreased throughout the season during the 2008 season before drainage occurred (Figure 4-29). During drawdown, ammonia concentrations increased significantly in all wetlands. This was most likely due to the scouring of nutrient rich sediments within the wetlands.

Total Kjeldahl nitrogen concentrations remained relatively constant in modified drainage wetlands throughout the 2008 season at around $2 \mathrm{mg} / \mathrm{L}$ (Figure 4-30). During the drainage period, total Kjeldahl nitrogen levels increased. This is likely due to the scouring of nutrient rich soils and periphyton from increased flow during drawdown. 


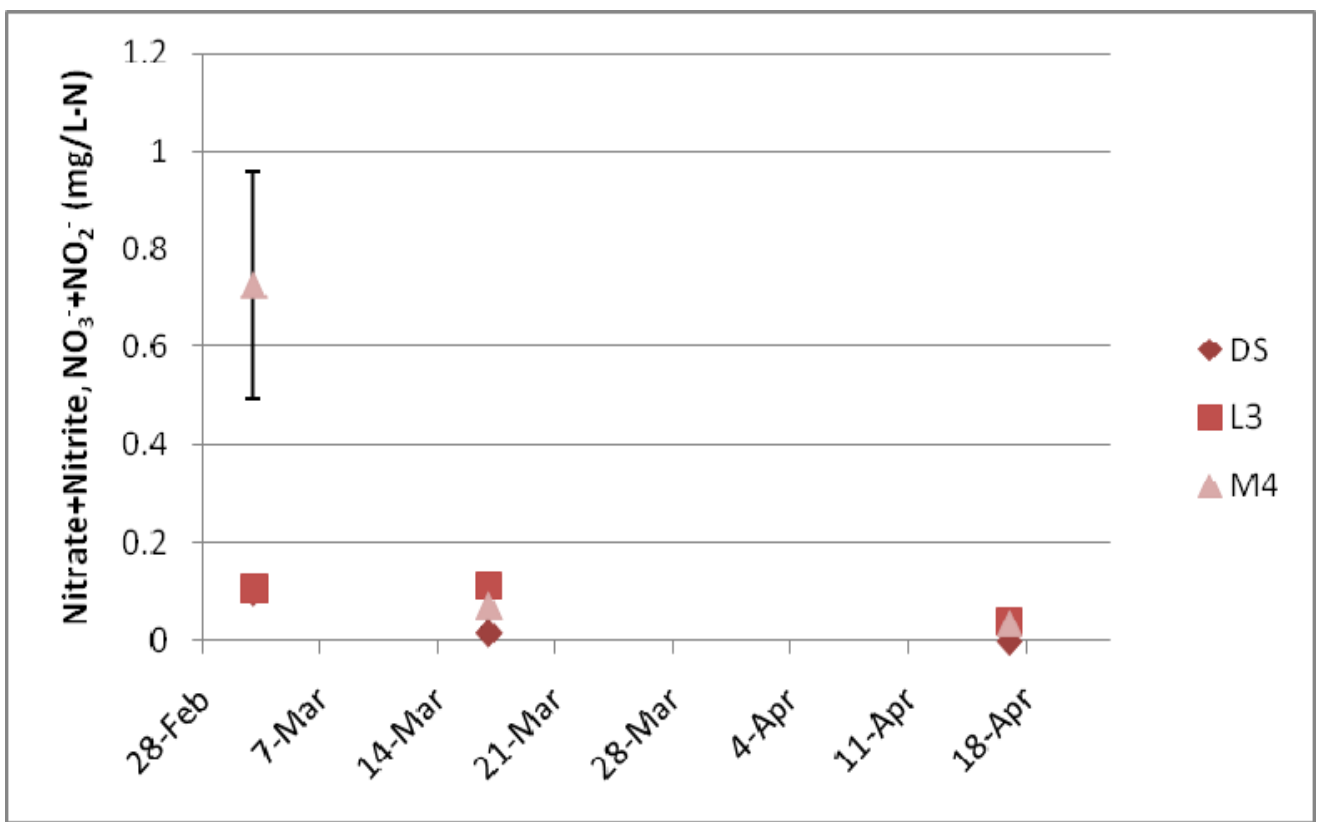

Figure 4-26: Nitrate + Nitrite nitrogen concentrations in modified drainage wetlands for the 2007 sampling season.

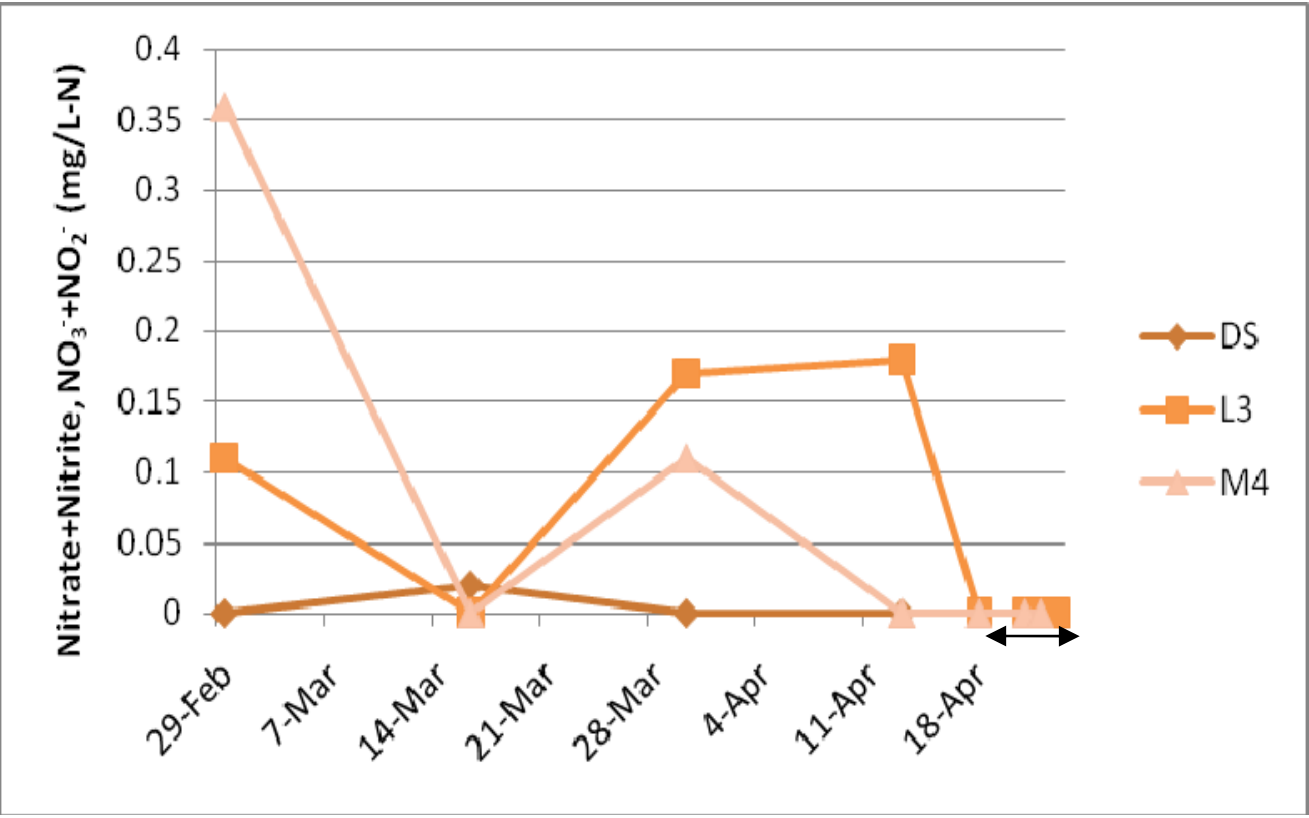

Figure 4-27: Nitrate + Nitrite nitrogen concentrations in modified drainage wetlands for the 2008 sampling season. The drawdown period is indicated by the line with arrows. 


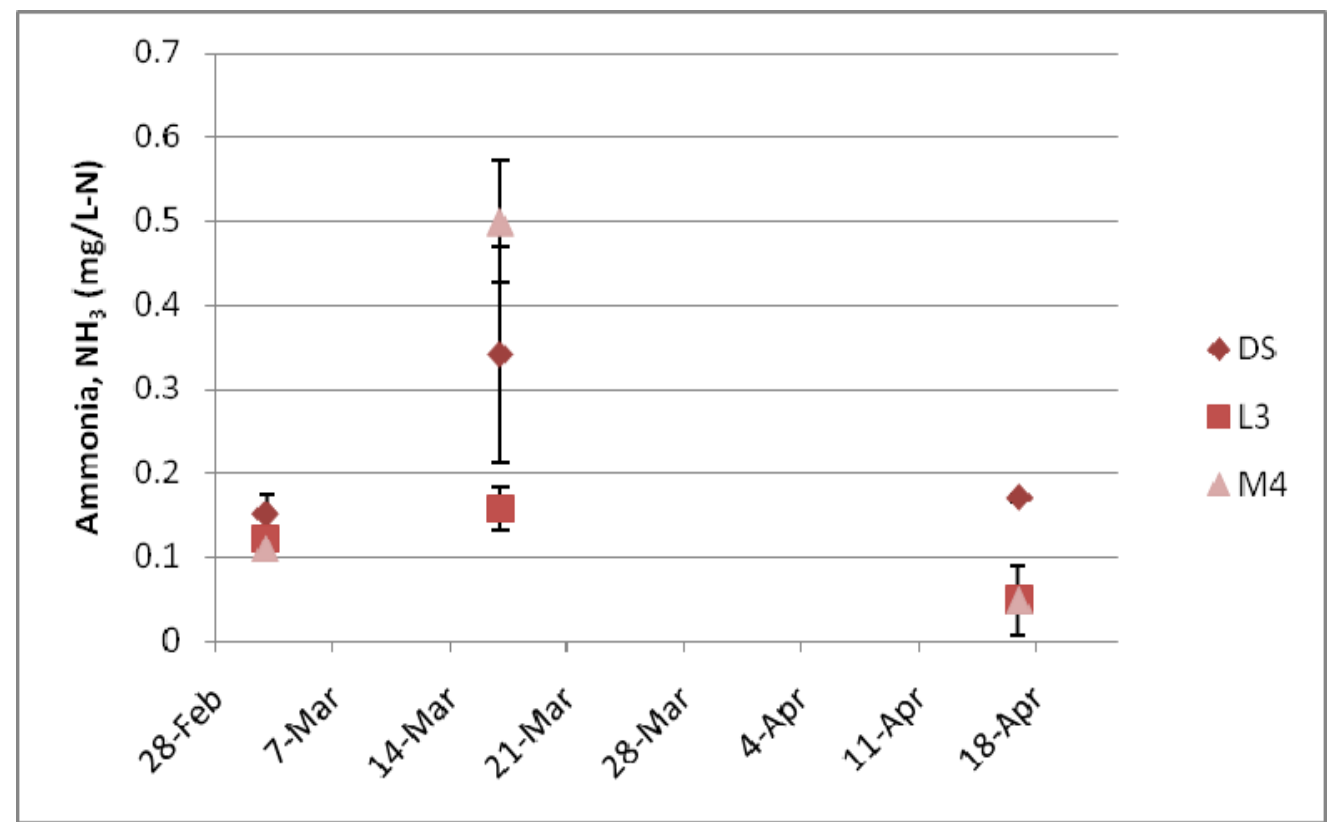

Figure 4-28: Total ammonia nitrogen concentrations in modified drainage wetlands for the 2007 sampling season.

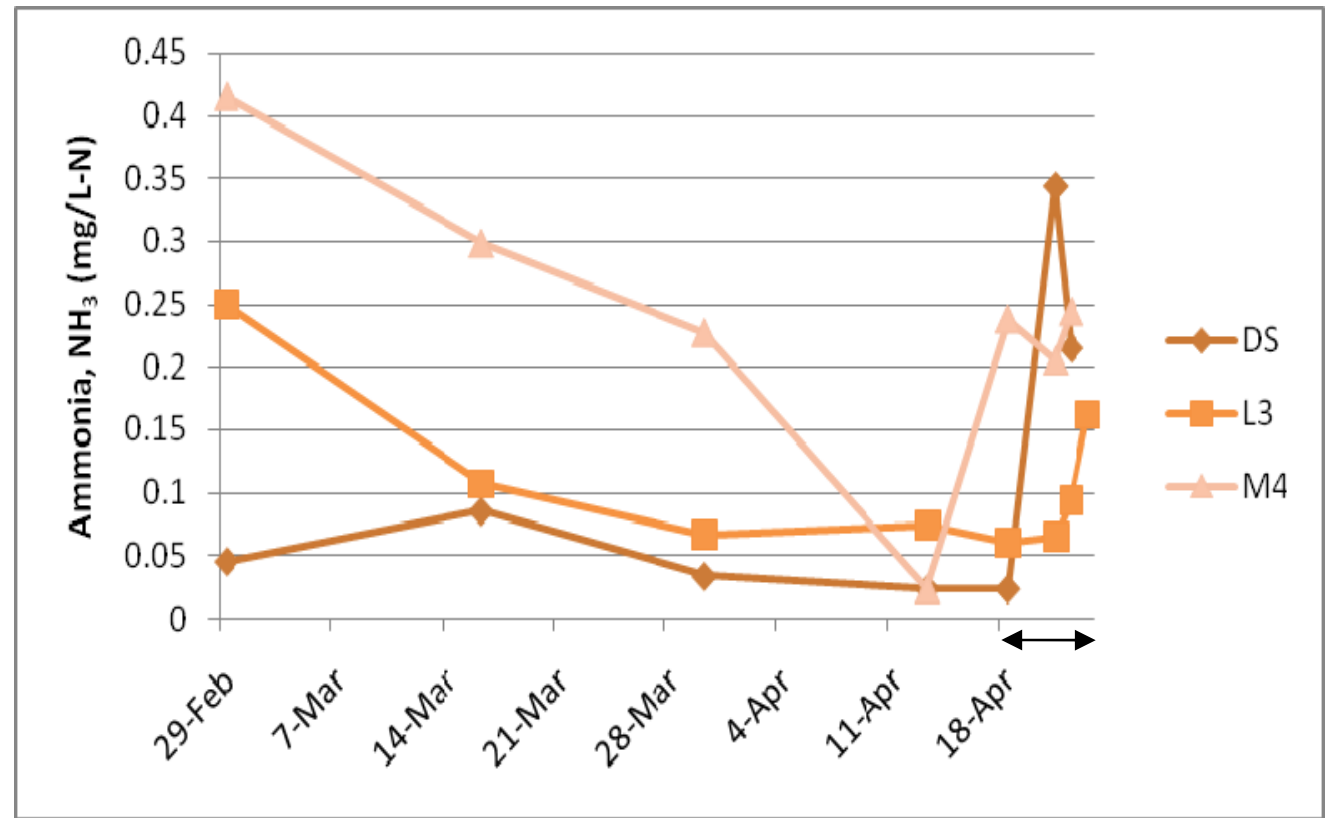

Figure 4-29: Total ammonia nitrogen concentrations in modified drainage wetlands for the 2008 sampling season. The drawdown period is indicated by the line with arrows. 


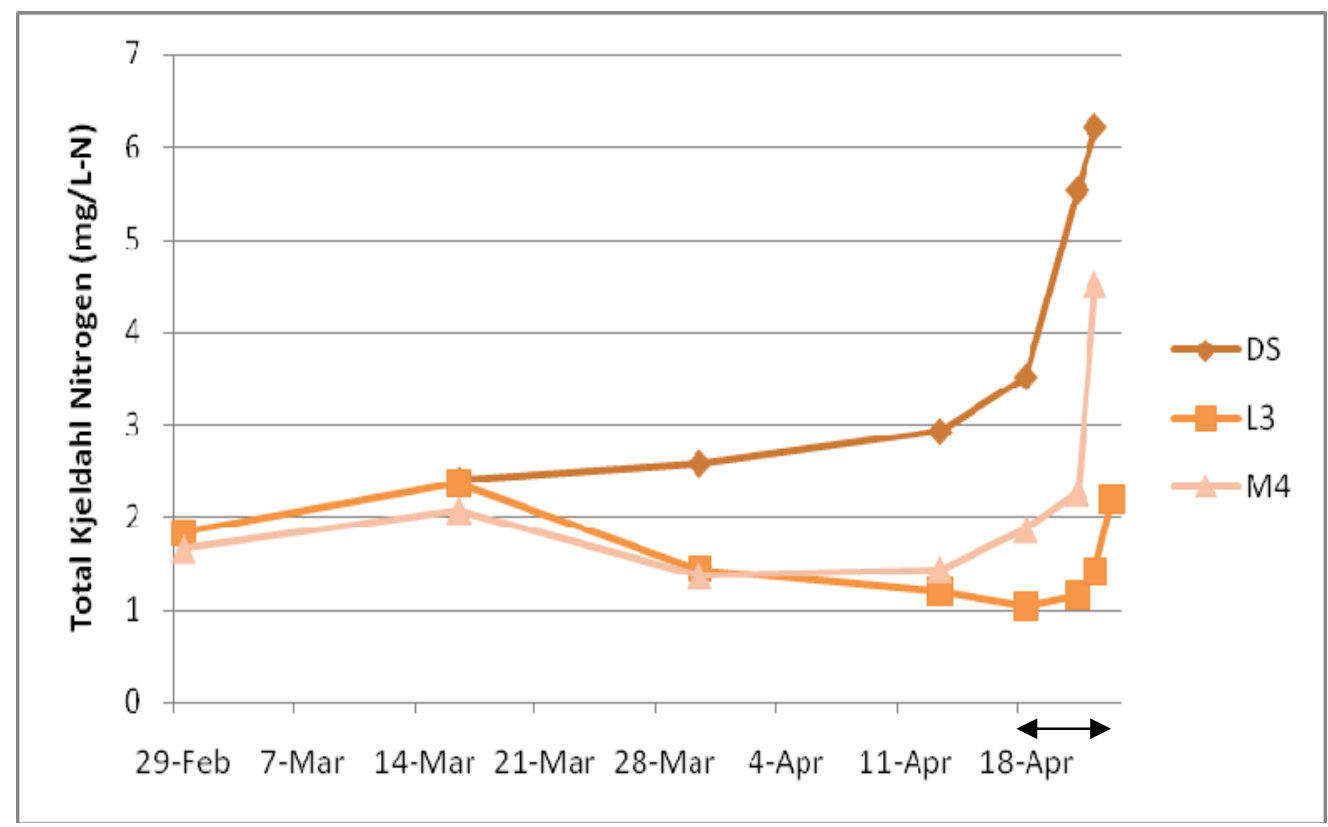

Figure 4-30: Total Kjeldahl nitrogen concentrations in modified drainage wetlands for the 2007 sampling season. The drawdown period is indicated by the line with arrows.

\subsubsection{Drainage Sites}

$\mathrm{NO}_{3}{ }^{-}+\mathrm{NO}_{2}{ }^{-}$levels varied dramatically at the drainage sites (Figure 4-31). Ammonia concentrations varied slightly between 0.035 and $0.095 \mathrm{mg} / \mathrm{L}-\mathrm{N}$ (Figure 4-32). Total Kjeldahl nitrogen concentrations increased slightly throughout the season but remained below 2 mg/L (Figure 4-33). No response from drawdown of wetlands was observed for any forms of nitrogen. 


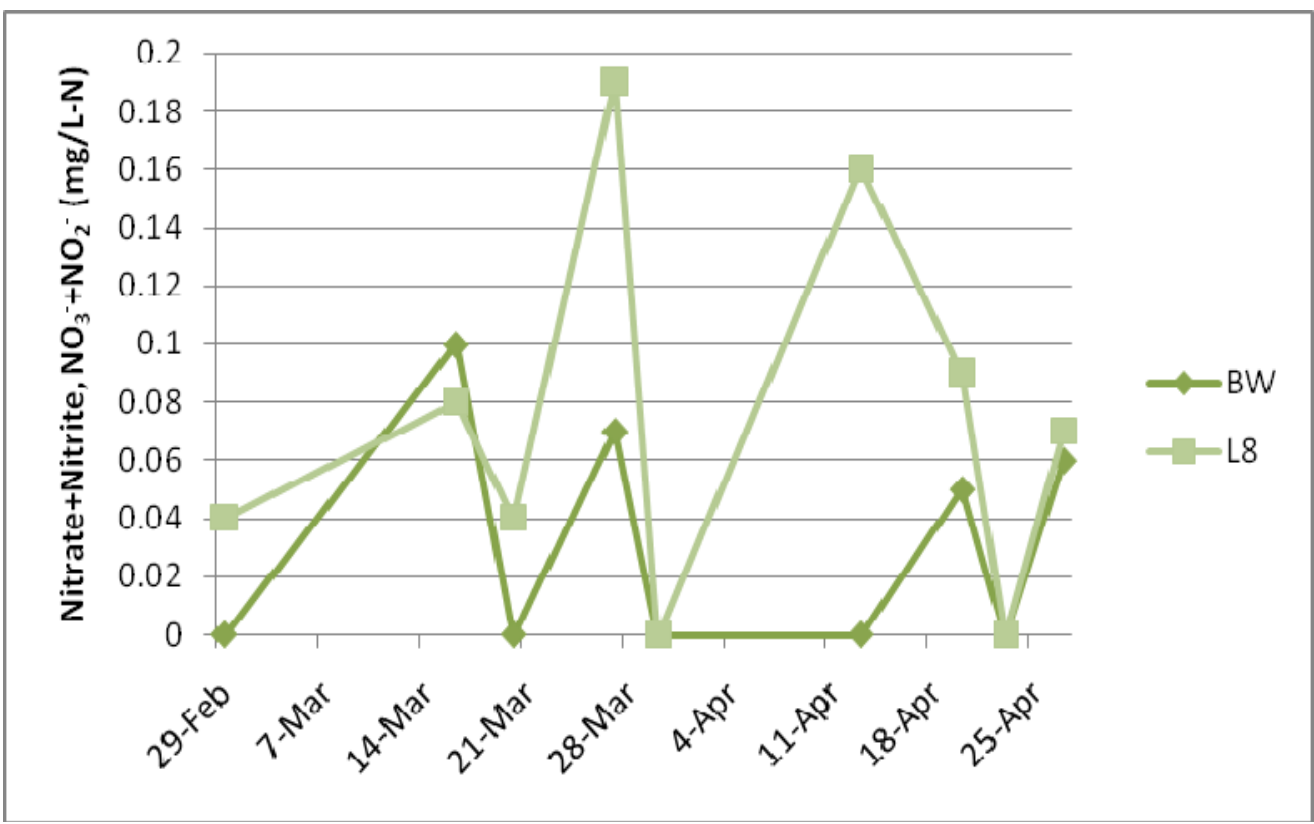

Figure 4-31: Nitrate + Nitrite nitrogen concentrations at the drainage sites for the 2008 sampling season.

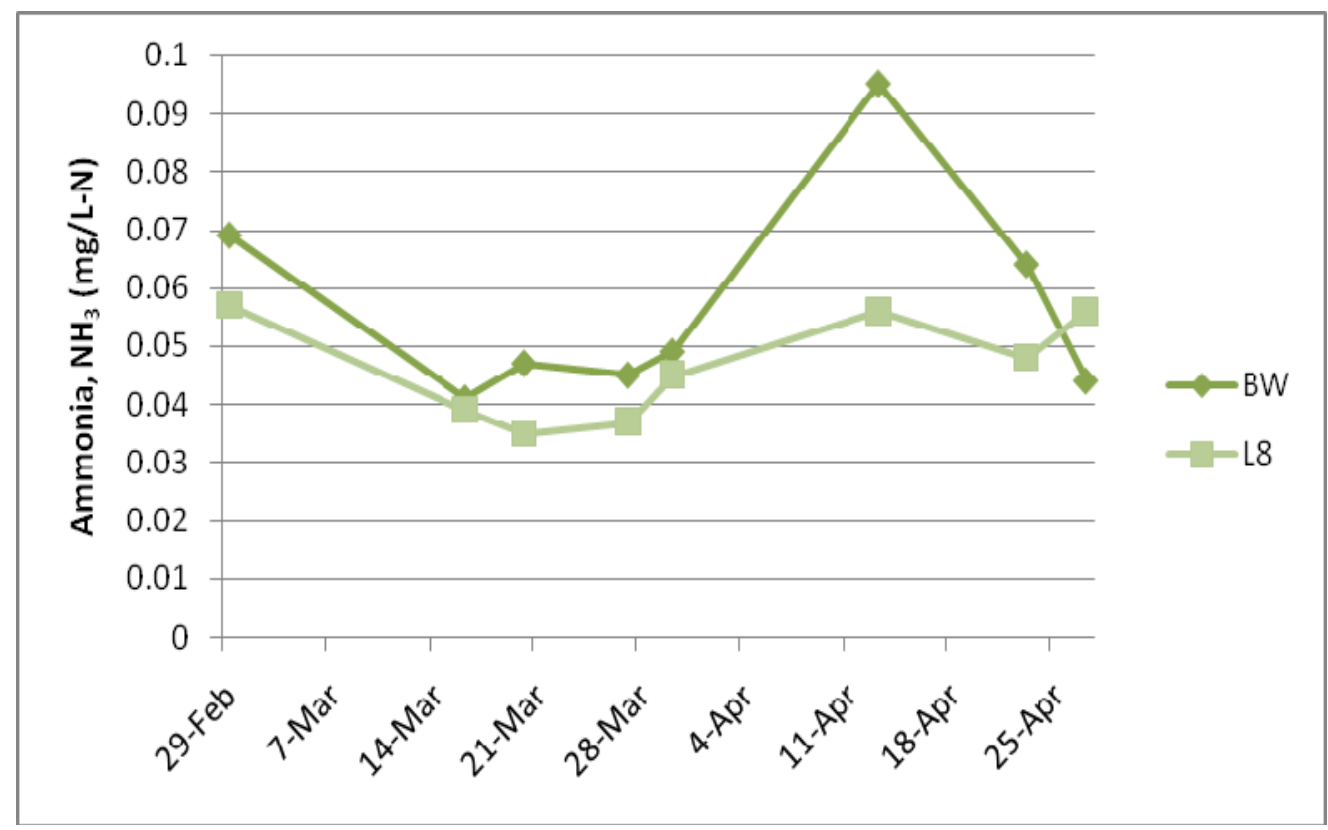

Figure 4-32: Total ammonia nitrogen concentrations at the drainage sites for the 2008 sampling season. 


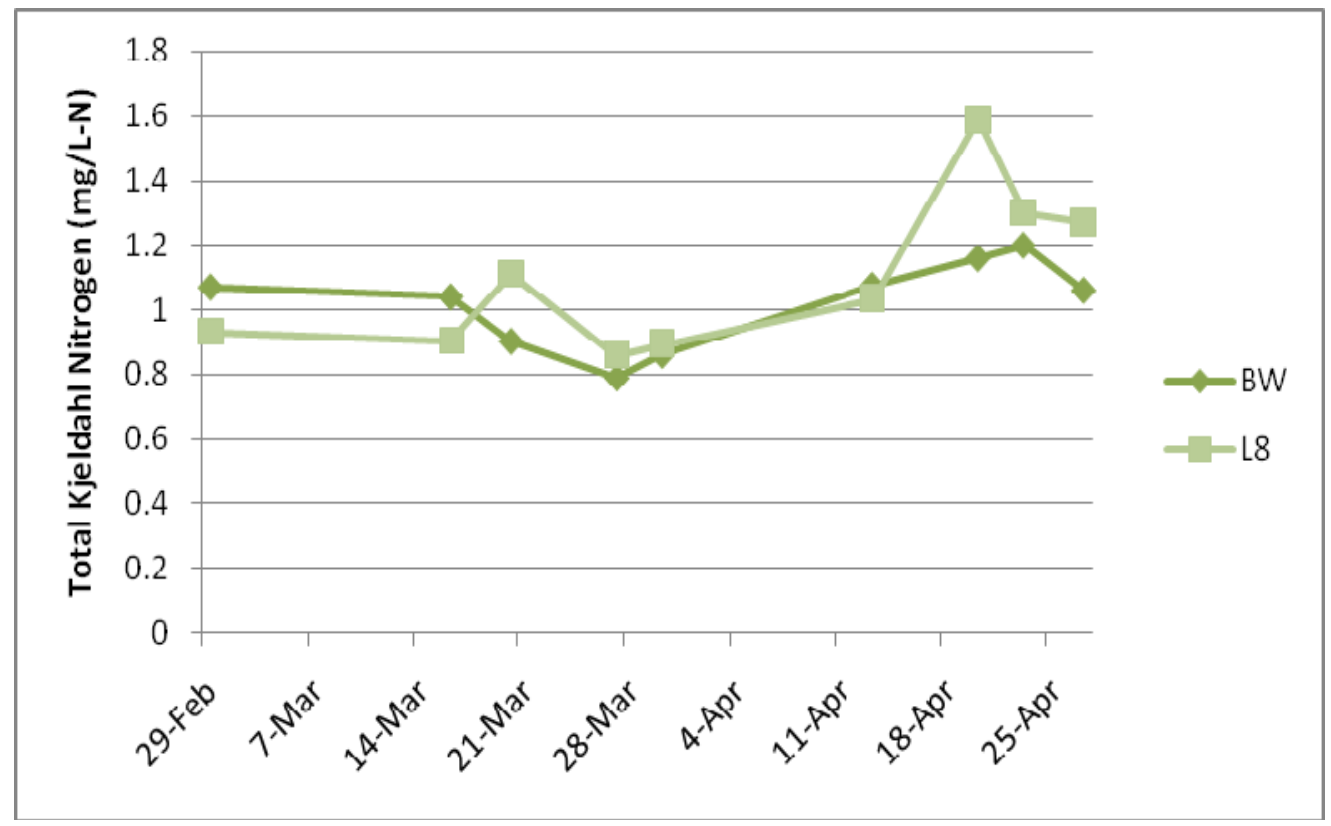

Figure 4-33: Total Kjeldahl nitrogen concentrations at the drainage sites for the 2008 sampling season.

\subsubsection{Phosphorus}

Phosphorus results are presented below. Orthophosphate and total phosphorus forms were analyzed.

\subsubsection{Traditional Wetlands}

In traditionally drained wetlands phosphate concentrations were consistently below 0.4 mg/L (Figure 4-34 and Figure 4-35). Phosphate levels increased in two of three wetlands during the 2007 season (Figure 4-34). Total phosphorus concentrations increased in all three wetlands in the 2007 season (Figure 4-36). During the 2008 season, phosphate levels increased in all three wetlands but remained below $0.09 \mathrm{mg} / \mathrm{L}$ (Figure 4-35). Total phosphorus concentrations decreased in two of three wetlands (Figure 4-37) and were below $0.3 \mathrm{mg} / \mathrm{L}$. 


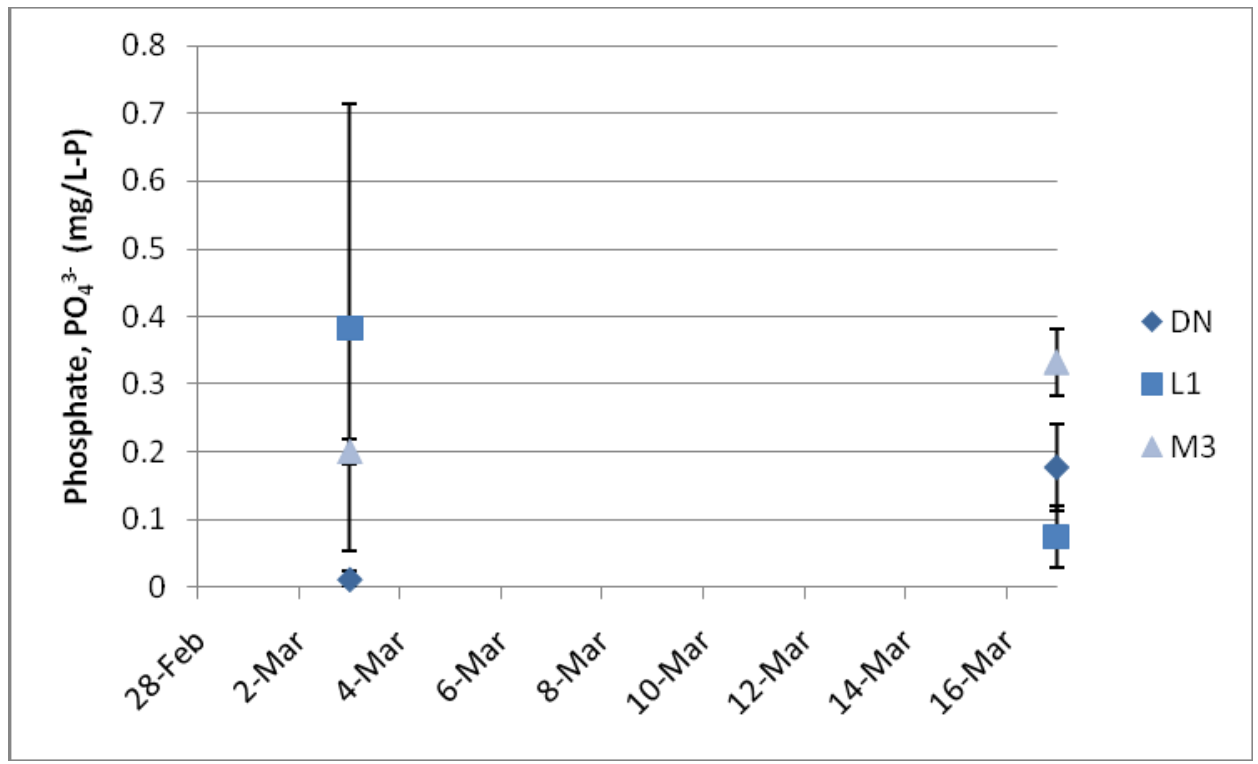

Figure 4-34: Phosphate concentrations in traditional drainage wetlands for the 2007 sampling season.

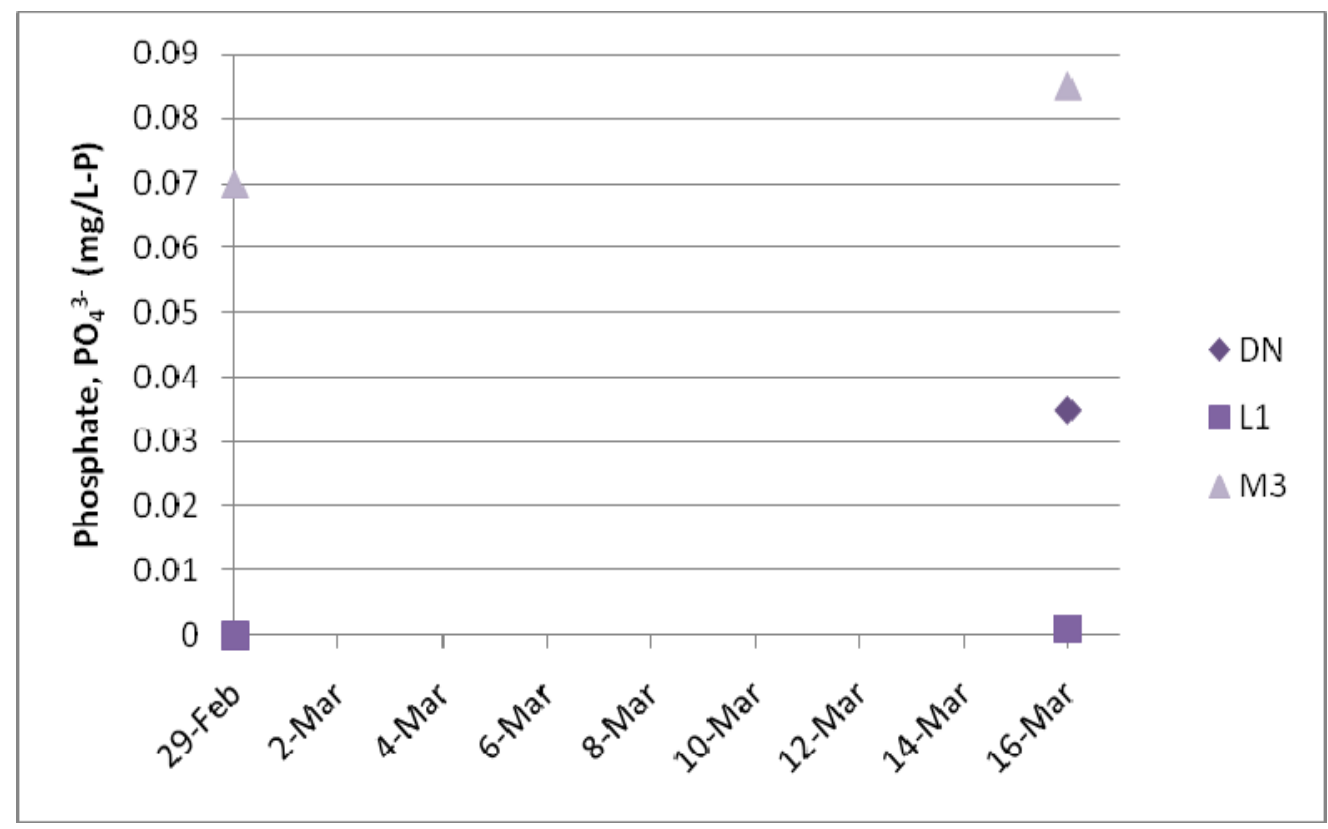

Figure 4-35: Phosphate concentrations in traditional drainage wetlands for the 2008 sampling season. 


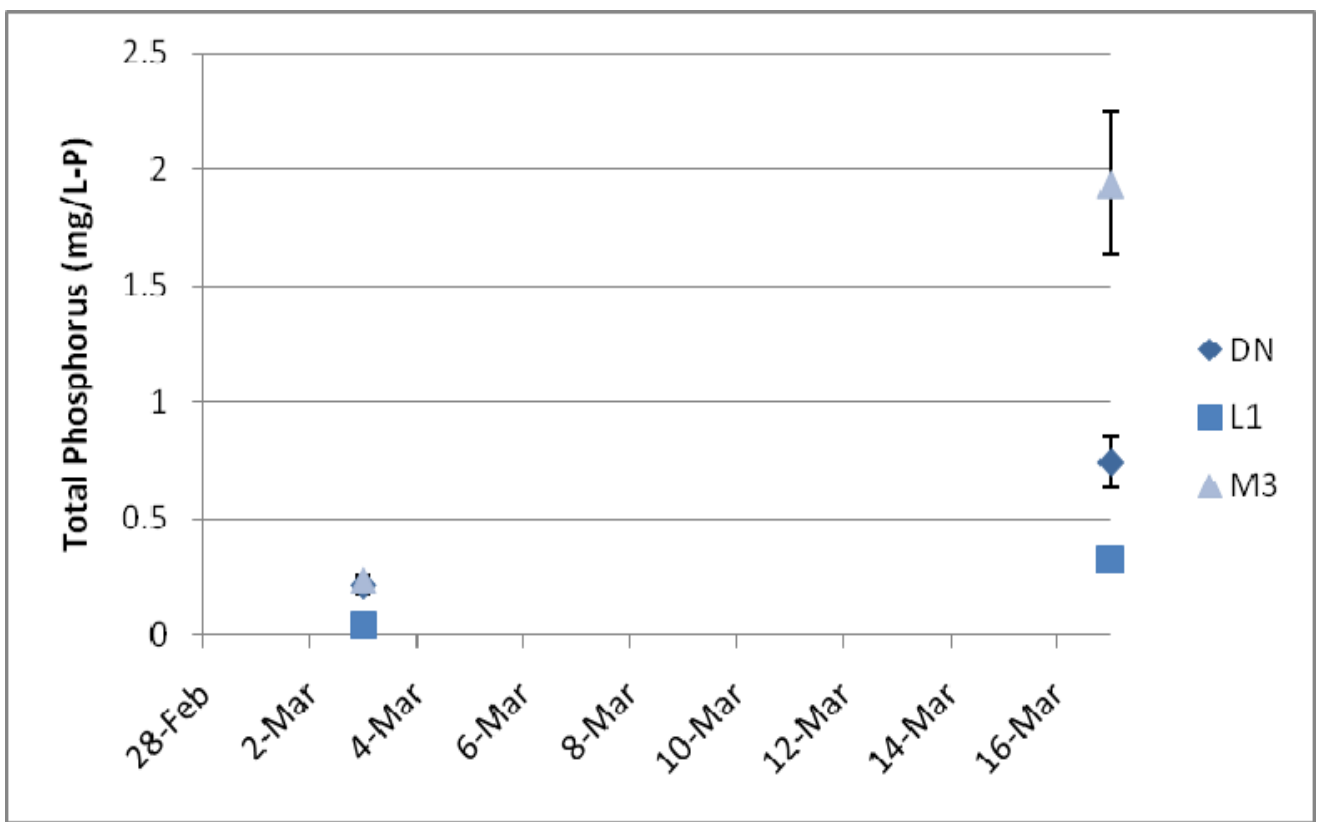

Figure 4-36: Total phosphorus concentrations in traditional drainage wetlands for the 2007 sampling season.

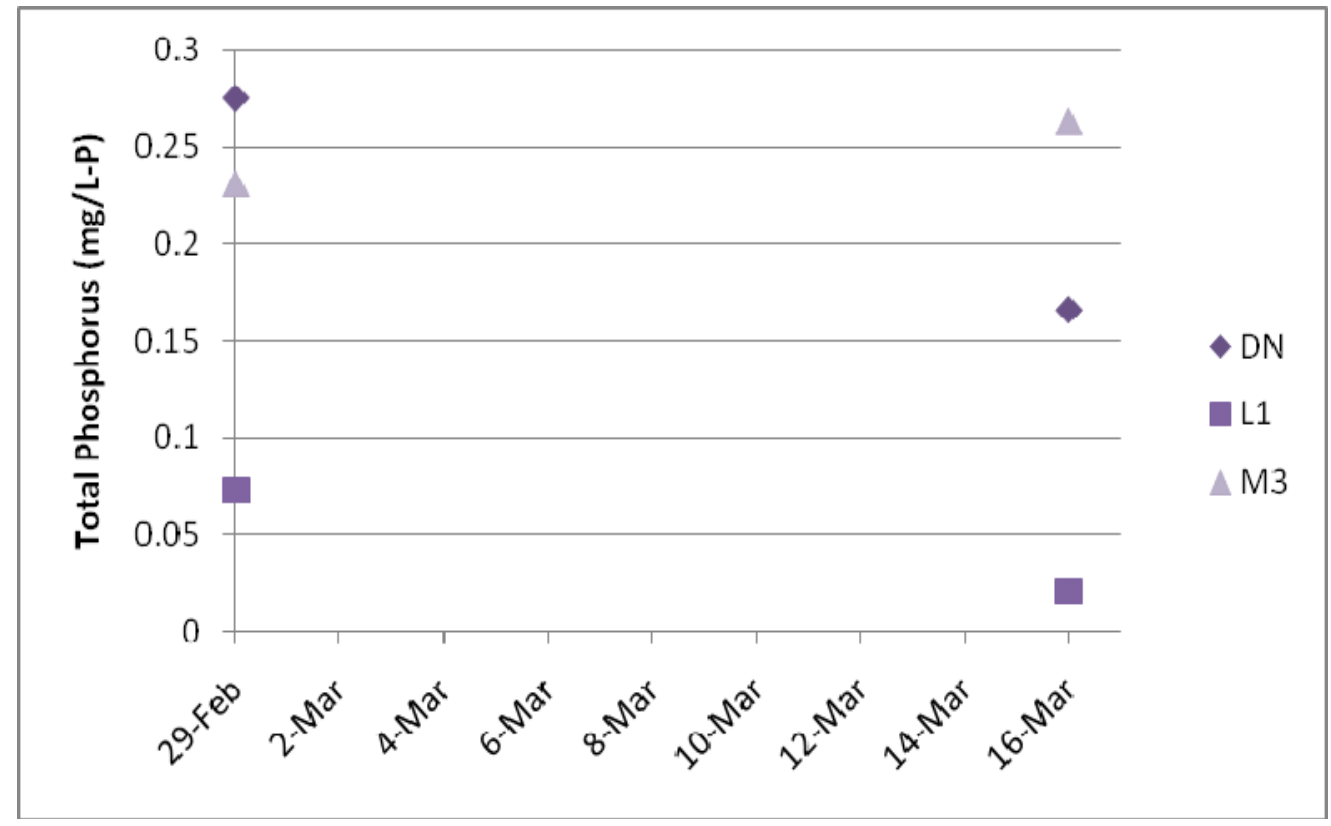

Figure 4-37: Total phosphorus concentrations in traditional drainage wetlands for the 2008 sampling season.

\subsubsection{Modified Wetlands}

During the 2007 season, phosphate levels remained below $0.4 \mathrm{mg} / \mathrm{L}$ in the modified drainage wetlands. There was an initial increase in phosphate concentrations followed by 
a decrease during the extended flood period (Figure 4-38). Total phosphorus level followed the same trend except for Ducky Strike South, which increased in total phosphorus through the extended flood period (Figure 4-39). Total phosphorus levels remained below $1 \mathrm{mg} / \mathrm{L}$.

During the 2008 season, phosphate levels remained below $0.2 \mathrm{mg} / \mathrm{L}$, but did not follow a trend (Figure 4-39). During drainage, phosphate levels increased initially then decreased in all two of three wetlands. Phosphate levels in Ducky Strike South increased throughout drainage. Total phosphorus levels remained below $1 \mathrm{mg} / \mathrm{L}$. Concentrations increased during the extended flood period in all three wetlands. During drainage, there was an initial decrease in total phosphorus concentrations followed by a large increase. The large increase is likely due to the scouring of nutrient rich sediments and periphyton during drawdown.

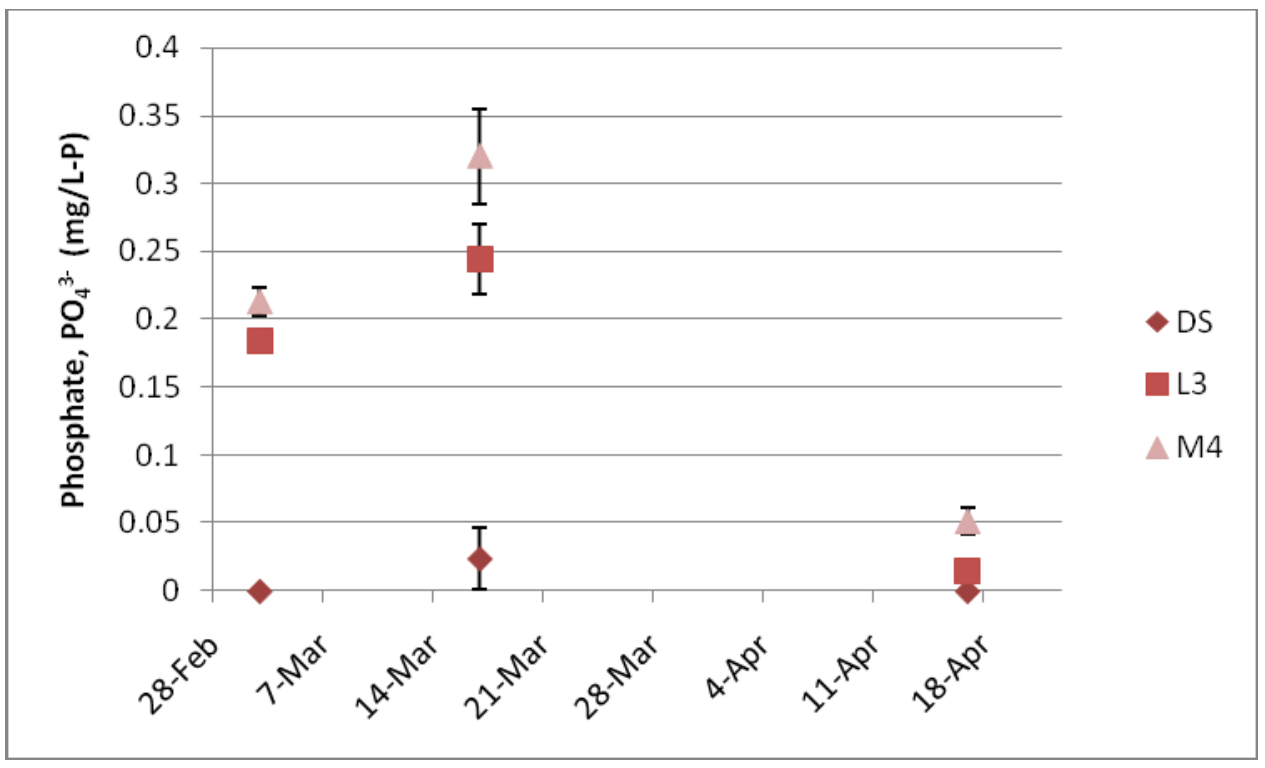

Figure 4-38: Phosphate concentrations in modified drainage wetlands for the 2007 sampling season. 


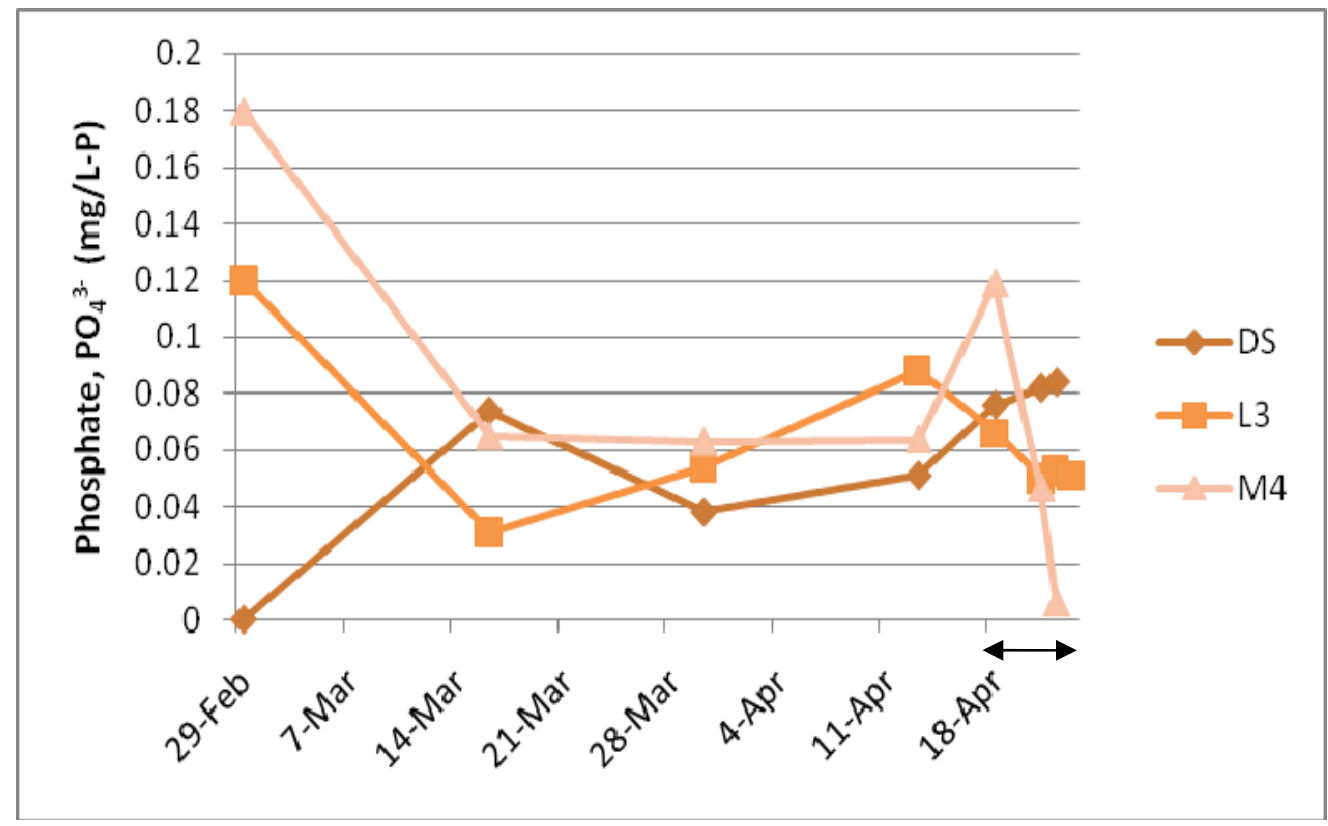

Figure 4-39: Phosphate concentrations in modified drainage wetlands for the 2008 sampling season. The drawdown period is indicated by the line with arrows.

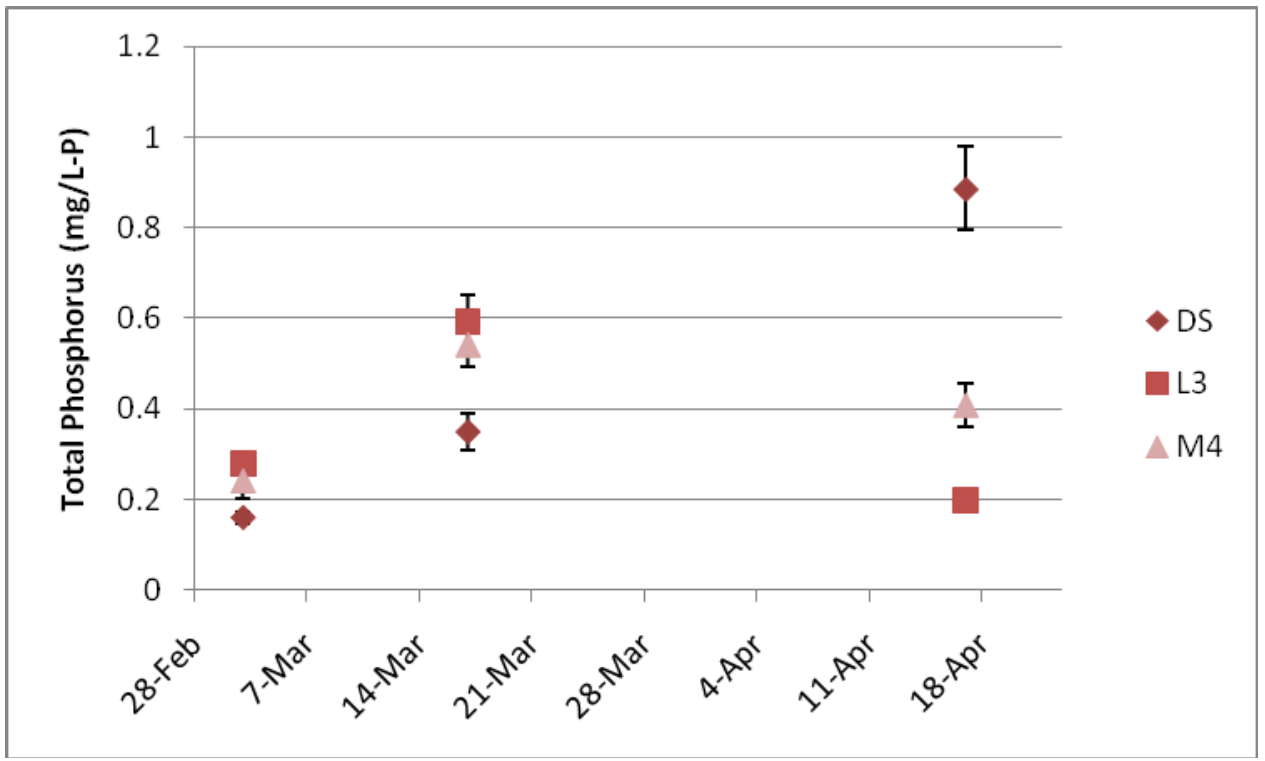

Figure 4-40: Total phosphorus concentrations in modified drainage wetlands for the 2007 sampling season. 


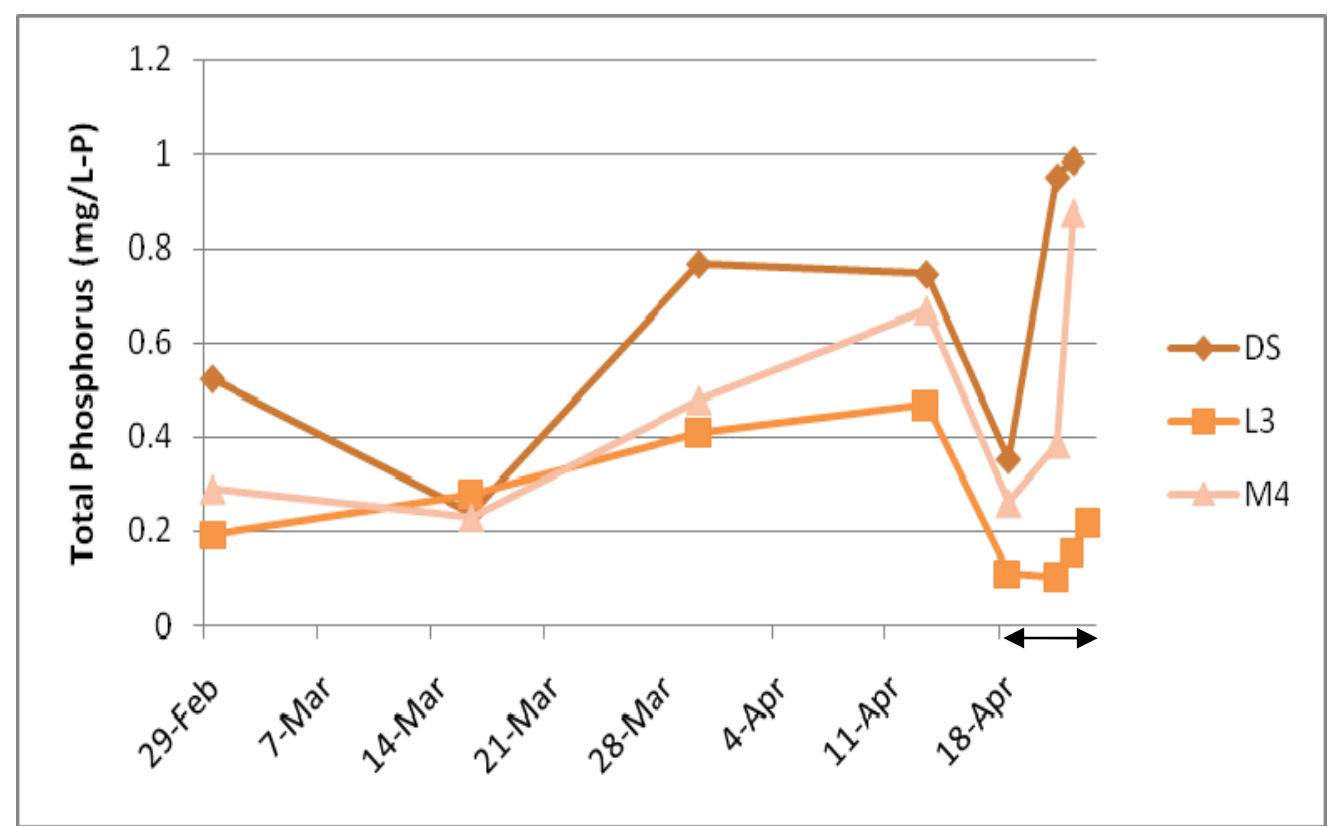

Figure 4-41: Total phosphorus concentrations in modified drainage wetlands for the 2008 sampling season. The drawdown period is indicated by the line with arrows.

\subsubsection{Drainage Sites}

Phosphate levels at the drainage sites remained below $0.25 \mathrm{mg} / \mathrm{L}$ at the drainage sites during the 2008 sampling season (Figure 4-42). There was a slight increase in phosphate levels at both sites throughout the season. Total phosphorus levels remained below 1 $\mathrm{mg} / \mathrm{L}$ (Figure 4-43). No change in phosphate or total phosphorus concentrations was noticed during drawdown of the studied wetlands. 


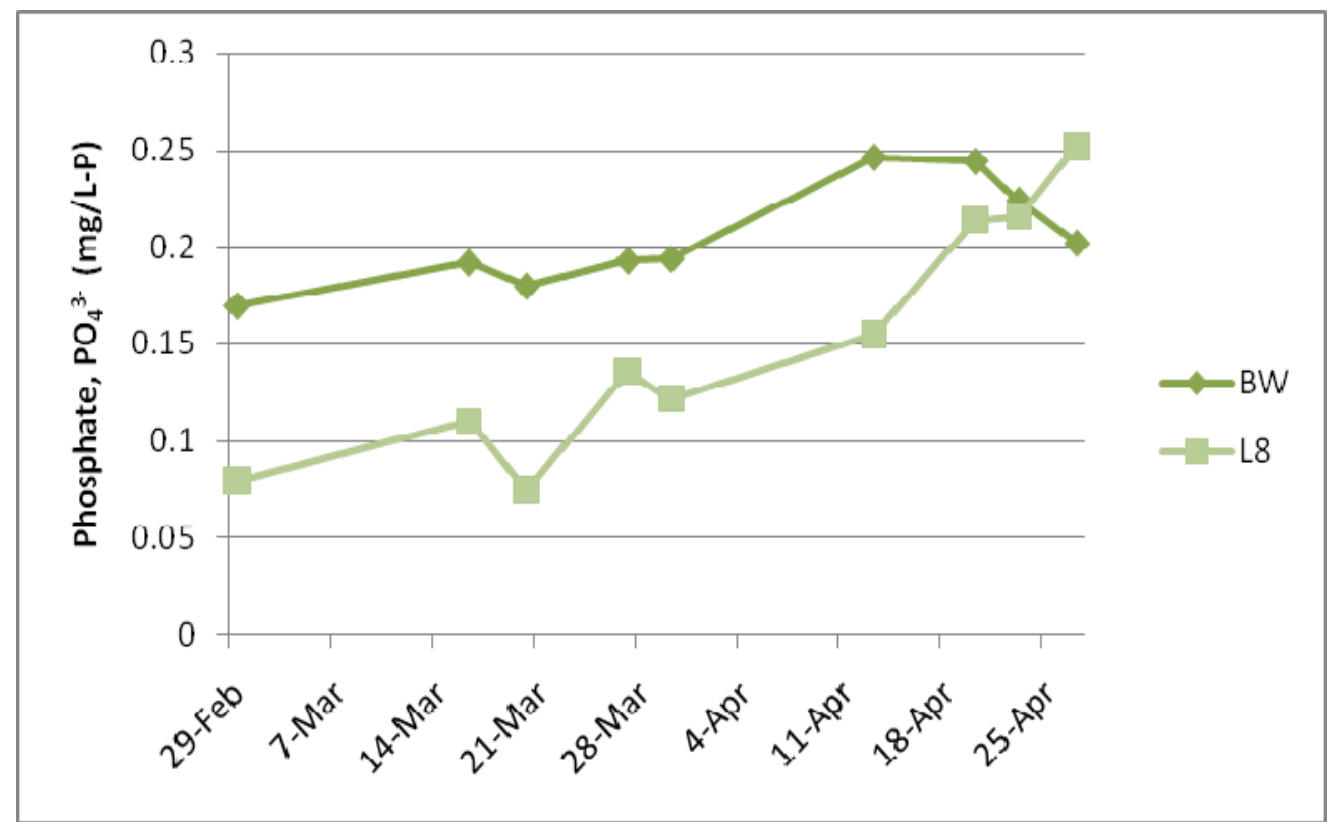

Figure 4-42: Phosphate concentrations at drainage sites for the 2008 sampling season.

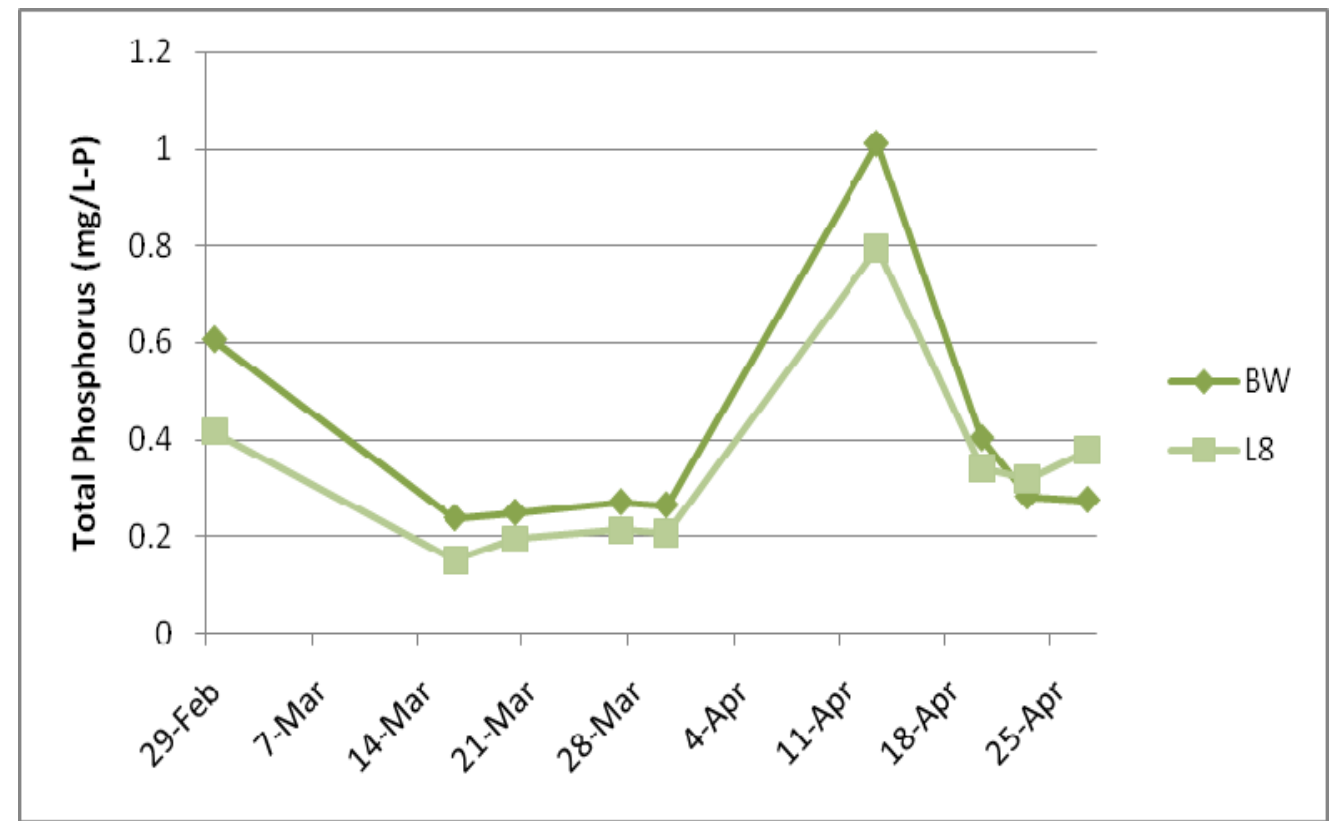

Figure 4-43: Total phosphorus concentrations at drainage sites for the 2008 sampling season.

\subsubsection{Organic Carbon}

Total and dissolved organic carbon was measured during the 2008 sampling season. Organic carbon levels remained constant throughout the flooded period. During 
drawdown, both dissolved and total organic carbon levels increased substantially as seen in Figure 4-46 and Figure 4-47. At all sites, the majority of the total organic carbon consisted of dissolved organic carbon. Using all 2008 data points, dissolved organic carbon contributed $80+/-13 \%$ (mean $+/$ - standard deviation) of the total organic carbon than the other traditional wetlands.

\subsubsection{Traditional Wetlands}

Dissolved and total organic carbon remained constant for all traditional wetlands throughout the season (Figure 4-44 and Figure 4-45). Ducky Strike North had consistently more dissolved and total organic carbon.

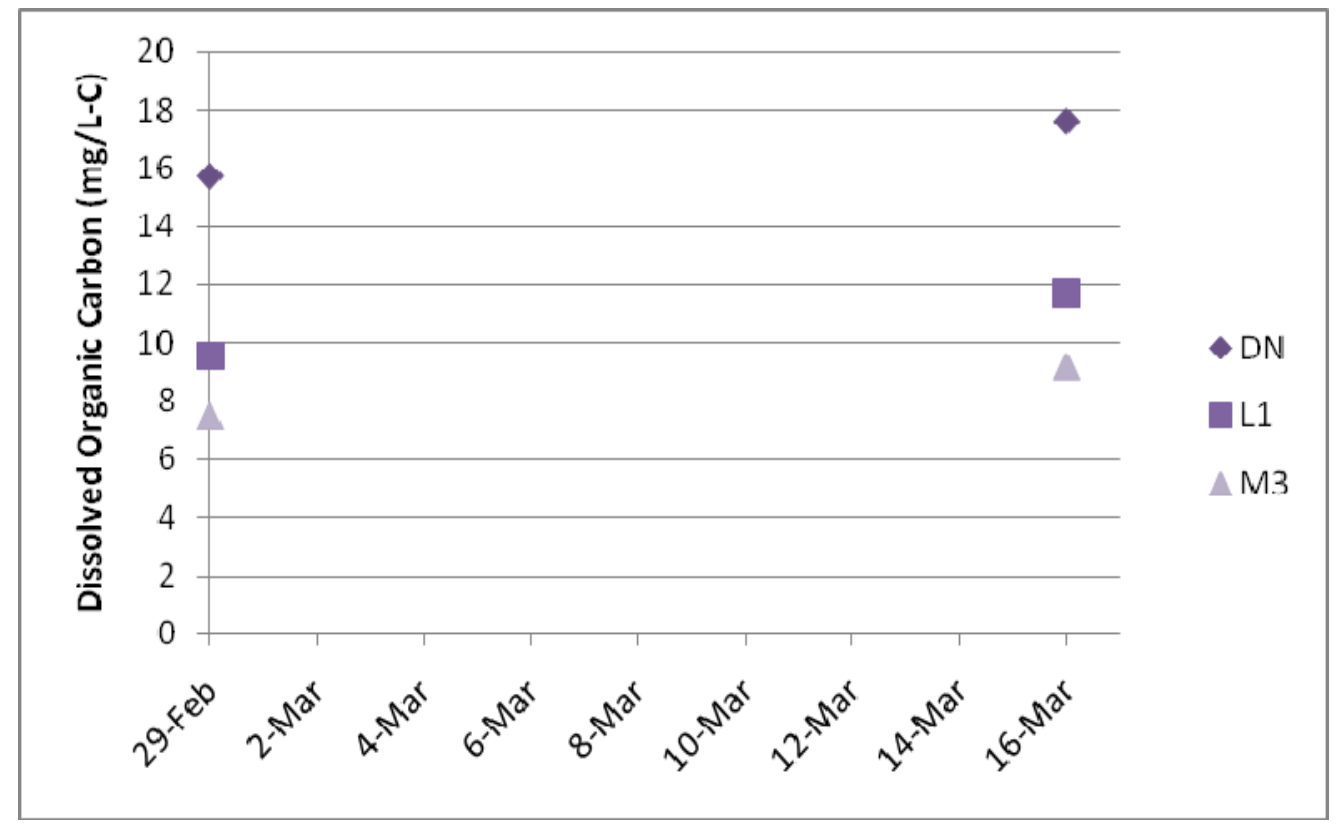

Figure 4-44: Dissolved organic carbon concentrations in traditional drainage wetlands for the 2008 sampling season. 


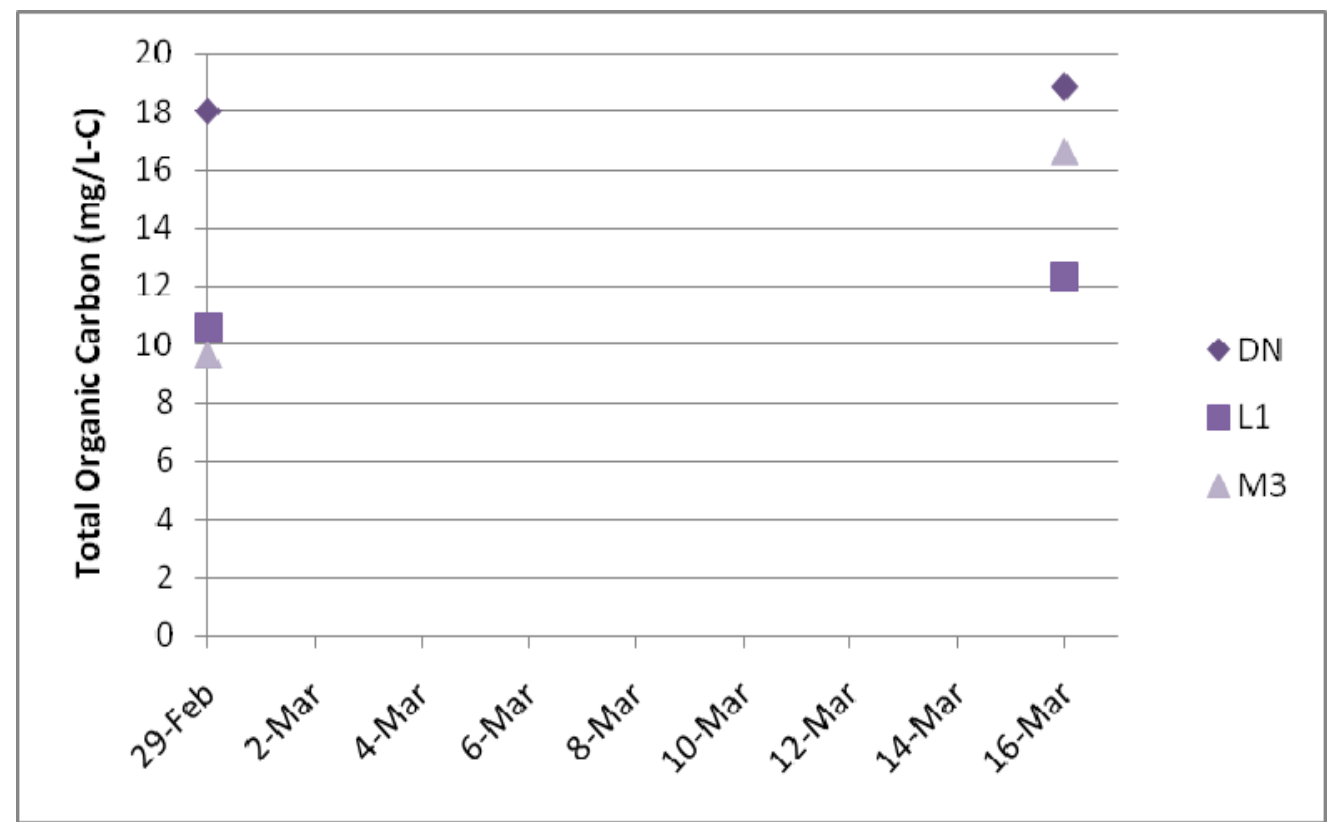

Figure 4-45: Total organic carbon concentrations in traditional drainage wetlands for the 2008 sampling season. Particulate organic carbon was estimated at $52 \%$ of VSS.

\subsubsection{Modified Wetlands}

Dissolved and total organic carbon concentrations remained constant throughout the season in Los Banos 33 and Mud Slough 4b, while a general increase was observed throughout the season in Ducky Strike South (Figure 4-46 and Figure 4-47). Levels of organic carbon increased substantially in all three wetlands during the drawdown period due to scouring of nutrient rich sediments and periphyton. Total organic carbon levels reached as high as $65.7 \mathrm{mg} / \mathrm{L}-\mathrm{C}$ in Ducky Strike South. 


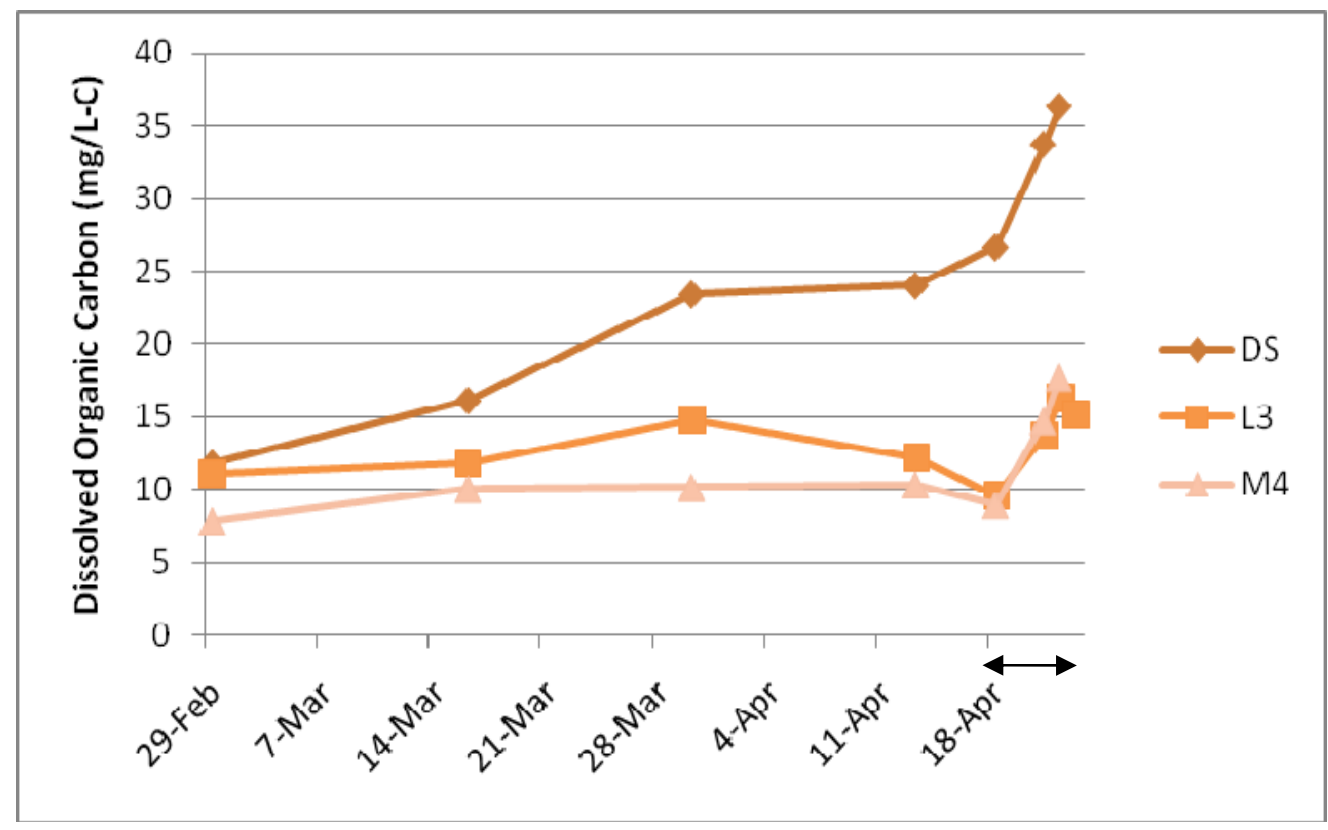

Figure 4-46: Dissolved organic carbon concentrations in modified drainage wetlands for the 2008 sampling season. The drawdown period is indicated by the line with arrows.

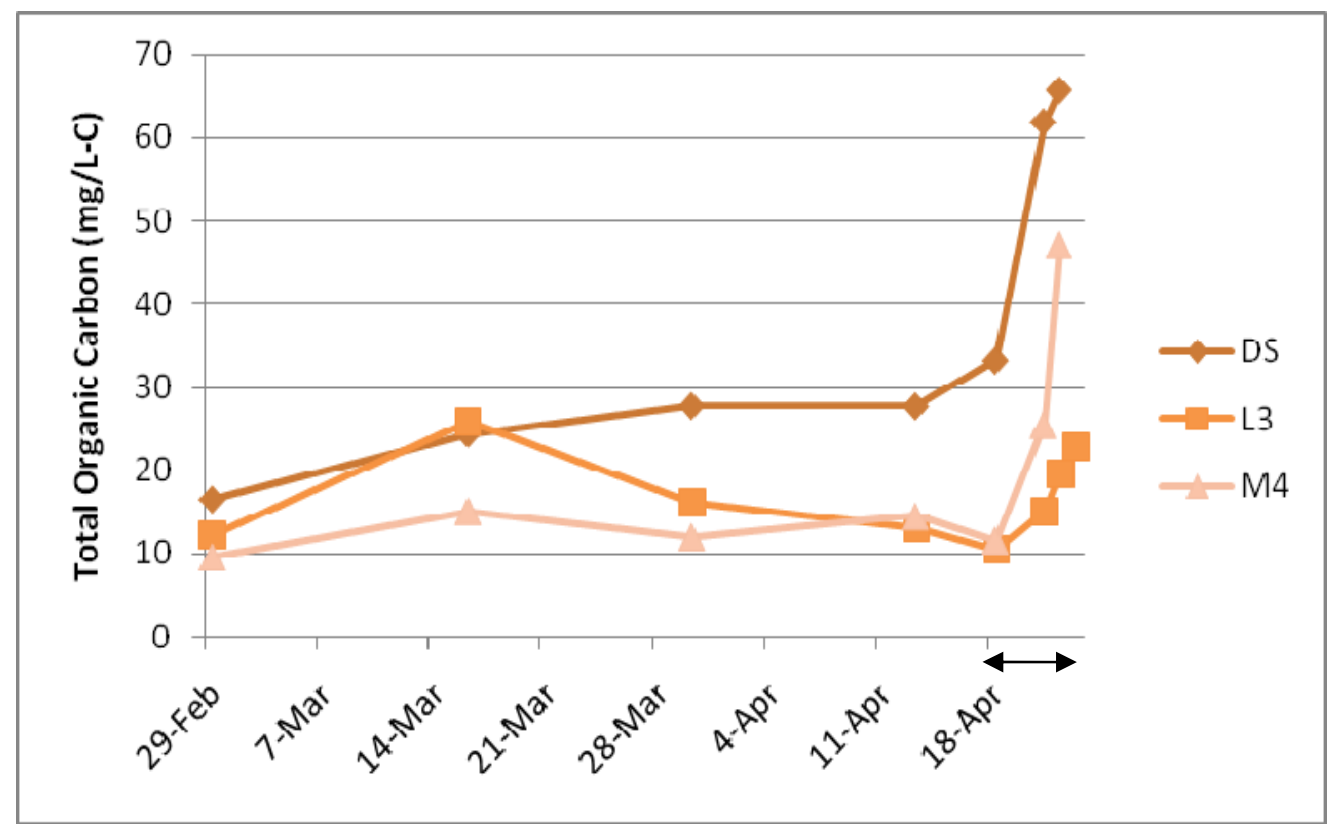

Figure 4-47: Total organic carbon concentrations in modified drainage wetlands for the 2008 sampling season. Particulate organic carbon was estimated at $52 \%$ of VSS. The drawdown period is indicated by the line with arrows. 


\subsubsection{Drainage Sites}

Total and dissolved organic carbon levels remained between $10-18 \mathrm{mg} / \mathrm{L}-\mathrm{C}$ at the drainage sites (Figure 4-48 and Figure 4-49). Two spikes in concentration are noticed at both sites approximately one week after drawdown of the studied sites. These spikes are likely due to scouring of nutrient rich sediments and periphyton in upstream wetlands. At the drainage sites, dissolved organic carbon contributed $88+/-3 \%$ (mean $+/-$ standard deviation) of total organic carbon concentrations.

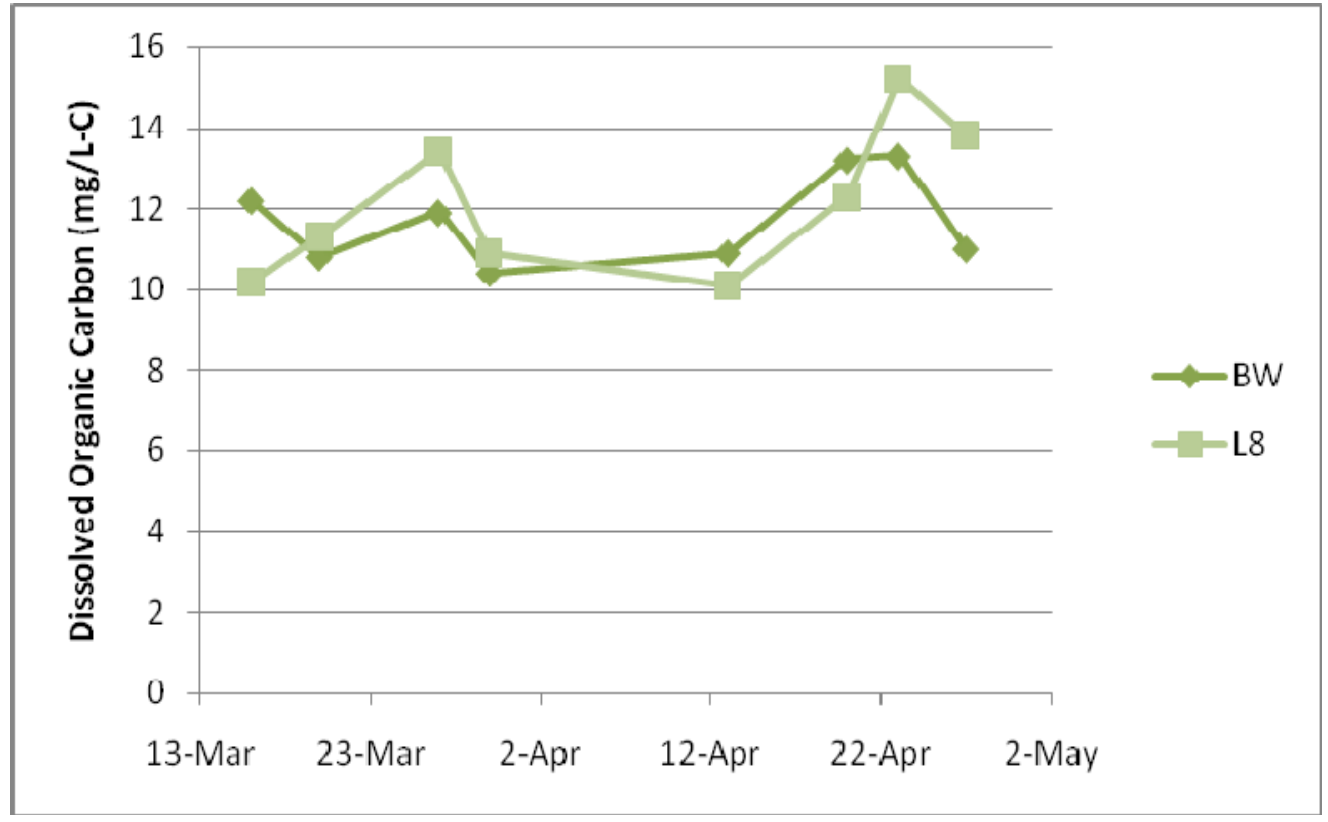

Figure 4-48: Dissolved organic carbon concentrations at drainage sites for the 2008 sampling season. 


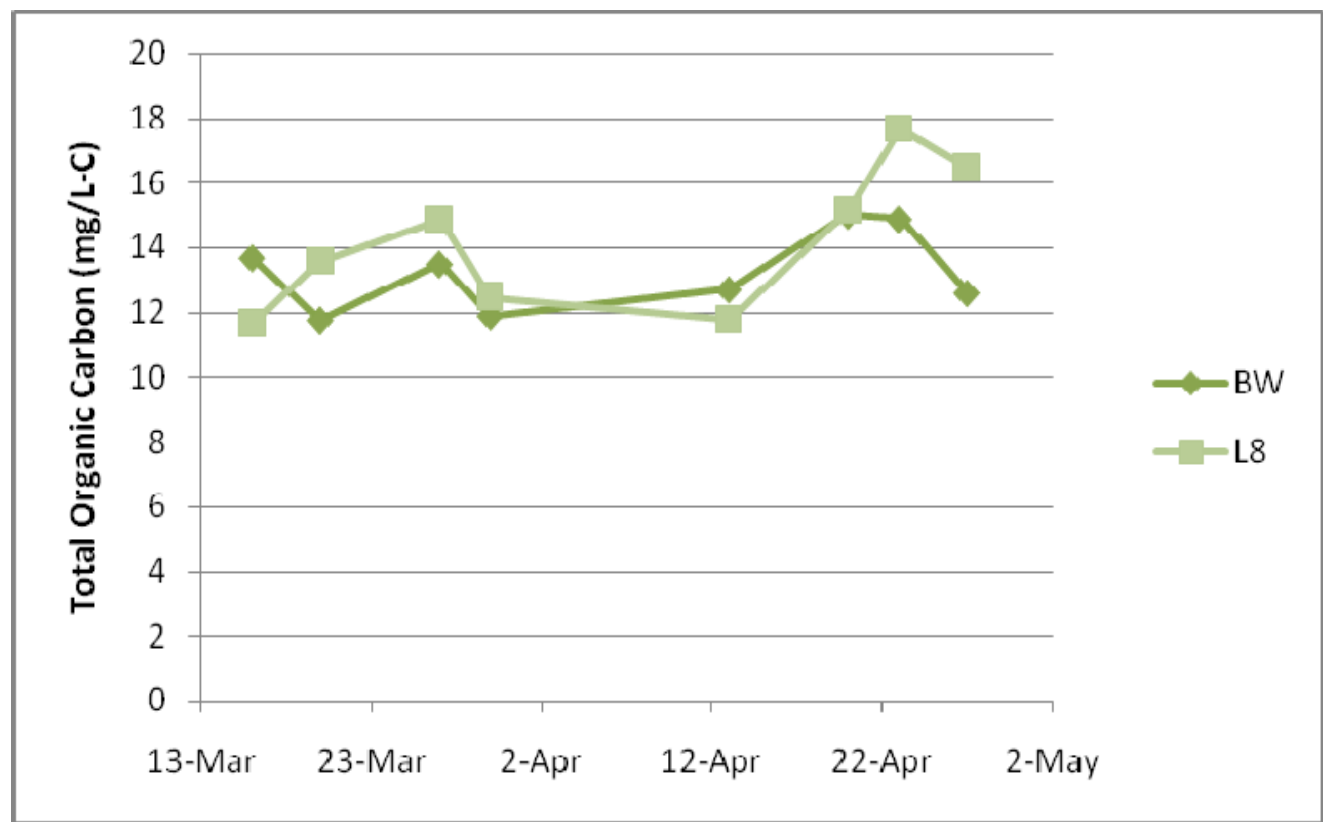

Figure 4-49: Total organic carbon concentrations at drainage sites for the 2008 sampling season. Particulate organic carbon was estimated at $52 \%$ of VSS.

\subsubsection{Salinity}

Salinity was measured by conductivity and chloride concentration. A strong correlation was found between chloride concentration and conductivity during the 2007 season (Figure 4-50). Since not all samples were tested for conductivity, this correlation was used to convert chloride concentrations to conductivity measurements. 


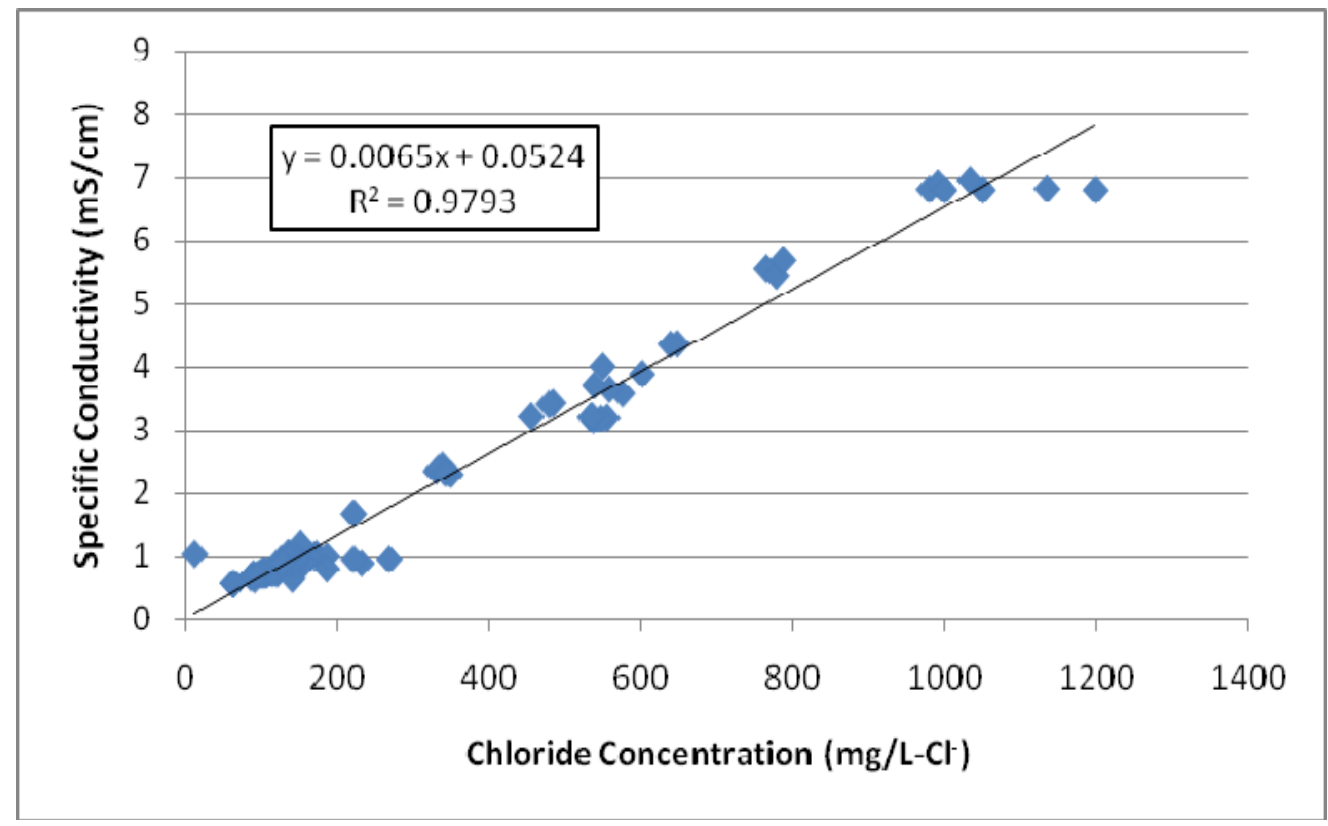

Figure 4-50: Correlation between specific conductivity and chloride concentration. Data is from the 2007 sampling season.

\subsubsection{Traditional Wetlands}

Specific conductivity readings increased slightly in two of three traditional drainage wetlands during the 2007 sampling season (Figure 4-51). In the Los Banos 31b wetland, specific conductivity values slightly decreased. This may be due to the introduction of freshwater during the season. The Los Banos wetlands are also deeper than the other wetlands and are less prone to evapotranspiration. During the 2008 season, specific conductivity readings increased in all three traditional drainage wetlands. The largest increases were noticed in the Ducky Strike North, which are shallower than the other wetlands and are more susceptible to the effects of evapotranspiration. 


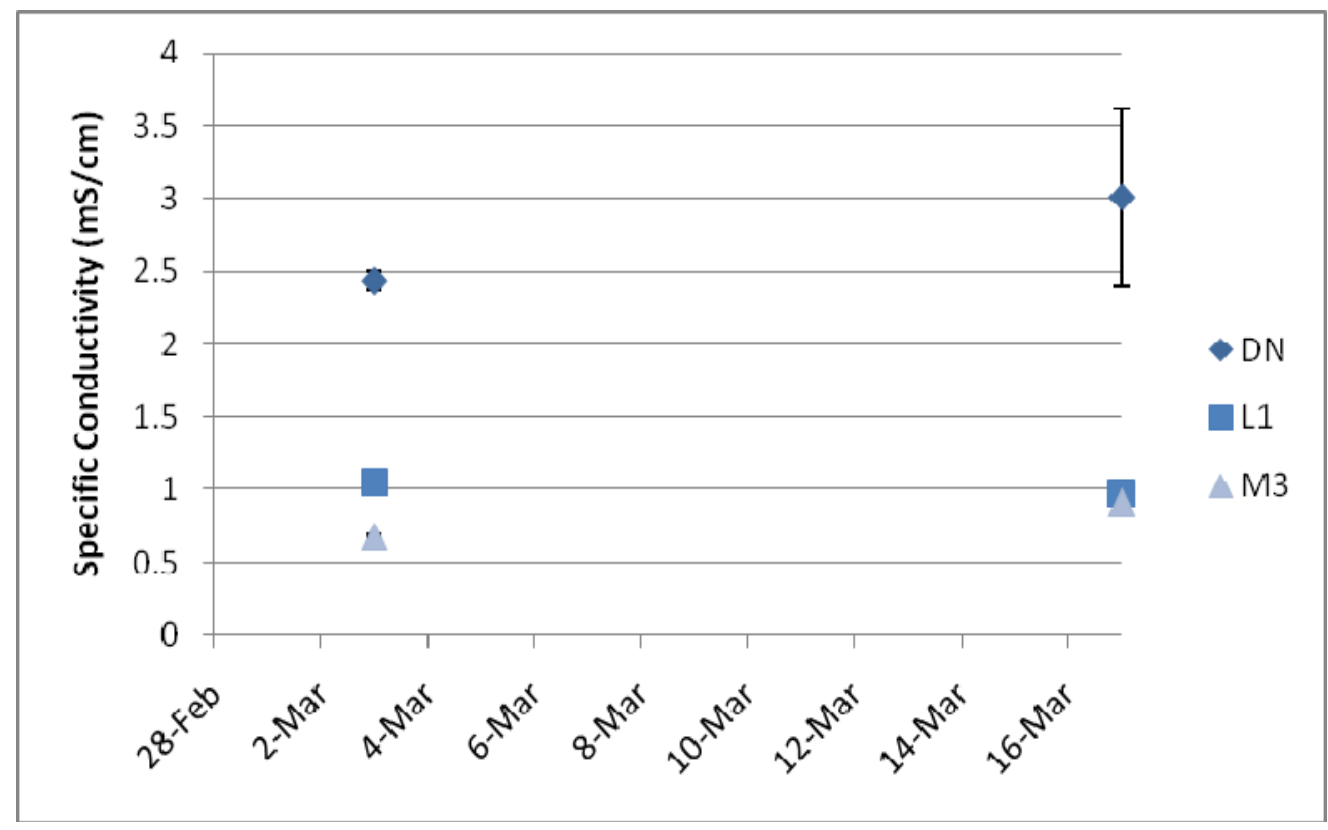

Figure 4-51: Specific conductivity readings from traditional drainage wetlands for the 2007 sampling season.

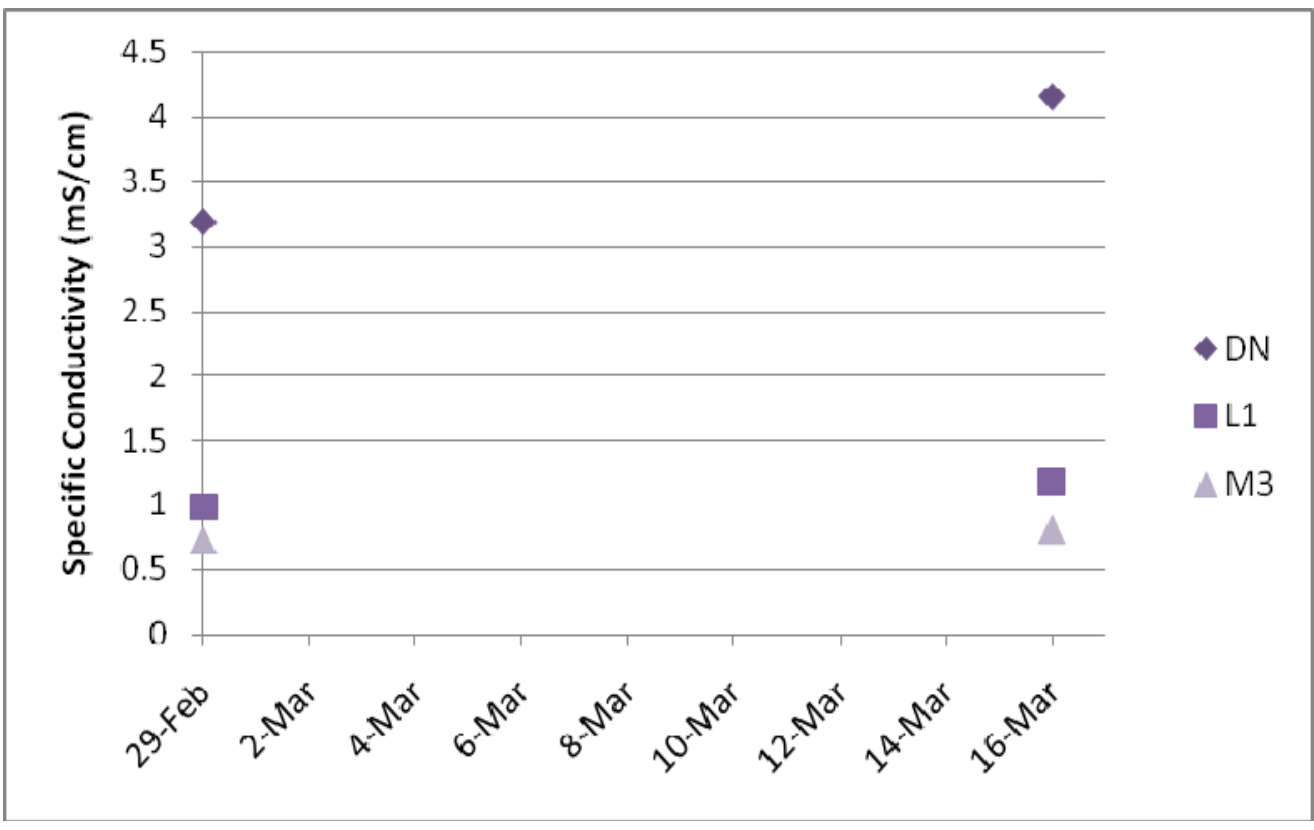

Figure 4-52: Specific conductivity readings from traditional drainage wetlands for the 2008 sampling season.

\subsubsection{Modified Wetlands}

Specific conductivity readings slightly increased in two of three modified drainage wetlands during the 2007 sampling season (Figure 4-53). In the Los Banos 33 wetland, 
specific conductivity values slightly decreased. This may be due to the introduction of freshwater during the season. The Los Banos wetlands are also deeper than the other wetlands and are less prone to evapotranspiration. Specific conductivity values increased in all three wetlands during the 2008 season (Figure 4-54). The greatest increases were seen in Ducky Strike South, which is shallower than the other wetlands and more susceptible to evapotranspiration. During the drawdown period of the 2008 season, specific conductivity values increased substantially reaching almost $9 \mathrm{mS} / \mathrm{cm}$ in the Ducky Strike South.

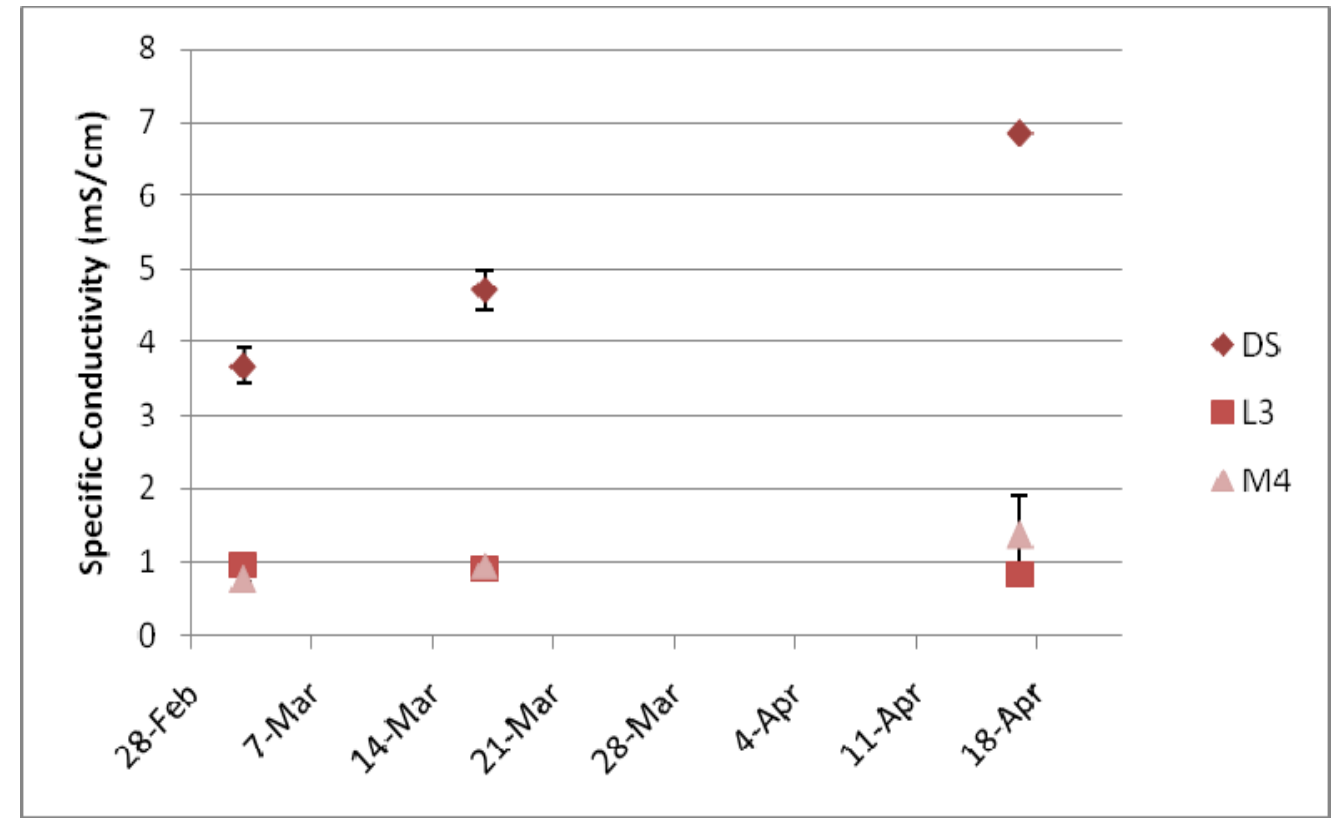

Figure 4-53: Specific conductivity readings from modified drainage wetlands for the 2007 sampling season. 


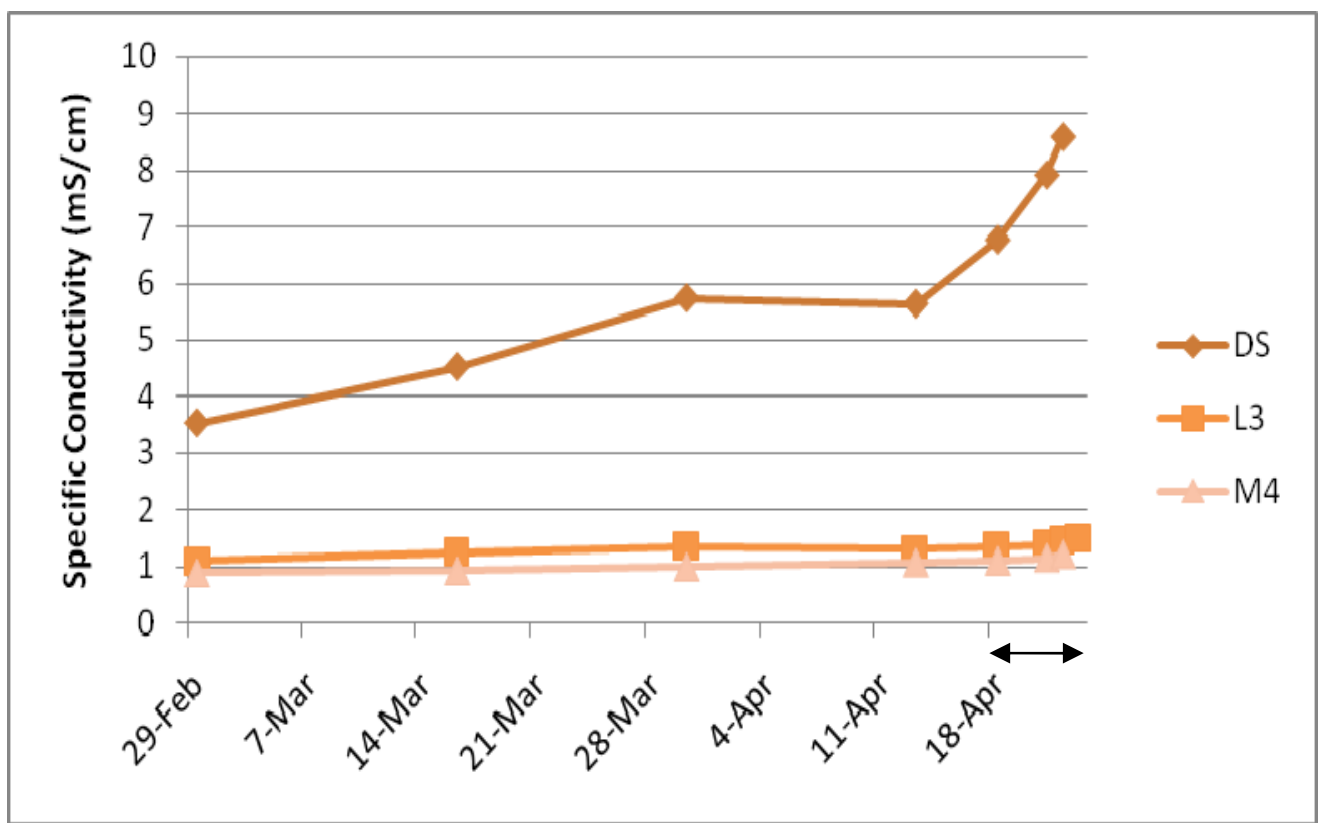

Figure 4-54: Specific conductivity readings from modified drainage wetlands for the 2008 sampling season. The drawdown period is indicated by the line with arrows.

\subsubsection{Drainage Sites}

At the drainage sites, specific conductivity values remained fairly constant (Figure 4-55).

There was a slight increase in specific conductivity, but these values remained below 2 $\mathrm{mS} / \mathrm{cm}$. There was no observed change in specific conductivity during the drawdown of the studied wetlands. 


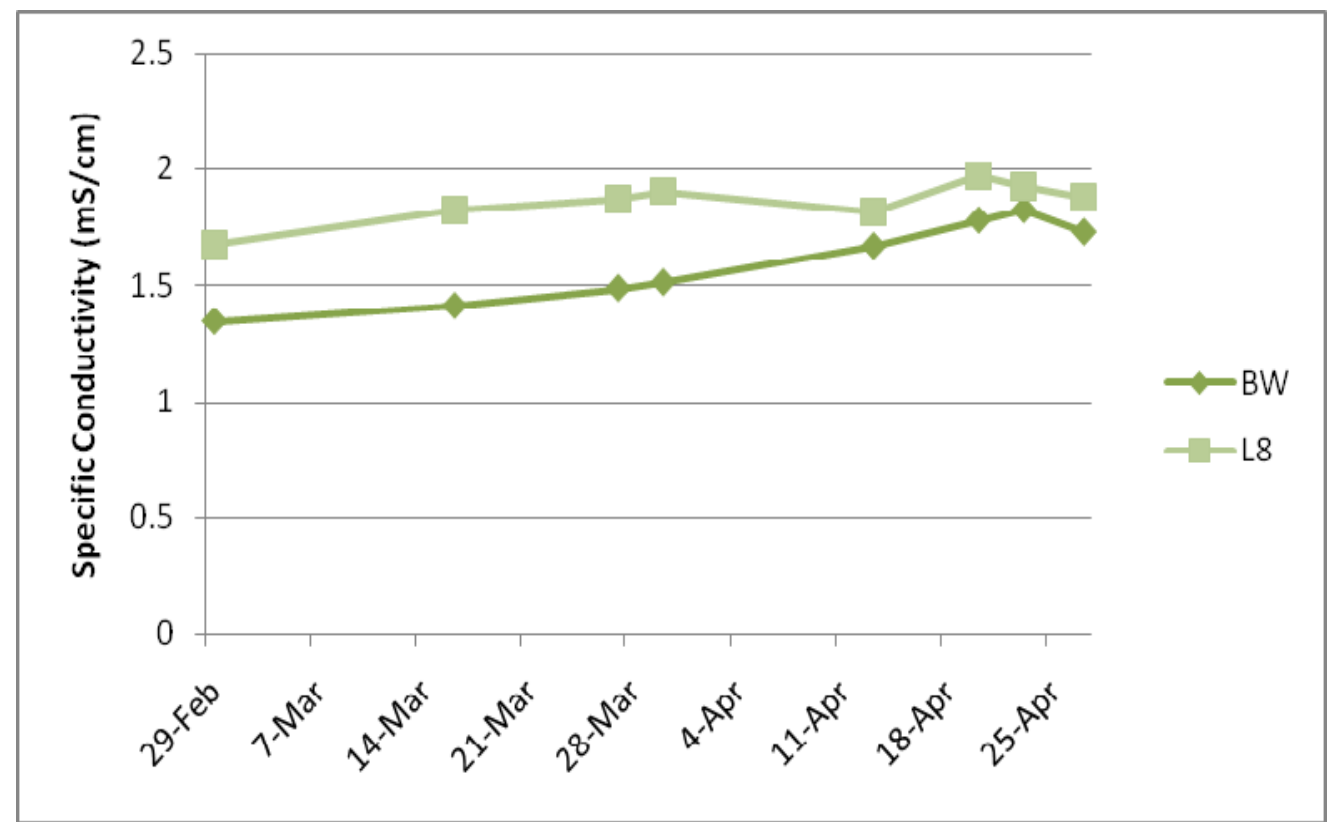

Figure 4-55: Specific conductivity readings from drainage sites for the 2008 sampling season.

\subsubsection{Turbidity-Volatile Suspended Solids Correlation}

A strong correlation was found between volatile suspended solids and turbidity throughout the study. This correlation could be used as a real-time management tool to monitor how much degradable organic matter is being discharged from the wetlands. The slopes for the correlations between wetland sites vary from 0.110 to 0.204 (Figure 4-56, Figure 4-57, Figure 4-58, and Figure 4-59). This variation may be due to different conditions between wetlands. An overall correlation is given in Figure 4-60. 


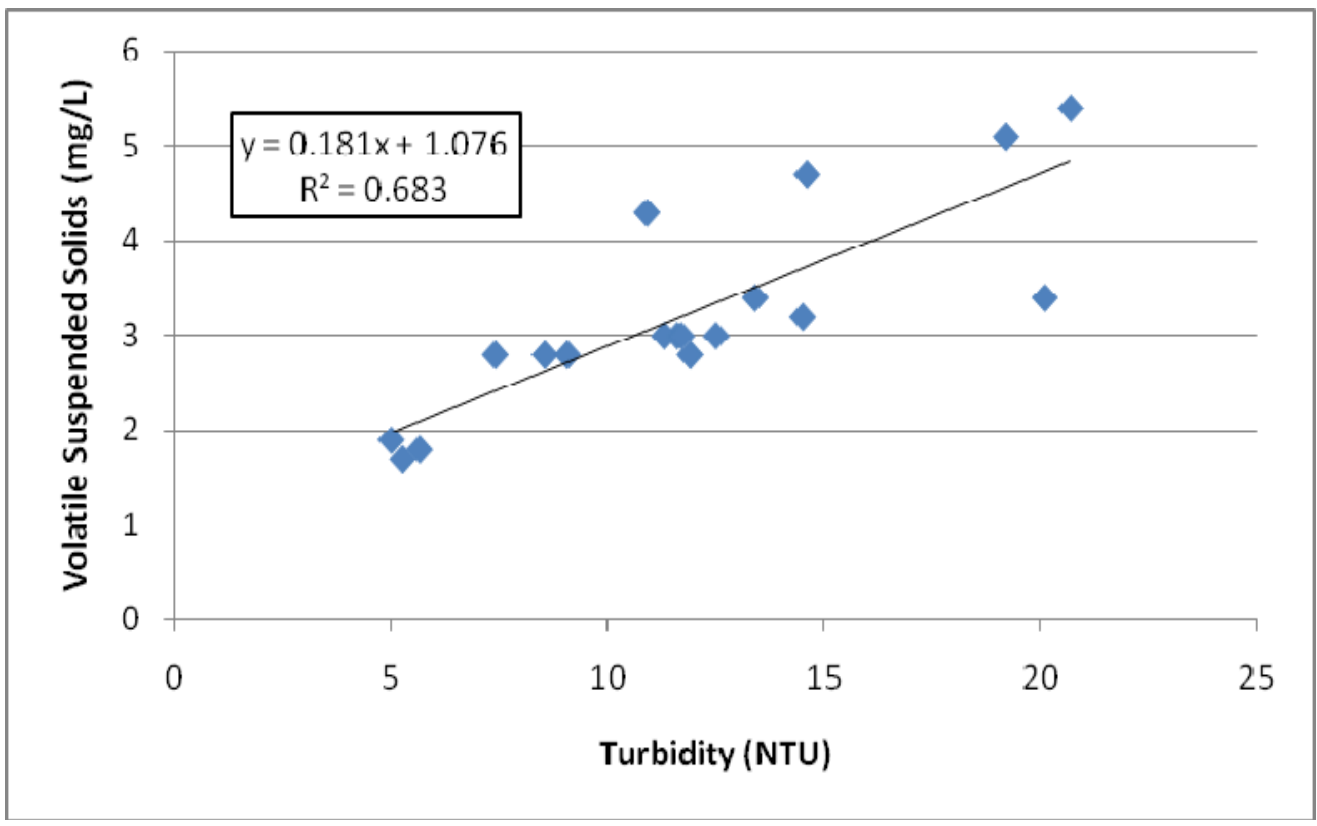

Figure 4-56: Correlation between volatile suspended solids and turbidity using drainage data from the 2008 sampling seasons.

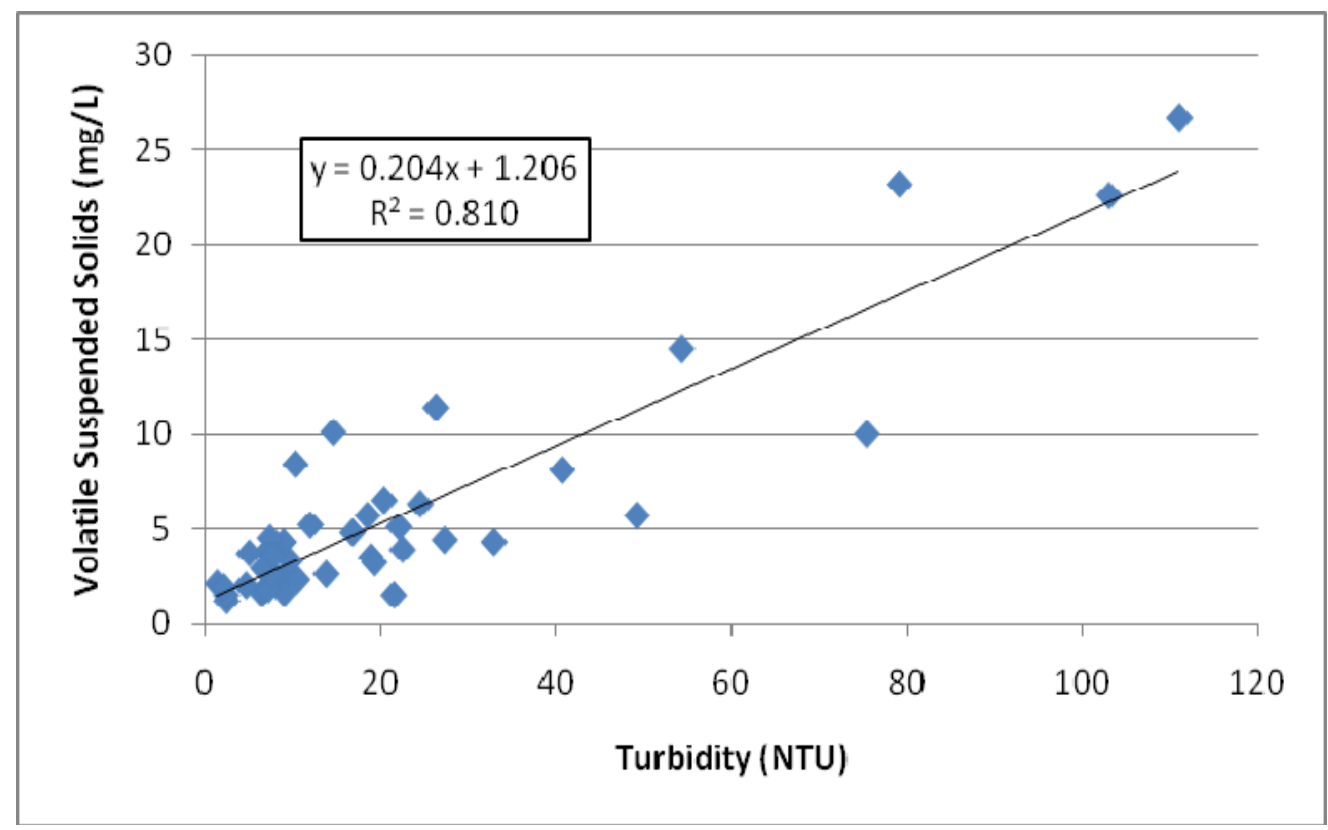

Figure 4-57: Correlation between volatile suspended solids and turbidity using Los Banos data from both sampling seasons. 


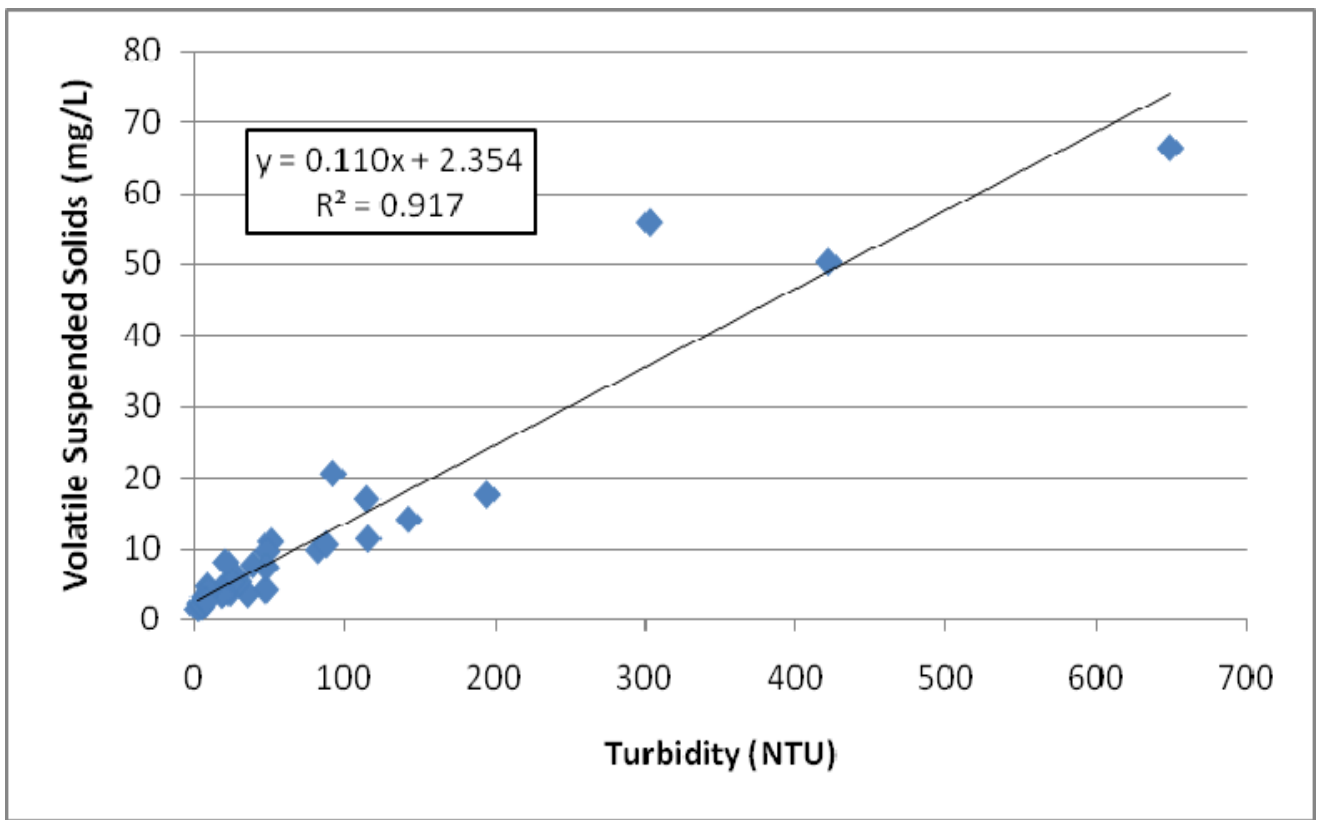

Figure 4-58: Correlation between volatile suspended solids and turbidity using Mud Slough data from both sampling seasons.

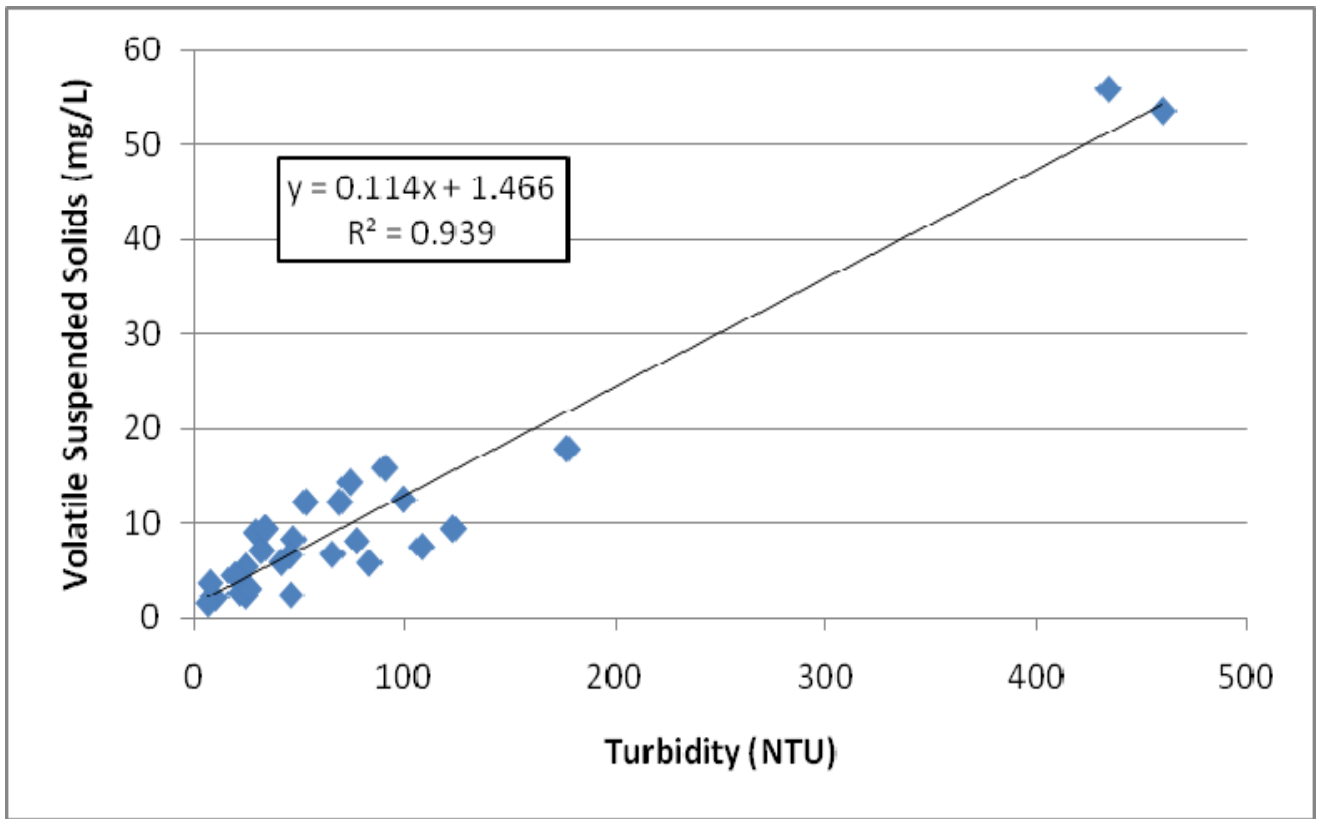

Figure 4-59: Correlation between volatile suspended solids and turbidity using Ducky Strike data from both sampling seasons. 


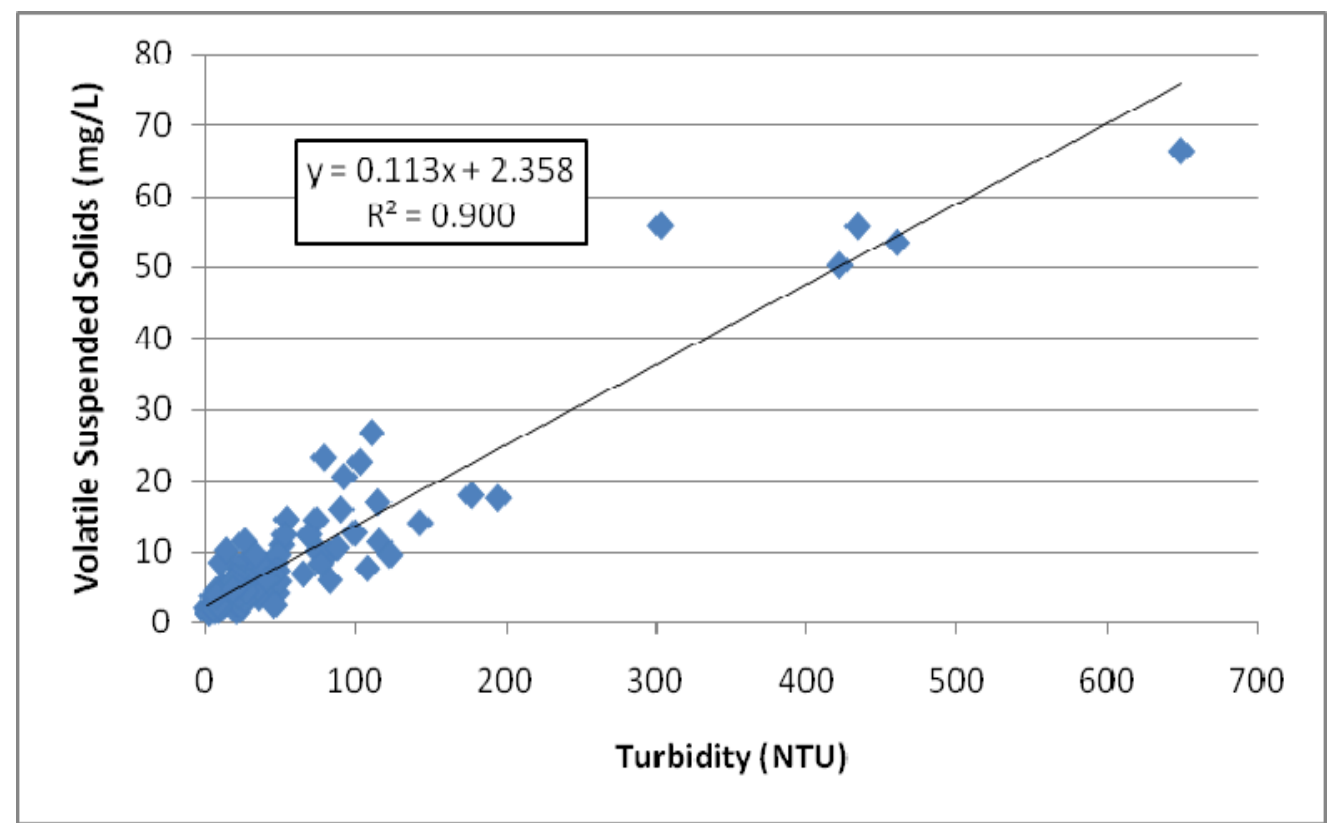

Figure 4-60: Correlation between volatile suspended solids and turbidity using all data from both sampling seasons.

\subsubsection{Water Quality Summary}

As in the previous summary, Table 4-5 and Table 4-6 summarize the water quality data in three columns:

1. Traditional

This column contains average values from all data points taken at the traditional wetland sites (Ducky Strike North, Los Banos 31B, and Mud Slough 4B).

2. Modified: Traditional Period

This column contains average values from all data points taken at the modified wetland sites (Ducky Strike South, Los Banos 33, and Mud Slough 3B) prior to the drawdown of the traditional wetlands.

3. Modified: Extended Period 
This column contains average values from all data points taken at the modified wetland sites (Ducky Strike South, Los Banos 33, and Mud Slough 4B) after the drawdown of the traditional wetlands, but before drainage of the modified wetlands had begun.

Specific conductivity values increased during the extended period in modified wetlands during both sampling seasons, likely due to evapotranspiration. Soluble nutrient concentrations decreased during the delayed drawdown period in 2007 but during 2008 . Organic carbon concentrations increased only slightly during the delayed drawdown.

Table 4-5: Water quality data summary for 2007. Data is expressed as the mean +/the standard deviation of the mean with the number of samples analyzed in parentheses.

\begin{tabular}{lccc}
\cline { 2 - 4 } & Traditional & $\begin{array}{c}\text { Modified: } \\
\text { Traditional Period }\end{array}$ & $\begin{array}{c}\text { Modified: } \\
\text { Extended Period }\end{array}$ \\
\hline $\mathrm{NO}_{3}{ }^{-}+\mathrm{NO}_{2}^{-}(\mathrm{mg} / \mathrm{L}-\mathrm{N})$ & $0.35+/-0.44(42)$ & $0.20+/-0.40(62)$ & $0.027+/-0.038(27)$ \\
$\mathrm{NH}_{3}(\mathrm{mg} / \mathrm{L}-\mathrm{N})$ & $0.23+/-0.43(43)$ & $0.22+/-0.21(60)$ & $0.11+/-0.091(26)$ \\
$\mathrm{PO}_{4}{ }^{3-}(\mathrm{mg} / \mathrm{L}-\mathrm{P})$ & $0.18+/-0.51(42)$ & $0.16+/-0.13(62)$ & $0.031+/-0.054(27)$ \\
$\begin{array}{l}\text { Specific Conductivity } \\
(\mathrm{mS} / \mathrm{cm})\end{array}$ & $1.4+/-1.0(42)$ & $1.9+/-1.5(63)$ & $2.5+/-2.7(27)$ \\
\hline
\end{tabular}

Table 4-6: Water quality data summary for 2008. Data is expressed as the mean $+/-$ the standard deviation of the mean with the number of samples analyzed in parentheses.

\begin{tabular}{|c|c|c|c|}
\hline & Traditional & $\begin{array}{c}\text { Modified: } \\
\text { Traditional } \\
\text { Period } \\
\end{array}$ & $\begin{array}{c}\text { Modified: } \\
\text { Extended Period }\end{array}$ \\
\hline $\mathrm{NO}_{3}{ }^{-}+\mathrm{NO}_{2}^{-}(\mathrm{mg} / \mathrm{L}-\mathrm{N})$ & $0.19+/-0.26(6)$ & $0.08+/-0.14(6)$ & $0.05+/-0.07(9)$ \\
\hline $\mathrm{NH}_{3}(\mathrm{mg} / \mathrm{L}-\mathrm{N})$ & $0.13+/-0.14(6)$ & $0.20+/-0.14(6)$ & $0.09+/-0.08(9)$ \\
\hline $\mathrm{PO}_{4}{ }^{3-}(\mathrm{mg} / \mathrm{L}-\mathrm{P})$ & $0.03+/-0.03(6)$ & $0.08+/-0.06(6)$ & $0.07+/-0.02(9)$ \\
\hline TOC (mg/L-C) & $11+/-1.6(6)$ & 11 +/- $1.1(6)$ & $15+/-2.3(9)$ \\
\hline $\mathrm{DOC}(\mathrm{mg} / \mathrm{L}-\mathrm{C})$ & $14+/-1.6(6)$ & $17+/-2.6(6)$ & $18+/-2.8(9)$ \\
\hline $\begin{array}{l}\text { Specific Conductivity } \\
(\mathrm{mS} / \mathrm{cm})\end{array}$ & $1.8+/-0.59(6)$ & $2.0+/-0.64(6)$ & $2.8+/-0.81(9)$ \\
\hline
\end{tabular}




\subsection{Seasonal Loading}

Loading throughout the sampling season was calculated for volatile suspended solids, organic carbon, and salinity. Both drainage sites and one wetland, Mud Slough 4b during the 2008 season, had a complete flow data set through the drawdown period. Since the majority of the loading occurs during drawdown, loading from other studied wetlands was not calculated. Loading was calculated for both drainage sites using flow data measured as described in Section 3.1.4. Table 4-7 summarizes the seasonal loading of volatile suspended solids (VSS), total dissolved solids (TDS), total organic carbon (TOC), and dissolved organic carbon (DOC) for the 2008 sampling season.

Table 4-7: Seasonal loading during the 2008 sampling season.

\begin{tabular}{ccccc}
\hline Site & $\begin{array}{c}\text { VSS Seasonal } \\
\text { Load (Ibs) }\end{array}$ & $\begin{array}{c}\text { TDS Seasonal } \\
\text { Load (tons) }\end{array}$ & $\begin{array}{c}\text { TOC Seasonal } \\
\text { Load (Ib) }\end{array}$ & $\begin{array}{c}\text { DOC Seasonal } \\
\text { Load (lb) }\end{array}$ \\
\hline Mud Slough 4b & 770 & 26 & 1200 & 760 \\
Button Willow & 1500 & 290 & 7300 & 6500 \\
Los Banos 38 & 2500 & 520 & 10,000 & 9200 \\
\hline
\end{tabular}

\subsubsection{Volatile Suspended Solids}

Volatile suspended solids loading for the Mud Slough 4b wetland, Los Banos 38, and Buttonwillow drainage sites are shown below. Figure 4-61 and Figure 4-63 show the changing load throughout the season. When Figure 4-61 is compared to the flow values in Figure 4-62, it can be seen that the Buttonwillow loading follows the same trend as the flow. However, the Los Banos 38 loading has two noticeable spikes that do not follow the flow trend. These spikes correspond with the drainage of the studied wetlands, the first spike coming after drainage of traditional wetlands (March 17, 2008) the other coming after the drainage of the modified wetlands (April 18, 2008). Loading for Mud 
Slough $4 \mathrm{~b}$ is shown in Figure 4-63. It can be seen that $79 \%$ of the total load occurs during drainage. Increases in loading are due to both increased flow and scouring of periphyton.

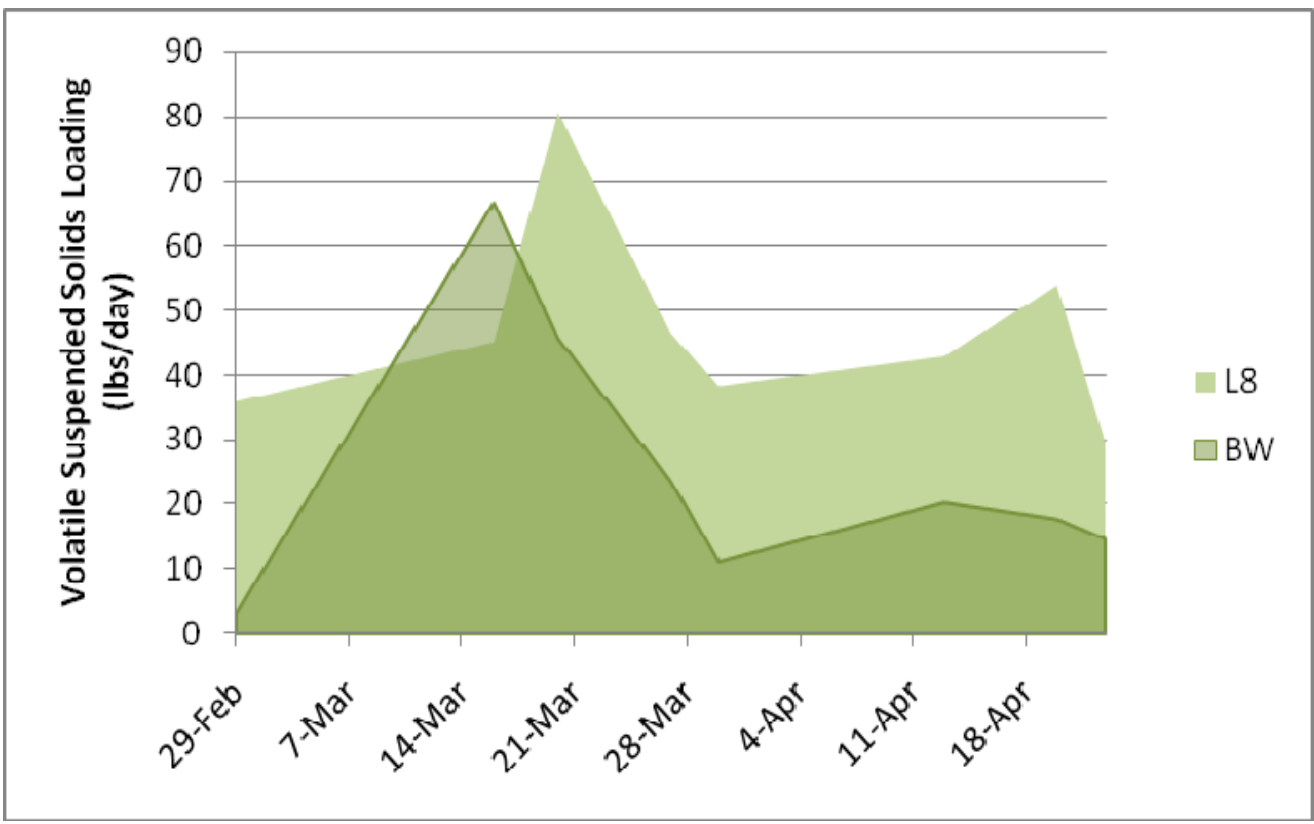

Figure 4-61: Volatile suspended solids loading from drainage sites during the 2008 season. The area under the curve represents the seasonal load.

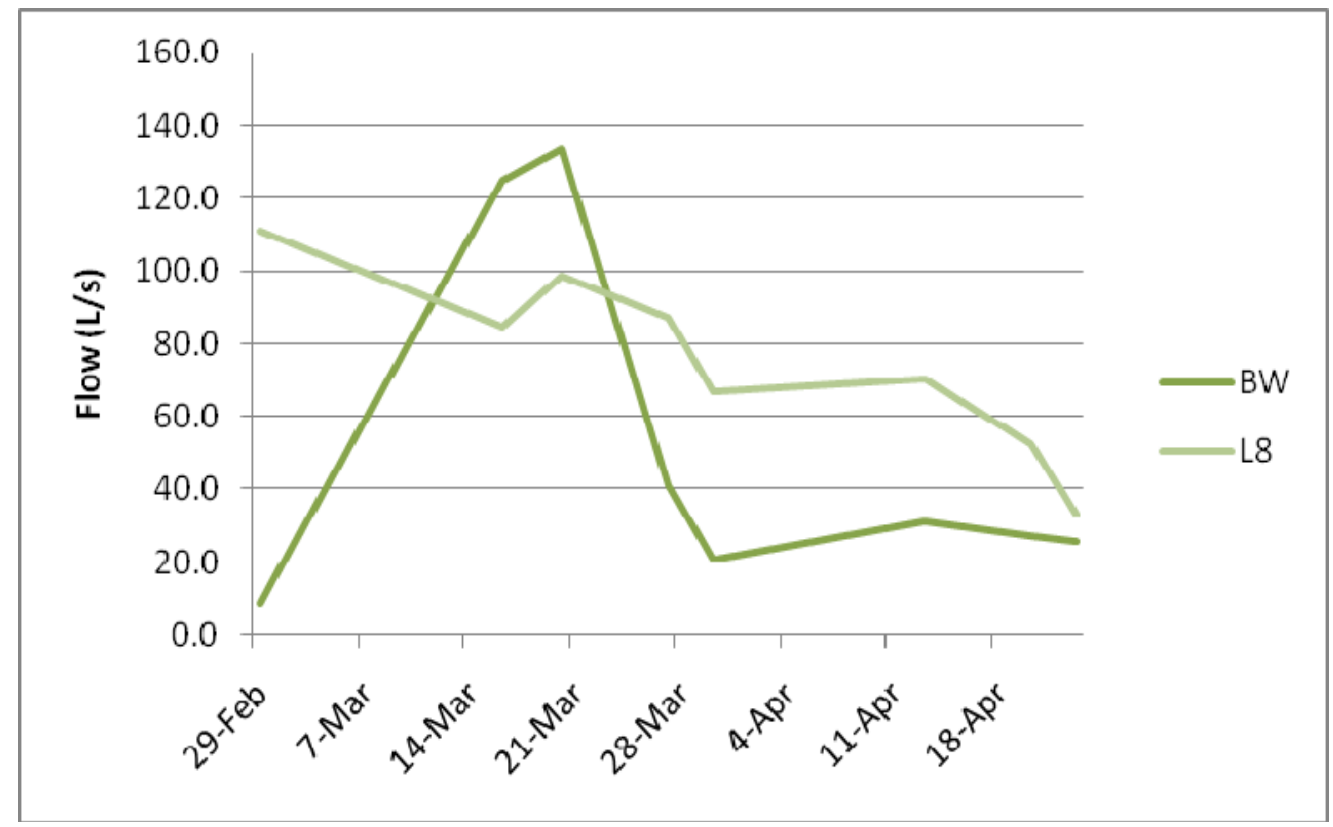

Figure 4-62: Flow from drainage sites during the 2008 season. 


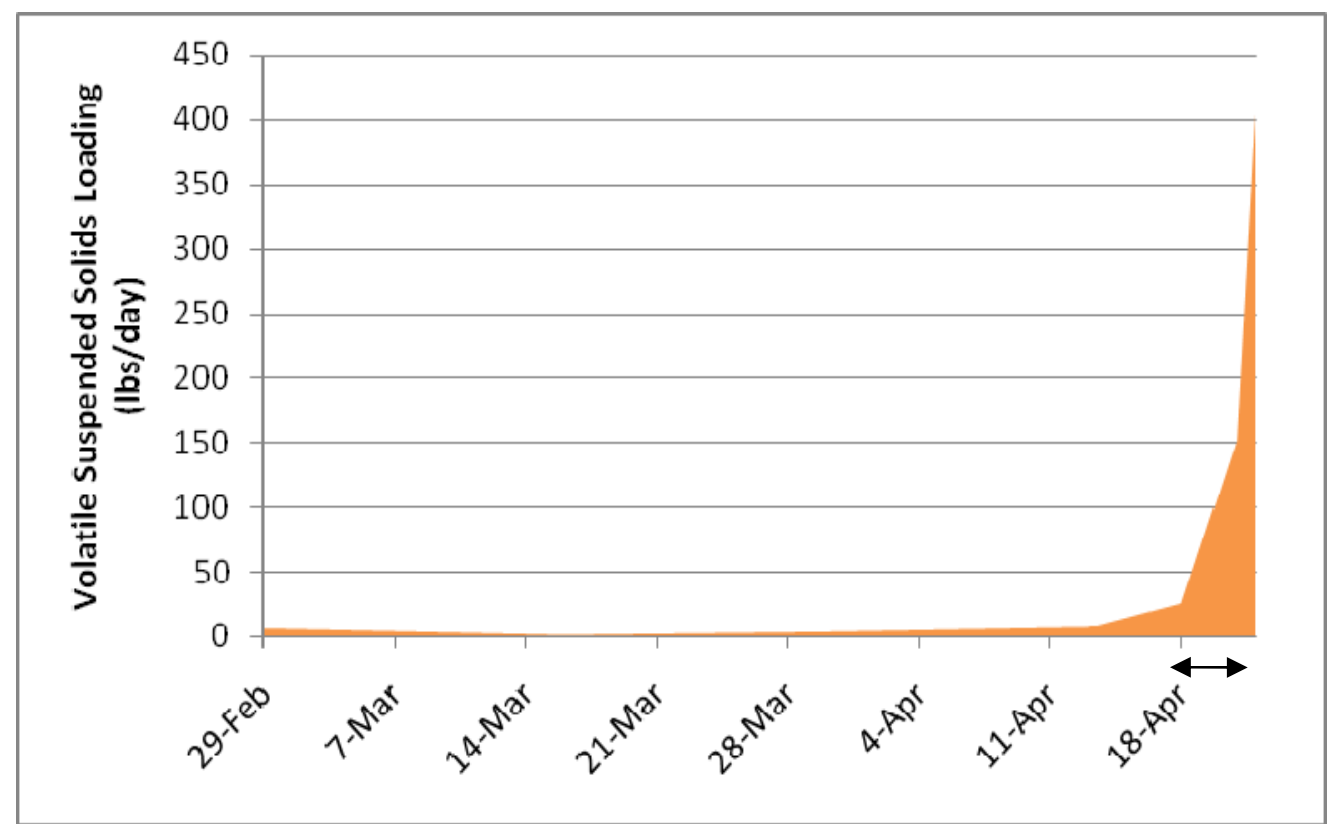

Figure 4-63: Volatile suspended solids loading from Mud Slough 4b during the 2008 season. The area under the curve represents the seasonal load. The drawdown period is indicated by the line with arrows.

\subsubsection{Organic Carbon}

Dissolved and total organic carbon loading for the drainage sites are shown in Figure 4-64 and Figure 4-65 respectively. Loading followed the same trend as flow data shown in Figure 4-62. No noticeable spikes were observed during the days following drainage of the studied wetlands. Dissolved and total organic loading for Mud Slough $4 \mathrm{~b}$ are shown in Figure 4-66 and Figure 4-67. The majority of the seasonal load occurred during drainage. The loading during drainage was calculated to be $45 \%$ and $54 \%$ of the seasonal load for dissolved organic carbon and total organic carbon respectively. This increase in loading is due to both increased flow and the scouring of periphyton and nutrient rich sediments. 


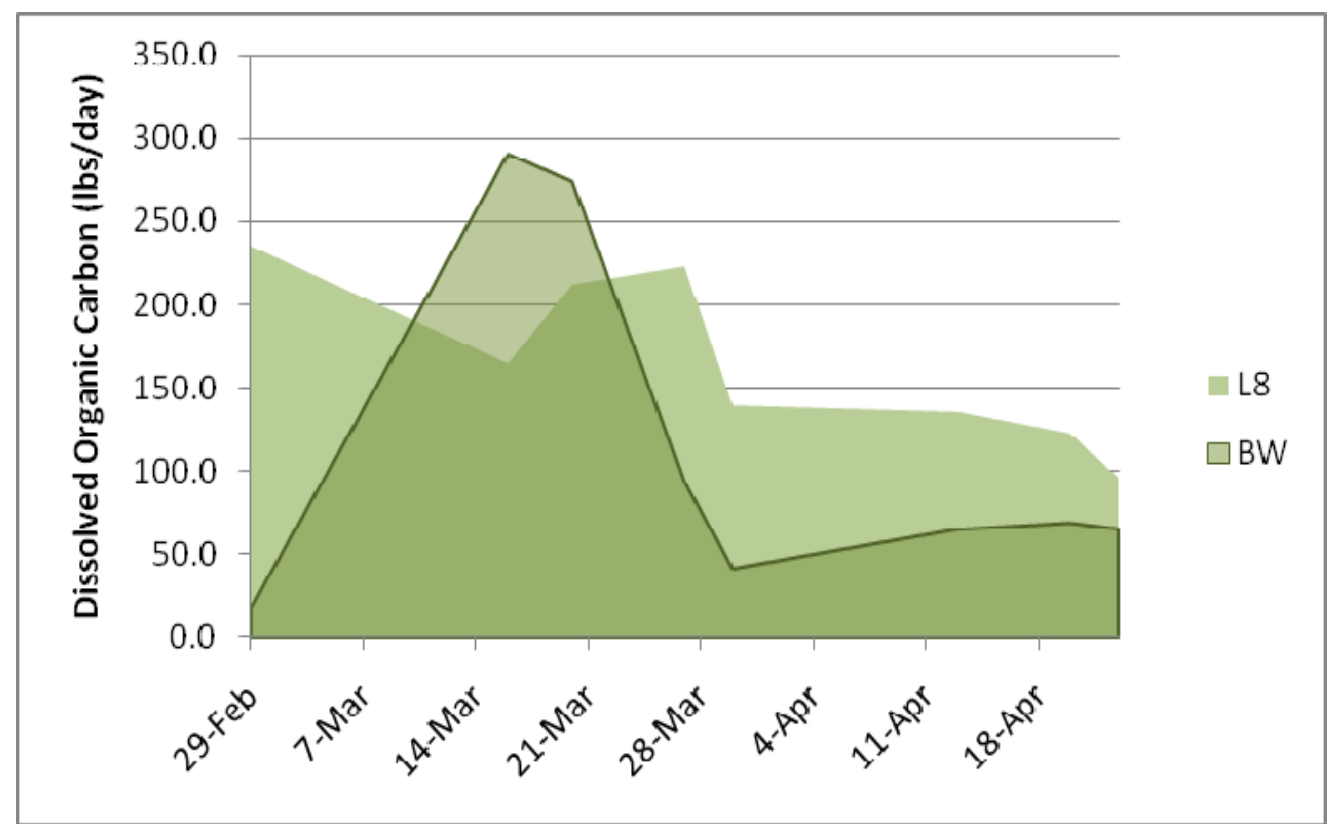

Figure 4-64: Dissolved organic carbon loading from drainage sites during the 2008 season. The area under the curve represents the seasonal load.

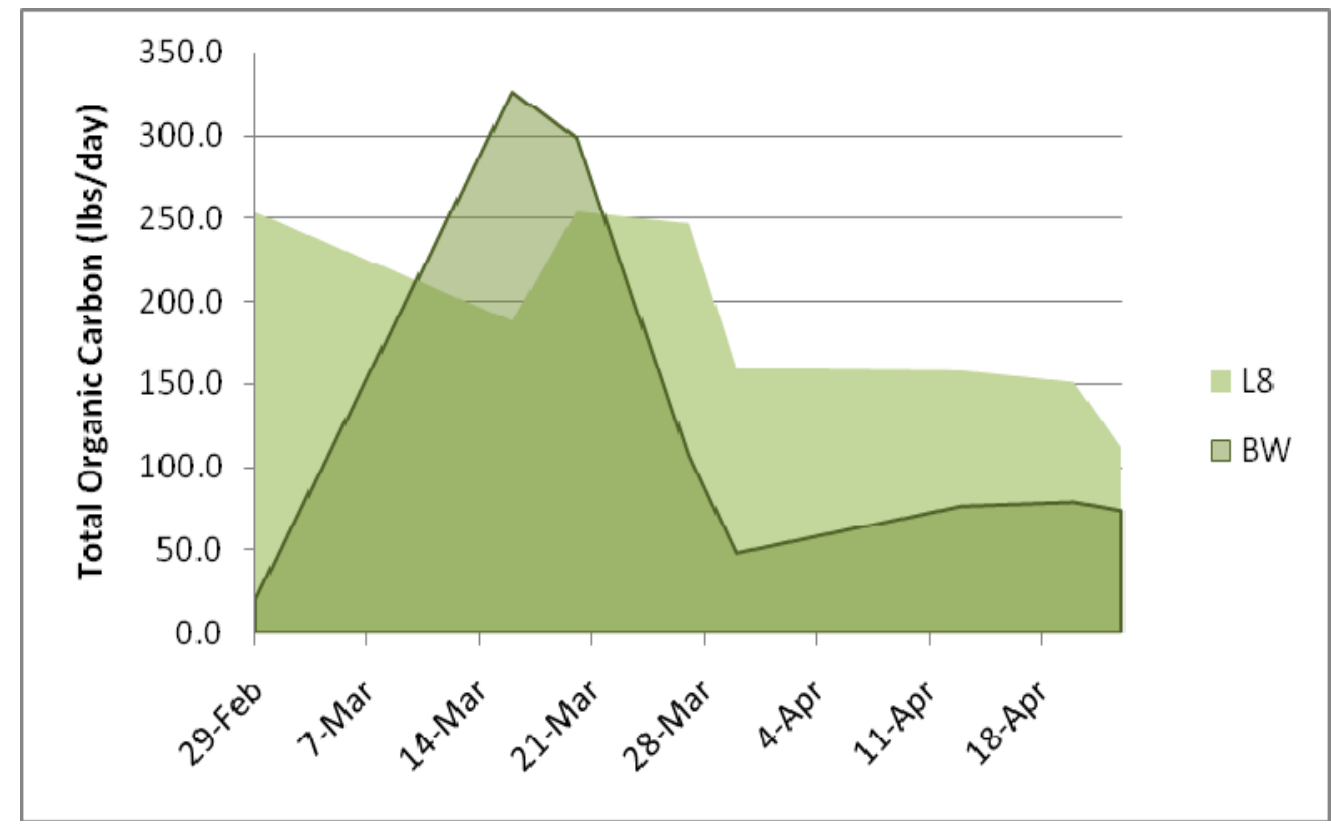

Figure 4-65: Total organic carbon loading from drainage sites during the 2008 season. Particulate organic carbon was estimated at $52 \%$ of VSS. The area under the curve represents the seasonal load. 


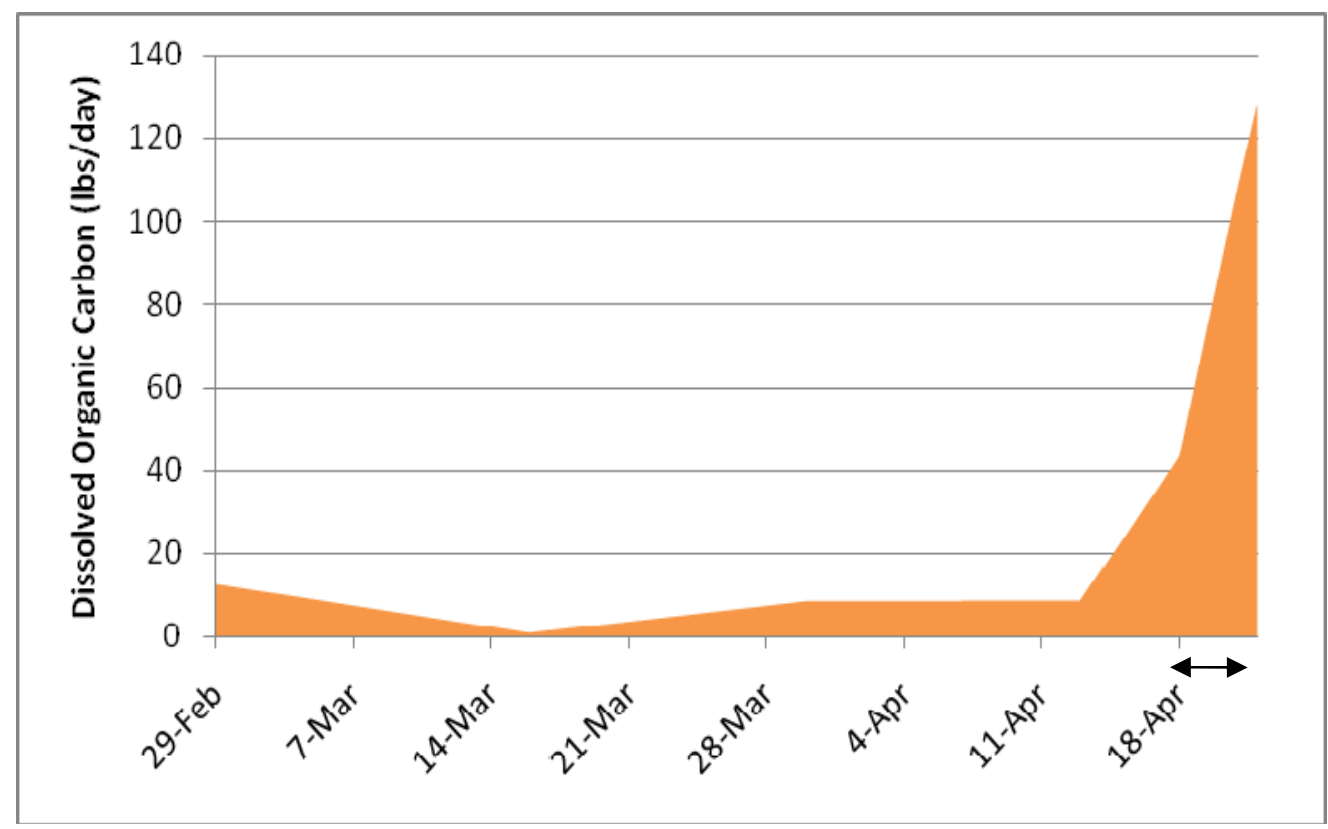

Figure 4-66: Dissolved organic loading from Mud Slough 4b during the 2008 season. The area under the curve represents the seasonal load. The drawdown period is indicated by the line with arrows.

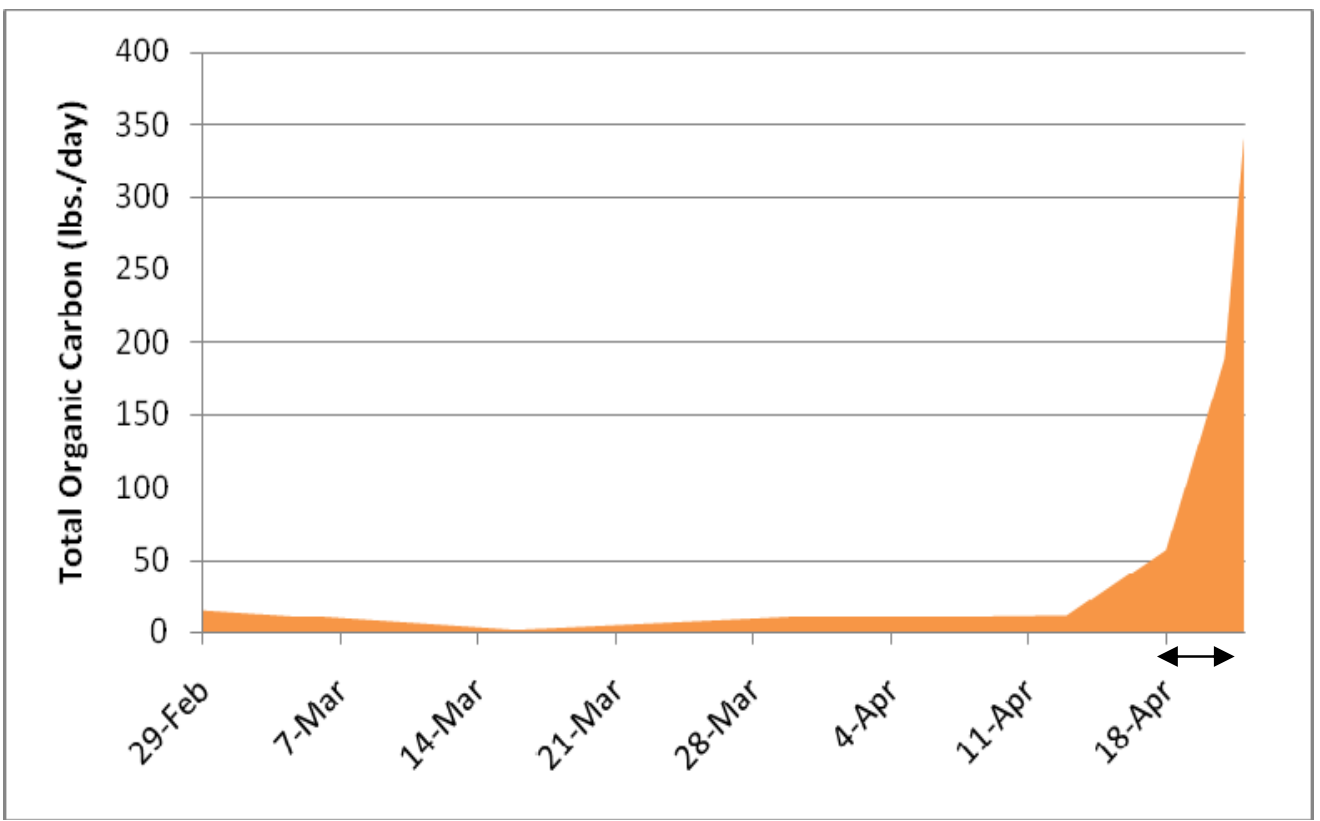

Figure 4-67: Total organic carbon loading from Mud Slough 4b during the 2008 season. The area under the curve represents the seasonal load. Particulate organic carbon was estimated at $52 \%$ of VSS. The drawdown period is indicated by the line with arrows. 


\subsubsection{Salinity}

Salinity loading results are given below. Specific conductivity was converted to total dissolved solids (TDS) using a conversion factor. The California Regional Water Quality Control Board found that specific conductivity to total dissolved solids ratios ranged from 0.61 to 0.69 in the Grasslands Ecological Area (Grober 1998). The ratio for Salt Slough was found to be 0.68 . This ratio was used to convert specific conductivity to total dissolved solids. Total seasonal loads of dissolved solids are shown in Table 4-7. Loading at the drainage sites (Figure 4-68) followed the same trend as flow data in Figure 4-62.

There were no observed spikes from drainage of the studied wetlands. Loading from Mud Slough $4 \mathrm{~b}$ is shown in Figure 4-69. Again most of the load came during drainage (39\%).

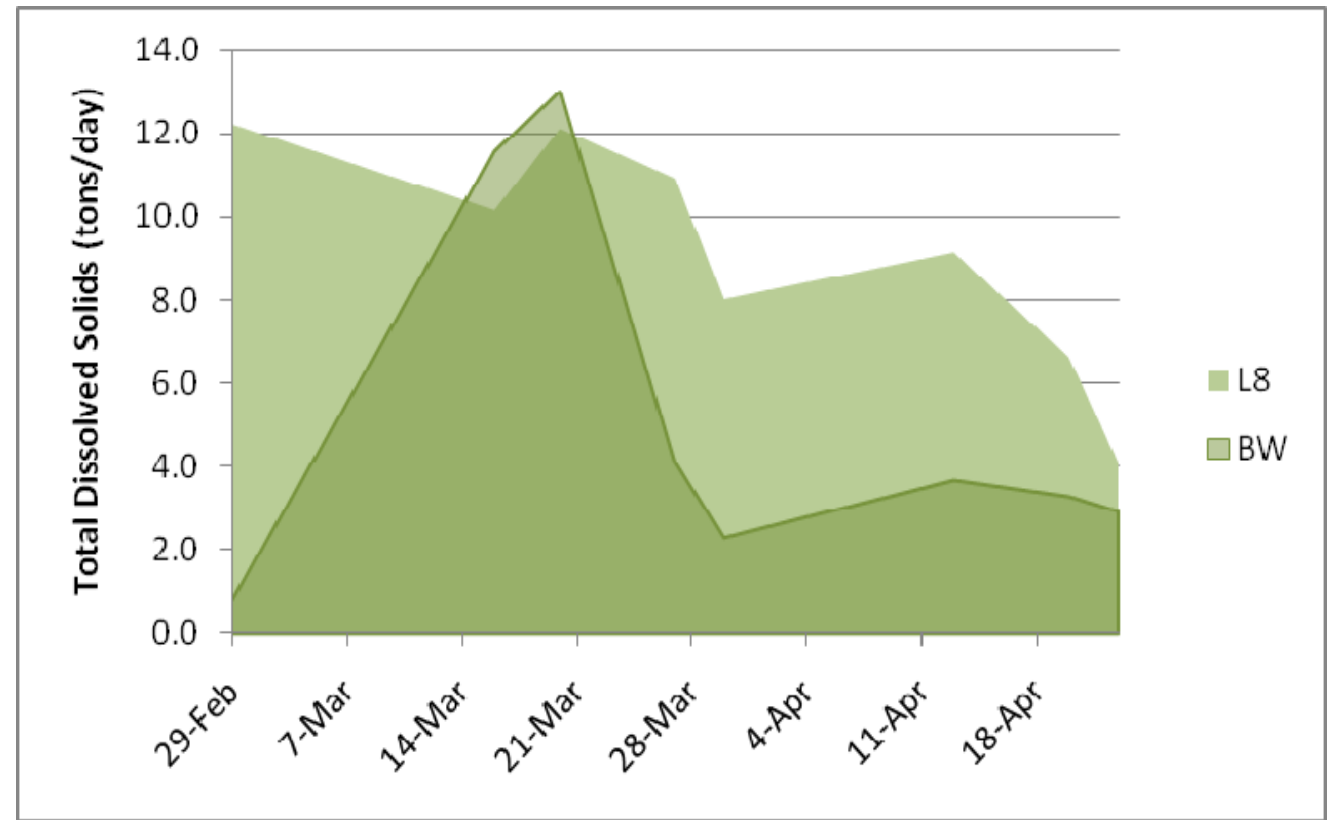

Figure 4-68: Total dissolved solids loading from drainage sites during the 2008 season. The area under the curve represents the seasonal load. 


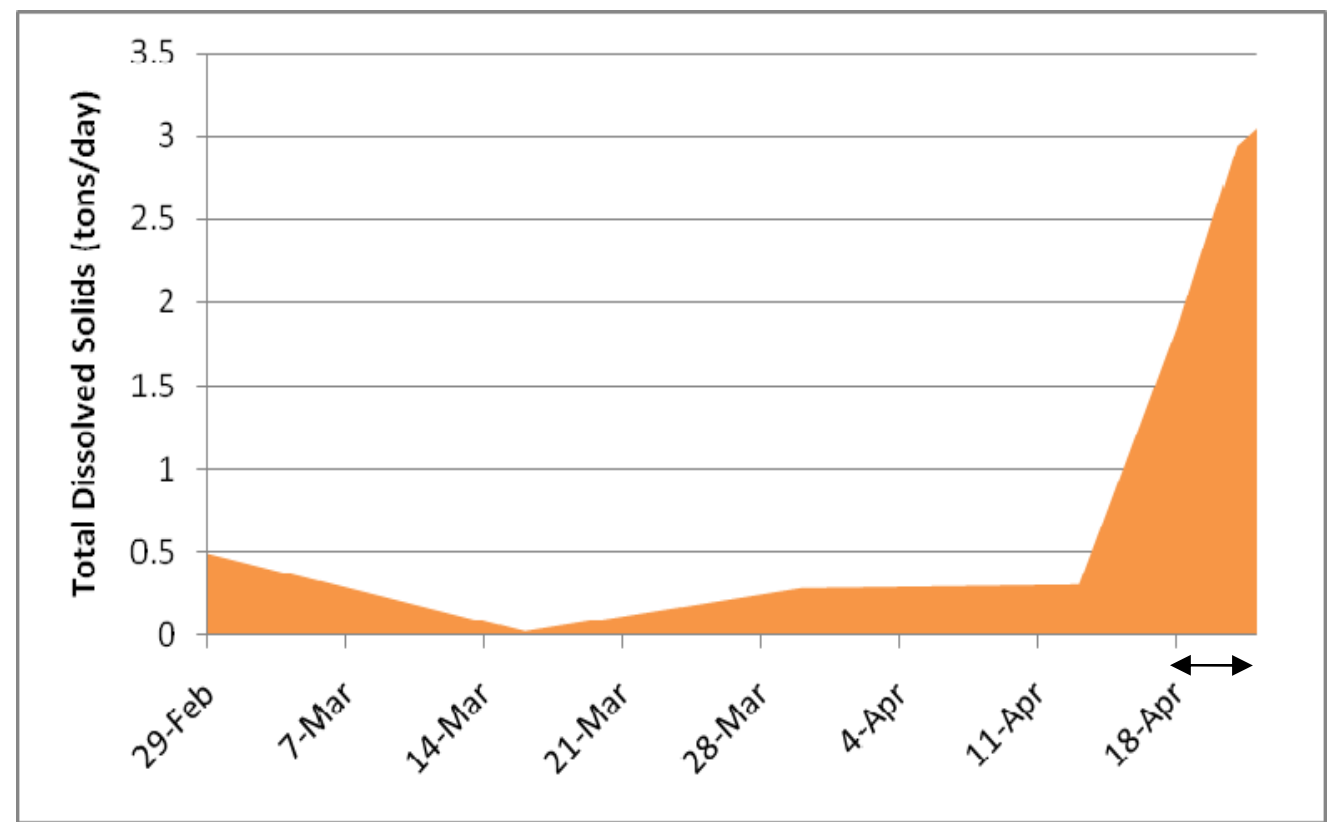

Figure 4-69: Total dissolved solids loading from Mud Slough 4 b during the 2008 season. The area under the curve represents the seasonal load. The drawdown period is indicated by the line with arrows. 


\section{CHAPTER 5: CONCLUSIONS}

This study was an initial screening of a broad range of information on the effects of delayed drawdown on water quality and aquatic biota. Since many of the variable values fluctuated considerably and the study was limited in the frequency and duration of sampling, more data will need to be gathered to test the initial hypotheses. If possible, future sample collection programs should be done when intensive avian survey programs are not also being conducted (as occurred during this study). The need to prevent bird disturbance before and during avian survey data collection limited wetland access for water sampling. This study gathered a significant amount of data regarding wetland water quality, densities of benthic and nektonic microinvertebrates, concentrations of phytoplankton, and the present species of phytoplankton and aquatic invertebrates. The data collected in this study will be especially useful when analyzed in conjunction with data from the concurrent hydrological studies of the same wetlands.

Due to the lack of adequate replication, statistical hypothesis testing was not conducted. However, observational conclusions can be made about some of the initial hypotheses.

\section{The increase in salt concentrations will be greater in the delayed wetland discharges than in the traditionally drained wetland discharges, on an annual average basis.}

Total dissolved solids concentrations remained constant in the Mud Slough and Los Banos wetlands. However, a trend of increasing salinity was observed in the 
Ducky Strike wetlands. It is reasonable to suspect that total dissolved solids concentrations will concentrate in the Ducky Strike wetlands throughout the delayed drawdown period.

2. Concentrations of oxygen-demanding substances (e.g., plankton) will be the same in the delayed wetland discharges as in the traditionally drained wetland discharges.

Using volatile suspended solids (VSS) as a proxy for organic carbon, VSS concentrations remained fairly constant in most wetlands during the flooded period. Significant increases were observed only during drawdown periods for both traditional and delayed drawdown wetlands. At the drainage sites, a slight positive trend was evident over the course of the 2008 season. No difference in the concentration of oxygen-demanding substances could be discerned between the discharges of the traditional and modified drainage wetlands.

\section{Nutrient concentrations and discharged mass will be less in the traditionally} drained wetland discharges than in the delayed wetland discharges.

Soluble nitrogen and phosphorus forms $\left(\mathrm{NO}_{3}^{-}+\mathrm{NO}_{2}^{-}, \mathrm{NH}_{3}, \mathrm{PO}_{4}{ }^{3-}\right)$ were consistently below $1 \mathrm{mg} / \mathrm{L}-\mathrm{N} / \mathrm{P}$. Most of the soluble nutrient data was highly variable. However, total nitrogen and total phosphorus concentrations remained fairly constant throughout the two seasons except for substantial increases during drawdown. Logically, these total nutrient trends followed a similar trend to 
phytoplankton concentrations. No difference in the nutrient concentration could be discerned between the discharges of the traditional and modified drainage wetlands.

\section{Zooplankton densities will increase in the treatment wetlands during the} extended flooded period.

Zooplankton data were highly variable, which is consistent with the boom-bust nature of these organisms. The only noticeable trend was a minor increase in density during the delayed drawdown period in 2007 and a significant increase in density during drawdown of modified wetlands during the 2008 season.

Zooplankton were identified to the order level and were found to be predominantly

Cladocera. Benthic invertebrates were identified to the family level and were

predominantly Chironomidae. Due to low concentrations, enumeration of algal populations was not performed. However, the observed species were predominantly diatoms, with some chlorophytes present.

Loading from the drainage sites was estimated for volatile suspended solids, total organic carbon, dissolved organic carbon, and total dissolved solids. The seasonal load of volatile suspended solids draining through the Buttonwillow site was estimated to be 1,500 lbs while it was estimated to be 2,500 lbs from the Los Banos 38 site. The seasonal load of total organic carbon draining through the Buttonwillow site was estimated to be $7300 \mathrm{lbs}$, 
while it was estimated to be $10,000 \mathrm{lbs}$ through the Los Banos 38 site. A large percentage of the total organic carbon load came from dissolved organic carbon with seasonal loads of $6500 \mathrm{lbs}$ and $9200 \mathrm{lbs}$ from Buttonwillow and Los Banos 38, respectively. The seasonal load of total dissolved solids draining through the Buttonwillow site was estimated to be 290 tons, while it was estimated to be 520 tons from the Los Banos 38 site.

Mud Slough 4B was the only wetland with a complete flow data set during the 2008 sampling season. Its seasonal load was estimated to be $770 \mathrm{lbs}$ volatile suspended solids, $1200 \mathrm{lbs}$ total organic carbon, $760 \mathrm{lbs}$ dissolved organic carbon, and 26 tons for total dissolved solids. The majority of the load for these constituents came during drawdown (79\% for VSS, $54 \%$ for TOC, $45 \%$ for DOC, and 39\% for TDS). This pulse was likely due to increased flow and the scouring of sediments.

Turbidity strongly correlated with volatile suspended solids concentrations. This correlation was seen in all wetland pairs, as well as the drainage sites. However, the slope varied between sites. With further data collection, a correlation could be made for different wetland types. This correlation could be used to monitor the amount of volatile suspended solids being discharged.

The data collected during this study provides a large inventory of useful information for wetlands in the Grassland Ecological Area. Although statistical analysis of the proposed hypotheses was not achieved, this information provides a starting point for further in 
depth analysis of effects of delayed drawdown on water quality and aquatic biota in seasonal wetlands. 


\section{REFERENCES}

APHA. 2005. Standard Methods for the Examination of Water and Wastewater, $21^{\text {st }}$ ed., American Public Health Association, American Water Works Association, and Water Environment Federation.

Batzer, D. P., F. De Szalay and V. H. Resh. "Opportunistic response of a benthic midge (Diptera: Chironomidae) to management of California seasonal wetlands." Environmental Entomology 42.2 (1997): 215-222.

California State Water Resources Control Board. 2006 303d List of Water Quality Limited Segments. October 9, 2007.

Cogswell, H. L. Water Birds of California. California Natural History Guides: 40. University of California Press, 1977.

Cooke, William (2008). Personal communication, California Department of Fish and Game, Los Banos Wildlife Area Field Office, February 8, Los Banos, California.

Craggs, R. C., et al. "Evaluation of the Algal Turf Scrubber/UV System for Tertiary Wastewater Treatment at Patterson, California." First Interim Reportm Environmental Engineering and Health Sciences Laboratory Report No. 94-1. 1994. 
Fredrickson, L. H. and T. S. Taylor. "Management of seasonally flooded impoundments for wildlife." Resource Publication 148. Washington D.C.: U.S. Dept. of the Interior, Fish and Wildlife Service, 1982.

Grassland Water District. 2008. 15 July $2008<$ http://www.grasslandwetlands.org/>.

Grassland Water District. "Ecological and Water Management Characterization of Grassland Water District." California State Water Resources Control Board and Central Valley Water Quality Control Board. Prepared by the Grassland Water District and the Grassland Water Task Force with assistance from Jones \& Stokes Associates, Inc., Stoddard \& Associates. 1986.

Green, F. B., et al. "Advanced Intergrated Wastewater Pond Systems for nitrogen removal." Water Science and Technology 33.7 (1996): 207-217.

Grober, L. F., J. Karkoski and T. Poole. "Water Quality Impact of Wetlands on San Joaquin River, CA." Advances. Houston, Texas: Department of Civil and Environmental Engineering, University of Houston, 1995. Advances in the Development and Use of Models in Water Resources: Proceedings of the American Water Resources Association.

Grober, L. F., Karkoski, J., Dinkler, L. "Loads of Salt, Boron, and Selenium in the San Joaquin River, October 1985 to September 1995; Raw Data Supplemental 
Appendix.” Regional Water Quality Control Board, Central Valey Region. Sacramento, CA. January 1998.

Hickman, M. and C. G. Jenkerson. "Phytoplankton primary productivity and population efficiency studies in a prairie parkland near Edmonton, Alberta, Canada." Internat. Rev. Gesamten Hydrobiol. 63.124 (1978).

Holmes, R. M., et al. "A Simple and Precise Method for Measuring Ammonium in Marine and Freshwater Ecosystems." Canadian Journal of Fisheries and Aquatic Sciences 56 (1999): 1801-1808.

Hooper, N. M. and G. G. C. Robinson. "Primary production of epiphytic agae in a marsh pond." Canadian Journal of Botany 54 (1976): 2810-2815.

Hooper-Reid, N. M. and G. G. C. Robinson. "Seasonal dynamics of epiphytic algal growth in a marsh pond: Productivity, standing crop, and community composition." Canadian Journal of Botany 56 (1978a): 2432-2440.

Horne, A. J. and T. C. Goldman. Limnology. New York: McGraw Hill, 1994.

Mason, H. L. A Flora of the Marshes of California. University of California Press, 1969. 
Mushet, D. M., N. H. Jr. Euliss and S. W. Harris. "Effects of irrigation on seed production and vegetative characteristics of four moist-soil plants on impounded wetlands in California." Wetlands 12.3 (1992).

Oswald, W. J. Syllabus on Advanced Integrated Wastewater Pond Systems and Wetlands. Berkeley: University of California, 1996.

Pennak, R. 1989. Freshwater invertebrates of the United States. Wiley, $3^{\text {rd }}$ edition.

Quinn, N. W. T. and J. Karkoski. "Potential for real time management of water quality in the San Joaguin Basin, California." Journal of the American Water Resources Association 36.6 (1998).

Quinn, N. W. T., et al. "Computer Model Improves Real-time Management of Water Quality." California Agriculture 51.5 (1997).

SJVDA (2003). CALFED Directed Action Proposal for Monitoring and Investigations of the San Joaquin River and Tributaries Related to Dissolved Oxygen, proposal to the CALFED Bay Delta Authority by the San Joaquin Valley Drainage Authority, March 13, 2003, pp. 145. 
Smith, W. D., G. L. Rollins and R. L. Shinn. A Guide to Wetland Habitat Management in the Central Valley. Sacramento, CA: California Dept. of Fish and Game, California Water Fowl Ass., 1995.

Vymazal, Jan. Algae and Element Cycling in Wetlands. Boca Raton, Florida: CRC Press, Inc., 1995. 
APPENDIX A: RAW DATA

\section{Raw Data}

\begin{tabular}{|c|c|c|c|c|c|c|c|}
\hline Label & Date & Depth $(\mathrm{cm})$ & $\begin{array}{c}\text { Water Temp } \\
\left({ }^{\circ} \mathrm{C}\right)\end{array}$ & $\begin{array}{c}\text { Turbidity } \\
\text { (NTU) }\end{array}$ & TSS (mg/L) & VSS (mg/L) & $\begin{array}{c}\text { Zooplankton } \\
\text { Density } \\
\text { (\#/L) }\end{array}$ \\
\hline L3I & 3-Mar & . & . & . & . & . & . \\
\hline L3I1 & 3-Mar & 17 & 13.5 & . & 10.9 & 4.6 & 26 \\
\hline L312 & 3-Mar & 14 & 17 & . & 26.5 & 7.1 & 80 \\
\hline L313 & 3-Mar & 18 & 15 & . & 10.4 & 2.5 & 25 \\
\hline L30 & 3-Mar & . & . & . & 17.8 & 4.7 & 87 \\
\hline L301 & 3-Mar & 29 & 14.6 & 18.9 & 15.2 & 3.5 & 16 \\
\hline L3O2 & 3-Mar & 50 & 14.8 & 40.7 & 41.4 & 8.1 & 9.5 \\
\hline L3O3 & 3-Mar & 70 & 14.6 & 19.3 & 14.9 & 3.2 & 36.7 \\
\hline L3B1 & 3-Mar & 26 & 11.5 & 32.9 & 27.9 & 4.3 & 16.7 \\
\hline L3B2 & 3-Mar & 22 & 12.5 & 49.2 & 43.0 & 5.7 & 11.5 \\
\hline L3B3 & 3-Mar & 28 & 12.5 & 75.4 & 85.7 & 10 & 13.5 \\
\hline L1I & 3-Mar & 91 & 15 & . & . & . & 0.5 \\
\hline L1I1 & 3-Mar & 30 & 17 & 4.66 & 5.3 & 2 & 35 \\
\hline L1/2 & 3-Mar & 40 & 16.2 & 8.99 & 9.4 & 1.6 & 82 \\
\hline L1/3 & 3-Mar & 45 & 15.8 & 8.94 & 15.6 & 4.3 & 23 \\
\hline L10 & 3-Mar & 79 & 12.1 & . & 2.5 & 1.4 & 32 \\
\hline L101 & 3-Mar & 45 & 14.6 & 21.5 & 3.2 & 1.5 & 150 \\
\hline L102 & 3-Mar & 35 & 15.5 & 2.43 & 3.0 & 1.5 & 119 \\
\hline L103 & 3-Mar & 30 & 16.5 & 2.13 & 2.8 & 1.9 & 285 \\
\hline L1B1 & 3-Mar & 31 & 13 & 7.07 & 10.3 & 3.8 & 1588 \\
\hline L1B2 & 3-Mar & 45 & 13 & 12 & 21.5 & 5.2 & 90 \\
\hline L1B3 & 3-Mar & 25 & . & . & 7.0 & 2.4 & 289 \\
\hline M3I & 3-Mar & . & . & . & 55.8 & 7.1 & . \\
\hline
\end{tabular}




\begin{tabular}{|c|c|c|c|c|c|c|c|}
\hline Label & Date & Depth (cm) & $\begin{array}{l}\text { Water Temp } \\
\left({ }^{\circ} \mathrm{C}\right)\end{array}$ & $\begin{array}{l}\text { Turbidity } \\
\text { (NTU) }\end{array}$ & TSS (mg/L) & VSS (mg/L) & $\begin{array}{c}\text { Zooplankton } \\
\text { Density } \\
\text { (\#/L) }\end{array}$ \\
\hline M3I1 & 3-Mar & 8 & . & 51.3 & 63.6 & 10.9 & 230 \\
\hline M312 & 3-Mar & 17 & . & 28.6 & 34.1 & 5.9 & 80 \\
\hline M313 & 3-Mar & 17 & $\cdot$ & . & 31.2 & 4.7 & 14 \\
\hline M30 & 3-Mar & 58 & 13.3 & 22.2 & 26.7 & 4.9 & 7.5 \\
\hline M301 & 3-Mar & 10 & 17.2 & 48.7 & 60.1 & 9.5 & 18 \\
\hline M3O2 & 3-Mar & 35 & 15.3 & 25.4 & 23.3 & 5.1 & 0 \\
\hline M303 & 3-Mar & 55 & 15.5 & 48.1 & 38.2 & 7.3 & 7 \\
\hline M3B1 & 3-Mar & 20 & 16.7 & 20.1 & 16.0 & 3.6 & 8 \\
\hline M3B2 & 3-Mar & 35 & 15.3 & 18.6 & 14.5 & 4.2 & 123 \\
\hline M3B3 & 3-Mar & 30 & 15.3 & 19.1 & 15.2 & 3.4 & 22 \\
\hline M4I & 3-Mar & . & . & $\cdot$ & 55.8 & 7.1 & . \\
\hline M4I1 & 3-Mar & 16 & . & $\cdot$ & 19.4 & 3.8 & 41 \\
\hline M412 & 3-Mar & 27 & . & 115 & 92.4 & 16.9 & 20 \\
\hline M4I3 & 3-Mar & 25 & . & 39.5 & 48.5 & 7.6 & 22 \\
\hline M40 & 3-Mar & 64 & 16.6 & . & 3.2 & 1.5 & 2 \\
\hline M401 & 3-Mar & 44 & 15.4 & 5.37 & 7.4 & 1.6 & 18 \\
\hline M402 & 3-Mar & 44 & 17.2 & 2.72 & 2.9 & 1.4 & 73 \\
\hline M403 & 3-Mar & 38 & 16.6 & 9.05 & 13.3 & 4.6 & 60 \\
\hline M4B1 & 3-Mar & 25 & . & 6.94 & 10.0 & 2.6 & 400 \\
\hline M4B2 & 3-Mar & 28 & . & . & 4.2 & 1.1 & 11.6 \\
\hline M4B3 & 3-Mar & 26 & . & . & 5.1 & 1.1 & 5.2 \\
\hline DSI & 3-Mar & 88 & . & 21.5 & 24.5 & 2.7 & 15.5 \\
\hline DSI1 & 3-Mar & 5 & . & 24.4 & 25.9 & 2.4 & 45 \\
\hline DSI2 & 3-Mar & 20 & . & 26.2 & 26.6 & 3.2 & 41 \\
\hline DSI3 & 3-Mar & $\cdot$ & . & 46.1 & 36.1 & 2.5 & $\cdot$ \\
\hline DSO & 3-Mar & 85 & . & . & 15.4 & 2 & 6 \\
\hline DSO1 & 3-Mar & 10 & . & . & 15.5 & 4.9 & 101 \\
\hline DSO2 & 3-Mar & 5 & . & . & 15.7 & 5.4 & 42 \\
\hline
\end{tabular}




\begin{tabular}{|c|c|c|c|c|c|c|c|}
\hline Label & Date & Depth $(\mathrm{cm})$ & $\begin{array}{l}\text { Water Temp } \\
\left({ }^{\circ} \mathrm{C}\right)\end{array}$ & $\begin{array}{c}\text { Turbidity } \\
\text { (NTU) }\end{array}$ & TSS (mg/L) & VSS (mg/L) & $\begin{array}{c}\text { Zooplankton } \\
\text { Density } \\
\text { (\#/L) }\end{array}$ \\
\hline DSO3 & 3-Mar & 20 & . & . & 19.7 & 2.9 & 10 \\
\hline DSB1 & 3-Mar & 5 & 23.4 & . & 20.5 & 4.9 & . \\
\hline DSB2 & 3-Mar & 5 & . & . & 23.0 & 4 & . \\
\hline DSB3 & 3-Mar & 15 & . & . & 30.9 & 3.5 & . \\
\hline DNI =DSO & 3-Mar & . & . & . & 15.4 & . & . \\
\hline DNI1 & 3-Mar & 20 & 17.7 & . & 9.4 & 2.2 & 31.3 \\
\hline DNI2 & 3-Mar & 32 & 18.1 & 10.3 & 9.7 & 2.2 & 61.3 \\
\hline DNI3 & 3-Mar & 8 & 19.7 & . & 26.7 & 4.4 & 50.7 \\
\hline DNO & 3-Mar & . & 19.5 & . & 11.3 & 2.2 & 9.6 \\
\hline DNO1 & 3-Mar & 17 & 17.5 & . & 11.2 & 3.4 & 224 \\
\hline DNO2 & 3-Mar & 42 & 19.2 & 6.64 & 4.5 & 1.6 & 24 \\
\hline DNO3 & 3-Mar & 26 & 19.7 & . & 9.4 & 2.7 & 76 \\
\hline DNB1 & 3-Mar & 12 & 21.6 & 24.6 & 23.6 & 5.5 & 26 \\
\hline DNB2 & 3-Mar & 7 & 20.7 & 45.5 & 50.6 & 6.7 & 108 \\
\hline DNB3 & 3-Mar & 7 & 20.7 & 41.3 & 37.5 & 6 & 52 \\
\hline L3I & 17-Mar & . & . & . & . & . & . \\
\hline L3I1 & 17-Mar & . & 26 & 10.3 & 19.1 & 8.4 & 64 \\
\hline L312 & 17-Mar & 16 & 26.3 & 7.23 & 7.4 & 1.8 & . \\
\hline L3I3 & 17-Mar & 18 & 25.2 & 7.56 & 10.0 & 2.6 & . \\
\hline L30 & 17-Mar & . & 23.6 & 10.5 & 8.8 & 2.3 & 18 \\
\hline L3O1 & 17-Mar & 30 & 24.7 & 9.68 & 10.4 & 3.3 & 12 \\
\hline L3O2 & 17-Mar & 60 & 23.8 & 79.1 & 133.2 & 23.2 & 72 \\
\hline L3O3 & 17-Mar & 48 & 24.6 & . & . & . & 114 \\
\hline L3B1 & 17-Mar & 20 & 26.2 & 22.5 & 20.1 & 3.9 & 15 \\
\hline L3B2 & 17-Mar & 30 & 26 & 103 & 172.3 & 22.6 & 26 \\
\hline L3B3 & 17-Mar & 39 & 25.2 & 27.3 & 26.2 & 4.4 & 30 \\
\hline L1I & 17-Mar & $\cdot$ & . & . & . & $\cdot$ & . \\
\hline L1I1 & 17-Mar & 15 & 25.7 & 16.8 & 21.7 & 4.8 & 4 \\
\hline
\end{tabular}




\begin{tabular}{|c|c|c|c|c|c|c|c|}
\hline Label & Date & Depth $(\mathrm{cm})$ & $\begin{array}{l}\text { Water Temp } \\
\left({ }^{\circ} \mathrm{C}\right)\end{array}$ & $\begin{array}{l}\text { Turbidity } \\
\text { (NTU) }\end{array}$ & TSS (mg/L) & VSS (mg/L) & $\begin{array}{c}\text { Zooplankton } \\
\text { Density } \\
\text { (\#/L) }\end{array}$ \\
\hline L1I2 & 17-Mar & 15 & 24.4 & 22.1 & 22.6 & 5.1 & . \\
\hline L1I3 & 17-Mar & 23 & 26.3 & 20.4 & 28.8 & 6.5 & . \\
\hline L10 & 17-Mar & 59 & 27.4 & 6.63 & 6.4 & 2.9 & . \\
\hline L101 & 17-Mar & 24 & 26.7 & 5.04 & 7.5 & 3.7 & . \\
\hline L1O2 & 17-Mar & 15 & 28.6 & 7.41 & 11.1 & 4.5 & 16 \\
\hline L103 & 17-Mar & 14 & 29.2 & 18.5 & 22.2 & 5.7 & 8 \\
\hline L1B1 & 17-Mar & 19 & 28.3 & 26.3 & 50.5 & 11.4 & 202 \\
\hline L1B2 & 17-Mar & 20 & 27.8 & 7.77 & 10.0 & 3.6 & 196 \\
\hline L1B3 & 17-Mar & 6 & 29.3 & 14.6 & 31.4 & 10.1 & 58 \\
\hline M3I & 17-Mar & . & . & . & . & . & . \\
\hline M3I1 & 17-Mar & . & . & . & . & . & . \\
\hline M312 & 17-Mar & . & . & . & . & . & . \\
\hline M313 & 17-Mar & . & . & . & . & . & . \\
\hline M30 & 17-Mar & 17 & 19 & . & 713.2 & 97.6 & · \\
\hline M301 & 17-Mar & 11 & 22 & 422 & 296.4 & 50.3 & 36 \\
\hline M302 & 17-Mar & . & . & . & $\cdot$ & . & . \\
\hline M303 & 17-Mar & . & . & . & . & . & . \\
\hline M3B1 & 17-Mar & 9 & 23.8 & 649 & 358.8 & 66.4 & 104 \\
\hline M3B2 & 17-Mar & . & . & . & . & . & . \\
\hline M3B3 & 17-Mar & . & . & . & . & . & . \\
\hline M4I & 17-Mar & . & . & . & . & . & . \\
\hline M4I1 & 17-Mar & . & 14.9 & 88.2 & 99.8 & 10.5 & 182 \\
\hline M412 & 17-Mar & 14 & 15.4 & 116 & 102.0 & 11.3 & 18 \\
\hline M413 & 17-Mar & 20 & 15 & 195 & 181.7 & 17.5 & 92 \\
\hline M4O & 17-Mar & 58 & 17.2 & 4.39 & 6.3 & 2.2 & 22 \\
\hline M401 & 17-Mar & 27 & 16.3 & 6.68 & 8.8 & 3.1 & 10 \\
\hline M402 & 17-Mar & 39 & 16.8 & 8.12 & 10.9 & 3.2 & 26 \\
\hline M403 & 17-Mar & 31 & 18.2 & 5.39 & 6.0 & 2 & 50 \\
\hline
\end{tabular}




\begin{tabular}{|c|c|c|c|c|c|c|c|}
\hline Label & Date & Depth $(\mathrm{cm})$ & $\begin{array}{l}\text { Water Temp } \\
\left({ }^{\circ} \mathrm{C}\right)\end{array}$ & $\begin{array}{c}\text { Turbidity } \\
\text { (NTU) }\end{array}$ & TSS (mg/L) & VSS (mg/L) & $\begin{array}{c}\text { Zooplankton } \\
\text { Density } \\
\text { (\#/L) }\end{array}$ \\
\hline M4B1 & 17-Mar & 16 & 16.7 & 9.84 & 15.3 & 4 & 88 \\
\hline M4B2 & 17-Mar & 20 & 18.7 & 6.91 & 9.1 & 2.7 & 37 \\
\hline M4B3 & 17-Mar & 17 & 18.3 & 8.58 & 10.3 & 2.5 & 112 \\
\hline DSI & 17-Mar & . & . & 203 & . & . & . \\
\hline DSI1 & 17-Mar & 13 & 25.8 & 74 & 197.9 & 14.4 & 98 \\
\hline DSI2 & 17-Mar & 24 & 24.2 & 65.6 & 66.7 & 6.8 & . \\
\hline DSI3 & 17-Mar & 23 & 23.9 & . & 78.1 & 8.6 & 34.7 \\
\hline DSO & 17-Mar & . & 24.8 & 123 & 113.7 & 9.5 & . \\
\hline DSO1 & 17-Mar & 22 & 24.7 & 108 & 96.8 & 7.6 & 96 \\
\hline DSO2 & 17-Mar & . & . & . & . & . & . \\
\hline DSO3 & 17-Mar & . & . & . & . & . & . \\
\hline DSB1 & 17-Mar & 7 & 28.1 & 7.7 & 15.3 & 3.8 & 12 \\
\hline DSB2 & 17-Mar & 3 & 28.7 & 52.9 & 98.4 & 12.3 & 28 \\
\hline DSB3 & 17-Mar & 13 & 25.3 & 19.2 & 26.3 & 4.6 & 54 \\
\hline DNI & 17-Mar & $\cdot$ & . & . & . & . & $\cdot$ \\
\hline DNI1 & 17-Mar & 26 & 24 & 177 & 152.5 & 17.9 & 98 \\
\hline DNI2 & 17-Mar & . & . & . & . & . & . \\
\hline DNI3 & 17-Mar & . & . & . & . & . & . \\
\hline DNO & 17-Mar & . & . & 77.1 & 62.5 & 8.2 & 54 \\
\hline DNO1 & 17-Mar & . & . & 69 & 71.3 & 12.3 & 33 \\
\hline DNO2 & 17-Mar & . & . & 33.7 & 47.3 & 9.5 & 978 \\
\hline DNO3 & 17-Mar & . & . & . & . & . & . \\
\hline DNB1 & 17-Mar & 5 & 26.7 & 83.1 & 75.7 & 5.9 & 62 \\
\hline DNB2 & 17-Mar & . & . & . & . & . & . \\
\hline DNB3 & 17-Mar & . & . & . & . & . & . \\
\hline L3I & 17-Apr & . & . & . & . & . & $\cdot$ \\
\hline L3I1 & 17-Apr & 7 & 21.5 & . & 4.9 & 2 & 33 \\
\hline L312 & 17-Apr & 7 & 20.9 & . & 8.3 & 3.7 & 100 \\
\hline
\end{tabular}




\begin{tabular}{|c|c|c|c|c|c|c|c|}
\hline Label & Date & Depth $(\mathrm{cm})$ & $\begin{array}{l}\text { Water Temp } \\
\left({ }^{\circ} \mathrm{C}\right)\end{array}$ & $\begin{array}{c}\text { Turbidity } \\
\text { (NTU) }\end{array}$ & TSS (mg/L) & VSS (mg/L) & $\begin{array}{c}\text { Zooplankton } \\
\text { Density } \\
\text { (\#/L) }\end{array}$ \\
\hline L313 & 17-Apr & 10 & 22.1 & . & 12.7 & 3 & 10 \\
\hline L30 & 17-Apr & 87 & 17.7 & . & 9.4 & 2.8 & 8.7 \\
\hline L301 & 17-Apr & 18 & 18 & . & 23.9 & 6.5 & 116 \\
\hline L3O2 & 17-Apr & 57 & 17.7 & . & 9.7 & 2.6 & 5 \\
\hline L3O3 & 17-Apr & 66 & 18 & . & 66.0 & 12.8 & 60 \\
\hline L3B1 & 17-Apr & 17 & 18.3 & . & 13.8 & 2.9 & 62 \\
\hline L3B2 & 17-Apr & 33 & 17.6 & . & 14.5 & 3.3 & 8.0 \\
\hline L3B3 & 17-Apr & 21 & 17.6 & . & 13.1 & 2.7 & 52.0 \\
\hline M4I & 17-Apr & . & . & . & . & . & . \\
\hline M4I1 & 17-Apr & 9 & 23.3 & . & 174.4 & 28.2 & 378.0 \\
\hline M412 & 17-Apr & 13 & 22.2 & . & 265.6 & 26.2 & 110.0 \\
\hline M4I3 & 17-Apr & 15 & 22.2 & . & 287.9 & 30.3 & 128.0 \\
\hline M40 & 17-Apr & 49 & 20.3 & . & 88.4 & 18.6 & 7.3 \\
\hline M401 & 17-Apr & 20 & 20.4 & . & 36.1 & 7.1 & 96.0 \\
\hline M402 & 17-Apr & 28 & 21.6 & . & 44.0 & 10 & 96.0 \\
\hline M403 & 17-Apr & 29 & 21.4 & . & 121.5 & 24.6 & . \\
\hline M4B1 & 17-Apr & 8 & 21.9 & . & 10.0 & 3.1 & 66.0 \\
\hline M4B2 & 17-Apr & 10 & 24.3 & . & 28.8 & 6.4 & 196.0 \\
\hline M4B3 & 17-Apr & 11 & 23.9 & . & 20.4 & 4.3 & . \\
\hline DSI & 17-Apr & . & . & . & . & . & . \\
\hline DSI1 & 17-Apr & 6 & 19.9 & . & 467.6 & 47.9 & 36.0 \\
\hline DSI2 & 17-Apr & 14 & 19.3 & . & 481.8 & 36.4 & 312.0 \\
\hline DSI3 & 17-Apr & 14 & 19.3 & . & 421.5 & 32.3 & 260.0 \\
\hline DSO & 17-Apr & 52 & 18.7 & . & 378.7 & 36.2 & . \\
\hline DSO1 & 17-Apr & 5 & 16.1 & . & 142.5 & 19.8 & 138.0 \\
\hline DSO2 & 17-Apr & 3 & . & . & 179.4 & 25 & 176.0 \\
\hline DSO3 & 17-Apr & 5 & . & . & 487.8 & 51.2 & 650.0 \\
\hline DSB1 & 17-Apr & . & . & . & . & . & . \\
\hline
\end{tabular}




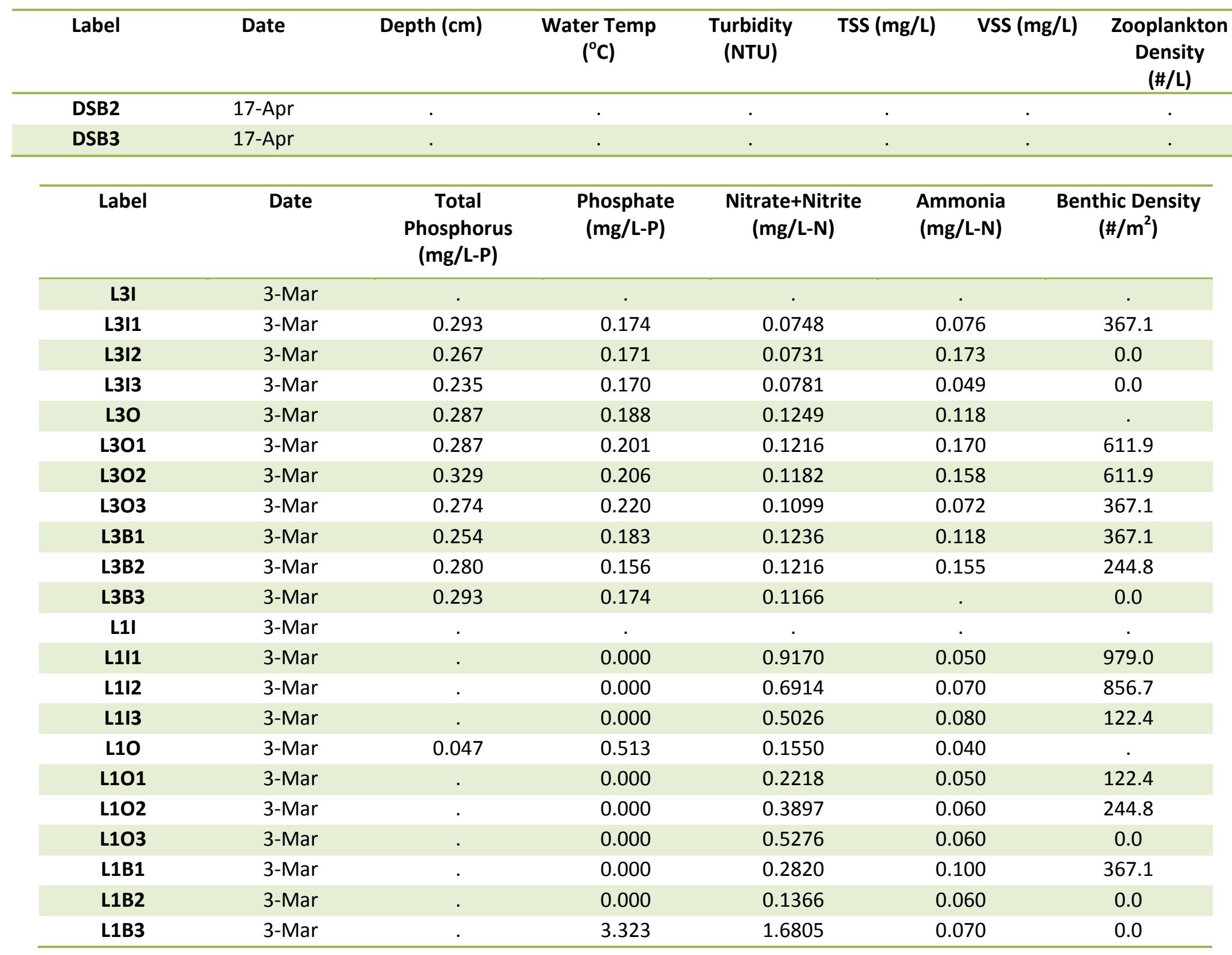




\begin{tabular}{|c|c|c|c|c|c|c|}
\hline Label & Date & $\begin{array}{c}\text { Total } \\
\text { Phosphorus } \\
\text { (mg/L-P) }\end{array}$ & $\begin{array}{l}\text { Phosphate } \\
\text { (mg/L-P) }\end{array}$ & $\begin{array}{c}\text { Nitrate+Nitrite } \\
\text { (mg/L-N) }\end{array}$ & $\begin{array}{l}\text { Ammonia } \\
\text { (mg/L-N) }\end{array}$ & $\begin{array}{c}\text { Benthic Density } \\
\left(\# / \mathrm{m}^{2}\right)\end{array}$ \\
\hline M3I & 3-Mar & 0.185 & . & . & 0.118 & . \\
\hline M3I1 & 3-Mar & 0.271 & 0.132 & 1.3312 & 0.079 & 367.1 \\
\hline M312 & 3-Mar & 0.189 & 0.145 & 1.3446 & 0.071 & 0.0 \\
\hline M3I3 & 3-Mar & 0.195 & 0.138 & 1.5919 & 0.072 & 1468.6 \\
\hline M30 & 3-Mar & 0.211 & 0.194 & 0.4340 & 0.265 & . \\
\hline M301 & 3-Mar & 0.309 & 0.176 & 0.5787 & 0.218 & 244.8 \\
\hline M302 & 3-Mar & 0.268 & 0.237 & 0.4118 & 0.256 & 122.4 \\
\hline M303 & 3-Mar & 0.280 & 0.188 & 0.5410 & 0.228 & 244.8 \\
\hline M3B1 & 3-Mar & 0.242 & 0.255 & 0.3882 & 0.275 & 0.0 \\
\hline M3B2 & 3-Mar & 0.246 & 0.237 & 0.3682 & 0.287 & 122.4 \\
\hline M3B3 & 3-Mar & 0.233 & 0.297 & 0.5987 & 0.247 & 856.7 \\
\hline M4I & 3-Mar & 0.185 & 0.213 & 1.9465 & 0.118 & . \\
\hline M4I1 & 3-Mar & 0.156 & 0.146 & 0.9150 & 0.087 & 0.0 \\
\hline M412 & 3-Mar & 0.631 & 0.176 & 1.7953 & 0.095 & 244.8 \\
\hline M413 & 3-Mar & 0.238 & 0.213 & 1.8798 & 0.103 & 122.4 \\
\hline M40 & 3-Mar & 0.188 & 0.192 & 0.0724 & 0.069 & . \\
\hline M401 & 3-Mar & 0.200 & 0.231 & 0.1147 & 0.079 & 0.0 \\
\hline M402 & 3-Mar & 0.188 & 0.219 & 0.0970 & 0.067 & 244.8 \\
\hline M403 & 3-Mar & 0.225 & 0.273 & 0.0903 & 0.082 & 0.0 \\
\hline M4B1 & 3-Mar & 0.222 & 0.231 & 0.3726 & 0.142 & 0.0 \\
\hline M4B2 & 3-Mar & 0.207 & 0.231 & 0.3482 & 0.181 & 244.8 \\
\hline M4B3 & 3-Mar & 0.216 & 0.225 & 0.3437 & 0.190 & 244.8 \\
\hline DSI & 3-Mar & 0.120 & 0.000 & 0.1072 & 0.336 & . \\
\hline DSI1 & 3-Mar & 0.142 & 0.000 & 0.0838 & 0.161 & 0.0 \\
\hline DSI2 & 3-Mar & 0.135 & 0.000 & 0.0896 & 0.156 & 0.0 \\
\hline DSI3 & 3-Mar & 0.185 & 0.000 & 0.1267 & 0.115 & 0.0 \\
\hline DSO & 3-Mar & 0.095 & 0.000 & 0.0974 & . & . \\
\hline DSO1 & 3-Mar & 0.148 & 0.000 & 0.0929 & 0.074 & 244.8 \\
\hline
\end{tabular}




\begin{tabular}{|c|c|c|c|c|c|c|}
\hline Label & Date & $\begin{array}{c}\text { Total } \\
\text { Phosphorus } \\
\text { (mg/L-P) }\end{array}$ & $\begin{array}{l}\text { Phosphate } \\
\text { (mg/L-P) }\end{array}$ & $\begin{array}{c}\text { Nitrate+Nitrite } \\
\text { (mg/L-N) }\end{array}$ & $\begin{array}{l}\text { Ammonia } \\
\text { (mg/L-N) }\end{array}$ & $\begin{array}{c}\text { Benthic Density } \\
\left(\# / \mathrm{m}^{2}\right)\end{array}$ \\
\hline DSO2 & 3-Mar & 0.160 & 0.000 & 0.0974 & 0.101 & 244.8 \\
\hline DSO3 & 3-Mar & 0.110 & 0.000 & 0.0996 & 0.231 & 122.4 \\
\hline DSB1 & 3-Mar & 0.226 & 0.000 & 0.1033 & 0.114 & 0.0 \\
\hline DSB2 & 3-Mar & 0.229 & 0.000 & 0.1130 & 0.101 & 1958.1 \\
\hline DSB3 & 3-Mar & 0.201 & 0.000 & 0.0955 & 0.114 & 244.8 \\
\hline DNI =DSO & 3-Mar & . & . & . & . & . \\
\hline DNI1 & 3-Mar & 0.157 & 0.000 & 0.0955 & 0.114 & 367.1 \\
\hline DNI2 & 3-Mar & 0.137 & 0.000 & 0.0966 & 0.161 & 734.3 \\
\hline DNI3 & 3-Mar & 0.199 & 0.000 & 0.0895 & 0.193 & 734.3 \\
\hline DNO & 3-Mar & 0.137 & 0.000 & 0.0850 & 0.136 & . \\
\hline DNO1 & 3-Mar & 0.239 & 0.000 & 0.0867 & 0.137 & 0.0 \\
\hline DNO2 & 3-Mar & 0.114 & 0.000 & 0.0935 & 0.170 & 367.1 \\
\hline DNO3 & 3-Mar & 0.131 & 0.000 & 0.1030 & 0.090 & 0.0 \\
\hline DNB1 & 3-Mar & 0.500 & 0.123 & 0.0974 & 0.131 & 122.4 \\
\hline DNB2 & 3-Mar & 0.297 & 0.000 & 0.0818 & 0.209 & 244.8 \\
\hline DNB3 & 3-Mar & 0.239 & 0.000 & 0.0916 & 0.161 & 0.0 \\
\hline L3I & 17-Mar & . & . & . & . & $\cdot$ \\
\hline L3I1 & 17-Mar & 0.550 & 0.257 & 0.0818 & 0.060 & 0.0 \\
\hline L312 & 17-Mar & 0.334 & 0.107 & 0.0946 & 0.092 & 0.0 \\
\hline L313 & 17-Mar & 0.307 & 0.187 & 0.1403 & 0.102 & 0.0 \\
\hline L30 & 17-Mar & 0.688 & 0.310 & 0.1251 & 0.248 & . \\
\hline L301 & 17-Mar & 0.681 & 0.390 & 0.1266 & 0.237 & 856.7 \\
\hline L3O2 & 17-Mar & 0.849 & 0.253 & 0.1477 & 0.252 & 367.1 \\
\hline L3O3 & 17-Mar & . & 0.168 & 0.1726 & . & 489.5 \\
\hline L3B1 & 17-Mar & 0.586 & 0.293 & 0.0672 & 0.118 & 122.4 \\
\hline L3B2 & 17-Mar & 0.776 & 0.284 & 0.0562 & 0.197 & 122.4 \\
\hline L3B3 & 17-Mar & 0.560 & 0.200 & 0.1317 & 0.115 & 856.7 \\
\hline L1I & 17-Mar & . & . & . & . & . \\
\hline
\end{tabular}




\begin{tabular}{|c|c|c|c|c|c|c|}
\hline Label & Date & $\begin{array}{c}\text { Total } \\
\text { Phosphorus } \\
\text { (mg/L-P) }\end{array}$ & $\begin{array}{l}\text { Phosphate } \\
\text { (mg/L-P) }\end{array}$ & $\begin{array}{c}\text { Nitrate+Nitrite } \\
\text { (mg/L-N) }\end{array}$ & $\begin{array}{l}\text { Ammonia } \\
\text { (mg/L-N) }\end{array}$ & $\begin{array}{c}\text { Benthic Density } \\
\left(\# / \mathrm{m}^{2}\right)\end{array}$ \\
\hline L1I1 & 17-Mar & 0.590 & 0.474 & 0.6576 & 0.062 & 489.5 \\
\hline L1/2 & 17-Mar & 0.371 & 0.081 & 0.2317 & 0.064 & 1835.7 \\
\hline L1/3 & 17-Mar & 0.329 & 0.032 & 0.1111 & 0.082 & 2325.2 \\
\hline L10 & 17-Mar & 0.265 & 0.000 & 0.0000 & 0.172 & . \\
\hline L101 & 17-Mar & 0.400 & 0.028 & 0.0000 & 0.311 & 0.0 \\
\hline L102 & 17-Mar & 0.236 & 0.067 & 0.0000 & 0.140 & 122.4 \\
\hline L103 & 17-Mar & 0.423 & 0.059 & 0.0452 & 0.080 & 489.5 \\
\hline L1B1 & 17-Mar & 0.304 & 0.000 & 0.0379 & 0.235 & 244.8 \\
\hline L1B2 & 17-Mar & 0.194 & 0.000 & 0.0000 & 0.137 & 244.8 \\
\hline L1B3 & 17-Mar & 0.178 & 0.000 & 0.0000 & 0.087 & 0.0 \\
\hline M3I & 17-Mar & . & . & . & . & . \\
\hline M3I1 & 17-Mar & . & . & . & . & 0.0 \\
\hline M312 & 17-Mar & . & . & . & . & 0.0 \\
\hline M313 & 17-Mar & . & . & . & . & 0.0 \\
\hline M30 & 17-Mar & 2.412 & 0.277 & 0.1766 & 0.509 & . \\
\hline M301 & 17-Mar & 1.360 & 0.287 & 0.0376 & 3.176 & 489.5 \\
\hline M302 & 17-Mar & . & . & . & . & 0.0 \\
\hline M303 & 17-Mar & . & . & . & . & 0.0 \\
\hline M3B1 & 17-Mar & 2.044 & 0.432 & 0.0000 & 3.191 & 1101.4 \\
\hline M3B2 & 17-Mar & . & . & . & . & 0.0 \\
\hline M3B3 & 17-Mar & . & . & . & . & 0.0 \\
\hline M4I & 17-Mar & . & . & . & . & . \\
\hline M4I1 & 17-Mar & 0.523 & 0.255 & 0.0633 & 0.181 & 856.7 \\
\hline M412 & 17-Mar & 0.466 & 0.223 & 0.1858 & 0.262 & 2570.0 \\
\hline M413 & 17-Mar & 0.493 & 0.148 & 0.4884 & 0.232 & 1713.3 \\
\hline M40 & 17-Mar & 0.390 & 0.261 & 0.0000 & 0.554 & . \\
\hline M401 & 17-Mar & 0.420 & 0.330 & 0.0000 & 0.298 & 0.0 \\
\hline M402 & 17-Mar & 0.435 & 0.309 & 0.0000 & 0.611 & 244.8 \\
\hline
\end{tabular}




\begin{tabular}{|c|c|c|c|c|c|c|}
\hline Label & Date & $\begin{array}{c}\text { Total } \\
\text { Phosphorus } \\
\text { (mg/L-P) }\end{array}$ & $\begin{array}{l}\text { Phosphate } \\
\text { (mg/L-P) }\end{array}$ & $\begin{array}{c}\text { Nitrate+Nitrite } \\
\text { (mg/L-N) }\end{array}$ & $\begin{array}{c}\text { Ammonia } \\
\text { (mg/L-N) }\end{array}$ & $\begin{array}{c}\text { Benthic Density } \\
\left(\# / \mathrm{m}^{2}\right)\end{array}$ \\
\hline M403 & 17-Mar & 0.409 & 0.287 & 0.0000 & 0.626 & 0.0 \\
\hline M4B1 & 17-Mar & 0.769 & 0.480 & 0.0000 & 0.775 & 0.0 \\
\hline M4B2 & 17-Mar & 0.747 & 0.475 & 0.0000 & 0.735 & 979.0 \\
\hline M4B3 & 17-Mar & 0.761 & 0.438 & 0.0000 & 0.722 & 856.7 \\
\hline DSI & 17-Mar & . & . & . & . & . \\
\hline DSI1 & 17-Mar & 0.495 & 0.000 & 0.0000 & 0.225 & 3426.6 \\
\hline DSI2 & 17-Mar & 0.271 & 0.159 & 0.0000 & 0.124 & 1101.4 \\
\hline DSI3 & 17-Mar & 0.268 & 0.000 & 0.0000 & 0.125 & 2814.7 \\
\hline DSO & 17-Mar & 0.459 & 0.000 & 0.0640 & 0.922 & . \\
\hline DSO1 & 17-Mar & 0.457 & 0.011 & 0.0508 & 0.921 & 4160.9 \\
\hline DSO2 & 17-Mar & . & . & . & . & 0.0 \\
\hline DSO3 & 17-Mar & . & . & . & . & 0.0 \\
\hline DSB1 & 17-Mar & 0.271 & . & . & 0.115 & 0.0 \\
\hline DSB2 & 17-Mar & 0.380 & 0.000 & 0.0000 & 0.125 & 1958.1 \\
\hline DSB3 & 17-Mar & 0.191 & 0.000 & 0.0000 & 0.165 & 489.5 \\
\hline DNI & 17-Mar & . & . & . & . & . \\
\hline DNI1 & 17-Mar & 1.051 & 0.295 & 0.0000 & 1.610 & 1223.8 \\
\hline DNI2 & 17-Mar & . & . & . & . & 0.0 \\
\hline DNI3 & 17-Mar & . & . & . & . & 0.0 \\
\hline DNO & 17-Mar & 0.810 & 0.028 & 0.0000 & 2.480 & . \\
\hline DNO1 & 17-Mar & 0.839 & 0.350 & 0.0000 & 0.700 & 4405.7 \\
\hline DNO2 & 17-Mar & 0.617 & 0.163 & 0.0000 & 0.160 & 734.3 \\
\hline DNO3 & 17-Mar & . & . & . & . & 0.0 \\
\hline DNB1 & 17-Mar & 0.395 & 0.053 & 0.0000 & 0.170 & 0.0 \\
\hline DNB2 & 17-Mar & . & . & . & . & 0.0 \\
\hline DNB3 & 17-Mar & . & . & . & . & 0.0 \\
\hline L3I & 17-Apr & . & . & . & . & . \\
\hline L3I1 & 17-Apr & 0.180 & 0.044 & 0.0739 & 0.037 & 856.7 \\
\hline
\end{tabular}




\begin{tabular}{|c|c|c|c|c|c|c|}
\hline Label & Date & $\begin{array}{c}\text { Total } \\
\text { Phosphorus } \\
\text { (mg/L-P) }\end{array}$ & $\begin{array}{l}\text { Phosphate } \\
\text { (mg/L-P) }\end{array}$ & $\begin{array}{l}\text { Nitrate+Nitrite } \\
\text { (mg/L-N) }\end{array}$ & $\begin{array}{l}\text { Ammonia } \\
\text { (mg/L-N) }\end{array}$ & $\begin{array}{c}\text { Benthic Density } \\
\left(\# / \mathrm{m}^{2}\right)\end{array}$ \\
\hline L312 & 17-Apr & 0.184 & 0.052 & 0.0655 & 0.032 & 122.4 \\
\hline L3I3 & 17-Apr & 0.205 & 0.029 & 0.0722 & 0.037 & 489.5 \\
\hline L30 & 17-Apr & 0.199 & 0.000 & 0.0000 & 0.059 & . \\
\hline L301 & 17-Apr & 0.196 & 0.017 & 0.0739 & 0.059 & 0.0 \\
\hline L3O2 & 17-Apr & 0.205 & 0.000 & 0.0000 & 0.052 & 611.9 \\
\hline L3O3 & 17-Apr & 0.258 & 0.000 & 0.0000 & 0.063 & 1713.3 \\
\hline L3B1 & 17-Apr & 0.193 & 0.000 & 0.0806 & 0.046 & 0.0 \\
\hline L3B2 & 17-Apr & 0.193 & 0.000 & 0.0000 & 0.050 & 0.0 \\
\hline L3B3 & 17-Apr & 0.162 & 0.000 & 0.0438 & 0.047 & 122.4 \\
\hline M4I & 17-Apr & . & . & . & . & . \\
\hline M4I1 & 17-Apr & 0.672 & 0.087 & 0.0448 & 0.152 & 367.1 \\
\hline M412 & 17-Apr & 0.471 & 0.021 & 0.1173 & 0.325 & 122.4 \\
\hline M4I3 & 17-Apr & 0.606 & 0.114 & 0.0786 & 0.395 & 3549.0 \\
\hline M40 & 17-Apr & 0.322 & 0.037 & 0.0000 & 0.049 & . \\
\hline M401 & 17-Apr & 0.326 & 0.056 & 0.0000 & 0.193 & 3181.9 \\
\hline M402 & 17-Apr & 0.303 & 0.017 & 0.0000 & 0.104 & 2937.1 \\
\hline M403 & 17-Apr & 0.357 & 0.040 & 0.0000 & 0.054 & 1835.7 \\
\hline M4B1 & 17-Apr & . & 0.257 & 0.0000 & . & 2080.5 \\
\hline M4B2 & 17-Apr & 0.319 & 0.044 & 0.0923 & 0.079 & 3916.2 \\
\hline M4B3 & 17-Apr & 0.303 & 0.048 & 0.0000 & 0.067 & 367.1 \\
\hline DSI & 17-Apr & . & . & . & . & . \\
\hline DSI1 & 17-Apr & 0.941 & 0.000 & 0.0000 & 0.181 & 611.9 \\
\hline DSI2 & 17-Apr & 0.979 & 0.000 & 0.0000 & 0.154 & 856.7 \\
\hline DSI3 & 17-Apr & 1.162 & 0.000 & 0.0000 & 0.160 & 122.4 \\
\hline DSO & 17-Apr & 0.914 & 0.000 & 0.0000 & 0.177 & . \\
\hline DSO1 & 17-Apr & 0.521 & 0.000 & 0.0000 & 0.161 & 244.8 \\
\hline DSO2 & 17-Apr & 0.586 & 0.000 & 0.0000 & 0.163 & 1468.6 \\
\hline DSO3 & 17-Apr & 1.103 & 0.000 & 0.0000 & 0.195 & 0.0 \\
\hline
\end{tabular}




\begin{tabular}{|c|c|c|c|c|c|c|}
\hline Label & Date & $\begin{array}{c}\text { Total } \\
\text { Phosphorus } \\
\text { (mg/L-P) }\end{array}$ & $\begin{array}{l}\text { Phosphate } \\
\text { (mg/L-P) }\end{array}$ & $\begin{array}{c}\text { Nitrate+Nitrite } \\
\text { (mg/L-N) }\end{array}$ & $\begin{array}{l}\text { Ammonia } \\
\text { (mg/L-N) }\end{array}$ & $\begin{array}{c}\text { Benthic Density } \\
\left(\# / \mathrm{m}^{2}\right)\end{array}$ \\
\hline DSB1 & 17-Apr & . & . & . & . & 1468.6 \\
\hline DSB2 & 17-Apr & . & . & . & . & 1713.3 \\
\hline \multirow[t]{22}{*}{ DSB3 } & 17-Apr & . & . & . & . & 0.0 \\
\hline & Label & Date & $\begin{array}{c}\text { Solar Radiation } \\
\text { (Ly/day) }\end{array}$ & $\begin{array}{c}\text { Chloride } \\
\text { Concentration } \\
\left(\mathrm{mg} / \mathrm{L}-\mathrm{Cl}^{-}\right)\end{array}$ & $\begin{array}{c}\text { Specific } \\
\text { Conductivity } \\
(\mathrm{mS} / \mathrm{cm})\end{array}$ & \\
\hline & L3I & 3-Mar & 401 & . & . & \\
\hline & L3I1 & 3-Mar & 401 & 220 & 1.674 & \\
\hline & L312 & 3-Mar & 401 & 149 & 1.11 & \\
\hline & L3I3 & 3-Mar & 401 & 145 & 1.042 & \\
\hline & L30 & 3-Mar & 401 & 115 & . & \\
\hline & L301 & 3-Mar & 401 & 114 & . & \\
\hline & L3O2 & 3-Mar & 401 & 115 & 0.811 & \\
\hline & L3O3 & 3-Mar & 401 & 115 & . & \\
\hline & L3B1 & 3-Mar & 401 & 116 & . & \\
\hline & L3B2 & 3-Mar & 401 & 117 & 0.829 & \\
\hline & L3B3 & 3-Mar & 401 & 117 & 0.825 & \\
\hline & L1I & 3-Mar & 401 & . & . & \\
\hline & L1I1 & 3-Mar & 401 & 163 & 1.01 & \\
\hline & L1I2 & 3-Mar & 401 & 152 & . & \\
\hline & L1I3 & 3-Mar & 401 & 165 & . & \\
\hline & L10 & 3-Mar & 401 & 10 & 1.036 & \\
\hline & L101 & 3-Mar & 401 & 170 & 1.032 & \\
\hline & L102 & 3-Mar & 401 & 171 & . & \\
\hline & L1O3 & 3-Mar & 401 & 170 & . & \\
\hline & L1B1 & 3-Mar & 401 & 170 & 1.02 & \\
\hline
\end{tabular}




\begin{tabular}{|c|c|c|c|c|}
\hline L1B2 & 3-Mar & 401 & 184 & 1 \\
\hline L1B3 & 3-Mar & 401 & 162 & 0.997 \\
\hline M3I & 3-Mar & 397 & . & . \\
\hline M3I1 & 3-Mar & 397 & 99 & 0.718 \\
\hline M312 & 3-Mar & 397 & 100 & 0.719 \\
\hline M3I3 & 3-Mar & 397 & 100 & 0.779 \\
\hline M30 & 3-Mar & 397 & 89 & 0.634 \\
\hline M301 & 3-Mar & 397 & 86 & . \\
\hline M3O2 & 3-Mar & 397 & 84 & 0.679 \\
\hline M303 & 3-Mar & 397 & 84 & 0.661 \\
\hline M3B1 & 3-Mar & 397 & 87 & . \\
\hline M3B2 & 3-Mar & 397 & 95 & . \\
\hline M3B3 & 3-Mar & 397 & 95 & 0.701 \\
\hline M4I & 3-Mar & 397 & 119 & 0.741 \\
\hline M4I1 & 3-Mar & 397 & 133 & 1.05 \\
\hline M412 & 3-Mar & 397 & 118 & • \\
\hline M4I3 & 3-Mar & 397 & 118 & 0.721 \\
\hline M40 & 3-Mar & 397 & 102 & 0.7 \\
\hline M401 & 3-Mar & 397 & 96 & 0.727 \\
\hline M402 & 3-Mar & 397 & 98 & 0.696 \\
\hline M403 & 3-Mar & 397 & 105 & 0.707 \\
\hline M4B1 & 3-Mar & 397 & 105 & . \\
\hline M4B2 & 3-Mar & 397 & 108 & 0.734 \\
\hline M4B3 & 3-Mar & 397 & 110 & 0.734 \\
\hline DSI & 3-Mar & 397 & 535 & 3.15 \\
\hline DSI1 & 3-Mar & 397 & 552 & . \\
\hline DSI2 & 3-Mar & 397 & 558 & . \\
\hline DSI3 & 3-Mar & 397 & 921 & . \\
\hline DSO & 3-Mar & 397 & 554 & 3.2 \\
\hline DSO1 & 3-Mar & 397 & 532 & 3.21 \\
\hline DSO2 & 3-Mar & 397 & 545 & 3.18 \\
\hline
\end{tabular}




\begin{tabular}{|c|c|c|c|c|}
\hline DSO3 & 3-Mar & 397 & 534 & 3.22 \\
\hline DSB1 & 3-Mar & 397 & 600 & 3.89 \\
\hline DSB2 & 3-Mar & 397 & 574 & 3.58 \\
\hline DSB3 & 3-Mar & 397 & 557 & 3.65 \\
\hline DNI =DSO & 3-Mar & 397 & . & . \\
\hline DNI1 & 3-Mar & 397 & 328 & 2.35 \\
\hline DNI2 & 3-Mar & 397 & 337 & 2.44 \\
\hline DNI3 & 3-Mar & 397 & 344 & 2.32 \\
\hline DNO & 3-Mar & 397 & 347 & 2.3 \\
\hline DNO1 & 3-Mar & 397 & 331 & 2.4 \\
\hline DNO2 & 3-Mar & 397 & 341 & . \\
\hline DNO3 & 3-Mar & 397 & 340 & 2.32 \\
\hline DNB1 & 3-Mar & 397 & 437 & . \\
\hline DNB2 & 3-Mar & 397 & 383 & . \\
\hline DNB3 & 3-Mar & 397 & 401 & . \\
\hline L3I & 17-Mar & 454 & . & . \\
\hline L3I1 & 17-Mar & 454 & 149 & 1.188 \\
\hline L312 & 17-Mar & 454 & 105 & 0.77 \\
\hline L3I3 & 17-Mar & 454 & 102 & . \\
\hline L30 & 17-Mar & 454 & 142 & 0.944 \\
\hline L301 & 17-Mar & 454 & 142 & . \\
\hline L3O2 & 17-Mar & 454 & 144 & 0.9 \\
\hline L3O3 & 17-Mar & 454 & 103 & . \\
\hline L3B1 & 17-Mar & 454 & 148 & 0.951 \\
\hline L3B2 & 17-Mar & 454 & 147 & . \\
\hline L3B3 & 17-Mar & 454 & 150 & 0.832 \\
\hline L1I & 17-Mar & 454 & . & . \\
\hline L1I1 & 17-Mar & 454 & 139 & 0.637 \\
\hline L1/2 & 17-Mar & 454 & 113 & 0.725 \\
\hline L1/3 & 17-Mar & 454 & 230 & 0.888 \\
\hline L10 & 17-Mar & 454 & 215 & . \\
\hline
\end{tabular}




\begin{tabular}{|c|c|c|c|c|}
\hline L101 & 17-Mar & 454 & 184 & 0.799 \\
\hline L102 & 17-Mar & 454 & 155 & 0.908 \\
\hline L103 & 17-Mar & 454 & 162 & . \\
\hline L1B1 & 17-Mar & 454 & 206 & . \\
\hline L1B2 & 17-Mar & 454 & 220 & 0.95 \\
\hline L1B3 & 17-Mar & 454 & 267 & 0.952 \\
\hline M3I & 17-Mar & 458 & . & $\cdot$ \\
\hline M3I1 & 17-Mar & 458 & . & . \\
\hline M312 & 17-Mar & 458 & . & . \\
\hline M3I3 & 17-Mar & 458 & . & . \\
\hline M30 & 17-Mar & 458 & 136 & . \\
\hline M301 & 17-Mar & 458 & 139 & 0.913 \\
\hline M302 & 17-Mar & 458 & . & . \\
\hline M303 & 17-Mar & 458 & . & . \\
\hline M3B1 & 17-Mar & 458 & 143 & 0.891 \\
\hline M3B2 & 17-Mar & 458 & . & . \\
\hline M3B3 & 17-Mar & 458 & . & . \\
\hline M4I & 17-Mar & 458 & . & . \\
\hline M4I1 & 17-Mar & 458 & 155 & . \\
\hline M412 & 17-Mar & 458 & 140 & . \\
\hline M4I3 & 17-Mar & 458 & 136 & . \\
\hline M40 & 17-Mar & 458 & 132 & 0.915 \\
\hline M401 & 17-Mar & 458 & 131 & 0.873 \\
\hline M402 & 17-Mar & 458 & 135 & 0.873 \\
\hline M403 & 17-Mar & 458 & 134 & 0.876 \\
\hline M4B1 & 17-Mar & 458 & 146 & 0.974 \\
\hline M4B2 & 17-Mar & 458 & 146 & 0.963 \\
\hline M4B3 & 17-Mar & 458 & 144 & 0.976 \\
\hline DSI & 17-Mar & 458 & . & . \\
\hline DSI1 & 17-Mar & 458 & 764 & 5.56 \\
\hline DSI2 & 17-Mar & 458 & 776 & 5.45 \\
\hline
\end{tabular}




\begin{tabular}{|c|c|c|c|c|}
\hline DSI3 & 17-Mar & 458 & 786 & 5.69 \\
\hline DSO & 17-Mar & 458 & 548 & 4.01 \\
\hline DSO1 & 17-Mar & 458 & 559 & . \\
\hline DSO2 & 17-Mar & 458 & . & . \\
\hline DSO3 & 17-Mar & 458 & . & . \\
\hline DSB1 & 17-Mar & 458 & . & 4.59 \\
\hline DSB2 & 17-Mar & 458 & 646 & 4.37 \\
\hline DSB3 & 17-Mar & 458 & 637 & 4.36 \\
\hline DNI & 17-Mar & 458 & . & . \\
\hline DNI1 & 17-Mar & 458 & 454 & 3.22 \\
\hline DNI2 & 17-Mar & 458 & . & . \\
\hline DNI3 & 17-Mar & 458 & . & . \\
\hline DNO & 17-Mar & 458 & 482 & 3.43 \\
\hline DNO1 & 17-Mar & 458 & 477 & 3.41 \\
\hline DNO2 & 17-Mar & 458 & 537 & 3.71 \\
\hline DNO3 & 17-Mar & 458 & . & . \\
\hline DNB1 & 17-Mar & 458 & 644 & . \\
\hline DNB2 & 17-Mar & 458 & . & . \\
\hline DNB3 & 17-Mar & 458 & . & . \\
\hline L3I & 17-Apr & 583 & . & . \\
\hline L3I1 & 17-Apr & 583 & 60 & 0.569 \\
\hline L312 & 17-Apr & 583 & 61 & 0.565 \\
\hline L313 & 17-Apr & 583 & 62 & 0.572 \\
\hline L30 & 17-Apr & 583 & 125 & 0.918 \\
\hline L3O1 & 17-Apr & 583 & 119 & 0.887 \\
\hline L3O2 & 17-Apr & 583 & 124 & 0.961 \\
\hline L3O3 & 17-Apr & 583 & 132 & . \\
\hline L3B1 & 17-Apr & 583 & 136 & 0.942 \\
\hline L3B2 & 17-Apr & 583 & 135 & 1.033 \\
\hline L3B3 & 17-Apr & 583 & 135 & 0.987 \\
\hline M4I & 17-Apr & 583 & . & . \\
\hline
\end{tabular}




\begin{tabular}{|c|c|c|c|c|}
\hline M4I1 & 17-Apr & 583 & 88 & 0.684 \\
\hline M412 & 17-Apr & 583 & 87 & 0.719 \\
\hline M413 & 17-Apr & 583 & 88 & 0.685 \\
\hline M40 & 17-Apr & 583 & 93 & 0.713 \\
\hline M401 & 17-Apr & 583 & 127 & 0.909 \\
\hline M402 & 17-Apr & 583 & 126 & 0.892 \\
\hline M403 & 17-Apr & 583 & 95 & . \\
\hline M4B1 & 17-Apr & 583 & 958 & . \\
\hline M4B2 & 17-Apr & 583 & 169 & . \\
\hline M4B3 & 17-Apr & 583 & 159 & . \\
\hline DSI & 17-Apr & 583 & . & . \\
\hline DSI1 & 17-Apr & 583 & 978 & 6.82 \\
\hline DSI2 & 17-Apr & 583 & 1198 & 6.81 \\
\hline DSI3 & 17-Apr & 583 & 990 & 6.91 \\
\hline DSO & 17-Apr & 583 & 998 & 6.81 \\
\hline DSO1 & 17-Apr & 583 & 1133 & 6.83 \\
\hline DSO2 & 17-Apr & 583 & 1049 & 6.81 \\
\hline DSO3 & 17-Apr & 583 & 1032 & 6.96 \\
\hline DSB1 & 17-Apr & 583 & . & . \\
\hline DSB2 & 17-Apr & 583 & . & . \\
\hline DSB3 & 17-Apr & 583 & . & . \\
\hline
\end{tabular}


$\underline{2008 \text { Raw Data }}$

\begin{tabular}{|c|c|c|c|c|c|c|}
\hline Label & Date & TSS (mg/L) & VSS (mg/L) & $\begin{array}{l}\text { Unscreened } \\
\text { VSS (mg/L) }\end{array}$ & Turbidity (NTU) & $\begin{array}{c}\text { Solar Radiation } \\
\left(\mathrm{W} / \mathrm{m}^{2}\right)\end{array}$ \\
\hline BW & 29-Feb & 10.8 & 1.9 & 0 & 4.99 & 188 \\
\hline L8 & 29-Feb & 5.8 & 1.7 & 0 & 5.25 & 188 \\
\hline L1 & 29-Feb & 4.0 & 2.1 & 1.9 & 1.41 & 188 \\
\hline L3 & 29-Feb & 8.7 & 2.4 & 1 & 8.38 & 188 \\
\hline M3 & 29-Feb & 37.5 & 4.1 & 0.7 & 47.8 & 188 \\
\hline M4 & 29-Feb & 27.2 & 3.5 & 1 & 36 & 188 \\
\hline DN & 29-Feb & 17.6 & 4.4 & 4 & 20.9 & 188 \\
\hline DS & 29-Feb & 30.3 & 9.1 & 0 & 29.4 & 188 \\
\hline BW & 16-Mar & 11.0 & 2.8 & 0.4 & 8.54 & 227 \\
\hline L8 & 16-Mar & 8.6 & 2.8 & 0.2 & 7.39 & 227 \\
\hline L1 & 16-Mar & 1.4 & 1.2 & 1.6 & 2.45 & 227 \\
\hline L3 & 16-Mar & 122.2 & 26.7 & 0 & 111 & 227 \\
\hline M3 & 16-Mar & 112.0 & 14 & 0 & 143 & 227 \\
\hline M4 & 16-Mar & 72.0 & 9.7 & 2.8 & 82.4 & 227 \\
\hline DN & 16-Mar & 9.4 & 2.4 & 0 & 8.59 & 227 \\
\hline DS & 16-Mar & 97.0 & 15.9 & 0 & 90.5 & 227 \\
\hline BW & 20-Mar & 5.8 & 1.8 & 0.4 & 5.64 & 229 \\
\hline L8 & 20-Mar & 13.3 & 4.3 & 0 & 10.9 & 229 \\
\hline BW & 27-Mar & 17.0 & 3 & 0.1 & 11.6 & 206 \\
\hline L8 & 27-Mar & 9.6 & 2.8 & 0 & 9.06 & 206 \\
\hline BW & 30-Mar & 16.2 & 2.8 & 0.5 & 11.9 & 212 \\
\hline L8 & 30-Mar & 11.0 & 3 & 0.5 & 11.3 & 212 \\
\hline L3 & 30-Mar & 12.4 & 2.6 & 1.4 & 13.8 & 212 \\
\hline M4 & 30-Mar & 22.6 & 3.7 & 1.1 & 23.9 & 212 \\
\hline DS & 30-Mar & 46.0 & 8.4 & 0.4 & 47 & 212 \\
\hline BW & 13-Apr & 16.8 & 3.4 & 0 & 13.4 & 305 \\
\hline
\end{tabular}




\begin{tabular}{|c|c|c|c|c|c|c|}
\hline Label & Date & TSS (mg/L) & VSS (mg/L) & $\begin{array}{l}\text { Unscreened } \\
\text { VSS (mg/L) }\end{array}$ & Turbidity (NTU) & $\begin{array}{c}\text { Solar Radiation } \\
\left(\mathrm{W} / \mathrm{m}^{2}\right)\end{array}$ \\
\hline L8 & 13-Apr & 15.2 & 3.2 & 0.8 & 14.5 & 305 \\
\hline L3 & 13-Apr & 4.6 & 1.6 & 0.6 & 6.45 & 305 \\
\hline M4 & 13-Apr & 36.0 & 8 & 0 & 21.3 & 305 \\
\hline DS & 13-Apr & 21.2 & 7.2 & 1.6 & 32 & 305 \\
\hline L3 & 18-Apr & 6.0 & 1.8 & 1 & 6.82 & 291 \\
\hline M4 & 18-Apr & 25.5 & 5.2 & 0 & 30.3 & 291 \\
\hline DS & 18-Apr & 93.3 & 12.6 & 2 & 99.4 & 291 \\
\hline BW & 20-Apr & 15.2 & 3.4 & 0.4 & 20.1 & 317 \\
\hline L8 & 20-Apr & 20.6 & 5.4 & 0.5 & 20.7 & 317 \\
\hline L3 & 21-Apr & 9.6 & 2.6 & 0.6 & 9.45 & 312 \\
\hline M4 & 21-Apr & 88.5 & 20.5 & 0 & 92.6 & 312 \\
\hline DS & 21-Apr & 407.0 & 53.5 & 6.5 & 460 & 312 \\
\hline L3 & 22-Apr & 27.1 & 6.3 & 0.6 & 24.5 & 190 \\
\hline M4 & 22-Apr & 250.0 & 55.9 & 1.6 & 303 & 190 \\
\hline DS & 22-Apr & 393.0 & 55.8 & 6.3 & 434 & 190 \\
\hline BW & 23-Apr & 17.4 & 3 & 0.4 & 11.7 & 239 \\
\hline L8 & 23-Apr & 16.7 & 4.7 & 0 & 14.6 & 239 \\
\hline L3 & 23-Apr & 57.3 & 14.5 & 3.5 & 54.3 & 239 \\
\hline BW & 27-Apr & 15.4 & 3 & 0.2 & 12.5 & 315 \\
\hline L8 & 27-Apr & 21.6 & 5.1 & 0.1 & 19.2 & 315 \\
\hline Label & Date & $\begin{array}{l}\text { Ave. Wind Spd } \\
\text { (MPH) }\end{array}$ & $\begin{array}{c}\text { Ave Daily Temp } \\
\left({ }^{\circ} \mathrm{F}\right)\end{array}$ & $\begin{array}{c}\text { Total } \\
\text { Phosphorus } \\
\text { (mg/L-P) }\end{array}$ & $\begin{array}{l}\text { Phosphate } \\
\text { (mg/L-P) }\end{array}$ & TKN (mg/L-N) \\
\hline BW & 29-Feb & 4.5 & 55.8 & 0.606 & 0.170 & 1.1 \\
\hline L8 & 29-Feb & 4.5 & 55.8 & 0.417 & 0.080 & 0.9 \\
\hline L1 & 29-Feb & 4.5 & 55.8 & 0.073 & . & 1.0 \\
\hline
\end{tabular}




\begin{tabular}{|c|c|c|c|c|c|c|}
\hline Label & Date & $\begin{array}{l}\text { Ave. Wind Spd } \\
\text { (MPH) }\end{array}$ & $\begin{array}{c}\text { Ave Daily Temp } \\
\left({ }^{\circ} \mathrm{F}\right)\end{array}$ & $\begin{array}{c}\text { Total } \\
\text { Phosphorus } \\
\text { (mg/L-P) }\end{array}$ & $\begin{array}{l}\text { Phosphate } \\
\text { (mg/L-P) }\end{array}$ & TKN (mg/L-N) \\
\hline L3 & 29-Feb & 4.5 & 55.8 & 0.192 & 0.120 & 1.8 \\
\hline M3 & 29-Feb & 4.5 & 55.8 & 0.231 & 0.070 & 1.4 \\
\hline M4 & 29-Feb & 4.5 & 55.8 & 0.288 & 0.180 & 1.7 \\
\hline DN & 29-Feb & 4.5 & 55.8 & 0.275 & . & 2.1 \\
\hline DS & 29-Feb & 4.5 & 55.8 & 0.525 & . & . \\
\hline BW & 16-Mar & 19.2 & 52.6 & 0.238 & 0.192 & 1.0 \\
\hline L8 & 16-Mar & 19.2 & 52.6 & 0.151 & 0.110 & 0.9 \\
\hline L1 & 16-Mar & 19.2 & 52.6 & 0.021 & 0.001 & 1.1 \\
\hline L3 & 16-Mar & 19.2 & 52.6 & 0.279 & 0.031 & 2.4 \\
\hline M3 & 16-Mar & 19.2 & 52.6 & 0.263 & 0.085 & 1.5 \\
\hline M4 & 16-Mar & 19.2 & 52.6 & 0.228 & 0.065 & 2.1 \\
\hline DN & 16-Mar & 19.2 & 52.6 & 0.166 & 0.035 & 2.0 \\
\hline DS & 16-Mar & 19.2 & 52.6 & 0.239 & 0.074 & 2.4 \\
\hline BW & 20-Mar & 6.0 & 52.5 & 0.249 & 0.180 & 0.9 \\
\hline L8 & 20-Mar & 6.0 & 52.5 & 0.195 & 0.075 & 1.1 \\
\hline BW & 27-Mar & 8.6 & 47.9 & 0.270 & 0.193 & 0.8 \\
\hline L8 & 27-Mar & 8.6 & 47.9 & 0.213 & 0.136 & 0.9 \\
\hline BW & 30-Mar & 10.5 & 51.1 & 0.264 & 0.194 & 0.9 \\
\hline L8 & 30-Mar & 10.5 & 51.1 & 0.208 & 0.122 & 0.9 \\
\hline L3 & 30-Mar & 10.5 & 51.1 & 0.410 & 0.054 & 1.4 \\
\hline M4 & 30-Mar & 10.5 & 51.1 & 0.478 & 0.063 & 1.4 \\
\hline DS & 30-Mar & 10.5 & 51.1 & 0.769 & 0.038 & 2.6 \\
\hline BW & 13-Apr & 4.3 & 70.3 & 1.011 & 0.246 & 1.1 \\
\hline L8 & 13-Apr & 4.3 & 70.3 & 0.795 & 0.155 & 1.0 \\
\hline L3 & 13-Apr & 4.3 & 70.3 & 0.469 & 0.088 & 1.2 \\
\hline M4 & 13-Apr & 4.3 & 70.3 & 0.669 & 0.064 & 1.4 \\
\hline DS & 13-Apr & 4.3 & 70.3 & 0.747 & 0.051 & 2.9 \\
\hline L3 & 18-Apr & 8.1 & 62.8 & 0.111 & 0.066 & 1.0 \\
\hline
\end{tabular}




\begin{tabular}{|c|c|c|c|c|c|c|}
\hline Label & Date & $\begin{array}{l}\text { Ave. Wind Spd } \\
\text { (MPH) }\end{array}$ & $\begin{array}{l}\text { Ave Daily Temp } \\
\left({ }^{\circ} \mathrm{F}\right)\end{array}$ & $\begin{array}{c}\text { Total } \\
\text { Phosphorus } \\
\text { (mg/L-P) }\end{array}$ & $\begin{array}{l}\text { Phosphate } \\
\text { (mg/L-P) }\end{array}$ & TKN (mg/L-N) \\
\hline M4 & 18-Apr & 8.1 & 62.8 & 0.259 & 0.119 & 1.9 \\
\hline DS & 18-Apr & 8.1 & 62.8 & 0.354 & 0.076 & 3.5 \\
\hline BW & 20-Apr & 6.8 & 47.5 & 0.403 & 0.244 & 1.2 \\
\hline L8 & 20-Apr & 6.8 & 47.5 & 0.342 & 0.214 & 1.6 \\
\hline L3 & 21-Apr & 5.0 & 49.5 & 0.103 & 0.050 & 1.2 \\
\hline M4 & 21-Apr & 5.0 & 49.5 & 0.385 & 0.047 & 2.3 \\
\hline DS & 21-Apr & 5.0 & 49.5 & 0.953 & 0.082 & 5.5 \\
\hline L3 & 22-Apr & 5.9 & 52.2 & 0.156 & 0.053 & 1.4 \\
\hline M4 & 22-Apr & 5.9 & 52.2 & 0.876 & 0.006 & 4.5 \\
\hline DS & 22-Apr & 5.9 & 52.2 & 0.987 & 0.084 & 6.2 \\
\hline BW & 23-Apr & 7.8 & 55.3 & 0.282 & 0.224 & 1.2 \\
\hline L8 & 23-Apr & 7.8 & 55.3 & 0.319 & 0.216 & 1.3 \\
\hline L3 & 23-Apr & 7.8 & 55.3 & 0.219 & 0.051 & 2.2 \\
\hline BW & 27-Apr & 4.1 & 71.1 & 0.275 & 0.202 & 1.1 \\
\hline L8 & 27-Apr & 4.1 & 71.1 & 0.378 & 0.252 & 1.3 \\
\hline
\end{tabular}

\begin{tabular}{cccccc}
\hline Label & Date & $\begin{array}{c}\text { Ammonia } \\
(\mathbf{m g} / \mathbf{L}-\mathbf{N})\end{array}$ & $\begin{array}{c}\text { Nitrate+Nitrite } \\
(\mathbf{m g} / \mathbf{L}-\mathbf{N})\end{array}$ & TOC (mg/L-C) & DOC (mg/L-C) \\
\hline BW & 29-Feb & 0.069 & 0.000 &. &. \\
L8 & $29-F e b$ & 0.057 & 0.040 & 10.5 & 9.5 \\
L1 & $29-F e b$ & 0.067 & 0.000 & 12.0 & 11.1 \\
L3 & $29-F e b$ & 0.25 & 0.110 & 10.2 & 7.5 \\
M3 & $29-F e b$ & 0.401 & 0.380 & 8.6 & 7.8 \\
M4 & $29-F e b$ & 0.415 & 0.360 & 18.2 & 15.7 \\
DN & $29-F e b$ & 0.188 & 0.000 & 13.7 & 11.8 \\
\hline DS & $29-F e b$ & 0.045 & 0.000 & & \\
\hline
\end{tabular}




\begin{tabular}{|c|c|c|c|c|c|}
\hline Label & Date & $\begin{array}{c}\text { Ammonia } \\
\text { (mg/L-N) }\end{array}$ & $\begin{array}{l}\text { Nitrate+Nitrite } \\
(\mathrm{mg} / \mathrm{L}-\mathrm{N})\end{array}$ & TOC (mg/L-C) & $\mathrm{DOC}(\mathrm{mg} / \mathrm{L}-\mathrm{C})$ \\
\hline BW & 16-Mar & 0.041 & 0.100 & 11.8 & 12.2 \\
\hline L8 & 16-Mar & 0.039 & 0.080 & 13.1 & 10.2 \\
\hline L1 & 16-Mar & 0.028 & 0.110 & 13.8 & 11.7 \\
\hline L3 & 16-Mar & 0.107 & 0.000 & 19.7 & 11.8 \\
\hline M3 & 16-Mar & 0.082 & 0.000 & 11.6 & 9.2 \\
\hline M4 & 16-Mar & 0.298 & 0.000 & 13.4 & 10.0 \\
\hline DN & 16-Mar & 0.038 & 0.640 & 20.1 & 17.6 \\
\hline DS & 16-Mar & 0.085 & 0.020 & 21.5 & 16.1 \\
\hline BW & 20-Mar & 0.047 & 0.000 & 10.6 & 10.8 \\
\hline L8 & 20-Mar & 0.035 & 0.040 & 12.1 & 11.3 \\
\hline BW & 27-Mar & 0.045 & 0.070 & 10.3 & 11.9 \\
\hline L8 & 27-Mar & 0.037 & 0.190 & 11.2 & 13.4 \\
\hline BW & 30-Mar & 0.049 & 0.000 & 10.9 & 10.4 \\
\hline L8 & 30-Mar & 0.045 & 0.000 & 11.0 & 10.9 \\
\hline L3 & 30-Mar & 0.066 & 0.170 & 14.8 & 14.8 \\
\hline M4 & 30-Mar & 0.227 & 0.110 & 9.9 & 10.1 \\
\hline DS & 30-Mar & 0.033 & 0.000 & 22.4 & 23.4 \\
\hline BW & 13-Apr & 0.095 & 0.000 & . & 10.9 \\
\hline L8 & 13-Apr & 0.056 & 0.160 & . & 10.1 \\
\hline L3 & 13-Apr & 0.074 & 0.180 & . & 12.2 \\
\hline M4 & 13-Apr & 0.023 & 0.000 & . & 10.3 \\
\hline DS & 13-Apr & 0.023 & 0.000 & . & 24.0 \\
\hline L3 & 18-Apr & 0.06 & 0.000 & . & 9.6 \\
\hline M4 & 18-Apr & 0.238 & 0.000 & . & 8.9 \\
\hline DS & 18-Apr & 0.023 & 0.000 & . & 26.6 \\
\hline BW & 20-Apr & . & 0.050 & . & 13.2 \\
\hline L8 & 20-Apr & . & 0.090 & . & 12.3 \\
\hline L3 & 21-Apr & 0.065 & 0.000 & . & 13.7 \\
\hline M4 & 21-Apr & 0.205 & 0.000 & . & 14.7 \\
\hline
\end{tabular}




\begin{tabular}{|c|c|c|c|c|c|}
\hline Label & Date & $\begin{array}{l}\text { Ammonia } \\
\text { (mg/L-N) }\end{array}$ & $\begin{array}{c}\text { Nitrate+Nitrite } \\
\text { (mg/L-N) }\end{array}$ & TOC (mg/L-C) & $\mathrm{DOC}(\mathrm{mg} / \mathrm{L}-\mathrm{C})$ \\
\hline DS & 21-Apr & 0.344 & 0.000 & . & 33.7 \\
\hline L3 & 22-Apr & 0.094 & 0.000 & . & 16.3 \\
\hline M4 & 22-Apr & 0.244 & 0.000 & . & 17.7 \\
\hline DS & 22-Apr & 0.215 & 0.000 & . & 36.3 \\
\hline BW & 23-Apr & 0.064 & 0.000 & . & 13.3 \\
\hline L8 & 23-Apr & 0.048 & 0.000 & . & 15.2 \\
\hline L3 & 23-Apr & 0.162 & 0.000 & . & 15.2 \\
\hline BW & 27-Apr & 0.044 & 0.060 & . & 11.0 \\
\hline L8 & 27-Apr & 0.056 & 0.070 & . & 13.8 \\
\hline
\end{tabular}

\begin{tabular}{|c|c|c|c|c|c|}
\hline Label & Date & Weir Flow (L/s) & $\begin{array}{c}\text { Specific } \\
\text { Conductivity } \\
(\mathrm{mS} / \mathrm{cm})\end{array}$ & $\begin{array}{l}\text { Total Organic } \\
\text { Carbon (mg/L- } \\
\text { C) }\end{array}$ & $\begin{array}{c}\text { Dissolved } \\
\text { Organic Carbon } \\
(\mathrm{mg} / \mathrm{L}-\mathrm{C})\end{array}$ \\
\hline BW & 29-Feb & 9.1 & 1.34 & 11.5 & 10.5 \\
\hline $\mathbf{L 8}$ & 29-Feb & 111.2 & 1.68 & 12.0 & 11.1 \\
\hline L1 & 29-Feb & 0.0 & 0.99 & 10.6 & 9.5 \\
\hline L3 & 29-Feb & 4.4 & 1.09 & 12.4 & 11.1 \\
\hline M3 & 29-Feb & 3.8 & 0.73 & 9.7 & 7.5 \\
\hline M4 & 29-Feb & 8.4 & 0.89 & 9.6 & 7.8 \\
\hline DN & 29-Feb & 2.1 & 3.19 & 18.0 & 15.7 \\
\hline DS & 29-Feb & 0.0 & 3.53 & 16.6 & 11.8 \\
\hline BW & 16-Mar & 125.1 & 1.41 & 13.7 & 12.2 \\
\hline L8 & 16-Mar & 84.8 & 1.83 & 11.7 & 10.2 \\
\hline L1 & 16-Mar & 0.0 & 1.18 & 12.3 & 11.7 \\
\hline L3 & 16-Mar & 0.1 & 1.25 & 25.9 & 11.8 \\
\hline M3 & 16-Mar & 6.9 & 0.81 & 16.6 & 9.2 \\
\hline M4 & 16-Mar & 0.4 & 0.93 & 15.1 & 10.0 \\
\hline
\end{tabular}




\begin{tabular}{|c|c|c|c|c|c|}
\hline Label & Date & Weir Flow (L/s) & $\begin{array}{c}\text { Specific } \\
\text { Conductivity } \\
(\mathrm{mS} / \mathrm{cm})\end{array}$ & $\begin{array}{l}\text { Total Organic } \\
\text { Carbon (mg/L- } \\
\text { C) }\end{array}$ & $\begin{array}{c}\text { Dissolved } \\
\text { Organic Carbon } \\
\text { (mg/L-C) }\end{array}$ \\
\hline DN & 16-Mar & 0.8 & 4.16 & 18.9 & 17.6 \\
\hline DS & 16-Mar & 0.0 & 4.52 & 24.5 & 16.1 \\
\hline BW & 20-Mar & 133.4 & . & 11.8 & 10.8 \\
\hline L8 & 20-Mar & 98.5 & . & 13.6 & 11.3 \\
\hline BW & 27-Mar & 41.4 & 1.49 & 13.5 & 11.9 \\
\hline L8 & 27-Mar & 87.3 & 1.87 & 14.9 & 13.4 \\
\hline BW & 30-Mar & 21.0 & 1.51 & 11.9 & 10.4 \\
\hline L8 & 30-Mar & 67.2 & 1.91 & 12.5 & 10.9 \\
\hline L3 & 30-Mar & 0.3 & 1.35 & 16.2 & 14.8 \\
\hline M4 & 30-Mar & 4.4 & 1.00 & 12.1 & 10.1 \\
\hline DS & 30-Mar & 0.0 & 5.74 & 27.8 & 23.4 \\
\hline BW & 13-Apr & 31.4 & 1.67 & 12.7 & 10.9 \\
\hline L8 & 13-Apr & 70.5 & 1.82 & 11.8 & 10.1 \\
\hline L3 & 13-Apr & 4.4 & 1.30 & 13.0 & 12.2 \\
\hline M4 & 13-Apr & 4.4 & 1.07 & 14.5 & 10.3 \\
\hline DS & 13-Apr & 3.8 & 5.64 & 27.8 & 24.0 \\
\hline L3 & 18-Apr & . & 1.35 & 10.6 & 9.6 \\
\hline M4 & 18-Apr & . & 1.11 & 11.6 & 8.9 \\
\hline DS & 18-Apr & . & 6.78 & 33.3 & 26.6 \\
\hline BW & 20-Apr & 27.4 & 1.78 & 15.0 & 13.2 \\
\hline L8 & 20-Apr & 52.4 & 1.98 & 15.2 & 12.3 \\
\hline L3 & 21-Apr & . & 1.39 & 15.1 & 13.7 \\
\hline M4 & 21-Apr & . & 1.16 & 25.5 & 14.7 \\
\hline DS & 21-Apr & . & 7.93 & 61.9 & 33.7 \\
\hline L3 & 22-Apr & . & 1.46 & 19.6 & 16.3 \\
\hline M4 & 22-Apr & . & 1.22 & 47.2 & 17.7 \\
\hline DS & 22-Apr & $\cdot$ & 8.60 & 65.8 & 36.3 \\
\hline BW & 23-Apr & 25.8 & 1.83 & 14.9 & 13.3 \\
\hline
\end{tabular}




\begin{tabular}{ccccrr}
\hline Label & Date & Weir Flow (L/s) & $\begin{array}{c}\text { Specific } \\
\text { Conductivity } \\
(\mathbf{m S} / \mathbf{c m})\end{array}$ & $\begin{array}{c}\text { Total Organic } \\
\text { Carbon } \mathbf{( m g / L -} \\
\mathbf{C})\end{array}$ & $\begin{array}{c}\text { Dissolved } \\
\text { Organic Carbon } \\
(\mathbf{m g} / \mathrm{L}-\mathbf{C})\end{array}$ \\
\hline L8 & 23-Apr & 33.2 & 1.93 & 17.7 & 15.2 \\
L3 & $23-\mathrm{Apr}$ &. & 1.49 & 22.9 & 15.2 \\
BW & 27-Apr &. & 1.73 & 12.6 & 11.0 \\
\hline L8 & 27-Apr &. & 1.88 & 16.5 & 13.8 \\
\hline
\end{tabular}




\section{APPENDIX B: ION CHROMATOGRAPHY}

Nitrite, Nitrate, and Phosphorus where analyzed using ion chromatography. A Dionex DX 120 Ion Chromatograph was used with a setup including;

- AG9-HC IonPac ${ }^{\circledR}$ Guard Column

- AS9-HC 4mm IonPac ${ }^{\circledR}$ IC column

- DS4-1 Detection Stabilizer.

- AS40 Automated Sampler.

Sodium bicarbonate with a concentration of $9 \mathrm{mM}$ was used as eluent. The eluent was prepared by degassing Grade 1 DI water with Ultra High Purity helium for 30 minutes and diluting concentrated $0.5 \mathrm{M}$ sodium carbonate to create $9 \mathrm{mM}$ eluent for the various volumes needed. Ultra High Purity Helium was supplied to the IC at a pressure of $40 \mathrm{psi}$. Internal pressure of the IC was maintained between 2300 and 2500 psi. Flow of eluent was set to $1.10 \mathrm{ml} / \mathrm{min}$. The eluent was allowed to flow for at least 1 hour prior to running any samples through the column. The total run time for each sample was 30 minutes. The actual Chromel Program only recording peaks for 13 minutes allowing ions up to phosphate to be analyzed.

Standards were prepared using Dionex 7 Anion standard solution. Three separate dilutions were made to create a 3-point calibration curve. Samples were filtered through $0.22 \mu \mathrm{m}$ Millipore Express PLUS ${ }^{\circledR}$ Membrane filters with the assistance of a HDPE plunger. Samples were placed into $5 \mathrm{ml}$ Dionex poly vials and caped with Dionex $20 \mu \mathrm{m}$ filter caps. A spike of 7-anion solution was added to one sample for each series for quality assurance. At the start of each run a DI rinse was used prior to running any samples through. After any standards where run a DI blank was analyzed to confirm that had been no contamination and to show any background noise from the machine. If more than 15 samples were run in one sitting, a second 3-point calibration curve was used. 